MPR Reference No.: 6091-380

MATHEMATICA

Policy Research, Inc.

\title{
Kauffman Firm Survey (KFS) Second Follow Up Methodology Report
}

\section{Draft Report}

October 7, 2008

\author{
David DesRoches \\ Janice Ballou \\ Frank Potter \\ Betsy Santos \\ Zhanyun Zhao
}

Submitted to:

Ewing Marion Kauffman Foundation 4801 Rockhill Road

Kansas City, MO 64110

Project Officer:

E.J. Reedy
Submitted by:

Mathematica Policy Research, Inc. P.O. Box 2393

Princeton, NJ 08543-2393

Telephone: (609) 799-3535

Facsimile: (609) 799-0005

Project Director:

David DesRoches 
Electronic copy available at: http://ssrn.com/abstract=1284474 


\section{CONTENTS}

\section{Page}

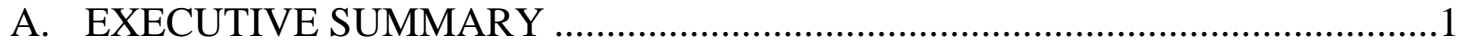

B. THE KAUFFMAN FIRM SURVEY: QUESTIONNAIRE DESIGN AND

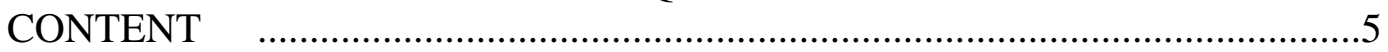

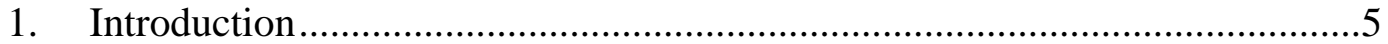

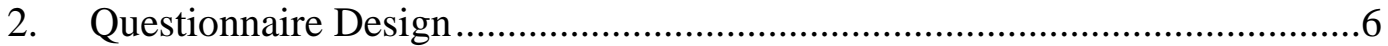

3. Screener and Questionnaire Content........................................................

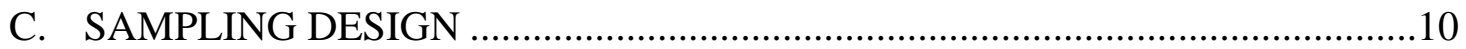

1. Target and Study Population....................................................................10

2. Sample Stratification................................................................................11

D. DATA COLLECTION PREPARATION ..........................................................12

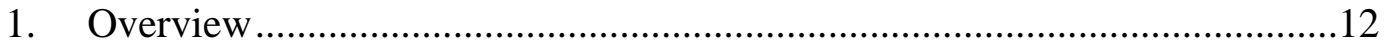

2. Respondent Materials Development ……………….......................................12

3. Interviewer Training Materials …………………........................................14

4. Survey Operations Center (SOC) Staff Training ...........................................15

5. Emails and Advance Mailings ……………...............................................16

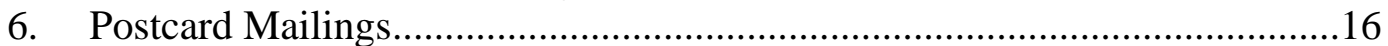

7. Response Protocols to Panel member Inquiries ................................................16

8. Respondent Incentives .................................................................................18

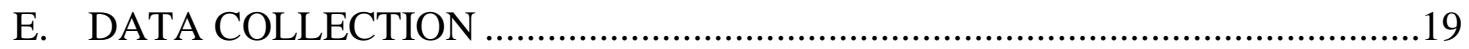

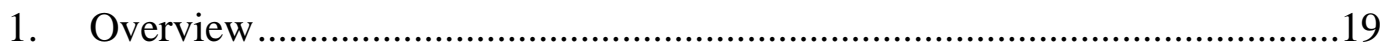

2. Timing of Sample Releases ...................................................................19

3. Schedule of Contacts to Panel Members......................................................21

4. Survey Management Techniques ..............................................................22

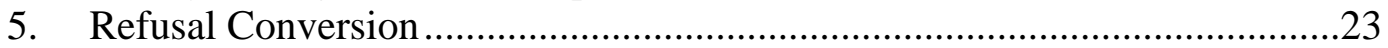

6. Handling Special Cases...............................................................................25

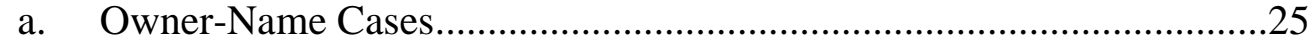

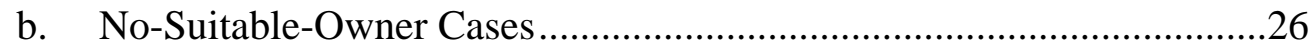

c. Web Partial Cases ..................................................................................26

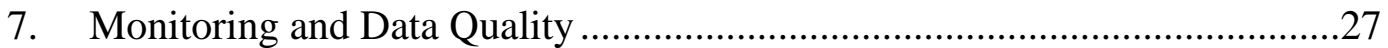

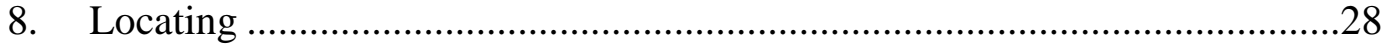

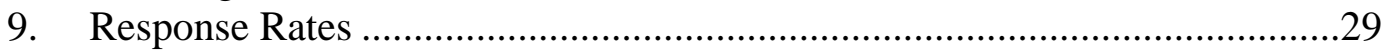




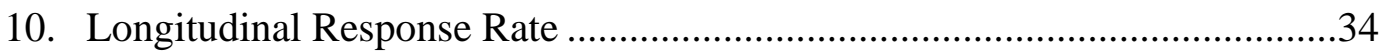

11. Panel Maintenance Packet ..............................................................................34

12. Summary of KFS Second Follow-Up Data Collection.....................................36

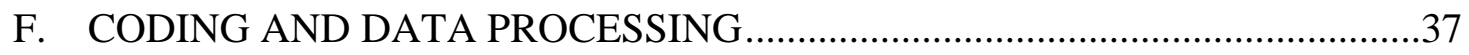

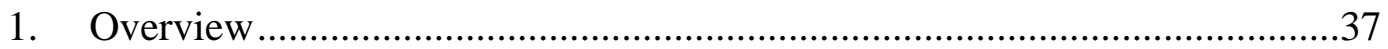

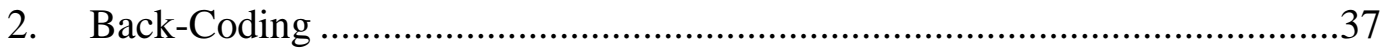

3. Industry Coding ……………….............................................................38

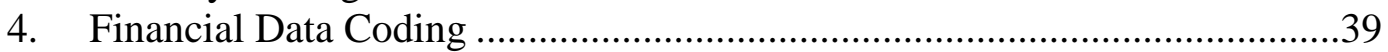

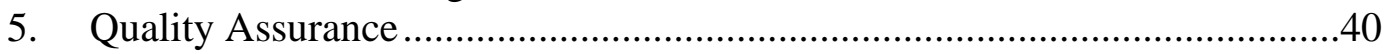

6. Data Cleaning and Frequency Review..............................................................41

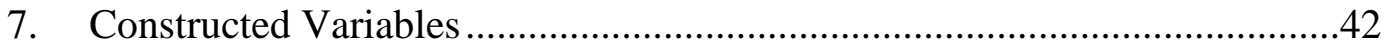

a. Financial Measures with Three Levels of Data .....................................43

b. Financial Variables with Two Levels of Data ......................................43

c. Variables Summing Financial Measures......................................................43

d. Intellectual Property Measures...................................................................44

8. Preparation of Codebook and Data Documentation .......................................4

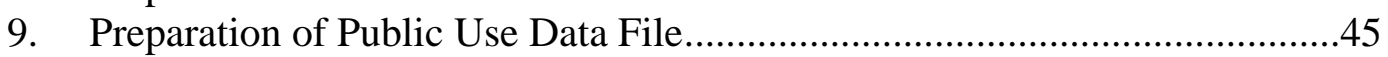

G. WEIGHTING AND NONRESPONSE ADJUSTMENTS ……….......................46

1. Second Follow-Up Response Analysis Summary ........................................46

2. Longitudinal Response Analysis Summary .................................................51

3. Sampling Weights ..................................................................................5

4. Nonresponse Adjustment .........................................................................57

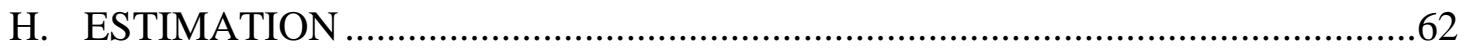

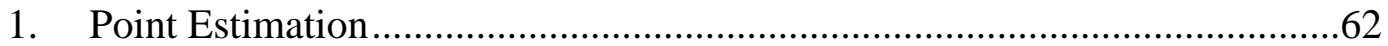

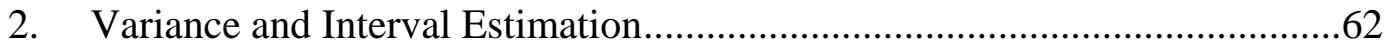

3. Selected Estimates and Variances..............................................................64

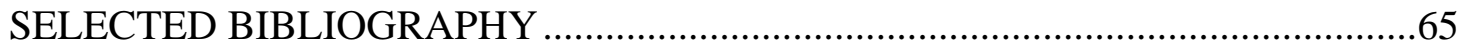


CONTENTS (continued)

APPENDIX A: KFS SECOND FOLLOW-UP QUESTIONNAIRE

PROPOSED CHANGES

APPENDIX B: KAUFFMAN FIRM SURVEY SECOND FOLLOW-UP QUESTIONNAIRE

APPENDIX C: RESPONDENT MATERIALS

APPENDIX D: $\quad$ DATA DOCUMENTATION MEMO

APPENDIX E: KAUFFMAN FIRM SURVEY SECOND FOLLOW-UP ANNOTATED QUESTIONNAIRE 



\section{LIST OF TABLES}

Table

Page

1 KFS MILESTONES 6

2 ESTIMATED COUNT AND SAMPLE FOR THE SECOND FOLLOW-UP SURVEY FROM THE D\&B DATABASE: BUSINESSES THAT HAD A 2004 START DATE AND COMPLETED THE BASELINE SURVEY.

3 KFS SECOND FOLLOW-UP RELEASES .19

4 WEIGHTED AND UNWEIGHTED AAPOR RESPONSE RATES ACROSS TECHNOLOGY SAMPLING STRATA UNDER BOTH ELIGIBILITY DEFINITIONS .32

5 DISTRIBUTION OF BUSINESSES IN THE FIRST AND SECOND FOLLOW-UP SURVEYS

6 WEIGHTED AND UNWEIGHTED AAPOR RESPONSE RATES ACROSS FIRST FOLLOW-UP RESPONSE LEVELS, BOTH ELIGIBILITY DEFINITIONS

7 WEIGHTED AND UNWEIGHTED LONGITUDINAL RESPONSE RATES ACROSS TECHNOLOGY SAMPLING STRATA

8 WEIGHTED LOCATION AND RESPONSE RATES FOR THE SECOND FOLLOW-UP SURVEY RELATIVE TO THE BASELINE SURVEY AMONG BUSINESSES IN THE KAUFFMAN FIRM SURVEY .47

9 WEIGHTED LOCATION AND RESPONSE RATES FOR THE SECOND FOLLOW-UP SURVEY RELATIVE TO THE BASELINE SURVEY AMONG BUSINESSES IN THE KAUFFMAN FIRM SURVEY: HIGH-TECHNOLOGY .... .48

10 WEIGHTED LOCATION AND RESPONSE RATES FOR THE SECOND FOLLOW-UP SURVEY RELATIVE TO THE BASELINE SURVEY AMONG BUSINESSES IN THE KAUFFMAN FIRM SURVEY: MEDIUM-TECHNOLOGY .49

11 WEIGHTED LOCATION AND RESPONSE RATES FOR THE SECOND FOLLOW-UP SURVEY RELATIVE TO THE BASELINE SURVEY AMONG BUSINESSES IN THE KAUFFMAN FIRM SURVEY: NON-TECHNOLOGY 
LIST OF TABLES (continued)

Table

Page

12 WEIGHTED LONGITUDINAL RESPONSE RATES FOR THE FIRST AND SECOND FOLLOW-UP SURVEYS RELATIVE TO THE BASELINE SURVEY AMONG BUSINESSES IN THE KAUFFMAN FIRM SURVEY .53

13 WEIGHTED LONGITUDINAL RESPONSE RATES FOR THE FIRST AND SECOND FOLLOW-UP SURVEYS RELATIVE TO THE BASELINE SURVEY AMONG BUSINESSES IN THE KAUFFMAN FIRM SURVEY: HIGH-TECHNOLOGY .54

14 WEIGHTED LONGITUDINAL RESPONSE RATES FOR THE FIRST AND SECOND FOLLOW-UP SURVEYS RELATIVE TO THE BASELINE SURVEY AMONG BUSINESSES IN THE KAUFFMAN FIRM SURVEY: MEDIUM-TECHNOLOGY

15 WEIGHTED LONGITUDINAL RESPONSE RATES FOR THE FIRST AND SECOND FOLLOW-UP SURVEYS RELATIVE TO THE BASELINE SURVEY AMONG BUSINESSES IN THE KAUFFMAN FIRM SURVEY: NON-TECHNOLOGY.

16 DESCRIPTIVE STATISTICS OF INITIAL SAMPLING WEIGHT FOR THE SECOND FOLLOW-UP SURVEY.

17 SUMMARY OF NONRESPONSE MODELS FOR THE SECOND FOLLOW-UP SURVEY WEIGHTS.

18 SUMMARY OF NONRESPONSE MODELS FOR THE LONGITUDINAL WEIGHTS. 61

19 VARIANCE ESTIMATION FOR SOME BUSINESS CHARACTERISTICS AND OWNER CHARACTERISTICS 


\section{A. EXECUTIVE SUMMARY}

Although entrepreneurship is crucial to a capitalist economy, little information is available about U.S. businesses in their first years of operation. As part of an effort to gather more data on new businesses in the United States, the Ewing Marion Kauffman Foundation sponsored the Kauffman Firm Survey (KFS), a panel study of businesses founded in 2004 and tracked over their first years of operation. The Foundation contracted with Mathematica Policy Research, Inc. (MPR) to conduct the KFS, which collects data about the nature of new business formation; characteristics of the strategy, offerings, and employment patterns; the nature of the financial and organizational arrangements of these businesses; and the characteristics of their founders. With the completion of the Second Follow-Up, the KFS has collected this information from the panel for three years, providing a unique look at business dynamics over this formative period.

Summary of KFS Sample Design. MPR created the panel by using a list frame sample of new businesses selected from the Dun \& Bradstreet Corporation (D\&B) database. We received from D\&B (in June 2005 and November 2005) two sampling frames containing roughly 250,000 businesses started in 2004. From these lists, we selected a sample to be contacted during the Baseline Survey (conducted in 2005 and 2006), screened for eligibility, and recruited into the study. In response to the Foundation's interest in understanding the dynamics of high-technology and woman-owned businesses, the sample design for the KFS included allocation across hightechnology (based on industry designation) and gender strata. Rather than a sample of new business founders, the unit of analysis for the KFS design is the sampled business, so if the same business changed ownership from one reporting period to another, it would remain in the sample.

Questionnaire Design. MPR conducted extensive questionnaire design prior to the Baseline Survey, which are documented in the KFS Baseline Methodology Report (DesRoches et al. 2007). These design issues included establishing consistent definitions of what constituted the 
start of a new business, as well as testing the most efficient methods for collecting data from sampled businesses.

The follow-up survey questionnaires contained many of the same questions as asked in the Baseline Survey (on business characteristics, strategy and innovation, business structure and benefits, financing, and demographics of the owner-operators), so that changes to how businesses obtain operating funds and perform can be tracked over the first few years of operations. A limited number of new questions were added to the First and Second Follow-Up surveys (conducted in 2006 and 2007, respectively) to provide a fuller picture of the balance sheet of the sampled business (such as owner-operators taking draws or dividends from the business, and year-end balances on debt sources the business used). Other additions to the questionnaire sought to identify indicators of business growth, such as the reasons the business location changed.

Further, techniques used during the First Follow-Up to shorten the questionnaire and to make it easier for businesses to respond were also employed in the Second Follow-Up. These included asking panel members to confirm information collected during previous rounds, and collecting new data only if the situation of the business had changed. Another strategy was to collect demographic information only from new owner-operators or from owner-operators for whom we did not already have it.

Second Follow-Up Survey Data Collection. The Second Follow-Up was conducted among the 4,523 businesses remaining in the KFS panel. The Baseline Survey had established eligibility for all businesses in the panel; therefore, the only eligibility criterion for the Second Follow-Up was whether the business was still in operation. Specifically, the remaining businesses were those that completed the Baseline Survey $(4,928)$, minus those identified as out of business (369) and those that had adamantly refused to participate in previous rounds (36). Panel members were 
contacted initially by email and invited to complete the KFS web survey. Those businesses without email addresses, or those not completing the web survey after being contacted by email, were contacted by U.S. mail. As in prior waves, respondents were paid $\$ 50$ for completing the Second Follow-Up. With the remaining eligible businesses, 3,390 interviews were completed, which resulted in a response rate of 84 percent after the sampling weights were applied. As in the First Follow-Up Survey, most interviews were completed on the web (63 percent), with the rest (37 percent) through computer-assisted telephone interviewing (CATI).

Data Processing and File Production. To ensure the highest-quality data possible, we used rigorous coding, data cleaning, and MPR's quality assurance (QA) methods when processing data collected during the Second Follow-Up Survey. MPR staff examined the open-ended responses and, where possible, "back-coded” (moved responses placed in “other-specify” fields into fields that matched one of the prelisted response categories for the question). We also coded the open-ended responses to the question on "primary industry of the business," using the North American Industry Classification System (NAICS) taxonomy. We reviewed answers to financial questions for consistency and corrected any obvious instances of double-counting of equity or debt amounts. The results of the coding and other data corrections were incorporated into the data file. MPR staff also added constructed variables to the data set, for ease of analysis by researchers. For example, much of the financial information collected on the KFS contained multiple levels, such as a "Yes/No" indicator for the type of financial measure, an exact financial measure for those businesses answering "Yes" to the indicator, and a set of ranges for those unable or unwilling to provide an exact value. The additional variables we constructed combined data from these different levels into one. Documentation to accompany the data file was produced, including (1) a copy of the questionnaire with related variables listed next to the questions; and (2) a memo that listed the data source for variables not found in the questionnaire 
and described the constructed variables. To create longitudinal files for both public and restricted use, we combined the Second Follow-Up data with the data collected during the Baseline Survey and the First Follow-Up.

MPR statisticians adjusted the set of sampling weights and nonresponse adjustments developed during the Baseline Survey and refined after the First Follow-Up. These weights were then applied to the businesses in the Second Follow-Up panel. As a result of the oversampling of businesses in high-technology industries, a weighting factor (the inverse of the probability of selection) was required so that estimates collected during the data collection would reflect the true population based on the full D\&B frame. The nonresponse adjustments to the weights were applied to account for those businesses that could not be contacted or interviewed. Using logistic propensity modeling and chi-squared automatic interaction detector (CHAID) analysis, MPR statisticians developed these adjustments for the final set of sampling weights. These final weights and adjustments were added to the longitudinal data file. 


\section{B. THE KAUFFMAN FIRM SURVEY: QUESTIONNAIRE DESIGN AND CONTENT}

\section{Introduction}

The KFS is a unique research program dedicated to advancing understanding of the early years of new-business development. This goal has broad implications for the U.S. economy, since entrepreneurship plays a major role in the economic growth of the country, and accurate information about the development and sustainability of new businesses is essential to the design of public and private programs to encourage their creation. The KFS is also special because of the design and implementation obstacles that were overcome to produce these data. Accurate information about new businesses is not easy to obtain, and few previous surveys have collected data about the dynamics of business development, since longitudinal surveys of new businesses faced the issue of business attrition. Surveys of new businesses also tend to be hard to implement and, because of the difficulty of obtaining cooperation from the owners, have typically produced low response rates. Such surveys have faced the added complexity of defining exactly what constitutes a new business and precisely when its operations begin, concepts that lend themselves to subjectivity if they are not carefully defined. As part of its commitment to advancing entrepreneurship and studying the creation and development of new businesses, the Foundation contracted with MPR to conduct the KFS to address the related informational and methodological gaps. Further information on the design and initial rounds of KFS data collection are available in the KFS Baseline methodology report (DesRoches et al. 2007) and the First Follow-Up methodology report (DesRoches et al. 2008). Table 1 provides the key milestones of the project. 
TABLE 1

KFS MILESTONES

\begin{tabular}{ll}
\hline Date & \\
\hline March 2004 & Project awarded to MPR \\
June 2004 & Principal investigator designated \\
& Received first D\&B database file \\
August 2004 & Pilot Test 1A—initial screening criteria \\
& Pilot Test 1B—additional screening criteria \\
& In-person developmental interviews \\
& Meeting in Washington, DC, to review sample design and \\
& questionnaire development status \\
& Questionnaire Review I-Draft of eligibility screening and \\
financial section of questionnaire sent to technical advisors & Questionnaire Review II-Complete draft questionnaire prepared \\
to send to technical advisors & Pilot Test 2—Sample test; full questionnaire test; 400 completed \\
interviews & Received second D\&B database file \\
January-March 2005 & KFS Baseline data collection; 4,928 completed interviews \\
November 2005 & KFS First Follow-Up data collection; 3,998 completed interviews \\
July 2005-July 2006 & KFS Second Follow-Up data collection; 3,390 completed \\
June 2006-January 2007 & interviews \\
May-December 2007 & \\
\hline
\end{tabular}

\section{Questionnaire Design}

In designing the KFS questionnaire, MPR developed a core set of questions to be asked annually of sampled businesses, with small adjustments made before each round. As with many longitudinal studies, the KFS faces the challenge of ensuring that enough panel members complete future rounds. Prior to the Second Follow-Up Survey, MPR proposed to the Foundation and the Principal Investigator (Dr. Scott Shane) a set of questionnaire changes, mainly involving rewording to ease administration of the interviews. (Appendix A describes the 
changes.) For example, we created general language for the introduction to accommodate businesses not responding to the First Follow-Up.

Other changes included additional questions about whether a business operated in multiple locations, the number of locations the business had, and the month and year the business opened another location.

\section{Screener and Questionnaire Content}

The Second Follow-Up Survey questionnaire was finalized in March 2007 and included the following sections.

Section A: Introduction. This section introduced the study, the sponsor, and MPR as the organization conducting the study. It also verified that the correct business was reached and was still in operation. Section A also ensured that the respondent for the business (most often the respondent during the First Follow-Up Survey) was an owner, an operator, and a founder of the business. Because the questions asked about the financial situation of the business were quite detailed, it was important to identify a person knowledgeable enough about the finances to provide accurate information. Therefore, this part of the questionnaire identified a founder and current owner who was also involved in the day-to-day operations. However, since the unit of analysis for the KFS is the business, the respondent could change from one survey round to the next. Finally, the business address was confirmed. If the business had ceased operations, we asked the reason for the closing and whether the business had filed for bankruptcy.

Section B: Eligibility Screening. As with the First Follow-Up Survey, there was no Section B, since business eligibility was established during the Baseline Survey.

Section C: Business Characteristics. The respondent was asked to confirm the legal status and primary industry description. If either was incorrect or had changed since the last interview (at the First Follow-Up or Baseline), the respondent was asked for updated information. Other 
data collected in this section included the names of other owner-operators and the number of both full- and part-time employees. This section also asked about the type of location from which the business operates and reasons for any changes in location since the last interview, and finished with the new questions on whether the business had opened another location.

Section D: Strategy and Innovation. This section included questions about whether the business offered a product or a service; whether the respondent believed that the business had a competitive advantage; and whether the business owned or licensed any intellectual property, such as patents, copyrights, or trademarks. Respondents were also asked whether the business had any sales during 2006 and what the percentage distribution was of such sales to individuals, government, and other businesses.

Section E: Business Organization and Human Resource Benefits. This section included questions about the number of employees who performed various functions within the business and the types of benefits offered. The questions about benefits for full- and part-time employees were asked separately.

Section F: Business Finances. The business finances section was the focus of the questionnaire. Topics included:

- Equity investment by owner-operators into the business in 2006

- Total equity investment by owner-operators over the life of the business

- Withdrawals of cash from the business by owner-operators in 2006

- Percentage of ownership by each owner, for multiple-owner businesses

- Sources and amount of debt financing by the business and its owners

- Amount of revenue, if any, the business received in 2006

- Total expenses incurred by the business in 2006

- Total expenses spent on salary and wages

- Profit or loss during 2006 
- Types of assets and liabilities and their estimated value

Section G: Work Behaviors and Demographics of Owner(s). This section collected demographic and other information on the owner-operators. Respondents were asked whether they were paid employees and how many hours they worked in an average week. They were also asked how many years of experience they had in the industry of the new business and whether they had started other new businesses. The rest of this section collected basic demographic characteristics on the owner-operators, such as age, gender, race, education level, and U.S. citizenship. For multiple-owner businesses, respondents were asked these questions about themselves and then about each of the other owner-operators.

Finally, contact information was updated for future follow-up surveys. This included the name, address, phone number, and email address of someone to contact if we were unable to reach the business for the next follow-up. It also asked for an email address of the respondent and a website for the business. The name and address of the person to whom the incentive check would be sent was also recorded. At the conclusion of the interview, the respondent was thanked and told that the incentive check would be sent in two or three weeks. The final Second FollowUp Survey questionnaire is in Appendix B. 


\section{SAMPLING DESIGN}

\section{Target and Study Population}

For the Baseline Survey, the target population was all new businesses started in calendar year 2004 in the United States (including the District of Columbia). The baseline target population includes any new, independent business that was created by a single person or a team of people, or was the purchase of an existing business or a franchise, and excludes any branch or subsidiary owned by an existing or inherited business. As discussed in the Baseline Survey methodology report, the study population was further defined by the source of the sampling frame: the $\mathrm{D} \& \mathrm{~B}$ database, which we chose because it is among the largest commercial lists available and offers information on linkages among establishments within enterprises (or businesses). In the Baseline Survey methodology report (DesRoches et al. 2007), we also discussed the screening process in the Baseline Survey to identify businesses that "started" in 2004.

For the Second Follow-Up Survey, the target population was the same as for the First Follow-Up: all new businesses that (1) were started in year 2004, (2) met the survey eligibility criteria, and (3) survived their second year. The study population (as described above) was a subset of the target population in that the businesses had to have been listed in the D\&B database with a start date of 2004. The Second Follow-Up Survey sample included all businesses that met the survey criteria and completed the Baseline Survey. In the Baseline Survey, the businesses that were refusals or unlocatable were possibly in operation after the initial year and are therefore part of our target population. The nonresponse adjustment procedures used on the weights for the Baseline Survey sample compensated for these refusals. Therefore, the Second Follow-Up Survey sample includes only eligible businesses from which we obtained complete data in the Baseline Survey, and this was the same sample used in the First Follow-Up. Thus the Second 
Follow-Up sample included the 525 panel members that did not respond to the First Follow-Up and were still operating. Businesses that were identified as out of business in the First Follow-Up Survey were also treated as out of business in the Second Follow-Up.

\section{Sample Stratification}

For the Baseline Survey, the D\&B database was our source file for the sampling frame. We partitioned the file into six sampling strata defined by industrial technology categories (based on industry designation ${ }^{1}$ ) and gender of the owner or CEO of the business (based on the data element in the D\&B database and additional information; see DesRoches et al (2007) for further details). In Table 2, we provide the estimated population count and sample count of businesses that met the survey eligibility criteria for each stratum.

TABLE 2

ESTIMATED COUNT AND SAMPLE FOR THE SECOND FOLLOW-UP SURVEY FROM THE D\&B DATABASE: BUSINESSES THAT HAD A 2004 START DATE AND COMPLETED THE BASELINE SURVEY

\begin{tabular}{lccc}
\hline $\begin{array}{c}\text { Technology Sampling } \\
\text { Strata }\end{array}$ & $\begin{array}{c}\text { Woman-Ownership } \\
\text { Sampling Strata }\end{array}$ & $\begin{array}{c}\text { Estimated Number of New } \\
\text { Businesses in 2004 }\end{array}$ & $\begin{array}{c}\text { Sample for Second } \\
\text { Follow-Up Survey }\end{array}$ \\
\hline Total & & $\mathbf{7 3 , 2 7 8}$ & $\mathbf{4 , 9 2 8}$ \\
High-technology & Yes & 1,313 & 705 \\
& No & 190 & 103 \\
Medium-technology & & 1,123 & 602 \\
& Yes & 9,675 & 1,329 \\
Non-technology & No & 2,026 & 271 \\
& & 7,649 & 1,058 \\
& Yes & 62,290 & 2,894 \\
& No & 14,366 & 513 \\
\hline
\end{tabular}

The estimated number of businesses is the weighted count of eligible responding businesses having a start date of 2004 and meeting the new-business-screening criteria (see DesRoches et al. 2007).

${ }^{1}$ The technology categories are based on the designation identified by the businesses' Standard Industry Classification (SIC) code, developed in the early 1990s by researchers from Bureau of Labor Statistics. For details, see Paul Hadlock et al. "High Technology Employment: Another View.” Monthly Labor Review, July 1991, pp. 2630. 


\section{DATA COLLECTION PREPARATION}

\section{Overview}

Preparation for the Second Follow-Up data collection generally followed the process used for the First Follow-Up. Data collection materials, training manuals, and interviewer training continued to stress retention in an effort to reduce survey attrition among the KFS panel. Most of the Second Follow-Up panel members had completed both the Baseline and the First Follow-Up Survey (3,998 of 4,523 , or 88 percent). This meant that most businesses had received $\$ 50$ incentives for completing interviews in the two previous years, and had also received panel maintenance packets after each survey to thank them for their participation. Since most panel members were likely to know about the study, a response rate similar to that achieved during the First Follow-Up was expected. The plan to collect the data, as in previous rounds, started with alerting panel members to the web survey with email messages, mailings, and reminders, and then following up through CATI with those not completing the web survey.

\section{Respondent Materials Development}

The goal for the Second Follow-Up Survey was to ensure that as many as possible of the 4,523 businesses remaining in the KFS panel would continue their participation. Our focus was to remind the panel members of their previous participation, repeat the information about the \$50 incentive and strict confidentiality, emphasize the importance of the longitudinal nature of the study, and urge continued participation. We emphasized that their previous participation meant that the selection process was over and that we could not replace their business with another.

Another point of emphasis in the materials sent to panel members in previous rounds was the "Kauffman Firm Survey" title, which was included in all materials sent to respondents and served as the first part of the email subject line. It had also been printed on the ballpoint pen included in the welcome packet after the Baseline Survey and the Post-It Notes included in the 
panel maintenance packets sent after the First Follow-Up. Our goal was to continue to "brand" the Kauffman Firm Survey name to increase recognition among panel members.

Several documents were produced by MPR project staff and used in the Second Follow-Up Survey. After the materials were drafted, they were reviewed by an independent MPR staff member in accordance with MPR's QA policies. After comments from the reviewer were incorporated, the materials were sent to MPR's editing department. Project staff finalized the edited versions before the survey director approved them for use in data collection.

The documents included the following:

- Email Message. We had asked for email addresses at the end of each of the previous surveys, and we had email addresses for 82 percent of Second Follow-Up panel members. The email message was the first contact with panel members who had provided an email address.

The email message reminded them of their previous participation, informed them that we could not replace their business with another, and explained why we were doing the third year of the study. This message included their unique web login and password, as well as an easy "click-through" to the website to participate in the study, which would pre-fill the login and password. This procedure greatly reduced respondent errors during login and facilitated completion of the questionnaire. The email message also provided contact information for MPR staff in case of questions.

- Reminder Email. This was sent as a brief reminder to panel members who had not completed the web survey after the initial email message. This message also included the same web login and password information and "click-through" to the website as the initial email message.

- Advance Letter. The advance letter was the first contact with Second Follow-Up panel members who had not provided an email address in either of the previous rounds. It introduced the study, asked for cooperation, and provided web login information. Like the email message, it provided contact information for MPR staff.

- Web Instructions. The web instructions, included with the advance letter, gave stepby-step instructions on how to access the KFS web survey. The instructions provided the web login information and showed a screenshot of the login page as a visual aid.

- Frequently Asked Questions (FAQs). This one-page document provided answers to some questions panel members were likely to have about the survey, MPR, and the Foundation. This was also included with the advance letter. 
- Reminder Postcard. The postcard was sent as a reminder to panel members who had not completed the web survey. It listed the website URL and encouraged respondents to log on and complete the survey. Because of confidentiality concerns, the postcard did not include the login or password.

- Refusal Letter. This letter was sent to the respondents who had refused to do the survey after they were contacted by telephone, or who had refused through email or a call-in. It was the first effort at refusal conversion.

Copies of these data collection materials are in Appendix C.

\section{Interviewer Training Materials}

Using the First Follow-Up materials as a base and making modifications as needed, project staff developed a set of training materials for the Second Follow-Up Survey. These materials focused on issues we expected to encounter during the Second Follow-Up, such as how to designate a new respondent for the business if the First Follow-Up respondent was no longer there or was unavailable during the data collection period, or if the business had not responded to the First Follow-Up. As noted in Section B, the instrument was designed to encourage the First Follow-Up respondent to answer in the Second Follow-Up, assuming the person was still an owner and operator of the business. Interviewers were taught that if the First Follow-Up respondent was unable to participate in the Second Follow-Up, the Baseline respondent was the next preferred respondent. Another owner-operator could answer if neither the Baseline nor the First Follow-Up respondent was still with the business, was no longer an owner-operator, or was unavailable during the data collection period. In addition, the training materials were updated using the experiences from previous rounds to reflect the slight differences in the survey instrument.

The first chapter of the telephone interviewer training manual provided information on the background of the study, explained the eligibility criteria for respondents, and stressed the importance of confidentiality. The second chapter covered general interviewing skills; reviewed 
the procedures for contacting panel members; and explained how to handle certain situations, such as scheduling appointments, requesting new letters or new emails, and dealing with privacy managers and cell phones. The third chapter covered effective engagement and rapport with panel members, refusal avoidance and conversion, and strategies for handling "gatekeepers.” Because this was the third round, the training materials emphasized that handling gatekeepers should be easier, as owner-operators would likely be familiar with the study. Because the owneroperators had participated in previous rounds, gatekeeper objections were easier to overcome.

The fourth and final chapter was a question-by-question review of the entire survey instrument. Questions were displayed through screenshots, and relevant information appeared below the screens. Additional exhibits, such as a copies of the email, advance letter, reminder postcard, and FAQs, were also included in the manual.

\section{Survey Operations Center (SOC) Staff Training}

The telephone interviewing staff included both interviewers who had worked on previous rounds of the KFS and those new to the project. All interviewers attended the full KFS training session regardless of prior experience on the project. The training was conducted over 12 hours, in two 4-hour "classroom” segments and 4 hours of "hands-on” practice with the CATI survey. Emphasis was placed on the importance of the initial contact, introducing the study effectively, and moving right into the interview. The last four hours of hands-on practice consisted of paired “mock" interviews, where one interviewer played the role of respondent and the other played the interviewer role. To ensure that each pair of interviewers had the same experiences, project staff developed detailed mock scripts for the "respondents." Part of this practice involved “engagement scenarios,” in which pairs of interviewers alternated between the respondent and the interviewer roles, but this time the focus was on overcoming objections and answering the questions that panel members were most likely to ask. 


\section{Emails and Advance Mailings}

As noted in Section 2 above, the first contact made with about 82 percent of the First Follow-Up sample was the email message. For those without email addresses (and for those whose email bounced back), the first notice of the survey was the advance letter.

Both the advance letter, printed on MPR's letterhead, and the initial email briefly introduced the study, reminded the business owner of the previous rounds, and asked for participation in the Second Follow-Up. They also supplied the project's toll-free number, website URL, email address, and contact information to offer panel members the option of contacting MPR if they had further questions or if they preferred to call in to complete the survey or make an appointment to do so. Before each mailing was delivered to the post office, MPR inspected 10 percent of the packets for consistency and accuracy.

\section{Postcard Mailings}

One week after the advance mailing, a reminder postcard was sent to each sampled business that had not yet completed the questionnaire on the web. The postcard included the name of the owner and the name and address of the business. An overview of the study, the website URL, and MPR contact information were also provided, and panel members were encouraged to contact MPR if they had lost or forgotten their password or login ID. The postcard labels were generated through MPR’s Sample Management System (SMS). Prior to mailing, postcards were also inspected for consistency with U.S. postal standards.

\section{Response Protocols to Panel member Inquiries}

Prompt and efficient handling of inquiries from panel members helps establish rapport and thus increases the chances that they will complete the survey. As in previous rounds of the KFS, panel members in the Second Follow-Up could contact MPR in several ways: 
- Toll-free telephone number

- KFS email

- Project staff telephone numbers

The toll-free number was monitored by MPR's trained SOC staff during business hours. A panel member could call in to complete the questionnaire on the telephone or make an appointment to have an interviewer call back and administer it. Another important function of the toll-free number was to provide the login ID and password to panel members who wanted to complete the web survey but had misplaced that information. Help desk staff were trained to identify each caller through a look-up file to make sure the person was indeed an owner of the sampled business. The survey director's phone number was also provided in case help desk staff could not answer all the questions a panel member posed.

Some panel members and gatekeepers who were called requested that an email message be sent with information explaining the survey and how to participate. The email that was sent in response to such requests was the same one used in the initial email and the reminder email. It included the panel member's password, login ID, and URL for the web survey.

Some panel members emailed with questions about the study, explanations about their businesses, and refusals. In the period after email invitations had been sent to one of the batches of sample, project staff monitored the KFS project mailbox seven days a week in order to be able to respond to questions promptly. Responses to questions were usually emailed within 24 hours of initial receipt of a panel member's email. When a panel member refused through email, staff would attempt a refusal conversion by addressing the stated reason, such as the amount of time the questionnaire would take to complete, and explaining the importance of the study. 


\section{Respondent Incentives}

We offered panel members $\$ 50$ to complete the Second Follow-Up (whether on the web or through CATI), the same amount as in the previous rounds. The incentive was not offered as a payment for the panel members' time but was instead referred to in the advance materials and during telephone calls as a "token of appreciation" for participation. We made this distinction because if the money was presented as compensation for their time, some owners might think the payment insufficient and refuse to participate. Instead, the incentive was presented as an honorarium, or a way of recognizing the owner's contribution to the success of the study.

KFS incentive checks were mailed weekly to ensure that respondents received them promptly. Payments returned to MPR without forwarding information were sent to MPR locating specialists for address updating. Each check was then reissued and sent to the new business location. If a check was returned with forwarding information, the panel member information was updated in the MPR SMS, and the check was reissued.

During the Second Follow-Up data collection, a few panel members indicated that they did not recall having received their \$50 payment for completion of the First Follow-Up Survey. In all cases, we determined that MPR had indeed sent the check to the respondent who completed the First Follow-Up questionnaire, although most had not been cashed. In these instances, project staff or a telephone interviewer would call or email back that the check had been sent but had not been cashed. We would then verify the address and send a new check. Some panel members wanted to receive their First Follow-Up check before they completed the Second Follow-Up Survey. MPR staff made sure that these panel members were contacted to complete the Second Follow-Up Survey within a week of being sent the replacement check. 


\section{E. DATA COLLECTION}

\section{Overview}

Data collection on the Second Follow-Up Survey closely mirrored that of the First FollowUp. Overall, the study continued to be successful in retaining panel businesses, achieving a response rate of 84 percent (weighted). We were also successful in slightly increasing the percentage of respondents who completed the web survey, (63 percent in the Second Follow-Up compared to 59 percent in the First Follow-Up). Figure 1 illustrates the data collection process for the Second Follow-Up.

\section{Timing of Sample Releases}

Data collection began on May 31, 2007, and concluded on December 1, 2007. There were three separate batches of Second Follow-Up sample (dates and sample sizes are in Table 3). Each batch or "release" began with an email message to panel members.

Although the web and CATI instruments were thoroughly tested before data collection began, the first sample release was deliberately small to permit a live test of the instrument and the systems involved in recording completes and refusals and in generating mailings.

TABLE 3

KFS SECOND FOLLOW-UP RELEASES

\begin{tabular}{lcc}
\hline Sample Release & Release Date & Sample Size \\
\hline 1 & $5 / 17 / 2007$ & 200 \\
2 & $5 / 31 / 2007$ & 2,000 \\
3 & $6 / 24 / 2007$ & 2,343 \\
\hline Total & & $\mathbf{4 , 5 2 3}$ \\
\hline
\end{tabular}


FIGURE 1. KAUFFMAN FIRM SURVEY SECOND FOLLOW-UP

DATA COLLECTION PROCESS

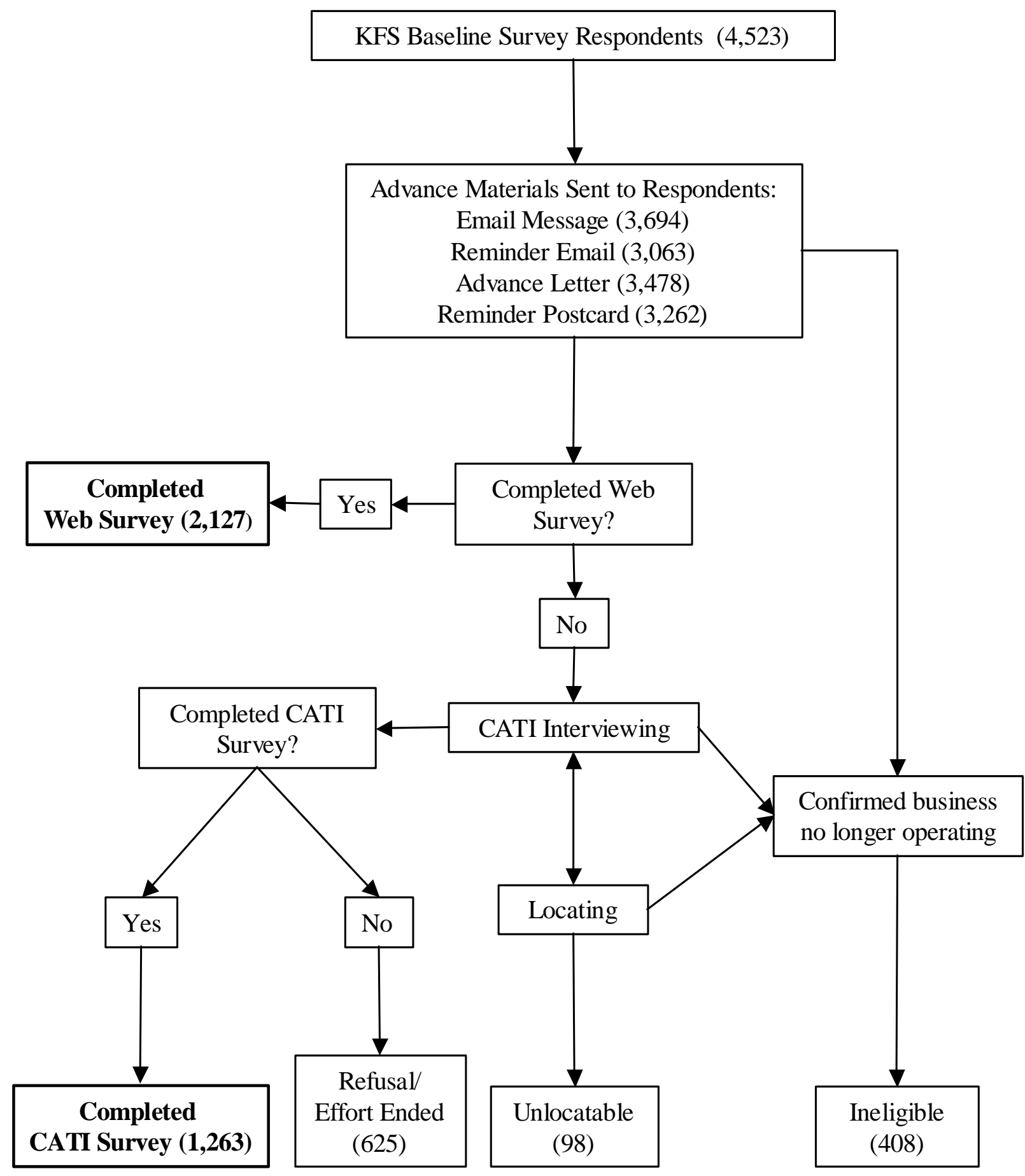


The initial email message displayed the subject line "Kauffman Firm Survey—Round 3." While the official titles of the KFS follow-up surveys are "First Follow-Up," "Second FollowUp,” etc., we thought such terminology might be confusing for panel members. We also wanted to include the number of rounds the respondents had been asked to participate in. The reminder email had the same text as the initial email. For all but the first release, the emails were sent out over either two or three days to prevent triggering various spam filters. This also spread out the web response to avoid overloading the server and preventing some panel members from being able to $\log$ in. Project staff examined email bouncebacks for obvious misspellings or other problems, and corrected and re-sent them as necessary. As in the previous rounds, MPR project staff conducted daily testing of the KFS website just before sending batches of emails.

In addition to bouncebacks from emails, some of the U.S. Postal Service addresses to which the advance mailing was sent were not accurate, and the materials were returned. When the returned mail included an updated address, this was recorded in the MPR SMS and the materials were re-sent. When there was notification of "no such address," the existing address was recorded as inaccurate to prevent any re-mails, and that panel member case was sent to locating staff to search for the new address.

\section{Schedule of Contacts to Panel Members}

As mentioned above, over 80 percent of business owners provided an email address, and they received their first contact about the Second Follow-Up through an email message. One week after that, the advance letter with the same type of materials used in previous rounds was sent to all businesses who had not completed the questionnaire. For the businesses that had not provided an email address, or whose email address had changed or expired, this was the first contact about the Second Follow-Up Survey. One week after the advance letter was mailed, we sent a reminder postcard. A week after the reminder postcard, CATI operations began. The main 
purpose of this contact schedule was to reduce CATI costs by giving panel members enough time to $\log$ on to the web and complete the survey. About 31 percent of panel members had completed by web before CATI operations began.

When CATI began, the CATI call scheduler was used to provide panel member information to interviewers to make telephone contact. This scheduler assures that callbacks are conducted at the appropriate time, and that telephone attempts which do not result in contact, such as answering machines and "no answers," are recontacted at different times of the day and evening and on weekends. A standard answering machine message was also left at periodic intervals. These intervals were designed to avoid irritating the panel member, and they also gave the panel member time to respond to the message before the next call. Cases with wrong numbers, and those with a series of no contacts, were sent to locating staff for updating. Along with setting scheduler parameters, sending emails on request, and following other procedures, a variety of additional steps helped make CATI more efficient.

\section{Survey Management Techniques}

Survey management involves scheduling, monitoring of progress, and evaluation of procedures to make CATI as efficient as possible. One of the most important aspects of efficient interviewing is proper matching of available sample and interviewer hours, so that calls to panel members are made shortly after they receive the advance materials. To this end, project staff coordinated training schedules and sample releases with interviewer schedules. This coordination was designed to ensure that interviewer hours were highest when new sample was released, so that the initial telephone contact with the panel members took place at the most opportune time. Project staff conducted weekly reviews of interviewer productivity, cooperation rates, calls per hour, and monitoring reports. 
Although we achieved a high response rate in the Second Follow-Up, many businesses either were still reluctant to participate or put off completing the questionnaire. As in most surveys, the final 10 percent of completes took considerably more resources than the first 90 percent. As the Second Follow-Up Survey was coming to an end, the remaining panel members who had not completed the interview had been provided multiple opportunities to respond. They had been contacted, and interviewers had made their best attempts to complete the interview with them. KFS project staff implemented several steps for these cases:

- Sending an email indicating that the study was coming to an end and that their time for participation was limited. This email also stressed that we had already received responses from more than 2,700 participants.

- Sending an additional letter to pending cases, emphasizing that the project needed their participation, reminding them of the $\$ 50$ incentive and their previous participation, and asking them to complete the questionnaire. The envelope also contained a $\$ 5$ bill as a pre-incentive.

- Adjusting interviewer schedules to ensure that cases in the Pacific time zone received sufficient call coverage.

- Developing a special answering machine message to replace the initial one, indicating that the study was ending and that this was the last opportunity to participate.

After these efforts were made, data collection on the Second Follow-Up Survey ended on December 1, 2007.

\section{Refusal Conversion}

Because the Second Follow-Up Survey was the third annual survey in which KFS panel members were asked to participate, KFS respondents usually remembered the previous surveys and required little persuasion. Nonetheless, there were some refusals, which necessitated a refusal conversion effort.

The main reason to try to convert refusals is to ensure that those completing the survey are representative of all sample members. Without refusal conversion, results could be skewed 
toward people who like to do surveys or who are interested in the particular topic. These sample members may answer the questions differently from people who initially refuse to participate in a research study. To obtain as representative a sample as possible, we used refusal conversion techniques to persuade and convert panel members who initially refused.

First, all refusal cases were put on hold for 14 days. During this time, a refusal letter was sent to the business, acknowledging the refusal but emphasizing the unique nature of the study and the importance of participation. The survey website URL was provided in the letter, along with the panel member's password and login ID. After the waiting period, if the panel member had not completed the survey on the web, interviewers trained in refusal conversion techniques called the case. Refusal conversion training was conducted for KFS interviewers who had demonstrated the ability to build rapport and had higher-than-average cooperation rates.

Project staff reviewed refusals periodically, especially the few adamant first refusals, to see whether they should be finalized without a conversion attempt. Project staff used their judgment to balance between avoiding calling people who were vehemently opposed to another call and giving business owners a chance to change their minds.

When businesses refused again after the conversion attempt, project staff examined the cases and put them into three different categories: (1) cases that might be converted by additional attempts; (2) cases that should be finalized for the Second Follow-Up but could be tried again during the Third Follow-Up; and (3) cases that should be finalized and not contacted again. Of the 4,523 cases in the Second Follow-Up, 404 initially refused, of which 66, or 16 percent, were converted and completed the questionnaire. 


\section{Handling Special Cases}

A number of other types of cases required special handling and review. These were assigned to interviewers with special training on how to resolve them.

\section{a. Owner-Name Cases}

After the First Follow-Up Survey, there were about 40 panel members that did not provide a full first and last name for one or more owner-operators. Unlike previous rounds of the KFS where we were missing the name of the respondent for the business in the previous round, these 40 were ones where we had a full name for the previous respondent but were missing the name of one or more of the other owner-operators. Being able to track individual owners through the early years of the business allows us to learn about the makeup of the ownership team that runs the business, and is an important analytical focus of the KFS. Therefore, cases that had owners without full first and last names were separated out and designated as "CATI-only." We did not want these cases completed on the web, because we had no way of ensuring that we would get the missing first and last names of owners. In addition, in some of these cases, respondents used initials or other identifiers, such as “Owner 2," but we needed a first and last name. Failing that, if the respondent insisted on such a designation, we needed assurance that the person identified as "Owner 2" in previous rounds was the same person identified as "Owner 2" in the Second Follow-Up. This process would also ensure that the proper demographic questions were asked.

These cases received a special letter that provided MPR contact information should they have any questions about the study or concerns about confidentiality. The letter also informed them that a professional telephone interviewer would be calling them shortly. Specially trained interviewers called to conduct the interview and try to obtain the complete names of all owners. 


\section{b. No-Suitable-Owner Cases}

In a limited number of cases (fewer than 10), there was no identifiable owner-operator in the Second Follow-Up. In these instances, the CATI supervisor reviewed the cases and referred them to the survey director, who would decide whether or not the interview should be completed with a manager.

\section{c. Web Partial Cases}

Web partials were cases in which the panel member logged on to the questionnaire on the web, completed one or more questions, and then logged off before finishing. Panel members partially completing the questionnaire were contacted by highly experienced interviewers who followed these procedures:

1. Examine the case before calling, to learn at what point in the questionnaire the panel member broke off. This enables the interviewer (1) to tell the panel member how much longer the interview will take to complete, and (2) to get to the first unanswered question quickly if the member agrees to complete the questionnaire.

2. Call the panel member, acknowledging that he or she did partially complete the study. Interviewers are trained to emphasize the business's previous participation and the \$50 incentive and to offer to have the panel member complete the survey over the phone. Interviewers tell the panel member how much time it will take to complete the questionnaire and assure the member of the confidentiality of the survey data.

3. Emphasize to anyone other than the panel member answering the phone that the panel member has already completed part of the questionnaire.

4. Include concise and complete notes for cases in which the panel member was contacted but did not complete the questionnaire.

In addition to these groups of cases, there were rare occasions such as when the web server went off-line for maintenance. After these occurrences, the project mailbox received email messages from panel members who had tried unsuccessfully to log on to the web to participate in the survey. Project staff responded quickly to these messages, apologized to the panel members 
affected, and let them know when the problem had been solved so they could log on to complete the interview.

\section{Monitoring and Data Quality}

Monitoring interviewer performance helps improve data quality and also provides an opportunity to improve interviewer techniques on panel member engagement and refusal avoidance. The monitoring process also helps identify unanticipated issues and provides support for interviewers who have questions about individual questionnaire items.

MPR emphasizes the importance of the monitoring process, and the MPR monitoring software allows the monitors to enter evaluations of interviewer performance into the system easily, where it is stored for retrieval by supervisors and project staff. So that they fully understood the project requirements, all Second Follow-Up Survey monitors attended the interviewer training. At the beginning of the data collection, project staff also monitored interviewers to evaluate the performance of the questionnaire and to provide feedback on the performance of individual interviewers.

Monitoring consisted of listening carefully as the interviewer engaged the panel member or gatekeeper, while also observing the interviewer's CATI screen to check for accurate coding and correct computer logic. After the monitors observed the interviewer and prepared evaluations, they would meet with the interviewer to review the case, point out interviewer strengths, and suggest improvements.

Monitoring reports were generated weekly and included data such as the number and type of mistakes each interviewer was making and the number of positive comments made by the monitor. Because of the experience level of the interviewers and the high cooperation rates, monitors reported very few problems with the interviews or with the survey instrument. 
An interviewer debriefing was conducted toward the end of the data collection period. Interviewers reported that the success of the Second Follow-Up was due to (1) the fact that respondents were familiar with and interested in KFS, (2) the incentive, and (3) prompt followup by project staff on missing checks from previous surveys. They also mentioned that the best refusal conversion technique was to emphasize that the interviewer would conduct the interview at a brisk pace out of respect for the owner's busy schedule.

As another step to ensure quality, data were reviewed at two benchmarks—after the first 25 interviews and again after about 250 had been completed. Project staff reviewed the data to examine skip patterns, “other-specify” fields, and other items for accuracy.

\section{Locating}

As mentioned earlier, cases that require locating may be systematically different from those that do not. Some new businesses will never become established. Others will move or change phone numbers, sometimes because they are home-based and the business owner moves. To ignore businesses that have moved or changed contact information runs the risk of excluding businesses that differ from those that are easier to contact. For the Second Follow-Up, a substantial locating effort was made to find each listed business that we could not contact using the information collected during the previous rounds. To update contact information about sampled businesses or principals, the KFS locating process used zip key, directory assistance, Lexis-Nexis, Accurint, and other web searches. Through systematic use of these resources, locators could sometimes determine whether a business was still operating and could find updated contact information. If cases were confirmed as still being in business, they were returned to interviewing for additional attempts. A supervisor would examine a case without any new leads to determine what further action, if any, should be taken. 
The MPR SMS was the clearinghouse for information about locating attempts, as well as all email and mail contacts attempted with panel members. Each email, letter, and postcard that was sent to panel members was recorded, as were new addresses, phone numbers, and owner names. Information gathered by telephone interviewers was also recorded in the SMS. For performance evaluation, the SMS also has management tools that allow locating supervisors to measure the effectiveness of individual locators. Finally, the SMS allows supervisors to review cases that had multiple contact attempts and, when no further locating action is warranted, to finalize them as “unlocatable."

During the Second Follow-Up Survey, more than 722 cases required some degree of locating services. Of these, 98 were finalized as unlocatable, which means that 86 percent of all cases sent to locating were found.

\section{Response Rates}

Response rates are often used as measures of the "potential" for nonresponse bias and of the quality and the validity of survey data. In general, unweighted response rates measure the proportion of the sample that resulted in usable information for analysis. Weighted response rates represent an estimate of the proportion of the survey population for which usable information is available. The weighted response rate is also considered to be a measure of the potential for nonresponse bias. Because we oversampled businesses in the high-tech sampling stratum, the weighted response rates may differ from the unweighted ones. To compute the response rate for the Second Follow-Up Survey, we used a standard algorithm recommended by the American Association for Public Opinion Research (AAPOR). ${ }^{2}$ In this computation, the unweighted

2 The response rate definitions recommended by AAPOR are available at [www.aapor.org/uploads/ standarddefs_4.pdf]. 
response rate is the count of the number of completed interviews among eligible businesses divided by the estimated total count of eligible businesses (the weighted response rate is comparable with weighted counts used instead of the unweighted counts). For the KFS, we provide these response rates using two definitions of eligibility:

1. Businesses that met the survey criteria, started in 2004, and (for the unweighted response rate) completed the Baseline Survey, and are in operation at the time of data collection.

2. Businesses that met the survey criteria, started in 2004, and (for the unweighted response rate) completed the Baseline Survey, and are in operation at the time of data collection, plus businesses that were not operating at the time of data collection. ${ }^{3}$

The two definitions differ only in that the second includes businesses that were not in operation at the time of the survey.

Using the AAPOR response rate algorithm (specifically, AAPOR's Rate \#3), we assumed that all businesses with unknown eligibility (under either definition) would be eligible at the same rate as businesses for which we obtained sufficient information to define eligibility. The AAPOR response rate under the first eligibility definition is:

$$
R R_{1}=\frac{\text { Completes }}{\text { Completes }+ \text { Elig. Non-completes }+[\text { Unknown Elig. } \times \text { Est. Elig. rate }]}
$$

where estimated eligibility rate is defined as:

$$
\text { Est. Elig. rate }=\frac{\text { Completes }+ \text { Elig. } \text { Non-completes }}{\text { Completes }+ \text { Elig. Non-completes }+ \text { Ineligibles }}
$$

\footnotetext{
${ }^{3}$ For a weighted response rate, the numerator and dominator are population-level estimates, and the weighted response rate is a measure of the potential for nonresponse bias in survey-based estimates, because it measures the proportion of the population that provided data. For the unweighted response rate, the numerator and dominator are sample-level counts and therefore need the restriction of "completed the Baseline Survey." The unweighted response rate is essentially an operational measure of data collection success, rather than a measure of the quality of the survey or the survey estimates.
} 
Businesses that had unknown eligibility either were unlocatable or were located but did not respond. Ineligible businesses were those that were non-operational at the time of the survey. The eligible non-completes were eligible for the Second Follow-Up Survey but refused to participate (such as a "break-off"). Because eligibility was determined as part of the interview and there were no break-offs, the number of eligible non-completes was zero.

Under the second eligibility definition, the AAPOR response rate is computed:

$$
R R_{2}=\frac{\text { Completes }+ \text { Non-operational Businesses }}{\text { Completes }+ \text { Non-operational Businesses }+ \text { Elig. Non-completes }+[\text { Unknown Elig. } \times \text { Est. Elig. rate }]}
$$

where estimated eligibility rate is defined as:

$$
\text { Est. Elig. rate }=\frac{\text { Completes }+ \text { Non }- \text { operational Businesses }+ \text { Elig. Non-completes }}{\text { Completes }+ \text { Non }- \text { operational Businesses }+ \text { Elig. Non-completes }+ \text { Ineligibles }}
$$

Once again, the difference between the two response rates, $R R_{1}$ and $R R_{2}$, is the classification of businesses that are not in operation at the time of the survey as eligible in $R R_{2}$.

Of the 4,928 panel members from the Baseline Survey, we completed interviews with 3,390 eligible businesses and identified 777 that were no longer in business. ${ }^{4}$ The other 761 cases had unknown eligibility (refusals or unlocatables). Because there were no eligible non-completes, the two equations are algebraically the same. The overall unweighted AAPOR response rate is computed as 84.6 percent; under the second definition, it is also 84.6 percent.

When the sampling weights are incorporated, the weighted AAPOR response rate is 84.1 percent under both eligibility definitions. Table 4 shows the unweighted/weighted response rates across the three technology sampling strata under both definitions.

\footnotetext{
${ }^{4}$ Among 777 businesses that were out of business, 369 were already identified as out of business in the First Follow-Up Survey.
} 
TABLE 4

\section{WEIGHTED AND UNWEIGHTED AAPOR RESPONSE RATES \\ ACROSS TECHNOLOGY SAMPLING STRATA UNDER \\ BOTH ELIGIBILITY DEFINITIONS}

\begin{tabular}{lccccc}
\hline $\begin{array}{c}\text { Technology } \\
\text { Sampling Strata }\end{array}$ & $\begin{array}{c}\text { Completes } \\
\text { (Count) }\end{array}$ & $\begin{array}{c}\text { Out of } \\
\text { Business } \\
\text { (Count) }\end{array}$ & $\begin{array}{c}\text { Unknown } \\
\text { Eligibility } \\
\text { (Count) }\end{array}$ & $\begin{array}{c}\text { Unweighted } \\
\text { AAPOR Response } \\
\text { Rate (Percentage) }\end{array}$ & $\begin{array}{c}\text { Weighted } \\
\text { AAPOR } \\
\text { Response Rate } \\
\text { (Percentage) }\end{array}$ \\
\hline Total & $\mathbf{3 , 3 9 0}$ & $\mathbf{7 7 7}$ & $\mathbf{7 6 1}$ & $\mathbf{8 4 . 6}$ & $\mathbf{8 4 . 1}$ \\
High-technology & 499 & 95 & 111 & 84.3 & 84.2 \\
$\begin{array}{l}\text { Medium- } \\
\text { technology }\end{array}$ & 953 & 192 & 184 & 86.2 & 85.9 \\
Non-technology & 1,938 & 490 & 466 & 83.9 & 83.8 \\
\hline
\end{tabular}

In the Second Follow-Up, we were able to convert some nonrespondents in the First FollowUp into completes. However, most nonrespondents in the First Follow-Up were still nonrespondents in the Second Follow-Up. Table 5 shows the number of businesses in each responding category in the First and Second Follow-Up surveys, and Table 6 shows the unweighted/weighted response rates in the Second Follow-Up Survey across response levels in the First Follow-Up. Businesses that did not respond in the First Follow-Up achieved a 33.7 percent (unweighted) and 32.7 percent (weighted) response rate in the Second Follow-Up, while businesses that were First Follow-Up respondents achieved a 91.1 percent (unweighted) and 90.8 percent (weighted) response rate in the Second Follow-Up. Businesses that did not respond in the previous round were much less likely to respond in the next. We expect that in the next rounds, it is even less likely that they will respond if they did not respond in multiple consecutive rounds. In any longitudinal survey, the serial nonrespondents are the most difficult group from which to obtain completed responses. 
TABLE 5

DISTRIBUTION OF BUSINESSES IN THE FIRST AND SECOND FOLLOW-UP SURVEYS

\begin{tabular}{lccccc}
\hline & \multicolumn{5}{c}{ Second Follow-Up Status } \\
\cline { 2 - 4 } $\begin{array}{c}\text { First Follow-Up } \\
\text { Status }\end{array}$ & Completes & Refusals & Unlocatable & $\begin{array}{c}\text { Out of } \\
\text { Business }\end{array}$ & Total \\
\hline $\begin{array}{l}\text { Completes } \\
\text { Refusals }\end{array}$ & 3,282 & 329 & 60 & 327 & 3,998 \\
Unlocatable & 89 & 319 & 22 & 59 & 489 \\
Out of Business & 19 & 15 & 16 & 22 & 72 \\
Total & -- & -- & -- & 369 & 369 \\
\end{tabular}

TABLE 6

WEIGHTED AND UNWEIGHTED AAPOR RESPONSE RATES

ACROSS FIRST FOLLOW-UP RESPONSE LEVELS, BOTH ELIGIBILITY DEFINITIONS

\begin{tabular}{|c|c|c|c|c|c|}
\hline $\begin{array}{l}\text { First Follow-Up } \\
\text { Response Level }\end{array}$ & $\begin{array}{l}\text { Completes } \\
\text { (Count) }\end{array}$ & $\begin{array}{l}\text { Out of } \\
\text { Business } \\
\text { (Count) }\end{array}$ & $\begin{array}{l}\text { Unknown } \\
\text { Eligibility } \\
\text { (Count) }\end{array}$ & $\begin{array}{c}\text { Unweighted } \\
\text { AAPOR Response } \\
\text { Rate (Percentage) }\end{array}$ & $\begin{array}{c}\text { Weighted } \\
\text { AAPOR } \\
\text { Response Rate } \\
\text { (Percentage) }\end{array}$ \\
\hline Total & 3,390 & 777 & 761 & 84.6 & 84.1 \\
\hline $\begin{array}{l}\text { First Follow-Up } \\
\text { Respondents }\end{array}$ & 3,282 & 696 & 389 & 91.1 & 90.8 \\
\hline $\begin{array}{l}\text { First Follow-Up } \\
\text { Nonrespondents }\end{array}$ & 108 & 81 & 372 & 33.7 & 32.7 \\
\hline
\end{tabular}




\section{Longitudinal Response Rate}

Because of the longitudinal design of the KFS, we also report the longitudinal response rates. In the first two rounds of follow-up surveys, the longitudinal response rate shows the longitudinal respondents in both the First and the Second Follow-Up Survey as a proportion of the estimated number of eligible business at the time of the Baseline Survey. In view of this definition, a longitudinal respondent is defined as a business that responded to both the First and the Second Follow-Up Survey. As was the case for the response rates for the Second Follow-Up Survey alone, the longitudinal response rates are the same under the first and second eligibility definitions. Table 7 gives the longitudinal response rates under two eligibility definitions.

TABLE 7

WEIGHTED AND UNWEIGHTED LONGITUDINAL RESPONSE RATES ACROSS TECHNOLOGY SAMPLING STRATA

\begin{tabular}{lccc}
\hline Technology Sampling Strata & Respondents & $\begin{array}{c}\text { Unweighted } \\
\text { Response Rate } \\
\text { (Percentage) }\end{array}$ & $\begin{array}{c}\text { Weighted Response } \\
\text { Rate } \\
\text { (Percentage) }\end{array}$ \\
\hline Total & $\mathbf{3 , 9 7 8}$ & $\mathbf{8 0 . 7}$ & $\mathbf{8 0 . 3}$ \\
High-technology & 560 & 79.4 & 79.4 \\
Medium-technology & 1,098 & 82.6 & 82.4 \\
Non-technology & 2,320 & 80.2 & 80.0 \\
\hline
\end{tabular}

\section{Panel Maintenance Packet}

The strength and the uniqueness of the data collected during the KFS is the longitudinal information they provide for analysis. To minimize attrition in the panel between surveys, we made a significant effort to express appreciation to panel members. The $\$ 50$ incentive was one way both to thank the respondents for participation in each survey and to encourage participation 
in future follow-ups. Another technique to remind panel members about the KFS is the packet of materials sent after they completed a round of the KFS. For the Second Follow-Up, the "panel maintenance packet" consisted of a letter of appreciation and a solar calculator with "Kauffman Firm Survey” printed on it. The letter thanked respondents for completing the survey and reminded them of the interview in the upcoming year. It also contained contact information for MPR's survey director. So that it would not be discarded or ignored as just another piece of junk mail, the welcome packet was designed to appear attractive and important: a padded envelope was used to protect the calculator, with the MPR logo and project number printed in color on the upper left. The envelope also had a first-class stamp instead of the bulk rate imprint common to mass mailings.

For the Second Follow-Up Survey, 3,390 welcome packets were sent in two separate mailings. As with previous surveys, these generated some returned packets, some of which contained updated addresses. Those addresses were recorded and the packets re-mailed.

Another aspect of reducing panel attrition is to deal promptly with respondent requests, especially when dealing with incentives provided to respondents. During the Second Follow-Up Survey, respondents called in to say they had not received their \$50 incentive, and MPR staff verified through the respondent payment system that the checks were sent but never cashed. Any missing address information, usually a suite or apartment number, was obtained and entered into the SMS, and the checks were reissued. This updated contact information was collected and stored for use on future follow-up surveys. 


\section{Summary of KFS Second Follow-Up Data Collection}

In summary, the KFS Second Follow-Up Survey data collection illustrates the need for appropriate techniques for a successful longitudinal study:

- Email contacts coupled with an available web survey can be an effective method of maintaining a panel of new businesses.

- Panel maintenance packets, incentives, and collection of updated contact data all help maintain the panel and encourage their participation.

These steps were crucial for achieving a high response rate for the Second Follow-Up Survey. The value of the high rate gives researchers confidence that the KFS data accurately reflect the experiences of the KFS population and increase the potential for quality data in future rounds. These results also show the feasibility of creating and maintaining a panel of new businesses over several years, which will provide data to track new business sustainability. 


\section{F. CODING AND DATA PROCESSING}

\section{Overview}

As with other Second Follow-Up operations, the coding and data processing were aided by the experiences and processes created in earlier rounds. The previous programs and procedures were used during the Second Follow-Up, and many needed little or no updating. High-quality coding and data-processing procedures help to provide the highest-quality data file for analysis.

\section{Back-Coding}

Sixteen questions in the Second Follow-Up Survey contained open-ended responses, with all but one having an "other-specify" alternative if respondents did not think their answers fit into one of the existing categories. Each of these responses was entered verbatim by the interviewer (or, on the web survey, by the respondent) and was reviewed for possible back-coding (the process of determining whether the answer actually fits into one of the existing categories). Back-coding reduces the percentage of responses in the "other" category, providing a higher level of specificity and data quality. Sometimes respondents do not hear all the answer categories during a telephone interview, do not read them carefully on a web survey, or interpret a category incorrectly. Although some of these responses could not be back-coded, many could. Qualified and experienced coding staff performed the back-coding of the "other-specify" responses to these questions:

- A10 (Reason for being out of business)

- C1z2 (Form of legal status of business)

- C8 (Primary location where business operates)

- C9 (Reason for change in location)

- E1h (Key responsibilities of employees)

- E2a.1 (Employee benefits provided to full-time employees) 
- E2b.1 (Employee benefits provided to part-time employees)

- F3g (Sources of equity)

- F7f (Sources of respondent debt)

- F9f (Sources of other owner debt)

- F11k (Sources of debt of the business)

- F28g (Other business owner property)

- F28h (Other assets)

- F30c (Other liabilities)

- G6 (Race)

These questions had also been included in the First Follow-Up questionnaire. So that consistency would be maintained across rounds, the back-coding in the Second Follow-Up used the results from back-coding of the previous rounds as a guide.

\section{Industry Coding}

Question C1b (principal activity of the business) is used to determine the North American Industry Classification System (NAICS) ${ }^{5}$ code. The NAICS system, developed by the U.S. Census Bureau, is the standard establishment classification for all federal surveys, replacing the Standard Industry Classification (SIC) codes. The Second Follow-Up asked respondents to confirm the industry description for their business, which was obtained either from the Baseline Survey D\&B record or from a back-coding of a response in either the Baseline Survey or the First Follow-Up. If the respondent disagreed with the primary industry description, the web questionnaire (or telephone interviewer) asked for an updated description. Coders then reviewed these verbatim descriptions and identified the most appropriate NAICS code. MPR used coders

\footnotetext{
${ }^{5}$ See [www.census.gov/epcd/www/naics.html] for more information on NAICS.
} 
with substantial experience in industry and, specifically, NAICS coding, and they were instructed to leave the six-digit code from the First Follow-Up Survey if they could not code to a six-digit NAICS based on the description collected during the Second Follow-Up.

As in the previous rounds, the next step was to ensure that the NAICS descriptions for the updated NAICS code were entered into the case records. This required obtaining the listing of NAICS codes and associated descriptions, matching them to the cases with updated NAICS codes, and data the matching description into the data file for that business. This revised description was put into place for use on the Third Follow-Up Survey.

\section{Financial Data Coding}

Once again, financial data back-coding presented a number of challenges. Not all owners of new businesses have a clear understanding of financial accounting, asset categories, or even the difference between debt and equity. While the numbers of cases in this category of coding decreased in the Second Follow-Up, there were still some complex cases requiring review by project staff.

Because the questions in the business finances section included dollar values, back-coding these also required adding the amount of the back-coded question to the appropriate response category. For example, if a respondent indicated in the "other-specify” for equity investment that “Dad" had invested $\$ 10,000$ in the business, the $\$ 10,000$ would have to be added to any amount already entered into the section that recorded amounts invested by "parents, in-laws, or children of owners of the business.” Many of the financial back-codes were obvious after review by project staff. In addition, the programs developed during the previous rounds of coding were used to correct these problems. The programs moved the back-coded responses from the "otherspecify" field into the correct response category and added the related dollar amount into the 
proper field. This allowed the response and the corresponding amount to be back-coded to the appropriate category.

Responses to some other questions were somewhat more complex. For example, many respondents did not make a clear distinction between the two "other asset” categories in Question F28, and these had to be adjusted as well. "Any other business property” (F28g) was designed to record tangible assets, while the "any other assets" category (F28h) was designed to record intangible assets such as patents, trademarks, and copyrights, as well as financial assets such as long-term bonds.

Some of the "other-specify" fields required extensive review and case-by-case recoding. In some cases, account balances had to be moved from debt to equity and vice versa. When the intended response was not clear, responses were kept as reported, but when it was clear that the respondent had put account information in the incorrect response category, appropriate adjustments were made to the data for that case.

\section{Quality Assurance}

QA is included in all MPR's survey operations and was also used throughout the KFS coding process. The coding supervisor reviewed all work completed by coders and made corrections before sending the results to project staff, who also did QA. Project staff commented on any cases they changed, so that the coders would have feedback for future rounds. These were primarily reminders about procedures for handling responses that could not be back-coded. As mentioned above, QA checks were also made between the Second Follow-Up codes and those of previous rounds to ensure consistency across rounds. One of these checks was the owner number: because each owner-operator is identified by a unique ID number, project staff ensured that the same number followed that owner in the Second Follow-Up. 
MPR programmers tested all back-coding programs on a test data set for accuracy. Both the programming and the project staff examined the adjusted data set to make sure that all changes were made accurately and that each step of the process was documented. As previously mentioned, the NAICS coding description and six-digit code had to be inserted into the CATI program to prepare for the Third Follow-Up Survey. Both were checked to ensure that the new descriptions were accurate. Additional checks were made to ensure that back-coded financial items and their associated amounts had been properly transferred.

Project staff also looked for common "other-specify" answers to any question, to determine whether the responses should form a new response category in the Third Follow-Up. If any response to an "other-specify" category appeared in at least 3 percent of the cases, addition of a new response category would be considered. As in previous surveys, however, no Second Follow-Up question had an "other-specify" response that reached this threshold.

\section{Data Cleaning and Frequency Review}

For the Second Follow-Up process to ensure data quality, the same set of specifications developed during the Baseline Survey and the First Follow-Up to machine-edit the data was used. The specifications for these computer edits began by using the skip patterns and consistency checks in the CATI questionnaire, which were then expanded at each round to cover other data consistency issues identified.

After these cleaning specifications were finalized, they were programmed into SAS and applied to the original, unedited data. After these processes were completed, a set of frequency distributions was generated and then reviewed by project staff for quality control to ensure that the cleaning statements were implemented properly and to check for any other data inconsistencies. As with the previous data files, a number of variables were not included in the analysis files, such as those MPR created to help manage the data collection, as well as variables 
that would identify businesses or owners. The frequency distributions included only those variables to be included in the final data file.

During the initial review of the frequencies, any inconsistent data values were noted for revision. Inconsistent values usually come from web cases since, to avoid increasing respondent frustration that can result in not completing the questionnaire, the web program had fewer builtin data checks than the CATI program. The frequency review also served as a final check that “other-specify" responses were back-coded properly, with any additional responses that could be back-coded noted so that they could be corrected. After the initial review, we compiled a list of values to be edited, and these were implemented through SAS. To ensure that all inconsistent values were corrected, we produced a second set of frequency distributions after cleaning.

Once the Second Follow-Up data file was finalized (all cleaning was completed and reviewed) and the constructed variables were added (discussed in the next section), the Second Follow-Up data were added to the KFS longitudinal file. Second Follow-Up variables were given a "_S" suffix to distinguish them from variables from earlier data collection rounds. This combined file went through a final quality control review to ensure that the process of combining the two files did not create any unexpected errors or complications. The longitudinal file was provided to the KFS data enclave for restricted use by approved researchers.

\section{Constructed Variables}

For the Second Follow-Up data, we created a set of constructed variables identical in construction to those created for the data collected in previous rounds. These variables were created to consolidate data reporting in different questions with different levels of specificity in order to facilitate analysis of these data. Below is a review of the different categories of constructed variables. 


\section{a. Financial Measures with Three Levels of Data}

When asked about different sources of business financing, such as equity or debt, respondents were first asked whether these sources were used (an "indicator" question). Respondents reporting that the business had used one of these types of financing were then asked for an exact dollar amount for the reference period. Respondents unable or unwilling to provide an exact dollar amount (either through a “don’t know” or “refused” response in CATI or by not answering a response field on the web) were provided a set of ranges and asked to select the appropriate one. The goal of constructing variables for these financial measures was to combine these values into one variable that would inform researchers about both the incidence of usage and the amounts used or acquired during the reference period. Respondents answering "no" to the indicator question were given a "0" in the constructed variable. For exact-value responses, the value associated with the range the value fell into was placed in the new constructed variable. For example, if a respondent indicated that the business had a year-end personal credit card balance of $\$ 20,000$ (question F8b), the value " 6 " was placed in the constructed variable, indicating the range $\$ 10,001$ to $\$ 25,000$. For respondents who gave a range response to the question, these values were placed in the constructed variable as is.

\section{b. Financial Variables with Two Levels of Data}

We also created constructed variables for measures that did not include an indicator variable, such as total expenses (F17) and total wage expenses (F18). For these constructed variables, we used the process as described above to translate exact values into ranges.

\section{c. Variables Summing Financial Measures}

The KFS instrument asked about equity and debt in terms of specific sources, such as from owner-operators, family members, banks, and other organizations. By summing all discrete 
sources falling into a particular category, we created a set of constructed variables that provided subtotals of equity and debt provided by owner-operators and non-owner-operators, as well as a total from all sources.

\section{d. Intellectual Property Measures}

The KFS questions on patents, copyrights, and trademarks asked an indicator question for each type, and businesses that reported having these types of properties were asked how many they had. The constructed variables were created to provide both the incidence and the quantities of these items by entering a " 0 " for cases reporting no patents, copyrights, or trademarks, and for those reporting them, the number of the specific type was entered into the constructed variable.

Once the constructed variables were created and reviewed for quality control, the clean data file was provided to MPR statisticians so that the survey weights and nonresponse adjustment variables could be added.

\section{Preparation of Codebook and Data Documentation}

The main codebook for the Second Follow-Up Survey is the questionnaire, which was annotated to include the variable names in the data file next to the appropriate questions from which the variables were derived. An annotated questionnaire created for use with the restricteduse longitudinal data file, which is in Appendix D. A full list of the variables constructed for the Second Follow-Up Survey data file, as well as more about their construction, is in the data documentation memo in Appendix E. This memo provides information about variables not derived directly from the questionnaire, including:

- Sampling variables, such as those used in the technology and gender strata

- Weighting variables for each round of the KFS, such as nonresponse and poststratification adjustments, as well as the longitudinal weight variable 
- Survey management variables, such as the unique ID number given to cases, final dispositions, number of contacts made to businesses, and so on

- D\&B-derived variables, such as industry codes and other descriptive measures provided with the D\&B file

- Constructed variables, as discussed in Section F.7

\section{Preparation of Public Use Data File}

In addition to the restricted-use data file we provided to the KFS data enclave, MPR produced a file for public use, available on the Foundation website [www.kauffman.org/kfs/ request_download.cfm]. To create this file, we used several strategies to ensure that respondent confidentiality was not compromised. These included removing geographic variables (with the exception of “census region”), exact value variables for financial questions, and all "otherspecify” variables. We reviewed the remaining variables file for values or cells containing small numbers of respondents, and “top-coded” those values into a summary statistic. QA on the public use data file was conducted by MPR staff with extensive experience in producing such files for federal agencies. Once approved, copies of the file were produced in SAS, SPSS, and STATA and provided to the Foundation, along with an annotated questionnaire and data documentation memo specifically designed for use with the public use data file. 


\section{G. WEIGHTING AND NONRESPONSE ADJUSTMENTS}

\section{Second Follow-Up Response Analysis Summary}

For the purpose of nonresponse analysis in the Second Follow-Up alone, we classified the 4,928 panel members into two categories: located and unlocated. The located cases were further classified into “completes” and "nonrespondents.” Completes included businesses (1) for which we obtained either a web survey questionnaire or a CATI interview, or (2) that were classified as ineligible (ceased operations). Using information from the Baseline Survey, we located nearly the entire sample in the Second Follow-Up Survey-the overall location rate (the weighted percentage of eligible businesses in the Baseline Survey that were located in the Second FollowUp Survey) is 97.9 percent. The weighted location and response rates relative to the Baseline Survey for the full sample are given in Table 8 and by technology stratum in tables 9 to 11 .

In general, businesses in the high-technology and medium-technology sampling strata responded at a slightly higher rate than did non-technology businesses. Because businesses in the non-technology sampling stratum account for the majority of the study population (85 percent), the overall location and response rates will generally reflect the pattern of the businesses in the non-technology stratum. In addition to the technology sampling strata, we analyzed the response patterns by gender, age category, education, experience in the industry of the responding owner, legal status, physical location (residence or not), and number of employees, as well as by financial information (total debt, total revenue, etc.). All these characteristics are from data collected in the Baseline Survey or the First Follow-Up. 
TABLE 8

WEIGHTED LOCATION AND RESPONSE RATES FOR THE SECOND FOLLOW-UP SURVEY RELATIVE TO THE BASELINE SURVEY AMONG BUSINESSES IN THE KAUFFMAN FIRM SURVEY

\begin{tabular}{|c|c|c|c|c|c|c|}
\hline & $\begin{array}{l}\text { Sample } \\
\text { Count }\end{array}$ & Located & $\begin{array}{l}\text { Weighted } \\
\text { Percentage } \\
\text { Located }\end{array}$ & Completes $^{\mathrm{a}}$ & $\begin{array}{c}\text { Weighted } \\
\text { Percentage } \\
\text { Complete/Located }\end{array}$ & $\begin{array}{c}\text { Weighted } \\
\text { Response Rate }\end{array}$ \\
\hline All & 4,928 & 4,830 & 97.9 & 4,167 & 85.9 & 84.1 \\
\hline \multicolumn{7}{|l|}{ Technology Sampling } \\
\hline \multicolumn{7}{|l|}{ Strata } \\
\hline High-technology & 705 & 698 & 99.1 & 594 & 85.0 & 84.2 \\
\hline Medium-technology & 1,329 & 1,300 & 97.9 & 1,145 & 87.8 & 85.9 \\
\hline Non-technology & 2,894 & 2,832 & 97.9 & 2,428 & 85.6 & 83.8 \\
\hline \multicolumn{7}{|l|}{ Sole Proprietorship } \\
\hline Yes & 1,635 & 1,583 & 97.0 & 1,412 & 89.0 & 86.3 \\
\hline No & 3,293 & 3,247 & 98.4 & 2,755 & 84.2 & 82.8 \\
\hline \multicolumn{7}{|l|}{ Number of Employees } \\
\hline 0 & 2,838 & 2,775 & 97.7 & 2,428 & 86.9 & 84.9 \\
\hline At least 1 & 2,090 & 2,055 & 98.2 & 1,739 & 84.5 & 82.9 \\
\hline \multicolumn{7}{|l|}{$\begin{array}{l}\text { Primary Location of } \\
\text { the Business }\end{array}$} \\
\hline Residence & 2,483 & 2,424 & 97.5 & 2,170 & 88.7 & 86.5 \\
\hline Others & 2,445 & 2,406 & 98.3 & 1,997 & 83.1 & 81.7 \\
\hline \multicolumn{7}{|l|}{ Total Revenue } \\
\hline 0 & 1,704 & 1,652 & 97.0 & 1,402 & 84.0 & 81.4 \\
\hline$\$ 1$ to $\$ 25,000$ & 1,321 & 1,300 & 98.3 & 1,168 & 88.9 & 87.4 \\
\hline$\$ 25,001$ or more & 1,903 & 1,878 & 98.5 & 1,597 & 85.5 & 84.1 \\
\hline \multicolumn{7}{|l|}{ Total Debt } \\
\hline 0 & 2,231 & 2,181 & 97.8 & 1,902 & 87.0 & 85.1 \\
\hline Positive & 2,697 & 2,649 & 98.0 & 2,265 & 85.0 & 83.3 \\
\hline \multicolumn{7}{|l|}{ Age of the Responding } \\
\hline \multicolumn{7}{|l|}{ Owner } \\
\hline 34 or younger & 864 & 834 & 97.2 & 695 & 81.9 & 79.5 \\
\hline 35 to 44 & 1,618 & 1,587 & 98.0 & 1,356 & 85.7 & 84.0 \\
\hline 45 to 54 & 1,447 & 1,425 & 98.1 & 1,238 & 87.3 & 85.7 \\
\hline 55 or older & 999 & 984 & 98.2 & 878 & 87.9 & 86.3 \\
\hline \multicolumn{7}{|l|}{ Responding Owner's } \\
\hline \multicolumn{7}{|l|}{ Years of Experience } \\
\hline 0 to 10 & 2,577 & 2,514 & 97.5 & 2,159 & 85.5 & 83.3 \\
\hline 11 to 20 & 1,305 & 1,284 & 98.4 & 1,096 & 85.7 & 84.3 \\
\hline 21 or more & 1,046 & 1,032 & 98.6 & 912 & 87.2 & 86.0 \\
\hline \multicolumn{7}{|l|}{ Responding Owner’s } \\
\hline \multicolumn{7}{|l|}{ Education } \\
\hline $\begin{array}{l}\text { Associate’s degree } \\
\text { or lower }\end{array}$ & 2,395 & 2,331 & 97.1 & 1,976 & 84.9 & 82.5 \\
\hline $\begin{array}{l}\text { Bachelor's degree or } \\
\text { higher }\end{array}$ & 2,533 & 2,499 & 98.7 & 2,191 & 87.0 & 85.9 \\
\hline
\end{tabular}

${ }^{\text {a }}$ Completed cases include businesses with complete data for applicable questions. These include Second Follow-Up completes and ineligible businesses (businesses that were not operational). 
TABLE 9

WEIGHTED LOCATION AND RESPONSE RATES FOR THE SECOND FOLLOW-UP SURVEY

RELATIVE TO THE BASELINE SURVEY AMONG BUSINESSES

IN THE KAUFFMAN FIRM SURVEY: HIGH-TECHNOLOGY

\begin{tabular}{|c|c|c|c|c|c|c|}
\hline & $\begin{array}{l}\text { Sample } \\
\text { Count }\end{array}$ & Located & $\begin{array}{l}\text { Weighted } \\
\text { Percentage } \\
\text { Located }\end{array}$ & Completes $^{\mathrm{a}}$ & $\begin{array}{c}\text { Weighted } \\
\text { Percentage } \\
\text { Complete/Located }\end{array}$ & $\begin{array}{c}\text { Weighted } \\
\text { Response Rate }\end{array}$ \\
\hline All & 705 & 698 & 99.1 & 594 & 85.0 & 84.2 \\
\hline \multicolumn{7}{|l|}{ Sole Proprietorship } \\
\hline Yes & 153 & 151 & 98.7 & 131 & 86.7 & 85.5 \\
\hline No & 552 & 547 & 99.2 & 463 & 84.5 & 83.9 \\
\hline \multicolumn{7}{|l|}{ Have Competitive Advantage } \\
\hline Yes & 478 & 475 & 99.3 & 405 & 85.2 & 84.7 \\
\hline No & 227 & 223 & 98.6 & 189 & 84.5 & 83.3 \\
\hline \multicolumn{7}{|l|}{ Number of Owners } \\
\hline 1 & 331 & 325 & 98.2 & 283 & 87.3 & 85.8 \\
\hline 2 or higher & 374 & 373 & 99.9 & 311 & 82.9 & 82.8 \\
\hline \multicolumn{7}{|l|}{ Total Assets } \\
\hline$\$ 0$ to $\$ 10,000$ & 223 & 219 & 98.3 & 195 & 88.9 & 87.4 \\
\hline$\$ 10,001$ to $\$ 100,000$ & 259 & 259 & 100.0 & 228 & 88.1 & 88.1 \\
\hline$\$ 100,001$ or more & 223 & 220 & 98.8 & 171 & 77.5 & 76.5 \\
\hline \multicolumn{7}{|l|}{ Total Revenue } \\
\hline$\$ 0$ & 253 & 249 & 98.5 & 216 & 86.6 & 85.3 \\
\hline$\$ 1$ to $\$ 100,000$ & 239 & 236 & 98.6 & 206 & 87.2 & 86.0 \\
\hline$\$ 100,001$ or more & 213 & 213 & 100.0 & 172 & 80.9 & 80.9 \\
\hline \multicolumn{7}{|l|}{ Responding Owner's Education } \\
\hline Associate’s degree or lower & 346 & 343 & 99.2 & 284 & 82.9 & 82.3 \\
\hline Bachelor’s degree or higher & 359 & 355 & 99.0 & 310 & 87.0 & 86.1 \\
\hline \multicolumn{7}{|l|}{ Age of the Responding Owner } \\
\hline 34 or younger & 78 & 76 & 97.9 & 66 & 86.5 & 84.7 \\
\hline 35 to 44 & 216 & 214 & 99.3 & 176 & 81.4 & 80.8 \\
\hline 45 to 54 & 248 & 246 & 99.1 & 206 & 84.2 & 83.4 \\
\hline 55 or older & 163 & 162 & 99.3 & 146 & 90.1 & 89.5 \\
\hline \multirow{2}{*}{\multicolumn{7}{|c|}{$\begin{array}{l}\text { Responding Owner's } \\
\text { Years of Experience }\end{array}$}} \\
\hline & & & & & & \\
\hline 0 to 10 & 314 & 312 & 99.3 & 265 & 84.6 & 84.0 \\
\hline 11 to 20 & 202 & 199 & 98.7 & 165 & 82.3 & 81.2 \\
\hline 21 or more & 189 & 187 & 98.9 & 164 & 88.7 & 87.7 \\
\hline
\end{tabular}

${ }^{a}$ Completed cases include businesses with complete data for applicable questions. These include Second Follow-Up completes and ineligible businesses (businesses that were not operational). 
TABLE 10

WEIGHTED LOCATION AND RESPONSE RATES FOR THE SECOND FOLLOW-UP SURVEY

RELATIVE TO THE BASELINE SURVEY AMONG BUSINESSES

IN THE KAUFFMAN FIRM SURVEY: MEDIUM-TECHNOLOGY

\begin{tabular}{|c|c|c|c|c|c|c|}
\hline & $\begin{array}{l}\text { Sample } \\
\text { Count }\end{array}$ & Located & $\begin{array}{l}\text { Weighted } \\
\text { Percentage } \\
\text { Located }\end{array}$ & Completes $^{\mathrm{a}}$ & $\begin{array}{c}\text { Weighted } \\
\text { Percentage } \\
\text { Complete/Located }\end{array}$ & $\begin{array}{c}\text { Weighted } \\
\text { Response Rate }\end{array}$ \\
\hline All & 1,329 & 1,300 & 97.9 & 1,145 & 87.8 & 85.9 \\
\hline \multicolumn{7}{|l|}{ Number of Employees } \\
\hline 0 & 828 & 807 & 97.4 & 720 & 89.0 & 86.7 \\
\hline At least 1 & 501 & 493 & 98.5 & 425 & 86.0 & 84.7 \\
\hline \multicolumn{7}{|l|}{ Have Competitive Advantage } \\
\hline Yes & 905 & 888 & 98.3 & 785 & 88.1 & 86.6 \\
\hline No & 424 & 412 & 96.9 & 360 & 87.2 & 84.5 \\
\hline \multicolumn{7}{|l|}{ Primary Location of the Business } \\
\hline Residence & 873 & 852 & 97.5 & 779 & 91.2 & 89.0 \\
\hline Others & 456 & 448 & 98.4 & 366 & 81.6 & 80.2 \\
\hline \multicolumn{7}{|l|}{ Total Assets } \\
\hline$\$ 0$ to $\$ 3,000$ & 420 & 405 & 96.5 & 357 & 87.8 & 84.7 \\
\hline$\$ 3,001$ to $\$ 25,000$ & 488 & 479 & 98.2 & 438 & 91.3 & 89.7 \\
\hline$\$ 25,001$ or more & 421 & 416 & 98.7 & 350 & 83.9 & 82.8 \\
\hline \multicolumn{7}{|l|}{ Total Revenue } \\
\hline$\$ 0$ & 433 & 417 & 96.3 & 361 & 86.3 & 83.1 \\
\hline$\$ 1$ to $\$ 25,000$ & 412 & 405 & 98.4 & 376 & 92.8 & 91.3 \\
\hline$\$ 25,001$ or more & 484 & 478 & 98.8 & 408 & 85.0 & 84.0 \\
\hline \multicolumn{7}{|l|}{ Age of the Responding Owner } \\
\hline 34 or younger & 233 & 218 & 93.8 & 189 & 86.3 & 80.9 \\
\hline 35 to 44 & 428 & 420 & 98.2 & 362 & 86.2 & 84.7 \\
\hline 45 to 54 & 378 & 376 & 99.5 & 326 & 86.1 & 85.7 \\
\hline 55 or older & 290 & 286 & 98.5 & 268 & 93.4 & 92.0 \\
\hline \multicolumn{7}{|l|}{$\begin{array}{l}\text { Responding Owner's } \\
\text { Years of Experience }\end{array}$} \\
\hline 0 to 10 & 556 & 538 & 96.9 & 472 & 87.6 & 84.8 \\
\hline 11 to 20 & 436 & 430 & 98.7 & 368 & 85.3 & 84.2 \\
\hline 21 or more & 337 & 332 & 98.4 & 305 & 91.5 & 90.0 \\
\hline \multicolumn{7}{|l|}{ Responding Owner's Education } \\
\hline Associate’s degree or lower & 423 & 409 & 96.7 & 350 & 85.5 & 82.6 \\
\hline Bachelor’s degree or higher & 906 & 891 & 98.4 & 795 & 88.9 & 87.4 \\
\hline
\end{tabular}

${ }^{\text {a }}$ Completed cases include businesses with complete data for applicable questions. These include Second Follow-Up completes and ineligible businesses (businesses that were not operational). 
TABLE 11

WEIGHTED LOCATION AND RESPONSE RATES FOR THE SECOND FOLLOW-UP SURVEY

RELATIVE TO THE BASELINE SURVEY AMONG BUSINESSES

IN THE KAUFFMAN FIRM SURVEY: NON-TECHNOLOGY

\begin{tabular}{|c|c|c|c|c|c|c|}
\hline & $\begin{array}{c}\text { Sample } \\
\text { Count }\end{array}$ & Located & $\begin{array}{l}\text { Weighted } \\
\text { Percentage } \\
\text { Located }\end{array}$ & Completes $^{\mathrm{a}}$ & $\begin{array}{c}\text { Weighted } \\
\text { Percentage } \\
\text { Complete/Located }\end{array}$ & $\begin{array}{c}\text { Weighted } \\
\text { Response Rate }\end{array}$ \\
\hline All & 2,894 & 2,832 & 97.9 & 2,428 & 85.6 & 83.8 \\
\hline \multicolumn{7}{|l|}{ Sole Proprietorship } \\
\hline Yes & 1,056 & 1,024 & 97.1 & 913 & 89.0 & 86.4 \\
\hline No & 1,838 & 1,808 & 98.3 & 1,515 & 83.7 & 82.3 \\
\hline \multicolumn{7}{|l|}{ Number of Owners } \\
\hline 1 & 1,754 & 1,712 & 97.7 & 1,494 & 87.1 & 85.1 \\
\hline 2 or more & 1,140 & 1,120 & 98.2 & 934 & 83.3 & 81.8 \\
\hline \multicolumn{7}{|l|}{ Total Revenue } \\
\hline$\$ 0$ & 1,018 & 986 & 97.0 & 825 & 83.6 & 81.1 \\
\hline$\$ 1$ to $\$ 25,000$ & 780 & 767 & 98.3 & 679 & 88.2 & 86.7 \\
\hline$\$ 25,001$ or more & 1,096 & 1,079 & 98.4 & 924 & 85.6 & 84.2 \\
\hline \multicolumn{7}{|l|}{ Total Debt } \\
\hline 0 & 1,205 & 1,176 & 97.8 & 1,025 & 87.0 & 85.0 \\
\hline Positive & 1,689 & 1,656 & 98.0 & 1,403 & 84.6 & 82.9 \\
\hline \multicolumn{7}{|l|}{ Age of the Responding Owner } \\
\hline 34 or younger & 553 & 540 & 97.6 & 440 & 81.2 & 79.3 \\
\hline 35 to 44 & 974 & 953 & 97.9 & 818 & 85.7 & 84.0 \\
\hline 45 to 54 & 821 & 803 & 97.8 & 706 & 87.6 & 85.7 \\
\hline 55 or older & 546 & 536 & 98.1 & 464 & 86.8 & 85.2 \\
\hline \multicolumn{7}{|l|}{$\begin{array}{l}\text { Responding Owner's } \\
\text { Years of Experience }\end{array}$} \\
\hline 0 to 6 & 1,300 & 1,266 & 97.4 & 1,084 & 85.6 & 83.4 \\
\hline 7 to 15 & 756 & 742 & 98.1 & 630 & 84.7 & 83.1 \\
\hline 16 or more & 838 & 824 & 98.4 & 714 & 86.4 & 85.0 \\
\hline \multicolumn{7}{|l|}{ Responding Owner's Education } \\
\hline Associate's degree or lower & 1,626 & 1,579 & 97.1 & 1,342 & 84.9 & 82.4 \\
\hline Bachelor’s degree or higher & 1,268 & 1,253 & 98.8 & 1,086 & 86.5 & 85.5 \\
\hline \multicolumn{7}{|l|}{ Gender of the Responding Owner } \\
\hline Female & 843 & 831 & 98.6 & 702 & 84.7 & 83.5 \\
\hline Male & 2,051 & 2,001 & 97.5 & 1,726 & 86.0 & 83.9 \\
\hline
\end{tabular}

${ }^{\text {a }}$ Completed cases include businesses with complete data for applicable questions. These include Second Follow-Up completes and ineligible businesses (primarily businesses that were not operational). 
Generally speaking, the age of the responding owner was positively correlated with response to the Second Follow-Up Survey. However, among businesses in the non-technology stratum, those whose owners were between 45 and 54 years old had a response rate essentially the same as businesses whose owners were older than 55, and among businesses in the high-technology stratum, those whose owners were between 35 and 54 years old had a lower response rate than the businesses whose owners were 34 or younger. Businesses whose responding owner had at least a bachelor's degree responded at a higher rate across all technology strata, though the differential was smaller among businesses in the non-technology sampling stratum than in the other two strata. Sole proprietorships responded at a higher rate across all strata. Overall, businesses whose revenues were between $\$ 1$ and $\$ 25,000$ had a higher response rate than others, and the differential was larger for businesses in the medium-technology sampling stratum than in the high-technology and non-technology strata.

\section{Longitudinal Response Analysis Summary}

For the purpose of longitudinal nonresponse analysis in the First and Second Follow-Up surveys, we classified the 4,928 panel members into two categories: completes and nonrespondents. Completes included businesses (1) for which we obtained either a web survey questionnaire or a telephone interview in both rounds, or (2) that were classified as ineligible (ceased operations) in both rounds, or (3) that completed an interview in the First Follow-Up and then were classified as out of business in the Second Follow-Up. The weighted response rates for the full sample are given in Table 12 and by technology stratum in tables 13 to 15 .

In general, businesses in the medium-technology and non-technology sampling strata responded at a higher rate than did high-technology businesses. Because businesses in the nontechnology sampling stratum account for the majority of the study population (85 percent), the overall location and response rates will generally reflect the pattern of the businesses in the non- 
technology stratum. As we did for the nonresponse analysis for the Second Follow-Up Survey alone, we analyzed the response patterns by gender, age category, education, experience in the industry of the responding owner, legal status, physical location (residence or not), and number of employees, as well as by financial information (total debt, total revenue, etc.). All these characteristics are from data collected in the Baseline Survey or the First Follow-Up.

For the longitudinal response, the age of the responding owner was positively correlated with response. However, among businesses in the high-technology stratum, those whose owners were between 35 and 44 had a lower response rate than those whose owners were 34 or younger. Businesses whose responding owner had at least a bachelor's degree responded at a higher rate across all technology strata, though the differential was smaller among businesses in the nontechnology sampling stratum than in the other two strata. Sole proprietorships responded at a higher rate across all strata. In medium-technology and non-technology strata, businesses whose revenues were between $\$ 1$ and $\$ 25,000$ had a higher response rate than others, and the differential was larger for businesses in the medium-technology sampling stratum than in the non-technology stratum. In the high-technology stratum, businesses having no revenue had the highest response rate, and businesses with higher revenue (over \$25,000) had the lowest. 
TABLE 12

WEIGHTED LONGITUDINAL RESPONSE RATES FOR THE FIRST AND SECOND FOLLOW-UP SURVEYS RELATIVE TO THE BASELINE SURVEY AMONG BUSINESSES IN THE KAUFFMAN FIRM SURVEY

\begin{tabular}{|c|c|c|c|}
\hline & Sample Count & Completes $^{\mathrm{a}}$ & $\begin{array}{c}\text { Weighted Response } \\
\text { Rate }\end{array}$ \\
\hline All & 4,928 & 3,978 & 80.3 \\
\hline \multicolumn{4}{|l|}{ Technology Sampling Strata } \\
\hline High-technology & 705 & 560 & 79.4 \\
\hline Medium-technology & 1,329 & 1,098 & 82.4 \\
\hline Non-technology & 2,894 & 2,320 & 80.0 \\
\hline \multicolumn{4}{|l|}{ Sole Proprietorship } \\
\hline Yes & 1,635 & 1,348 & 82.4 \\
\hline No & 3,293 & 2,630 & 79.2 \\
\hline \multicolumn{4}{|l|}{ Number of Employees } \\
\hline 0 & 2,838 & 2,330 & 81.5 \\
\hline At least 1 & 2,090 & 1,648 & 78.7 \\
\hline \multicolumn{4}{|l|}{ Primary Location of the Business } \\
\hline Residence & 2,483 & 2,083 & 82.8 \\
\hline Others & 2,445 & 1,895 & 77.9 \\
\hline \multicolumn{4}{|l|}{ Total Revenue } \\
\hline 0 & 1,704 & 1,340 & 77.6 \\
\hline$\$ 1$ to $\$ 25,000$ & 1,321 & 1,125 & 84.4 \\
\hline$\$ 25,001$ or more & 1,903 & 1,513 & 79.9 \\
\hline \multicolumn{4}{|l|}{ Total Debt } \\
\hline 0 & 2,231 & 1,812 & 81.2 \\
\hline Positive & 2,697 & 2,166 & 79.6 \\
\hline \multicolumn{4}{|l|}{ Age of the Responding Owner } \\
\hline 34 or younger & 864 & 649 & 74.5 \\
\hline 35 to 44 & 1,618 & 1,285 & 79.8 \\
\hline 45 to 54 & 1,447 & 1,188 & 81.9 \\
\hline 55 or older & 999 & 856 & 84.4 \\
\hline \multicolumn{4}{|l|}{ Responding Owner's } \\
\hline \multicolumn{4}{|l|}{ Years of Experience } \\
\hline 0 to 10 & 2,577 & 2,051 & 79.5 \\
\hline 11 to 20 & 1,305 & 1,040 & 79.8 \\
\hline 21 or more & 1,046 & 887 & 83.6 \\
\hline \multicolumn{4}{|l|}{ Responding Owner's Education } \\
\hline Associate’s degree or lower & 2,395 & 1,870 & 78.1 \\
\hline Bachelor's degree or higher & 2,533 & 2,108 & 82.7 \\
\hline
\end{tabular}

${ }^{\text {a }}$ Completed cases include businesses with complete data for applicable questions. These include (1) businesses that completed both the First and the Second Follow-Up, (2) businesses that were out of business in both the First and the Second Follow-Up, and (3) businesses that completed the First Follow-Up and went out of business in the Second Follow-Up. 
TABLE 13

WEIGHTED LONGITUDINAL RESPONSE RATES FOR THE FIRST AND SECOND FOLLOW-UP SURVEYS RELATIVE TO THE BASELINE SURVEY AMONG BUSINESSES IN THE KAUFFMAN FIRM SURVEY: HIGH-TECHNOLOGY

\begin{tabular}{|c|c|c|c|}
\hline & Sample Count & Completes $^{\mathrm{a}}$ & $\begin{array}{c}\text { Weighted Response } \\
\text { Rate }\end{array}$ \\
\hline All & 705 & 560 & 79.4 \\
\hline \multicolumn{4}{|l|}{ Sole Proprietorship } \\
\hline Yes & 153 & 127 & 82.8 \\
\hline No & 552 & 433 & 78.5 \\
\hline \multicolumn{4}{|l|}{ Have Competitive Advantage } \\
\hline Yes & 478 & 377 & 79.1 \\
\hline No & 227 & 183 & 80.2 \\
\hline \multicolumn{4}{|l|}{ Number of Owners } \\
\hline 1 & 331 & 273 & 82.6 \\
\hline 2 or higher & 374 & 287 & 76.5 \\
\hline \multicolumn{4}{|l|}{ Total Assets } \\
\hline$\$ 0$ to $\$ 10,000$ & 223 & 181 & 81.2 \\
\hline$\$ 10,001$ to $\$ 100,000$ & 259 & 219 & 84.8 \\
\hline$\$ 100,001$ or more & 223 & 160 & 71.4 \\
\hline \multicolumn{4}{|l|}{ Total Revenue } \\
\hline$\$ 0$ & 253 & 208 & 82.4 \\
\hline$\$ 1$ to $\$ 100,000$ & 239 & 194 & 80.8 \\
\hline$\$ 100,001$ or more & 213 & 158 & 74.3 \\
\hline \multicolumn{4}{|l|}{ Responding Owner’s Education } \\
\hline Associate’s degree or lower & 346 & 266 & 76.8 \\
\hline Bachelor’s degree or higher & 359 & 294 & 82.1 \\
\hline \multicolumn{4}{|l|}{ Age of the Responding Owner } \\
\hline 34 or younger & 78 & 60 & 77.1 \\
\hline 35 to 44 & 216 & 164 & 75.3 \\
\hline 45 to 54 & 248 & 195 & 78.9 \\
\hline 55 or older & 163 & 141 & 86.6 \\
\hline \multicolumn{4}{|l|}{ Responding Owner's } \\
\hline \multicolumn{4}{|l|}{ Years of Experience } \\
\hline 0 to 10 & 314 & 248 & 78.7 \\
\hline 11 to 20 & 202 & 153 & 75.4 \\
\hline 21 or more & 189 & 159 & 84.8 \\
\hline
\end{tabular}

${ }^{\text {a }}$ Completed cases include businesses with complete data for applicable questions. These include (1) businesses that completed both the First and the Second Follow-Up, (2) businesses that were out of business in both the First and the Second Follow-Up, and (3) businesses that completed the First Follow-Up and went out of business in the Second Follow-Up. 
TABLE 14

WEIGHTED LONGITUDINAL RESPONSE RATES FOR THE FIRST AND SECOND FOLLOW-UP SURVEYS

RELATIVE TO THE BASELINE SURVEY AMONG BUSINESSES IN

THE KAUFFMAN FIRM SURVEY: MEDIUM-TECHNOLOGY

\begin{tabular}{|c|c|c|c|}
\hline & Sample Count & Completes $^{\mathrm{a}}$ & $\begin{array}{c}\text { Weighted Response } \\
\text { Rate }\end{array}$ \\
\hline All & 1,329 & 1,098 & 82.4 \\
\hline \multicolumn{4}{|l|}{ Number of Employees } \\
\hline 0 & 828 & 690 & 83.1 \\
\hline At least 1 & 501 & 408 & 81.3 \\
\hline \multicolumn{4}{|l|}{ Have Competitive Advantage } \\
\hline Yes & 905 & 754 & 83.2 \\
\hline No & 424 & 344 & 80.7 \\
\hline \multicolumn{4}{|l|}{ Primary Location of the Business } \\
\hline Residence & 873 & 751 & 85.8 \\
\hline Others & 456 & 347 & 76.1 \\
\hline \multicolumn{4}{|l|}{ Total Assets } \\
\hline$\$ 0$ to $\$ 3,000$ & 420 & 342 & 81.2 \\
\hline$\$ 3,001$ to $\$ 25,000$ & 488 & 426 & 87.3 \\
\hline$\$ 25,001$ or more & 421 & 330 & 78.1 \\
\hline \multicolumn{4}{|l|}{ Total Revenue } \\
\hline$\$ 0$ & 433 & 346 & 79.7 \\
\hline$\$ 1$ to $\$ 25,000$ & 412 & 362 & 88.0 \\
\hline$\$ 25,001$ or more & 484 & 390 & 80.3 \\
\hline \multicolumn{4}{|l|}{ Age of the Responding Owner } \\
\hline 34 or younger & 233 & 177 & 75.9 \\
\hline 35 to 44 & 428 & 342 & 80.0 \\
\hline 45 to 54 & 378 & 318 & 83.7 \\
\hline 55 or older & 290 & 261 & 89.6 \\
\hline \multicolumn{4}{|l|}{ Responding Owner’s } \\
\hline \multicolumn{4}{|l|}{ Years of Experience } \\
\hline 0 to 10 & 556 & 446 & 80.2 \\
\hline 11 to 20 & 436 & 355 & 81.2 \\
\hline 21 or more & 337 & 297 & 87.6 \\
\hline \multicolumn{4}{|l|}{ Responding Owner's Education } \\
\hline Associate’s degree or lower & 423 & 331 & 78.2 \\
\hline Bachelor’s degree or higher & 906 & 767 & 84.3 \\
\hline
\end{tabular}

${ }^{a}$ Completed cases include businesses with complete data for applicable questions. These include (1) businesses that completed both the First and the Second Follow-Up, (2) businesses that were out of business in both the First and Second Follow-Up, and (3) businesses that completed the First Follow-Up and went out of business in the Second Follow-Up. 
TABLE 15

WEIGHTED LONGITUDINAL RESPONSE RATES FOR THE FIRST AND SECOND FOLLOW-UP SURVEYS RELATIVE TO THE BASELINE SURVEY AMONG BUSINESSES IN THE KAUFFMAN FIRM SURVEY: NON-TECHNOLOGY

\begin{tabular}{|c|c|c|c|}
\hline & Sample Count & Completes $^{\mathrm{a}}$ & $\begin{array}{c}\text { Weighted Response } \\
\text { Rate }\end{array}$ \\
\hline All & 2,894 & 2,320 & 80.0 \\
\hline \multicolumn{4}{|l|}{ Sole Proprietorship } \\
\hline Yes & 1,056 & 871 & 82.4 \\
\hline No & 1,838 & 1,449 & 78.6 \\
\hline \multicolumn{4}{|l|}{ Number of Owners } \\
\hline 1 & 1,754 & 1,422 & 81.0 \\
\hline 2 or more & 1,140 & 898 & 78.5 \\
\hline \multicolumn{4}{|l|}{ Total Revenue } \\
\hline$\$ 0$ & 1,018 & 786 & 77.2 \\
\hline$\$ 1$ to $\$ 25,000$ & 780 & 655 & 83.8 \\
\hline$\$ 25,001$ or more & 1,096 & 879 & 79.9 \\
\hline \multicolumn{4}{|l|}{ Total Debt } \\
\hline 0 & 1,205 & 980 & 81.1 \\
\hline Positive & 1,689 & 1,340 & 79.2 \\
\hline \multicolumn{4}{|l|}{ Age of the Responding Owner } \\
\hline 34 or younger & 553 & 412 & 74.3 \\
\hline 35 to 44 & 974 & 779 & 79.9 \\
\hline 45 to 54 & 821 & 675 & 81.7 \\
\hline 55 or older & 546 & 454 & 83.4 \\
\hline \multicolumn{4}{|l|}{ Responding Owner’s } \\
\hline \multicolumn{4}{|l|}{ Years of Experience } \\
\hline 0 to 6 & 1,300 & 1,033 & 79.5 \\
\hline 7 to 15 & 756 & 601 & 79.2 \\
\hline 16 or more & 838 & 686 & 81.5 \\
\hline \multicolumn{4}{|l|}{ Responding Owner's Education } \\
\hline Associate's degree or lower & 1,626 & 1,273 & 78.1 \\
\hline Bachelor’s degree or higher & 1,268 & 1,047 & 82.4 \\
\hline \multicolumn{4}{|l|}{ Gender of the Responding Owner } \\
\hline Female & 843 & 678 & 80.6 \\
\hline Male & 2,051 & 1,642 & 79.7 \\
\hline
\end{tabular}

${ }^{a}$ Completed cases include businesses with complete data for applicable questions. These include (1) businesses that completed both the First and the Second Follow-Up, (2) businesses that were out of business in both the First and the Second Follow-Up, and (3) businesses that completed the First Follow-Up and went out of business in the Second Follow-Up. 


\section{Sampling Weights}

The initial sampling weight for the Second Follow-Up Survey is defined as the final analysis weight from the Baseline Survey, that is, the weight that includes the nonresponse adjustment and the post-stratification adjustment. Table 16 shows the descriptive statistics of the initial sampling weight.

TABLE 16

DESCRIPTIVE STATISTICS OF INITIAL SAMPLING WEIGHT FOR THE SECOND FOLLOW-UP SURVEY

\begin{tabular}{lccccc}
\hline & Minimum & Maximum & Mean & Median & Std Deviation \\
\cline { 2 - 6 } All & 1.17 & 46.98 & 14.87 & 17.69 & 8.69 \\
\hline High-technology & 1.17 & 3.42 & 1.86 & 1.84 & 0.34 \\
Medium-technology & 4.39 & 12.39 & 7.28 & 7.29 & 1.03 \\
Non-technology & 13.50 & 46.98 & 21.52 & 20.93 & 4.01 \\
\hline
\end{tabular}

\section{Nonresponse Adjustment}

In essentially all surveys, the sampling weights have to be adjusted to compensate for the panel members who cannot be located or who refuse to respond. The general approach was discussed in detail in DesRoches et al. (2007). For the Second Follow-Up Survey, we applied a similar strategy: we used weighted logistic propensity modeling separately for each technology stratum. Because of the high rate of locating the businesses, we incorporated both the location and the response status of sampled businesses into the modeling. That is, we used three response propensity logistic models (one for each technology sampling stratum). The two levels in the binary response for this model were "a located respondent" versus "nonrespondent or not located.” For the KFS, a sample member was classified as a respondent if the sample member 
completed the questionnaire (that is, was an eligible respondent) or was determined to be ineligible (that is, was out of business). We used the inverse of the propensity score as the response adjustment factor. The response-adjusted weight for each sample case is the product of the initial weight and the response adjustment factor. Finally, we computed a post-stratification factor in each technology stratum to ensure that the sums of the weights were the same before and after nonresponse adjustment.

We developed the models using data from the responses to the Baseline Survey and the First Follow-Up within the sampling technology groups. We evaluated the data as main effects and also investigated interactions among these variables. To identify candidate variables to be used as main effects and interactions among these variables for the modeling, we first ran a chisquared automatic interaction detector (CHAID) analysis in SPSS to find possible significant predictors and combinations of them. The variables and interactions we identified using CHAID were then processed using forward and backward stepwise regression (using the SAS logistic procedure with weights normalized to the sample size) to further refine the candidate variables and interaction terms. After identifying a smaller pool of main effects and interactions for potential inclusion in the final model, we evaluated a series of models to determine the final parsimonious model. Because the SAS logistic procedure does not incorporate the sampling design, the final selection of the covariates was accomplished with the logistic regression procedure in SUDAAN ${ }^{6}$ using various measures of goodness of fit and predictive ability. For selecting variables or interactions in a model, we included variables or interactions that have a statistical significance level (alpha level) of 0.30 or lower (instead of the standard 0.05). We used a higher significance level because the purpose of the model was to improve the estimation of the

\footnotetext{
${ }^{6}$ Research Triangle Institute. SUDAAN Language Manual, Release 9.0. Research Triangle Park, NC: Research Triangle Institute, 2004.
} 
propensity score, not to identify statistically significant factors related to response. In addition, the information sometimes reflected proxy variables for some underlying variable that was both unknown and unmeasured. The variables used as main effects and the interactions in the response model are summarized in Table 17. The value for the R-squared statistic ranged from 0.07 to 0.11 for the various final models, and the Hosmer-Lemeshow statistics ranged from 0.37 to 0.64 . These values are similar to those observed for other response propensity modeling efforts using logistic regression with design-based sampling weights.

We used essentially the same approach to construct the longitudinal weights. The two levels in the binary response for this model were "longitudinal respondent" versus "longitudinal nonrespondent.” For the purpose of longitudinal weighting, a sample member was classified as a respondent if the sample member completed the interview in both rounds (that is, was an eligible respondent) or was determined to be ineligible in both rounds (that is, was out of business), or completed the questionnaire in the First Follow-Up and then went out of business in the Second Follow-Up. The variables used as main effects and the interactions in the longitudinal response model are summarized in Table 18. The value for the R-squared statistic ranged from 0.09 to 0.15 for the various models, and the Hosmer-Lemeshow statistics ranged from 0.49 to 0.95 . These values are similar to those observed for other response propensity modeling efforts using logistic regression with design-based sampling weights. 
TABLE 17

SUMMARY OF NONRESPONSE MODELS FOR THE

SECOND FOLLOW-UP SURVEY WEIGHTS

\begin{tabular}{|c|c|c|c|c|}
\hline Variable & Level & High-tech & Medium-tech & Non-tech \\
\hline Responding owner's age & 4 & Interaction & & Interaction \\
\hline Responding owner's experience & 3 & Main Interaction & Main, Interaction & Main, Interaction \\
\hline Responding owner's education & 2 & Main & Interaction & Main, Interaction \\
\hline Responding owner's race & 2 & & & Main \\
\hline $\begin{array}{l}\text { Responding owner's full- } \\
\text { time/part-time }\end{array}$ & 2 & & & Main, Interaction \\
\hline Total assets & 3 & Interaction & Main, & Main \\
\hline Total revenue & 3 & Interaction & Interaction & Main, Interaction \\
\hline Total debt & 2 & Main, Interaction & & Main, Interaction \\
\hline Total expense & 3 & & Main, & Main, Interaction \\
\hline Total equity & 3 & Main, Interaction & Main, & Main, Interaction \\
\hline Total liability & 2 & & & Main \\
\hline Legal status & 2 & & & Interaction \\
\hline Primary location & 2 & Main Interaction & Main, Interaction & Main, Interaction \\
\hline Number of owners & 2 & Main, Interaction & Main, Interaction & \\
\hline Having sales & 2 & & Main & Main, Interaction \\
\hline Major industry & 2 & Interaction & Main, Interaction & Main \\
\hline Intellectual property & 2 & Main, Interaction & & \\
\hline R\&D expenditure & 2 & Interaction & Interaction & \\
\hline Competitive advantage & 2 & & Interaction & Main \\
\hline Full R-squared & & 0.199 & 0.168 & 0.120 \\
\hline Reduced R-squared & & 0.116 & 0.094 & 0.070 \\
\hline Hosmer-Lemeshow statistics & & 0.370 & 0.638 & 0.419 \\
\hline Percentage concordant & & 75.7 & 73.6 & 68.7 \\
\hline Percentage discordant & & 23.9 & 25.9 & 30.8 \\
\hline Percentage tied & & 0.4 & 0.5 & 0.6 \\
\hline
\end{tabular}


TABLE 18

SUMMARY OF NONRESPONSE MODELS FOR THE LONGITUDINAL WEIGHTS FOR THE FIRST AND SECOND FOLLOW-UP SURVEYS

\begin{tabular}{|c|c|c|c|c|}
\hline Variable & Level & High-tech & Medium-tech & Non-tech \\
\hline Responding owner's age & 4 & Main, Interaction & & Interaction \\
\hline Responding owner's experience & 3 & Main Interaction & Main & Main \\
\hline Responding owner’s gender & 2 & & Main, Interaction & Interaction \\
\hline Responding owner's education & 2 & Main & Main, Interaction & Interaction \\
\hline Responding owner's race & 2 & & Main, Interaction & \\
\hline Total assets & 3 & Main, Interaction & Main, Interaction & Main, Interaction \\
\hline Total revenue & 3 & Interaction & Main, Interaction & \\
\hline Total debt & 2 & & & Interaction \\
\hline Total expense & 3 & & & Main, Interaction \\
\hline Total equity & 3 & Main, Interaction & Main, Interaction & Main, Interaction \\
\hline Total liability & 2 & & Main, Interaction & Interaction \\
\hline Primary location & 2 & Main & Main, Interaction & Main, Interaction \\
\hline Number of employees & 2 & & Main, Interaction & Interaction \\
\hline Number of owners & 2 & Interaction & Main & \\
\hline Having sales & 2 & Main & Main, Interaction & Main, Interaction \\
\hline Providing services & 2 & Interaction & & \\
\hline Providing products & 2 & Main, Interaction & & \\
\hline Major industry & 2 & & & Main \\
\hline Intellectual property & 2 & Interaction & Main & \\
\hline R\&D expenditure & 2 & Interaction & Main & \\
\hline Competitive advantage & 2 & & Main & \\
\hline Full R-squared & & 0.238 & 0.200 & 0.139 \\
\hline Reduced R-squared & & 0.152 & 0.121 & 0.088 \\
\hline Hosmer-Lemeshow statistics & & 0.901 & 0.490 & 0.945 \\
\hline Percentage concordant & & 76.6 & 74.1 & 69.8 \\
\hline Percentage discordant & & 23.1 & 25.5 & 29.7 \\
\hline Percentage tied & & 0.3 & 0.5 & 0.5 \\
\hline
\end{tabular}




\section{H. ESTIMATION}

\section{Point Estimation}

The KFS uses a simple stratified sampling design. As described in DesRoches et al. (2007), the businesses in the high-technology sampling stratum were oversampled substantially (actually all were included in the sample). We also oversampled the medium-technology businesses relative to the non-technology ones. The sampling weights take this oversampling into account to remove the potential bias in the estimates relative to unweighted estimates. Moreover, as shown in Section G, the response rate differed by factors like legal status, ownership, and age and education of the owner. The nonresponse adjustments described in Section G were designed to minimize potential nonresponse bias in the estimates. We strongly recommend the use of the nonresponse-adjusted weights for all estimates using the KFS data.

\section{Variance and Interval Estimation}

Variance estimates calculated from KFS data must incorporate the sample design features to obtain the correct estimate. Most procedures in standard statistical packages such as SAS, STATA, and SPSS are not appropriate for the proposed design, because the assumptions in these software packages or procedures are of independent, identically distributed observations or simple random sampling with replacement. ${ }^{7}$ Although the simple random sample variance may approximate the true sampling variance for some surveys, it is likely to underestimate substantially the sampling variance with the KFS design.

The sampling variance is a measure of the variation of an estimator attributable to having sampled a portion of the full population of interest using a specific probability-based sampling design. The sampling variance is a measure of the variation of the estimate of a population

\footnotetext{
${ }^{7}$ STATA SAS, and SPSS software packages now contain procedures that account for the sampling design.
} 
parameter (for example, a population mean or proportion) over repeated samples, whereas the classic "population" variance is a measure of the variation among the observations in the population. The population variance is different from the sampling variance in the sense that the population variance is a constant, independent of any sampling issues, while the sampling variance becomes smaller as the sample size increases. The sampling variance is zero when the full population is observed, as in a census.

For the KFS, the sampling variance estimate is a function of the sampling design and the population parameter being estimated. Called the design-based sampling variance, it assumes the use of fully adjusted sampling weights. The fully adjusted sampling weights are derived from the sampling design, with adjustments to compensate for nonresponse among the businesses and additional adjustments to align the sampling totals to external totals, as previously described. We developed a single fully adjusted sampling weight and information on analysis parameters (that is, analysis stratification) necessary for the estimation of the sampling variance for a statistic using the Taylor series linearization approach. The fully adjusted sampling weight and the analysis parameters can be used in survey data analysis procedures in SUDAAN or in certain procedures in STATA, SAS, and SPSS to compute design-unbiased variance estimates. These variance estimates can be used to make interval estimates. For example, for a proportion ( $p$ ) of businesses (or owners) with certain characteristics, the 90 percent confidence interval is

$$
[p-1.645 \times(\operatorname{std} \text { err. }(p)), p+1.645 \times(\operatorname{std} \text { err. }(p))]
$$

To identify sampling levels or stages, the SUDAAN software requires specifying the survey design and STRATA variables. This is the stratum variable we used when drawing the sample (that is, the six-level variable defined by technology group and woman-owned status). 


\section{Selected Estimates and Variances}

The point and variance estimation procedures are straightforward, and we provide example estimates at the business level and the owner level here. These estimates are for the following variables (the question number and response categories are in parentheses).

Business level:

- Percentage of businesses that are sole proprietorships $(\mathrm{C} 1 \mathrm{z2}=1)$

- Percentage of businesses that are partnerships $(\mathrm{C} 1 \mathrm{z} 2=5,6)$

- Percentage of businesses whose primary location is a residence such as a home or garage $(\mathrm{C} 8=1)$

- Percentage of businesses that have any patents, copyrights, or trademarks (any D3 =1)

- Percentage of businesses that have R\&D expenditures $(\mathrm{F} 19=1)$

Owner level:

- Percentage of responding owners who are $25-44(G 4=2,3)$

- Percentage of responding owners with higher than bachelor's degree (G9 = 7, 8, 9, 10)

- Percentage of responding owners who work full-time $(\mathrm{G} 1 \mathrm{~b} 1=3,4,5,6)$

- Percentage of responding owners who are women $(\mathrm{G} 10=2)$

Table 19 shows these estimates and their standard errors (the square root of the variance). 
TABLE 19

VARIANCE ESTIMATION FOR SOME BUSINESS CHARACTERISTICS AND OWNER CHARACTERISTICS

\begin{tabular}{|c|c|c|c|c|}
\hline & High-tech & $\begin{array}{l}\text { Sample } \\
\text { Size }\end{array}$ & Estimate & $\begin{array}{l}\text { Standard } \\
\text { Error }\end{array}$ \\
\hline \multirow[t]{4}{*}{ Percentage of businesses that are sole proprietorships } & All & 3,390 & 33.0 & 0.94 \\
\hline & High-tech & 499 & 19.4 & 1.85 \\
\hline & Medium-tech & 953 & 27.1 & 1.45 \\
\hline & Non-tech & 1,938 & 34.3 & 1.09 \\
\hline \multirow[t]{4}{*}{ Percentage of businesses that are partnerships } & All & 3,390 & 4.9 & 0.45 \\
\hline & High-tech & 499 & 2.7 & 0.78 \\
\hline & Medium-tech & 953 & 2.9 & 0.56 \\
\hline & Non-tech & 1,938 & 5.3 & 0.53 \\
\hline \multirow{4}{*}{$\begin{array}{l}\text { Percentage of businesses that have any patents, copyrights, } \\
\text { or trademarks }\end{array}$} & All & 3,381 & 21.0 & 082 \\
\hline & High-tech & 498 & 33.8 & 2.21 \\
\hline & Medium-tech & 952 & 25.1 & 1.45 \\
\hline & Non-tech & 1,931 & 20.0 & 0.94 \\
\hline \multirow[t]{4}{*}{ Percentage of businesses that have $R \& D$ expenditures } & All & 3,380 & 18.8 & 0.79 \\
\hline & High-tech & 497 & 35.9 & 2.22 \\
\hline & Medium-tech & 949 & 21.4 & 1.38 \\
\hline & Non-tech & 1,934 & 18.0 & 0.91 \\
\hline \multirow[t]{4}{*}{$\begin{array}{l}\text { Percentage of businesses whose primary location is a } \\
\text { residence, such as a home or garage }\end{array}$} & All & 3,389 & 47.5 & 1.00 \\
\hline & High-tech & 499 & 33.3 & 2.15 \\
\hline & Medium-tech & 953 & 60.4 & 1.64 \\
\hline & Non-tech & 1,937 & 45.7 & 1.16 \\
\hline \multirow[t]{4}{*}{ Percentage of responding owners who are 25-44 } & All & 3,323 & 49.8 & 1.02 \\
\hline & High-tech & 486 & 39.1 & 2.30 \\
\hline & Medium-tech & 942 & 46.2 & 1.66 \\
\hline & Non-tech & 1,895 & 50.7 & 1.18 \\
\hline \multirow{4}{*}{$\begin{array}{l}\text { Percentage of responding owners with higher than a } \\
\text { bachelor's degree }\end{array}$} & All & 3324 & 488 & 101 \\
\hline & High-tech & 486 & 51.8 & 2.34 \\
\hline & Medium-tech & 943 & 70.4 & 1.53 \\
\hline & Non-tech & 1,895 & 45.2 & 1.17 \\
\hline \multirow[t]{4}{*}{ Percentage of responding owners who work full-time } & All & 3,316 & 66.4 & 0.95 \\
\hline & High-tech & 486 & 74.4 & 2.03 \\
\hline & Medium-tech & 943 & 60.8 & 1.61 \\
\hline & Non-tech & 1,887 & 67.2 & 1.10 \\
\hline \multirow[t]{4}{*}{ Percentage of responding owners who are women } & All & 3,324 & 30.0 & 0.72 \\
\hline & High-tech & 486 & 17.1 & 1.33 \\
\hline & Medium-tech & 943 & 23.2 & 0.97 \\
\hline & Non-tech & 1,895 & 31.4 & 0.85 \\
\hline
\end{tabular}



APPENDIX A

KFS SECOND FOLLOW-UP QUESTIONNAIRE PROPOSED CHANGES 

To: $\quad$ Alyse Freilich

FROM: $\quad$ Tom Barton and David DesRoches

DATE: $2 / 16 / 2007$

KFS - 69

SUBJECT: Kauffman Firm Survey Second Follow-up Questionnaire

\section{A. INTRODUCTION}

The purpose of this memo is to document potential issues about the Kauffman Firm Survey (KFS) Second Follow-up questionnaire and propose solutions to those issues. Unlike the revisions implemented for the First Follow-up Survey, the number of issues for the Second Follow-up is relatively small. Due to the longitudinal nature of the KFS, most questions will be asked in exactly the same way. While the only change in the wording of most questions will be the change in reference to the time period, there are a few issues to discuss and decide upon. Included with this memo is the latest version of the First Follow-up Survey document for reference.

\section{B. DISCUSSION OF SECOND FOLLOW-UP QUESTIONNAIRE ISSUES}

\section{Issues related to a change in respondent}

The first issue is whom to contact within the business when there were different respondents in the Baseline and First Follow-up Surveys. We recommend making the person who completed the First Follow-up interview the primary contact for the business, since this person is more likely to remember completing the KFS interview and has had more recent contact with the project than the Baseline respondent. If the First Follow-up respondent is not available during telephone followup and there are other owner-operators available, the emphasis should be on length of time of ownership. Therefore, if the First Follow-up respondent is not available, we recommend asking for qualified owner-operators in the following order:
a. the Baseline respondent
b. any owner-operators present with the business at Baseline
c. new owner-operators identified during the First Follow-up interview
d. any new owner-operators identified during the Second Follow-up interview 
MEMO TO: Alyse Freilich

FROM: $\quad$ Tom Barton and David DesRoches

DATE: $\quad 2 / 16 / 2007$

PAGE: 2

We do not anticipate many businesses in which there will be a choice of individuals to interview, so rather than adding questions about this issue to the instrument, we will instruct interviewers to follow this order of preference.

\section{Adding new owner-operators in the Second Follow-up}

When adding new owners in the Second Follow-up, we will need to check to see if the new owner-operator was an owner in the Baseline Survey who dropped out (either selling his or her interest or becoming nonoperating) but has now once again become an owner-operator. In the First Follow-up, a new owner-operator was new to the business in 2005, or was an owner in 2004 who was not an operator or founder. Because we are assigning individual owner IDs in order to track ownership changes throughout the life of the study, we now need to avoid assigning two owner IDs to one person. The number of cases where this could occur should be small, so rather than adding additional screening questions when new owner-operators are identified, we propose to check for owners reentering the business during data collection and the data cleaning process. To do this, we will compare owner names given in the Baseline Survey to those added in the Second Follow-up. For any names that appear to be similar, we will compare answers to demographic questions. If this comparison does not resolve the issue, or if we are still unsure whether we have a duplicate listing for the same person, a member of the project staff will contact the business to resolve the issue.

\section{Businesses that did complete the Baseline Survey but did not complete the First Follow-up Survey}

There are approximately 750 businesses in the KFS sample falling into this category. To avoid the assumption that all businesses we contact completed the First Follow-up Survey, we propose to add language that is neutral and can be presented to all sample members regardless of First Follow-up response status. For example, in Section $C$ the question about new owners in the First Follow-Up read "I want to record with you the first and last names of these owners. These are people who joined the business between December 31, 2004, and December 31, 2005.”

The current wording, with only the dates updated for the Second Follow-up, would ask businesses who did not respond to the First Follow-up for owner-operators joining the business from December 31, 2005 to December 31, 2006, and we would miss any owner-operators who joined during 2005. In order to capture all new owner-operators, we will change the wording to "I want to record with you the first and last names of these owners. These are the people who joined [NAME BUSINESS] between our last interview and December 31, 2006.”

Other than collecting this owner information, businesses not responding to the First Followup will not be asked for information as of the First Follow-up on other topics. Questions asked of all respondents during the Second Follow-up will focus on calendar year 2006 and year-end balances as of December 31, 2006. 


$\begin{array}{ll}\text { MEMO TO: } & \text { Alyse Freilich } \\ \text { FROM: } & \text { Tom Barton and David DesRoches } \\ \text { DATE: } & 2 / 16 / 2007 \\ \text { PAGE: } & 3\end{array}$

The Second Follow-up instrument will follow the procedures used in the First Follow-up regarding the demographic questions in Section G. Any new owner-operators identified during the Second Follow-up interview will be asked all the demographic questions, and only demographic questions that were unanswered during both the Baseline Survey and First Followup will be asked of owner-operators still with the business.

\section{Other individual question changes and proposed additional questions on multiple locations}

a. In the First Follow-up, we added questions about drawings and dividends received in both 2004 and 2005 in order to get a better estimate of total stockholders' equity. In the Second Follow-up we will ask about drawings and dividends in one year (2006).

b. In the First Follow-up, the respondent to the survey had to be an owner-operator to ensure that a person knowledgeable about the business's finances was interviewed. During data collection, we contacted a few businesses where the original owner(s) had turned over the operations of the business to a manager who was not an owner, and there was no longer an owner-operator available to complete the questionnaire. After discussions with the Foundation and the principal investigator, we decided that if we found a nonowner manager who was operating the business, we could interview that person after supervisory staff reviewed each case individually. We propose to use a similar system of supervisory review during the Second Follow-up. Because we anticipate more of these cases as time goes on, we also propose adding a new category of respondent in the questionnaire so the interviewer can code these cases as having no owner-operator. We will add an alternative response in question A5a that will say "No owner-operator available - enter name of manager." This will enable us to get a quick count of the special cases where a nonowner served as the respondent for the business.

c. In the First Follow-up, we added an additional question about location. If the primary location of the business had changed in the time between the Baseline and First Follow-up Surveys, we asked why it had changed. The purpose of this was to identify a potential milestone of a growing business that was becoming sustainable. For the Second Follow-up, we again propose adding a question (with related followup questions) that focuses on expansion. Specifically, we would like to ask if the business now operates in more than one location. If so, we will ask how many locations and when the second location opened. This expansion could be an early indicator of a high-potential business. The proposed questions are as follows: 
MEMO TO: Alyse Freilich

FROM: $\quad$ Tom Barton and David DesRoches

DATE: $\quad 2 / 16 / 2007$

PAGE: 4

C10 - As of December 31, 2006, did [NAME BUSINESS] operate in more than one location?

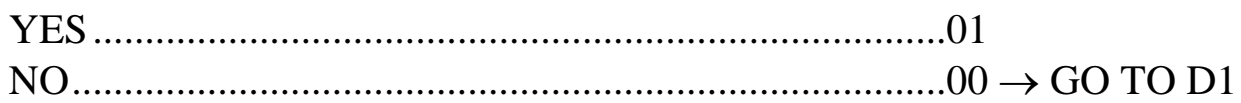

C11 - And as of December 31, 2006, in how many total locations did [NAME BUSINESS] operate?

|___ NUMBER OF LOCATIONS AS OF DECEMBER 31, 2006

C11a - In what month and year did [NAME BUSINESS] open its second location?

Month Year $|2|$

We will also allow the respondents to define what they mean as a separate location. Some businesses may have moved their headquarters out of their factory or retail store, or they may still have a home office in addition to renting a second location as retail space. Due to the number of possible definitions of a location, we will not try to define this term for the respondent.

We look forward to discussing these proposed changes further, either at one of the regularly scheduled project meetings or at another time convenient for you. 
APPENDIX B

KAUFFMAN FIRM SURVEY SECOND FOLLOW-UP QUESTIONNAIRE 

MPR Reference No.: 6091-310

MATHEMATICA

Policy Research, Inc.

Kauffman Firm Survey

Second Follow-Up

Final Questionnaire

January 30, 2008 



\section{A. INTRODUCTION}

INTRO: Hello, my name is . I'm calling on behalf of the Kauffman Foundation.

May I speak with ([CEO/OWNER]/the owner or CEO of [NAME BUSINESS])?

CEO/OWNER = First Follow-Up Respondent for Section A.

\begin{tabular}{|c|c|}
\hline OWNER/CEO_BAD TIME/CALL BACK $\ldots \ldots \ldots \ldots \ldots \ldots \ldots . \ldots 2 \rightarrow$ & GO TO A2a \\
\hline OWNER/CEO NOT AVAILABLE. & GO TO Inform \\
\hline OWNER/CEO NO LONGER WITH BUSINESS .............. $04 \cdot$ & $\begin{array}{l}\text { Go TO A1a } \\
\text { [then } A 4 w e b \\
\text { if } A 1 a=1]\end{array}$ \\
\hline BUSINESS NO LONGER IN OPERATION ...................05 & GO TO A10 \\
\hline DN'T KNOW ................................. & \\
\hline
\end{tabular}

A1a. Your business has been participating in the Kauffman Firm Survey. Last year we asked you some questions about [NAME BUSINESS]'s operations in 2004 and 2005. Now we'd like to ask about calendar year 2006.

We'd like to confirm that the name of the business is [NAME BUSINESS] and that [NAME BUSINESS] is still operating.

[NAME BUSINESS] IS THE CURRENT NAME

AND [NAME BUSINESS] IS STILL OPERATING ..........01

THE BUSINESS NAME IS INCORRECT ....................02 $\rightarrow$ GO TO A2Web

[NAME BUSINESS] IS OUT OF BUSINESS ................03 $\rightarrow$ GO TO A10

A1b. We'd like to confirm that you are [OWNER NAME] and you are you are still an owner of [NAME BUSINESS]?

[OWNER NAME] IS THE RESPONDENT AND IS

STILL AN OWNER OF [NAME BUSINESS]....

[OWNER NAME] IS THE RESPONDENT AND IS

STILL AN OWNER OF [NAME BUSINESS], BUT

CORRECT [OWNER NAME]'S NAME.

$02 \rightarrow$ GO TO A4aWeb

RESPONDENT IS NOT [OWNER NAME]

$03 \rightarrow$ GO TO A4Webz

THE RESPONDENT [OWNER NAME] IS NO

LONGER AN OWNER OF [NAME BUSINESS] 07 $\rightarrow$ GO TO A5a Box 
A1c. We'd like to confirm that the title of your position is [TITLE]? Is that correct?

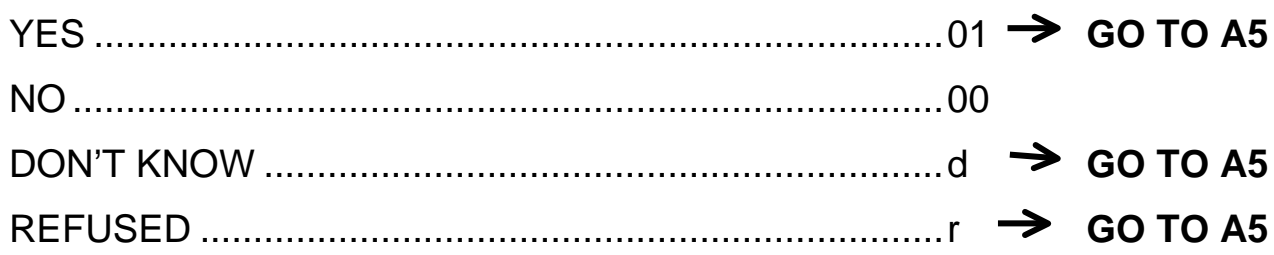

A1d. What is your job title?

INTERVIEWER: ENTER JOB TITLE.

Update Title

\section{GO TO A5}

A2a. I'm sorry. When would be a better time to reach (you/[OWNER])?

INTERVIEWER: ENTER CALLBACK DATE AND TIME.

READ: Is this the best number to reach you?

INTERVIEWER: UPDATE CONTACT INFORMATION AS NEEDED.

Thank you very much. Good-bye.

THANK AND TERMINATE

A2Web. What is the correct business name?

INTERVIEWER: TYPE IN BUSINESS NAME.

A3Web. Is this a corrected spelling, a name change but the same business, or a different business?

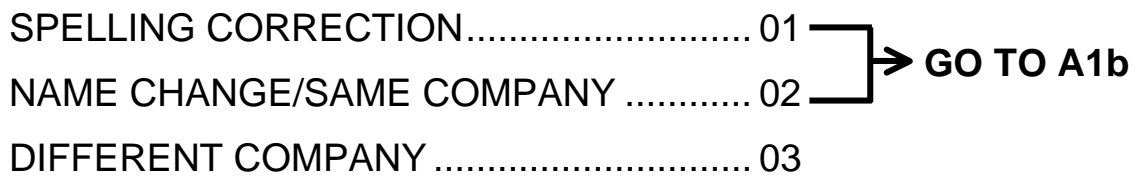


A3Webz. We are trying to find out what happened to [NAME BUSINESS]. Is [NAME BUSINESS] still in operation?

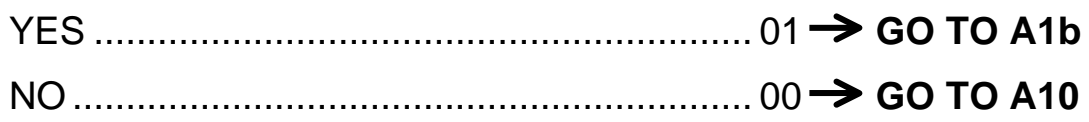

A4Webz Is [OWNER NAME] still an owner and actively involved in running [NAME BUSINESS]?

IF NEEDED: By actively involved, we mean providing regular assistance or advice with day-to-day operations of the business rather than providing only money or occasional operating assistance.

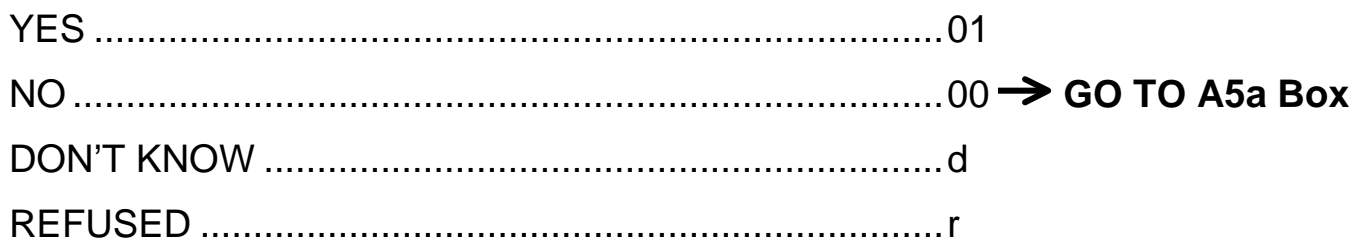

A4Webz1 Would [OWNER NAME] be available to do the study at another time?

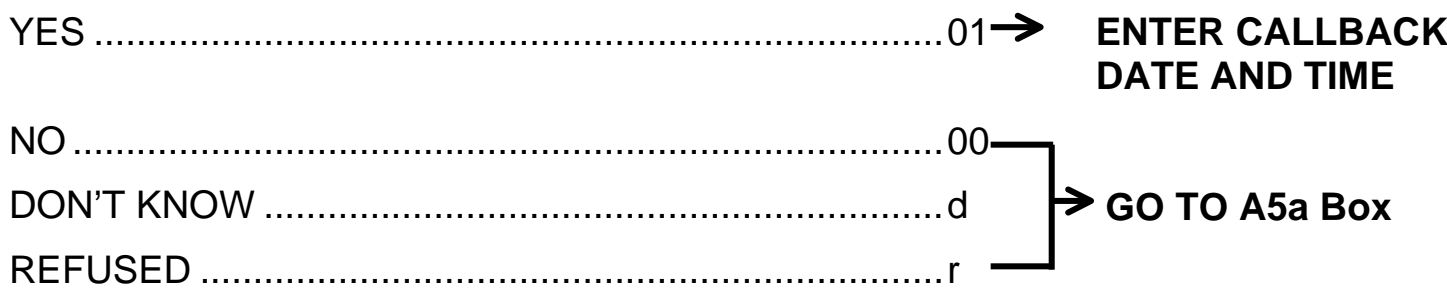

A4aWeb What is the correct spelling of your name?

NAME:

A5. Are you still actively involved in running [NAME BUSINESS]? By actively involved in running the business, we mean providing regular assistance or advice with day-to-day operations of the business rather than providing only money or occasional operating assistance.

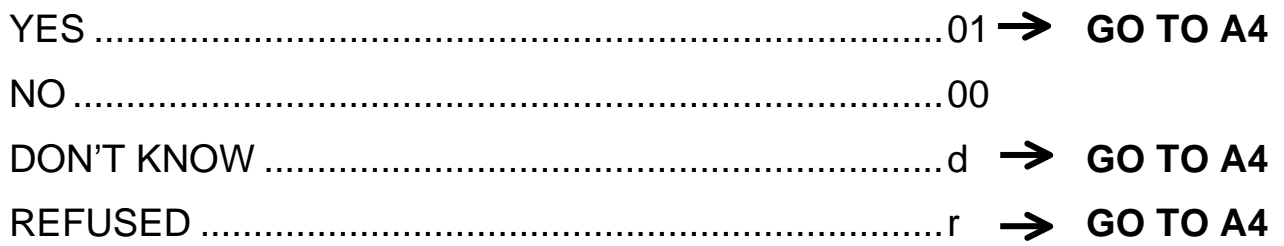




\section{A5A BOX: \\ IF MORE THAN ONE OWNER-OPERATOR- FOUNDER FROM FIRST FOLLOW-UP, ASK A5a. ELSE, ASK A4Web.}

A5a. During the last interview with your business, we recorded other owners of [NAME BUSINESS]. Please tell me the person who is an owner of the business, is actively involved in running [NAME BUSINESS], and will answer this study.

By actively involved in running the business, we mean providing regular assistance or advice with day-to-day operations of the business rather than providing only money or occasional operating assistance.

READ THE OWNER NAMES BELOW. SELECT ONLY ONE.

NEW OWNER-OPERATOR WILL ANSWER ......................00 $\rightarrow$ GO TO A5aweb1

$[$ NAME OWNER] ................................................. 2-9 $\rightarrow$ GO TO A7Title

NON-OWNER WILL ANSWER .......................................11 $\rightarrow$ GO TO A5aweb1

INTERVIEWER: CODE 11 ONLY WITH SUPERVISOR PERMISSION AND WRITE NOTE DOCUMENTING CIRCUMSTANCES

A4Web Who is currently an (OWNER/CEO) of [NAME BUSINESS]?

NAME:

A4Webz2 Are you (OWNER/CEO)?

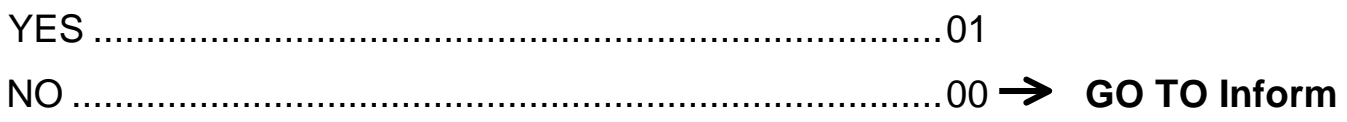

A5new. And are you actively involved in running [NAME BUSINESS]? By actively involved in running the business, we mean providing regular assistance or advice with day-to-day operations of the business rather than providing only money or occasional operating assistance.

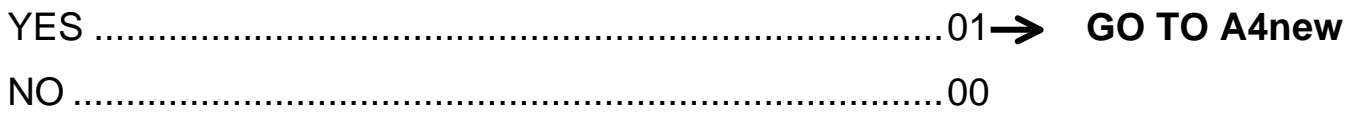


A7. Is there another owner of [NAME BUSINESS] who is actively involved in running [NAME BUSINESS], and can answer questions about the business?

PROBE: $\quad$ By actively involved in running the business, we mean providing regular assistance or advice with day-to-day operations of the business rather than providing only money or occasional operating assistance.

YES 01

NO $00 \rightarrow$ GO TO Stop5

A5aWeb1 Who is another owner of [NAME BUSINESS] who is actively involved in running [NAME BUSINESS], and can answer questions about the business?

ENTER FIRST NAME

ENTER LAST NAME

ENTER JOB TITLE

A4Webz2 Are you (OWNER/CEO)?

YES.

$01 \rightarrow$ GO TO A4new

NO .00

Inform. Do you know a good time and date I can call to contact (OWNER/CEO)?

INTERVIEWER: ENTER CALLBACK DATE AND TIME.

THANK AND TERMINATE

Stop5. Thank you for your time.

THANK AND TERMINATE

A7Title. What is the title of [OWNER NAME]?

A4Webz2 Are you (OWNER NAME)?

YES. 01 $\rightarrow$ GO TO A4new

NO $00 \rightarrow$ GO TO Inform 
A4. You participated last year in the Kauffman Firm Survey. We asked some questions about [NAME BUSINESS] operations in 2004 and 2005. Now we'd like to ask about the year 2006. Again, your answers will be completely confidential, and you will once again receive a $\$ 50$ payment as a token of our appreciation.

\section{GO TO A8}

A4new. Your business participated last year in the Kauffman Firm Study. We asked some questions about [NAME BUSINESS]'s operation in 2004 and 2005. Now we'd like to ask about the year 2006. Again, your answers will be kept confidential, and you will receive a $\$ 50$ payment as a token of our appreciation.

A8. I'd like to confirm your business' mailing address. Is [NAME BUSINESS]'s mailing address (ADDRESS, CITY, STATE, ZIP)?

WEB: Our records indicate that the mailing address for [NAME BUSINESS] is (ADDRESS, CITY, STATE, ZIP). Is this correct?

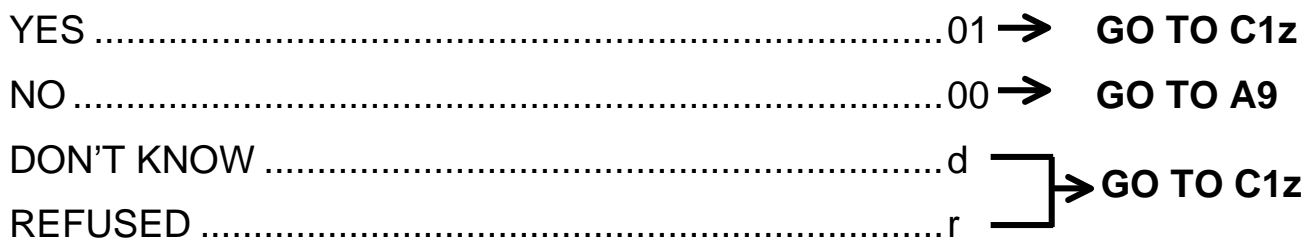

A9. What is [NAME BUSINESS]'s correct mailing address?

\section{INTERVIEWER: UPDATE MAILING ADDRESS INFORMATION.}

ADDRESS:

CITY:

STATE:

ZIP:

DON'T KNOW ....................................................... d

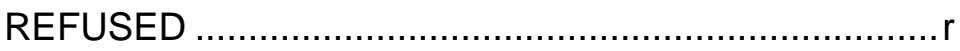

GO TO C1z 
A10. What is the main reason [NAME BUSINESS] is out of business?

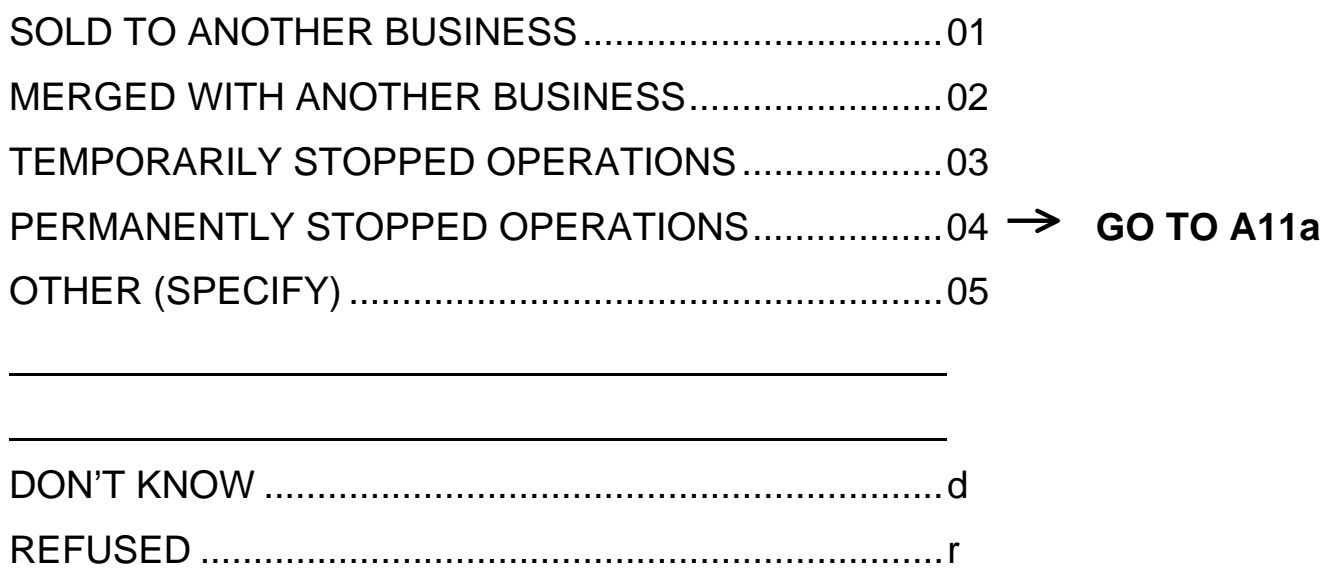

THANK AND TERMINATE

A11a. Did [NAME BUSINESS] file for bankruptcy?

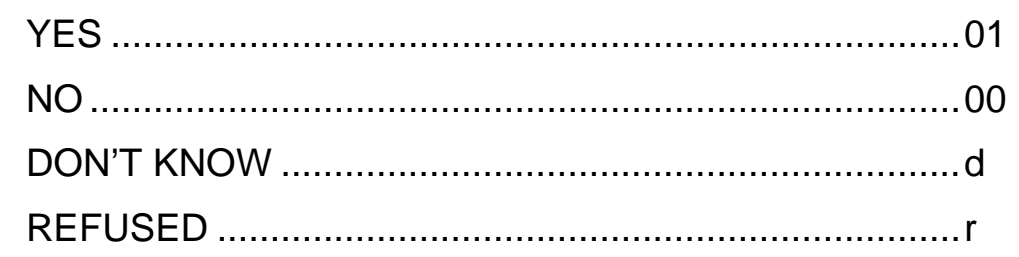

THANK AND TERMINATE 


NO SECTION B




\section{BUSINESS CHARACTERISTICS}

All of the following questions I'm going to ask are about [NAME BUSINESS]. Some of the questions will ask to confirm information about your business which you provided to us previously. As we go through the interview, please tell me if any of the information about your business is incorrect and needs to be updated.

C12. Our records show that [NAME BUSINESS] had a legal status of

[tOWNERshipModel]. As of December 31, 2006, is that still the legal status of [NAME BUSINESS]?

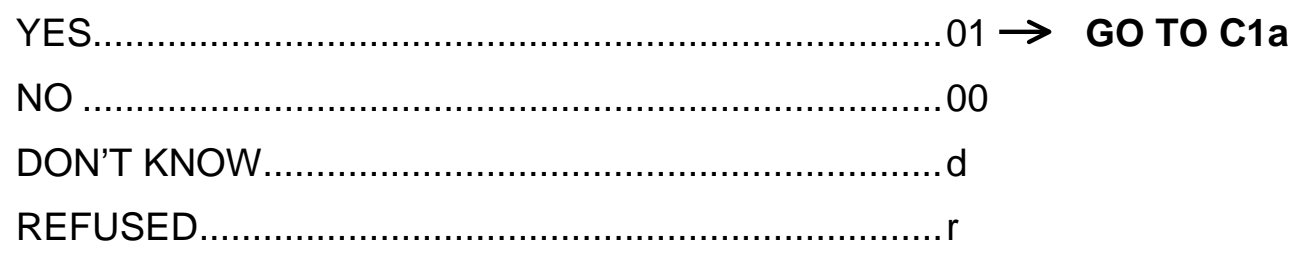


C1z2. I'm going to read you a list of some different forms of legal status a business can have. As of December 31, 2006, which form of legal status did [NAME BUSINESS] have? Was it a ...

\section{READ LIST AND READ DESCRIPTIONS AS NEEDED:}

Sole Proprietorship: A type of business ownership in which a business is owned and managed by one individual and no subchapter S-corporation or C-corporation has been established.

Limited Liability Company: A cross between a corporation and a partnership, and offering some of the benefits of both. Similar to S corporations, income produced by a limited liability company flows through to owners (known as "members") who pay their own taxes as individuals. Unlike S-corporations, however, limited liability companies are not subject to as many government restrictions.

Subchapter S-Corporation: Corporations in which all profits and losses are passed through to shareholders, just as they are passed through to partners in a partnership.

C-Corporation: Legal entities separate from their owners that may engage in business, make contracts, own property, pay taxes, and sue and be sued by others.

General Partnership: An association of two or more people who co-own a business for the purpose of making a profit and no subchapter S-corporation or C-corporation has been established.

Limited Partnership: A partnership in which one or more partners are general partners who manage the business and others are limited partners who invest in the business but forego any right to manage the company.

Sole Proprietorship, ........................................... 01

Limited Liability Company, ................................... 02

Subchapter S-Corporation, ..................................... 03

C-Corporation, ............................................... 04

General Partnership, ,......................................... 05

Limited Partnership, or........................................... 06

Something else? (SPECIFY) ................................ 07

DON'T KNOW....................................................

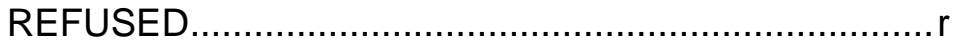


C1a. Our records indicate the principal activity of the business was [D\&B NAICS CODE DESCRIPTION]. Was that still the principal activity of the business as of December $31,2006 ?$

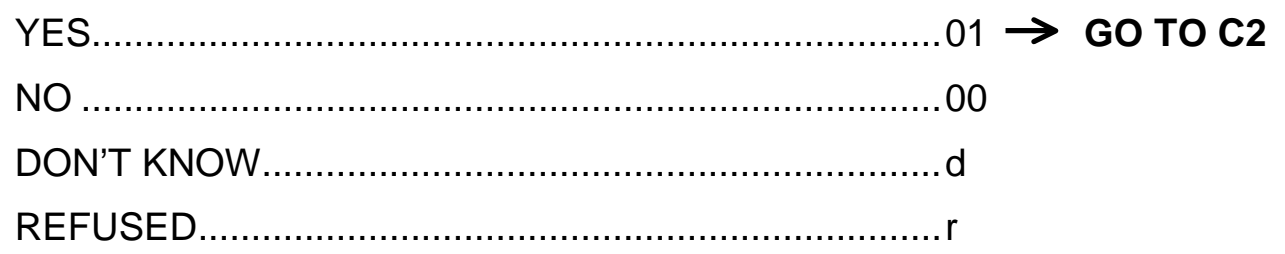

C1b. As of December 31, 2006, what was the principal activity of the business?

IF SOLE PROPRIETORSHIP IN [tOWNERshipModel] [or C1z2], GO TO C5.

C2. As of December 31, 2006, how many individuals or entities owned [NAME BUSINESS]? Please include all individuals or entities who owned shares in the business.

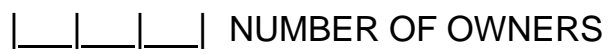

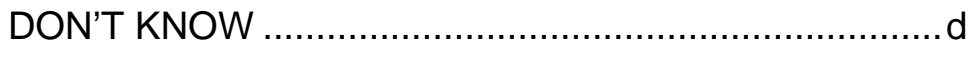

REFUSED ..........................................................

C3. Of the [NUMBER OF OWNERS FROM C2] owners as of December 31, 2006, how many owners actively helped to run [NAME BUSINESS]? By helped to run the business we mean that they provided regular assistance or advice with day-to-day operations of the business, rather than providing only money or occasional operating assistance.

I______ NUMBER OF OWNER/OPERATORS

DON'T KNOW .................................................. d

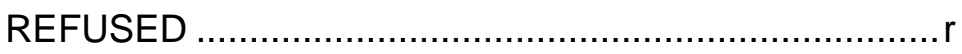


IF ONE OWNERIOPERATOR REPORTED AT C3, GO TO C5. IF MORE THAN ONE OWNER/OPERATOR REPORTED AT C3, ASK:

\section{C4. FOR EACH FIRST FOLLOW-UP OWNER/OPERATOR WHO IS NOT THE} RESPONDENT, ASK:

Was [OWNER NAME] still an owner who actively helped run [NAME BUSINESS]—as of December 31, 2006?

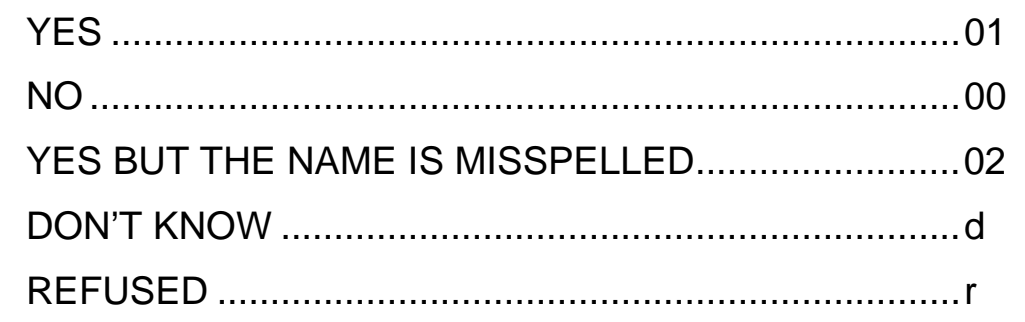

FOR ALL MISSPELLED NAMES, ASK:

How do you spell (your/his/her) name?

\section{INTERVIEWER: ENTER NAME}

\section{THEN ASK:}

How many other people, not previously listed, were owners actively helping to run [NAME BUSINESS] as of December 31, 2006.

\section{INTERVIEWER: PREVIOUSLY LISTED PEOPLE ARE STATED BELOW. NUMBER OF OWNERS STATED IN C3: [FILL FROM C3]}

I want to record with you the first and last names of these owners. These are the people who joined the business between the last time we talked to you and December 31, 2006. I'm going to be asking some questions about each of the owners who actively helped run [NAME BUSINESS]. Can you tell me the first and last name of the other owner(s) of $A B C$ Business?

\section{INTERVIEWER: ENTER FIRST AND LAST NAMES.}


C4Confirm. I have listed:

FIRST NAME

LAST NAME

OWNER A (RESPONDENT)

OWNER B

OWNER C

OWNER D

Are there any other owner-operators as of December 31, 2006 of [NAME BUSINESS] that I have not mentioned?

\section{INTERVIEWER: CONFIRM SPELLING OF NAMES. TO CORRECT NAMES, ARROW BACK TO TABLE.}

ADD ANOTHER NAME OR

CORRECT A MISSPELLING …................................ 01

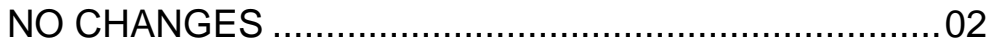

NOTE: UP TO 10 OWNER/OPERATOR/FOUNDERS WILL BE INCLUDED.

C5. Not counting owner(s), on December 31, 2006, how many people worked for [NAME BUSINESS]? Please include all full- and part-time employees, but exclude contract workers who work for the business either full- or part-time but are not on the business' official payroll.

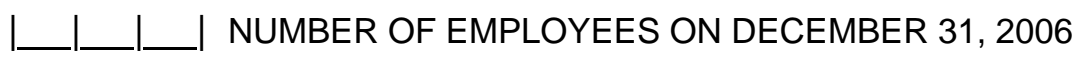

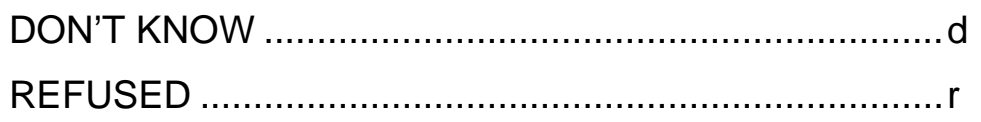

C5b. Was this change an increase, a decrease, or no change in the number of people who worked for [NAME BUSINESS] on December 31, 2006 compared to December 31, $2005 ?$

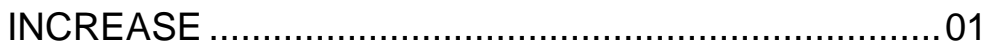

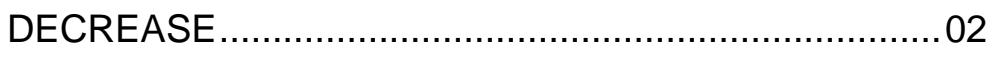

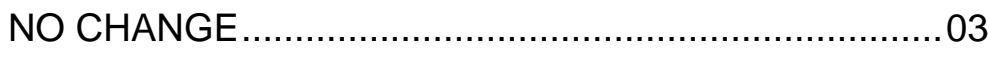

DON'T KNOW .................................................... d

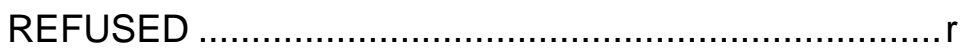


C5c. And what was the (increase/decrease) in the number of people who worked for [NAME BUSINESS] on December 31, 2006 compared to December 31, 2005? Your best estimate is fine.

\section{L____ CHANGE IN NUMBER OF EMPLOYEES}

DON'T KNOW ................................................. d

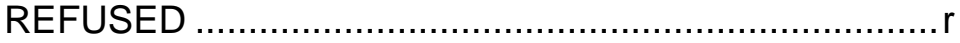

\section{IF BUSINESS REPORTED “0” EMPLOYEES AT C5, GO TO C8Z.}

C6. And of those [NUMBER FROM C5], how many were full-time? (IF NEEDED: Full-time is considered 35 hours or more per week)

I____ NUMBER OF DECEMBER 31, 2006 FULL-TIME EMPLOYEES

DON'T KNOW ........................................................

REFUSED ...........................................................

C7. And how many were part-time? (IF NEEDED: Part-time is considered less than 35 hours per week)

I_____ NUMBER OF DECEMBER 31, 2006 PART-TIME EMPLOYEES

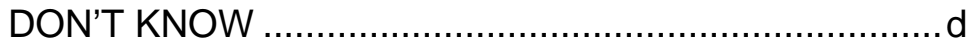

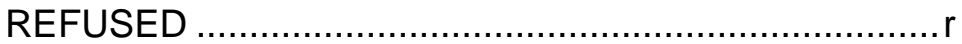

C8z. Our records show that the primary location where [NAME BUSINESS] operates is [tPrimaryLocation]. Is that correct?

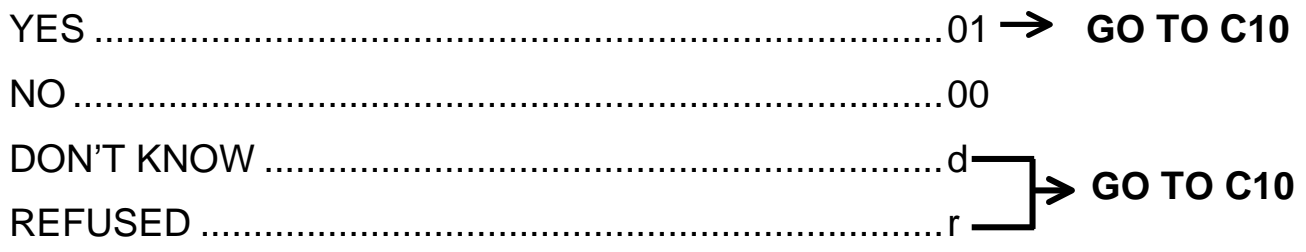


C8. How would you describe the primary location where [NAME BUSINESS] operates? Is it ...

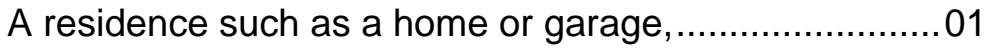

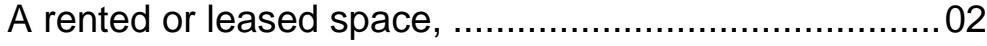

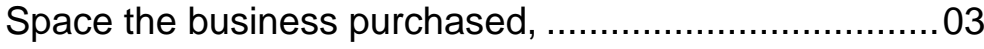

A site where a client is located, or ............................ 04

Some other location? (SPECIFY) .............................. 05

DON'T KNOW ….................................................. d

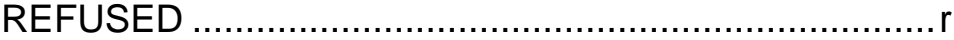

C9. What was the main reason for the change of location?

Previous location too expensive ................................ 01

Needed more space due to growth of business ..............02

Moved closer to customers ..................................... 03

Moved business and residence to new location ..............04

OTHER (SPECIFY) ......................................... 05

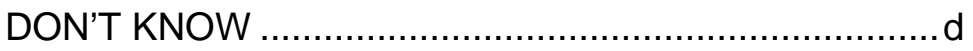

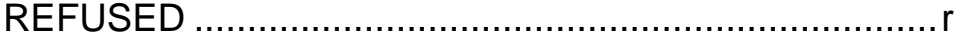

C10. As of December 31, 2006, did [NAME BUSINESS] operate in more than one location?

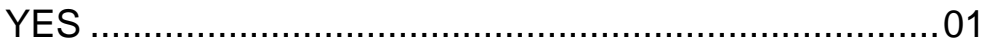

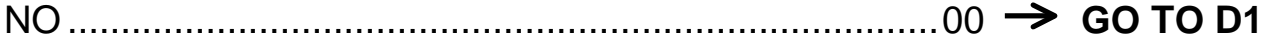

C11. And as of December 31, 2006, how many locations did [NAME BUSINESS] operate in? I____ NUMBER OF LOCATIONS AS OF DECEMBER 31, 2006

C11a. In what month and year did you open your second location? Month Year $\mid 2$ L 0 | 0 


\section{STRATEGY AND INNOVATION}

D1. Does [NAME BUSINESS] provide (READ ITEM)?

\begin{tabular}{|c|c|c|c|c|}
\hline & YES & NO & $\begin{array}{l}\text { DON'T } \\
\text { KNOW }\end{array}$ & REFUSED \\
\hline 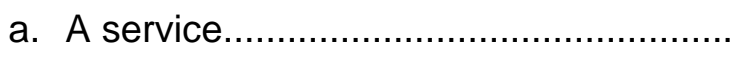 & 01 & 00 & d & $r$ \\
\hline 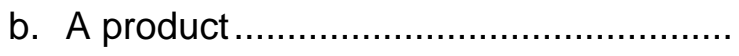 & 01 & 00 & $d$ & r \\
\hline
\end{tabular}

D2. Businesses often have to compete with other businesses. A competitive advantage is something unique or distinctive a business provides that gives it an advantage compared to competitors. In calendar year 2006, did [NAME BUSINESS] have a competitive advantage over its competitors?

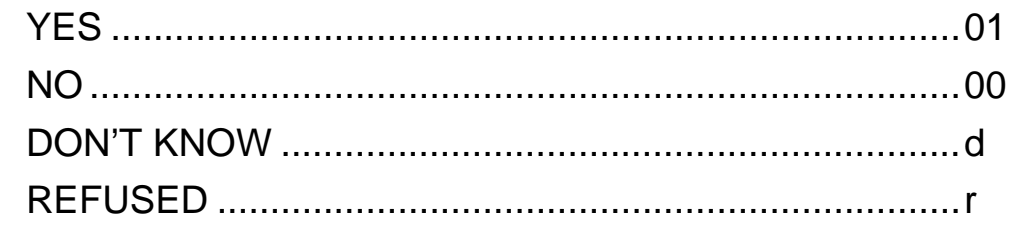

D3. Whether assigned by an owner or obtained in some other way, does [NAME BUSINESS] have any of the following? (READ LIST)

FOR EACH "YES," ASK: How many (READ ITEM) does [NAME BUSINESS] have?

\section{INTERVIEWERS IF NEEDED:}

Patent: A patent is a right given by the government to preclude others from making and selling an invention for 20 years from the date of application in return for disclosure of how the invention operates.

Copyright: The legal right granted to authors, composers, artists and publishers to protect their thoughts and ideas for exclusive publication, reproduction, sale and distribution of their works.

Trademark: Words, names, symbols or devices, or any combination of these used to identify the goods of a business and to distinguish these goods from the goods of others.

\begin{tabular}{|c|c|c|c|c|c|}
\hline & YES & NO & $\begin{array}{l}\text { DON'T } \\
\text { KNOW }\end{array}$ & REFUSED & $\begin{array}{c}\text { NUMBER } \\
\text { BUSINESS HAS }\end{array}$ \\
\hline a. Patents ...................... & 01 & 00 & $d$ & $r$ & 1 \\
\hline b. Copyrights ................. & 01 & 00 & $d$ & r & $\mathrm{l}$ \\
\hline c. Trademarks .............. & 01 & 00 & $d$ & r & 1 \\
\hline
\end{tabular}


D4. "Licensing out" is licensing patents, copyrights, or trademarks owned by the business to other parties under a licensing agreement. In calendar year 2006, did [NAME BUSINESS] license out any (READ ITEM)?

\begin{tabular}{|c|c|c|c|c|}
\hline & YES & NO & $\begin{array}{l}\text { DON'T } \\
\text { KNOW }\end{array}$ & REFUSED \\
\hline 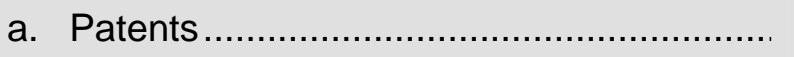 & 01 & 00 & d & r \\
\hline 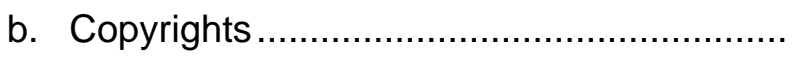 & 01 & 00 & $d$ & r \\
\hline 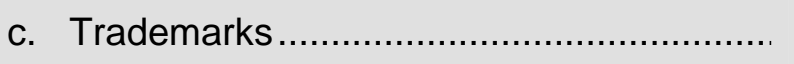 & 01 & 00 & $d$ & r \\
\hline
\end{tabular}

D5. "Licensing in" is acquiring the right to use intellectual property such as patents, copyrights, or trademarks created by someone outside the business through a licensing agreement. In calendar year 2006, did [NAME BUSINESS] license in any (READ ITEM)?

\begin{tabular}{|l|l|l|l|}
\hline YES & NO & KON'T & \\
KNOW & REFUSED \\
\hline
\end{tabular}
a. Patents
01
00
d
$r$
b. Copyrights.
$01 \quad 00$
d
$r$
c. Trademarks .
01
00
d
$r$

D6. Did [NAME BUSINESS] have any customers or sales in calendar year 2006?

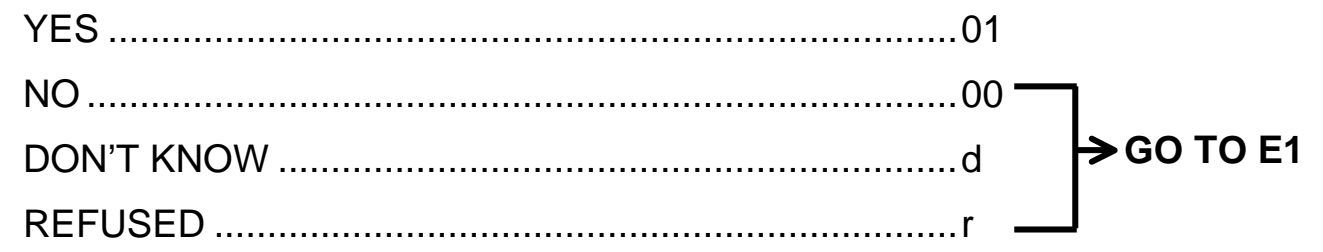


D7. l'd like to learn more about the type of customers that [NAME BUSINESS] had during calendar year 2006. I am going to ask you to estimate the percent of the business' sales that were made to individuals, businesses, and government agencies. The total should equal $100 \%$.

a. During calendar year 2006, what percentage of the business' sales were to private individuals?

L______ PERCENTAGE

DON'T KNOW …...................................................

REFUSED .....................................................

b. What percentage of the business' sales were to other businesses?

[IF NEEDED: Please include sales to for-profit and not-for-profit business.]

I_____ I PERCENTAGE

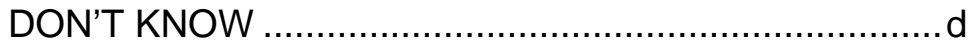

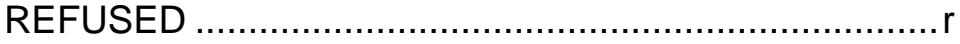

c. What percentage of the business' sales were to government agencies?

I______ PERCENTAGE

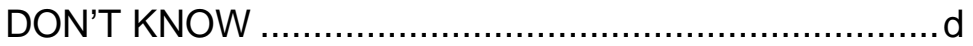

REFUSED ...................................................... 


\section{E. BUSINESS ORGANIZATION AND HR BENEFITS}

\section{IF ONE OWNER REPORTED AT C2 AND BUSINESS REPORTED "0" EMPLOYEES AT C5, GO TO F1.}

Next, l'd like to ask about how [NAME BUSINESS] is organized and about the benefits that are offered to employees.

E1. $\quad$ On December 31, 2006, how many employees or owners, if any, did [NAME BUSINESS] have who were primarily responsible for (READ ITEM)? Please include only full- and part-time employees, but not contract workers who work for the business but are not on the business' official payroll.

a. Human resources such as employee benefits, recruitment, or hiring

\begin{tabular}{|c|c|c|}
\hline NUMBER & & \\
EMPLOYEES & DON'T & \\
OR OWNERS & KNOW & REFUSED \\
\hline
\end{tabular}

b. Sales or Marketing such as sales, market research, customer analysis, or promotional activities

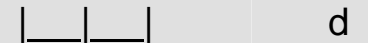

$r$

c. Executive administration functions such as strategic planning, competitive analysis, shareholder relations, or general management....

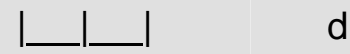

d $\quad r$

d. Research and development on new products or services

e. Production or manufacturing such as producing materials or products, production planning, production control, quality control, or storage .......

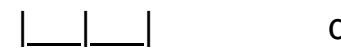

d $\quad r$

General administration such as office management, responding to maintenance requests, purchase supplies, or training employees in office procedures

g. Financial administration such as accounting procedures, budgeting, financial analysis, or investment activities

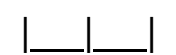

d

r

h. Does [NAME BUSINESS] have employees with any other key responsibilities? (SPECIFY)....

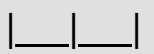

d $r$

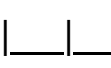

d r 
E2a. As of December 31, 2006, did [NAME BUSINESS] offer full-time employees or owners (READ ITEM):

\begin{tabular}{|c|c|c|c|c|}
\hline & YES & NO & $\begin{array}{l}\text { DON'T } \\
\text { KNOW }\end{array}$ & REFUSED \\
\hline 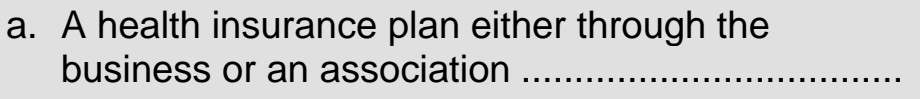 & 01 & 00 & $d$ & r \\
\hline $\begin{array}{l}\text { b. A retirement plan such as profit sharing, pension, } \\
\text { including } 401 \mathrm{~K} \text {, annuity, Keogh, etc. ........................ }\end{array}$ & 01 & 00 & $d$ & r \\
\hline c. Stock options or other stock ownership .................. & 01 & 00 & $d$ & r \\
\hline 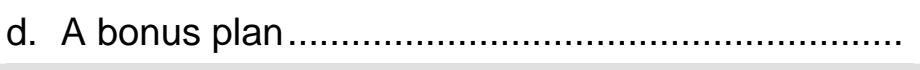 & 01 & 00 & d & r \\
\hline 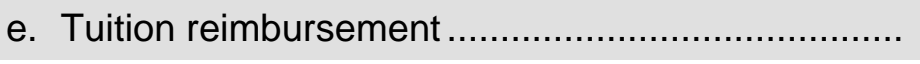 & 01 & 00 & $d$ & r \\
\hline 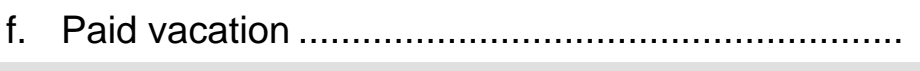 & 01 & 00 & d & r \\
\hline 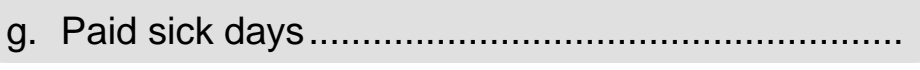 & 01 & 00 & d & r \\
\hline $\begin{array}{l}\text { h. Alternative work schedules such as flex time or } \\
\text { job sharing } \ldots \ldots \ldots \ldots \ldots \ldots \ldots \ldots \ldots \ldots \ldots \ldots \ldots \ldots \ldots \ldots \ldots \ldots \ldots \ldots \ldots \ldots \ldots \ldots \ldots \ldots \ldots \ldots \ldots \ldots \\
\ldots\end{array}$ & 01 & 00 & $d$ & r \\
\hline 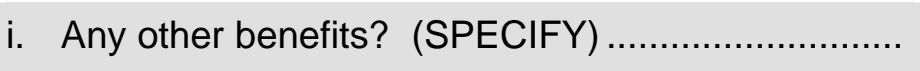 & 01 & 00 & $\mathrm{~d}$ & r \\
\hline
\end{tabular}

IF ZERO PART-TIME EMPLOYEES AT C7, GO TO F1.

E2b. As of December 31, 2006, did [NAME BUSINESS] offer part-time employees (READ ITEM):

\begin{tabular}{|c|c|c|c|c|}
\hline & YES & NO & $\begin{array}{l}\text { DON'T } \\
\text { KNOW }\end{array}$ & REFUSED \\
\hline $\begin{array}{l}\text { a. A health insurance plan either through the } \\
\text { business or an association }\end{array}$ & 01 & 00 & $d$ & r \\
\hline $\begin{array}{l}\text { b. A retirement plan such as profit sharing, pension, } \\
\text { including } 401 \mathrm{~K} \text {, annuity, Keogh, etc. .................... }\end{array}$ & 01 & 00 & d & r \\
\hline c. Stock options or other stock ownership ................. & 01 & 00 & d & r \\
\hline d. A bonus plan & 01 & 00 & d & r \\
\hline 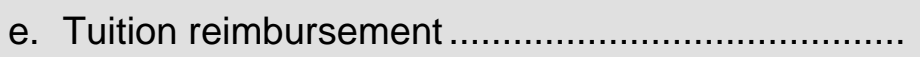 & 01 & 00 & d & r \\
\hline f. Paid vacation & 01 & 00 & d & r \\
\hline g. Paid sick days ........... & 01 & 00 & $d$ & r \\
\hline 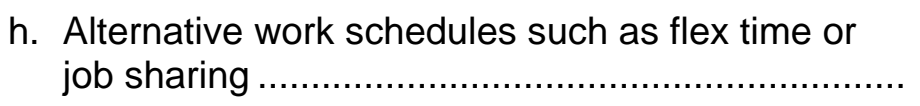 & 01 & 00 & d & r \\
\hline 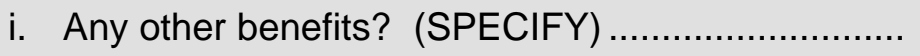 & 01 & 00 & $d$ & r \\
\hline
\end{tabular}




\section{F. BUSINESS FINANCES}

F1. Now l'd like to ask about [NAME BUSINESS]'s financing. Businesses can get money from the savings or investments of the owner(s), money from spouses, family or other individuals, from companies, borrowing in an owner's name, venture funds, or by borrowing in the name of the business. Some of the funds must be paid back and other funds represent an equity stake or share of the business. We will ask some questions about what happened during calendar year 2006, some questions about what has happened since the business began, and other questions about balances as of December 31, 2006.

F1a. First, in calendar year 2006, did [you/OWNER B-J] put any of your own money into [NAME BUSINESS] in return for an ownership share of the business? Please do not include any money borrowed from others or from credit cards.

IF NEEDED: This would include all additional money invested by [you/OWNER B-J] in the business during calendar year 2006.

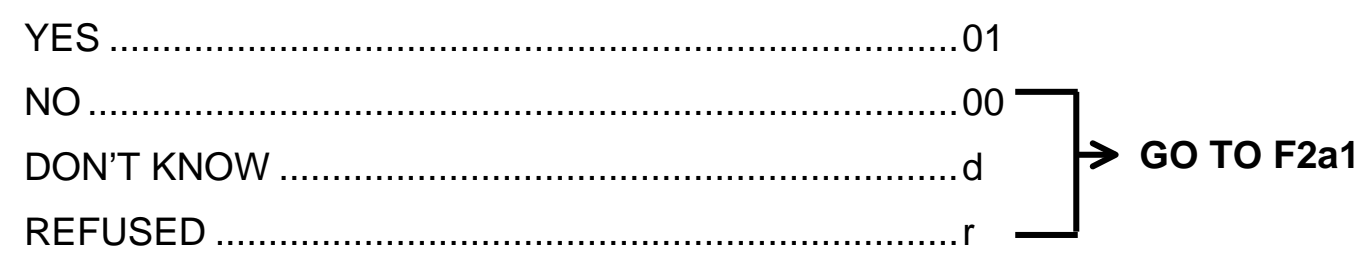


F2a. IF YES: How much of [your/her/his] own money did [you/he/she] put into the business during calendar year 2006?

IF NEEDED: Your best estimate is fine.

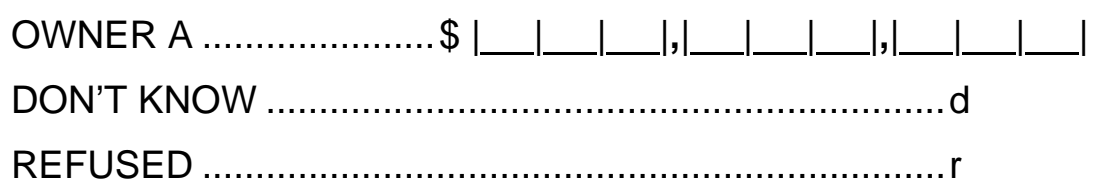

IF DON'T KNOW OR REFUSED, PROBE WITH RANGES: Would you say it was . .

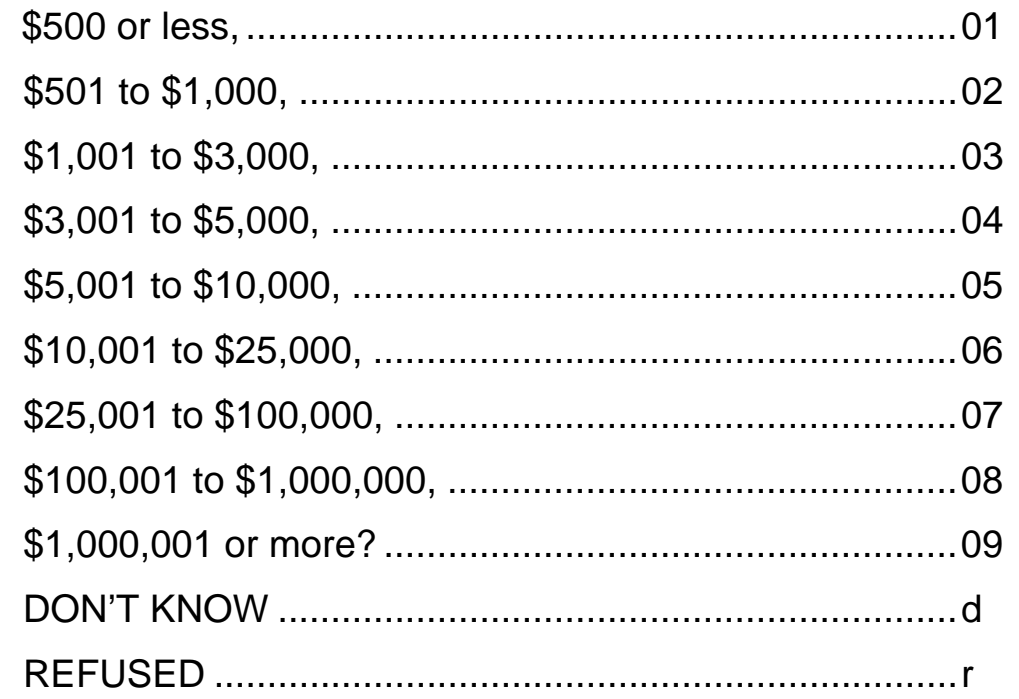


F2a1. Counting all years, how much of [your/OWNER B-J's] own money did [you/she/he] put into [NAME BUSINESS] as of December 31, 2006?

IF NEEDED: This includes all money [you/she/he] invested in the business as of December 31, 2006.

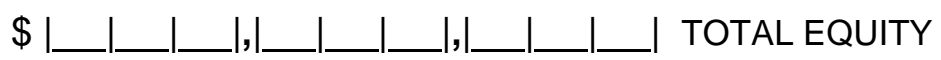

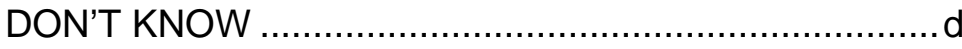

REFUSED ......................................................

\section{PROBE: IF DON'T KNOW OR REFUSED, PROBE WITH RANGES:}

Would you say it was...

$\$ 500$ or less, .......................................................... 01

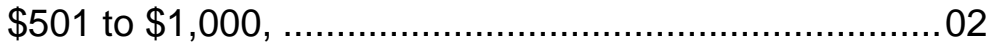

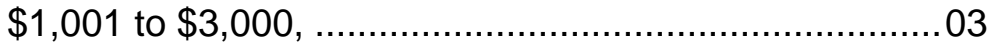

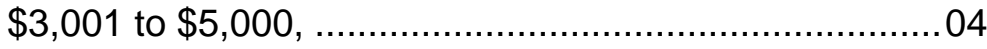

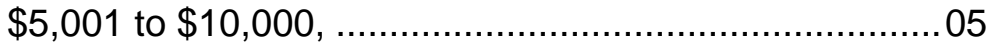

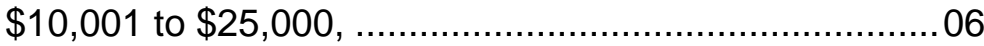

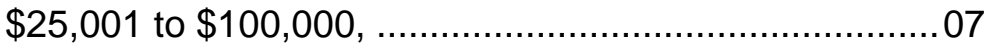

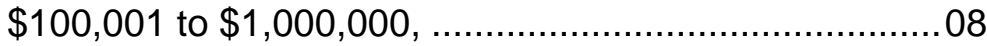

$\$ 1,000,001$ or more? ............................................... 09

DON'T KNOW .................................................... d

REFUSED .......................................................

\section{IF F2a IS GREATER THAN F2a1:}

I may have made a mistake. The amount invested in 2006 is greater than the amount invested in all years combined. Is there an error?

F2b. What percentage of the business did [you/OWNER B-J] own on December 31, 2006?

I______ PERCENTAGE OF BUSINESS

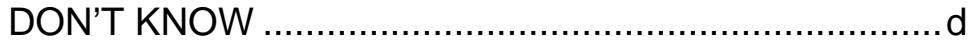

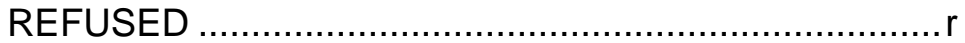

IF MORE THAN ONE OWNER/OPERATOR AT C4, ASK F1a-F2b FOR EACH

OWNER/OPERATOR. OTHERWISE, GO TO F3.

IF SOLE PROPRIETORSHIP AT QUESTION C1z OR C1z2, GO TO F6b. 
F3. Equity investment is money received in return for some portion of ownership, and it is another way to fund business expenses. During calendar year 2006, did the business obtain equity financing from any of the following sources?

\begin{tabular}{|c|c|c|c|c|c|}
\hline & & YES & NO & $\begin{array}{l}\text { DON'T } \\
\text { KNOW }\end{array}$ & REFUSED \\
\hline a. & $\begin{array}{l}\text { Spouses or life partners of owners of the business. This } \\
\text { does not include spouses or life partners already named } \\
\text { as owners }\end{array}$ & 01 & 00 & $d$ & r \\
\hline b. & Parents, in-laws or children of owners of the business ........ & 01 & 00 & $d$ & r \\
\hline c. & 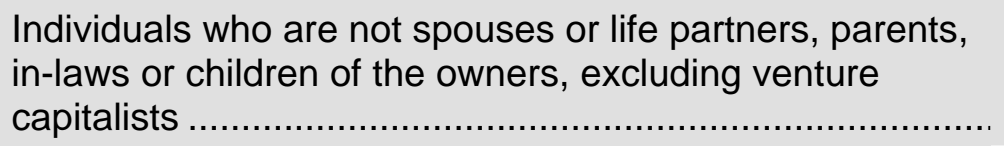 & 01 & 00 & d & r \\
\hline d. & 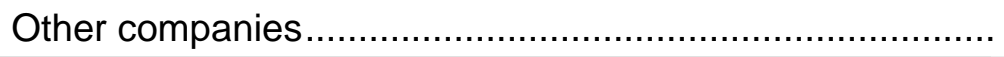 & 01 & 00 & d & r \\
\hline e. & Government agencies $\ldots \ldots \ldots \ldots \ldots \ldots \ldots \ldots \ldots \ldots \ldots \ldots \ldots \ldots \ldots \ldots$ & 01 & 00 & d & r \\
\hline f. & 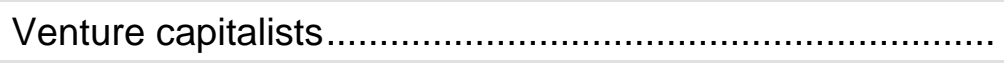 & 01 & 00 & d & r \\
\hline g. & Any other sources? (SPECIFY) & 01 & 00 & d & r \\
\hline
\end{tabular}

F4. FOR EACH EQUITY FINANCING OPTION REPORTED AS "YES" ABOVE, ASK:

In calendar year 2006, how much money did [NAME BUSINESS] receive from [EQUITY OPTION]?

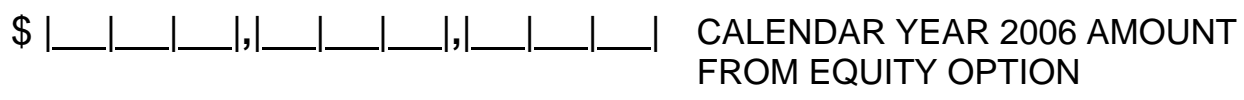

DON'T KNOW ................................................ d

REFUSED ......................................................

IF DON'T KNOW OR REFUSED, PROBE WITH RANGES: Would you say it was ...

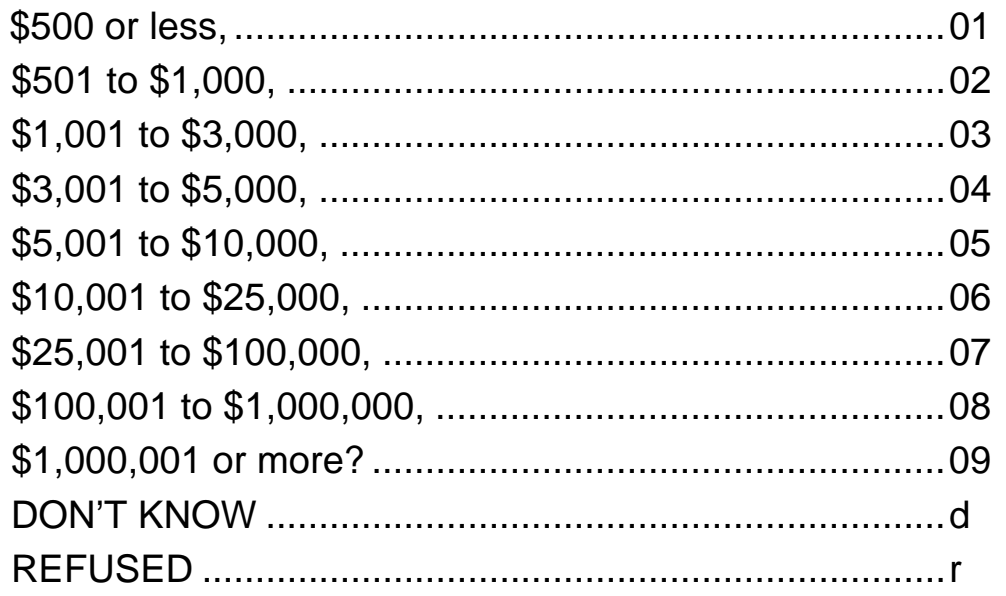


F4a. Counting all years, how much did [EQUITY OPTION] put into [NAME BUSINESS] as of December 31, 2006?

PROBE: This includes all money invested by [EQUITY OPTION] in all years.

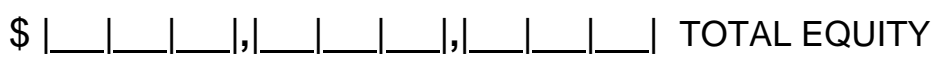

DON'T KNOW ..................................................

REFUSED ........................................................

PROBE: IF DON'T KNOW OR REFUSED, PROBE WITH RANGES: Would you say it was...

$\$ 500$ or less, ................................................................. 01

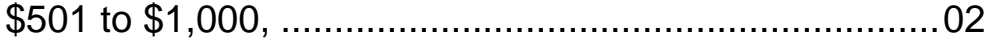

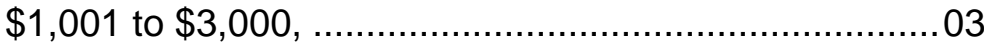

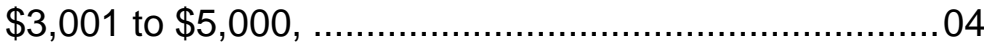

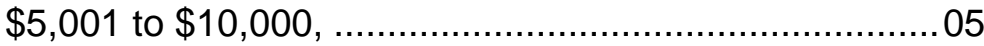

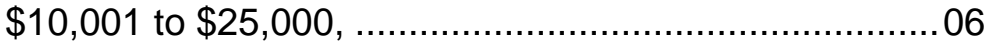

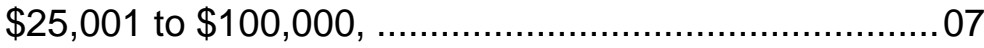

$\$ 100,001$ to $\$ 1,000,000, \ldots \ldots \ldots \ldots \ldots \ldots \ldots \ldots \ldots \ldots \ldots \ldots \ldots \ldots \ldots \ldots . . .08$

$\$ 1,000,001$ or more?

DON'T KNOW ……................................................

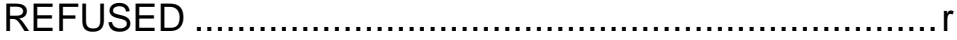

IF F4 IS GREATER THAN F4a:

I may have made a mistake. The amount invested in 2006 is greater than the amount invested in all years combined. Is there an error?

F5. FOR EACH EQUITY FINANCING OPTION REPORTED AS "YES" ABOVE, ASK: What was the total percentage of the business owned by the [EQUITY OPTION] who invested money in the business as of December 31, 2006?

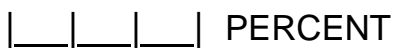

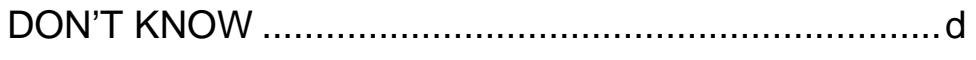

REFUSED ......................................................... 
IF TOTAL PERCENTAGE EQUALS $100 \%$, GO TO F6a

IF TOTAL EQUALS LESS OR MORE THAN $100 \%$

F6. So far, you've given me the following information on who owns [NAME BUSINESS]:

[LIST EQUITY INVESTORS FROM F2b AND F5]. Can we review this list?

\section{REVIEW LIST OF OWNERS AND PERCENTAGES WITH RESPONDENT. MAKE CHANGES AS NEEDED, ADDING NEW OWNERS ANDIOR PERCENTAGES AS NECESSARY.}

DON'T KNOW $d$

REFUSED $r$

F6a. Have you or other owners withdrawn money from the business for personal use in 2006?

INTERVIEWER: IF NEEDED This does not include owner salaries.

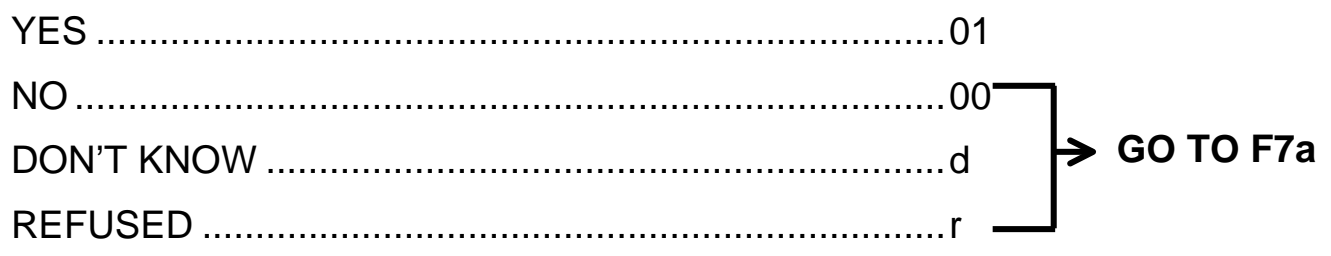


F6b. IF YES: Thinking of calendar year 2006 only, how much money, if any, did you and other owners withdraw from the business for personal use? This includes any dividends paid.

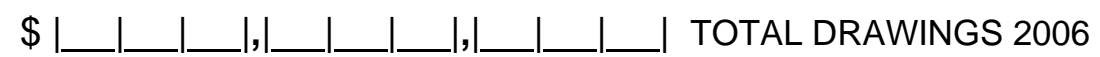

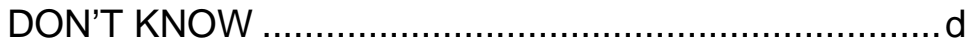

REFUSED ......................................................

IF DON'T KNOW OR REFUSED, PROBE WITH RANGES: Would you say it was . . .

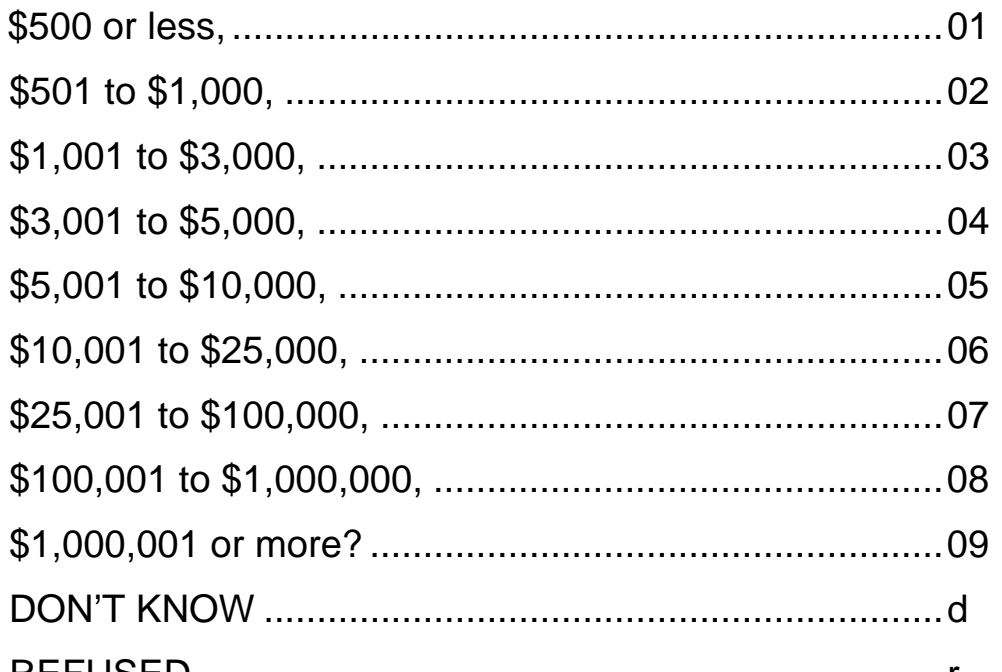

REFUSED ........................................................

F7a. Another way to finance a business is debt financing. Debt is money borrowed that has to be paid back with or without interest.

We will be talking about categories of debt based on who is responsible for paying it back. For each category, I'll ask you about several sources of debt business owners or businesses can use to fund operations. We want to make sure that any businessrelated debt is reported in the right category, and is reported only once. I will identify each category and remind you when I change categories. Here is the first category.

I'm going to ask you about some different types of debt financing you may have borrowed in your name on behalf of [NAME BUSINESS]. For each, please tell me if you used this type at any time during calendar year 2006. Did you use [NAME FINANCING OPTION FROM LIST]? 
F7b. IN BELOW LIST, FOR EACH DEBT FINANCING OPTION BUSINESS REPORTED, ASK: How many [NAME DEBT FINANCING OPTION] did you use to finance the operation of the business during calendar year 2006?

\begin{tabular}{|c|c|c|c|c|c|c|}
\hline & & YES & NO & $\begin{array}{l}\text { DON'T } \\
\text { KNOW } \\
\end{array}$ & REFUSED & $\begin{array}{c}\text { NUMBER } \\
\text { USED }\end{array}$ \\
\hline a. & $\begin{array}{l}\text { Personal credit cards for business- } \\
\text { related purposes............................... }\end{array}$ & 01 & 00 & d & r & 1 \\
\hline b. & $\begin{array}{l}\text { Personal loans from a bank or other } \\
\text { financial institution, such as a mortgage } \\
\text { or home equity loan used for the } \\
\text { business }\end{array}$ & 01 & 00 & $d$ & r & - \\
\hline c. & 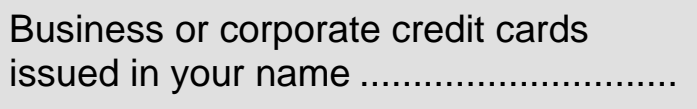 & 01 & 00 & d & r & \\
\hline d. & 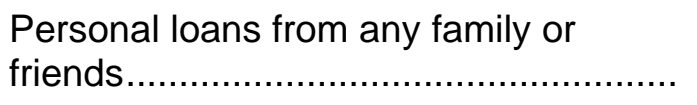 & 01 & 00 & $d$ & $r$ & I_L \\
\hline e. & $\begin{array}{l}\text { Personal loans from any other } \\
\text { individuals not associated with the } \\
\text { management of the business .................. }\end{array}$ & 01 & 00 & $d$ & r & I_L_ \\
\hline f. & Any other sources? (SPECIFY) ............ & 01 & 00 & $d$ & r & $\mathrm{l}$ \\
\hline
\end{tabular}


F8a. IF ANSWERED "YES" TO F7a ITEMS a, c, ASK: As of December 31, 2006, what was the maximum credit line on the [NAME DEBT FINANCING OPTION]?

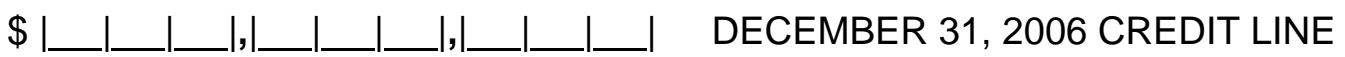

DON'T KNOW ................................................ d

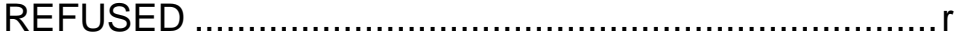

IF DON'T KNOW OR REFUSED, PROBE WITH RANGES: Would you say it was . .

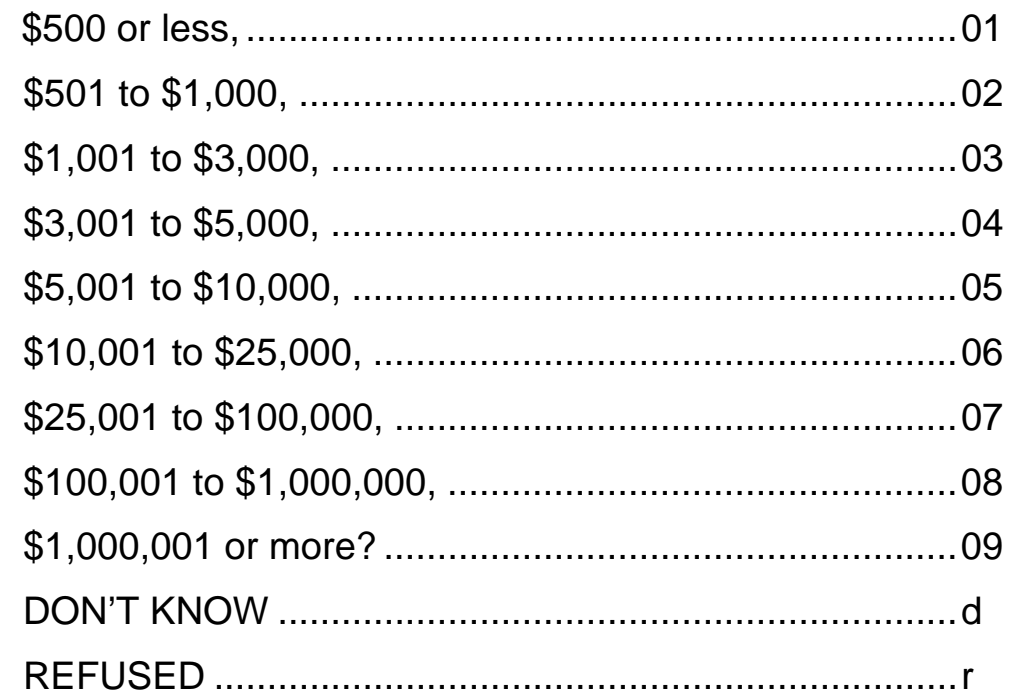


F8b. IF ANSWERED "YES" TO F7a ITEMS a, c, ASK: As of December 31, 2006, what was the outstanding balance on the [NAME DEBT FINANCING OPTION]?

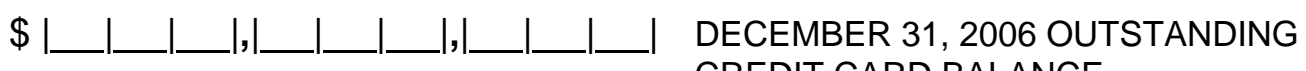
CREDIT CARD BALANCE

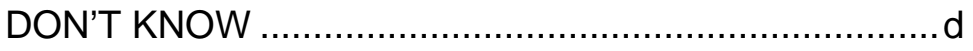

REFUSED .........................................................

IF DON'T KNOW OR REFUSED, PROBE WITH RANGES: Would you say it was . .

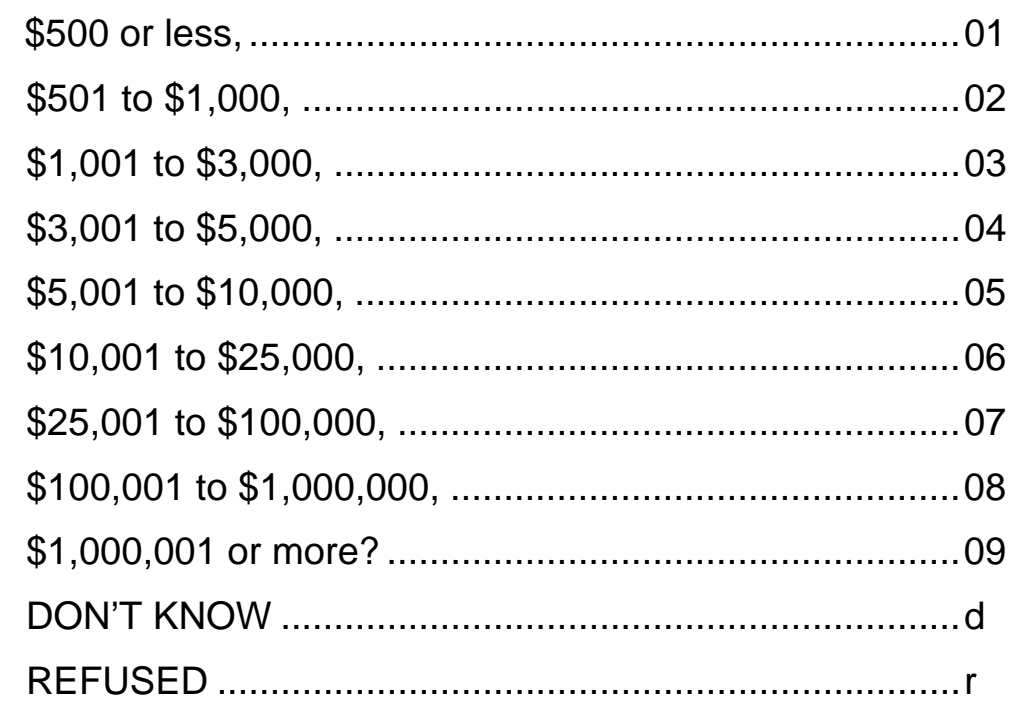

\section{IF F8b IS GREATER THAN F8a:}

Perhaps I made a mistake. The amount I recorded as the balance outstanding is greater than the amount reported as the maximum credit limit. 
F8c. IF ANSWERED "YES" TO F7a ITEMS b, d, e, f, ASK: In calendar year 2006, how much was obtained from the [NAME DEBT FINANCING OPTION]?

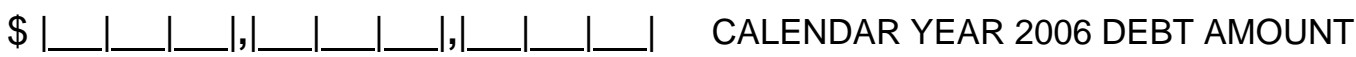

DON'T KNOW ................................................... d

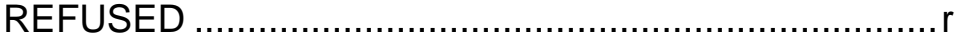

IF DON'T KNOW OR REFUSED, PROBE WITH RANGES: Would you say it was . .

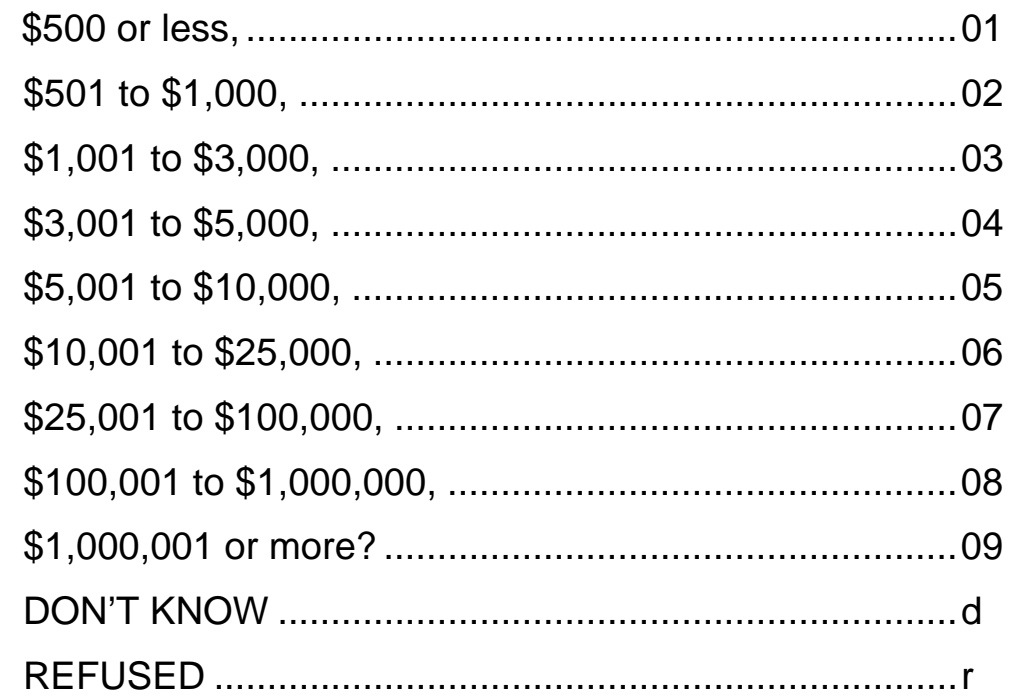


F8d. As of December 31, 2006, what was the estimated amount of the [NAME DEBT FINANCING OPTION] owed by you on behalf of [NAME BUSINESS]?

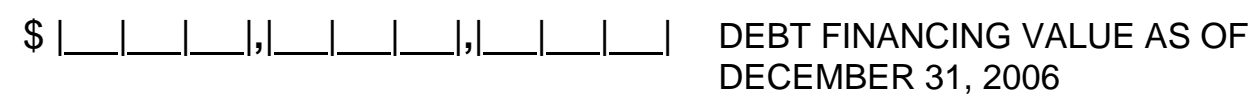

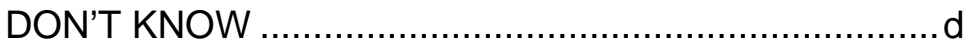

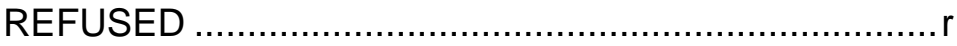

IF DON'T KNOW OR REFUSED, PROBE WITH RANGES: Would you say it was . . .

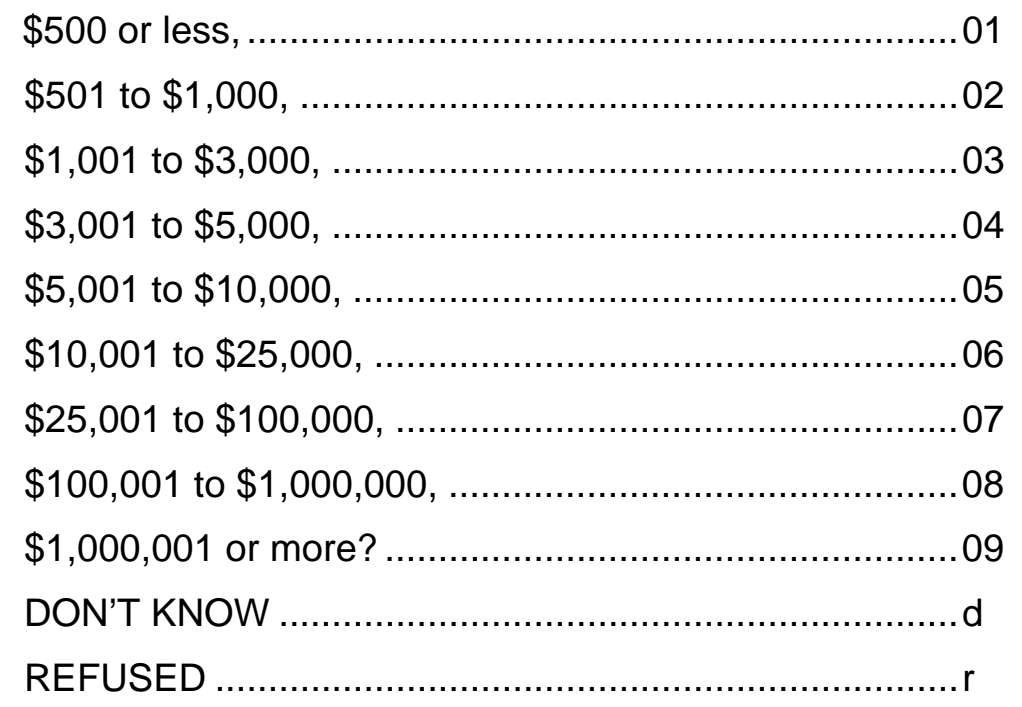




\section{IF MORE THAN ONE OWNER/OPERATOR AT C4, ASK F9a. OTHERWISE, GO TO}

F11a.

F9a. Here is the next debt category. I'm going to ask you about some different types of debt financing that other owners may have borrowed on behalf of [NAME BUSINESS]. This debt does not include amounts already reported in the previous section about your debt. For each, please tell me if other owners used this type at any time during calendar year 2006. Did other owners use [NAME DEBT FINANCING OPTION FROM LIST]?

F9b. IN BELOW LIST, FOR EACH DEBT FINANCING OPTION BUSINESS REPORTED, ASK: How many [NAME DEBT FINANCING OPTION] did other owners use to finance the operation of the business during calendar year 2006?

\begin{tabular}{|c|c|c|c|c|}
\hline V & NO & $\begin{array}{l}\text { DON'T } \\
\text { KNOW }\end{array}$ & REF & $\begin{array}{l}\text { NUMBER } \\
\text { USFD }\end{array}$ \\
\hline
\end{tabular}

a. Personal credit cards for business-related purposes

$0100 \quad d$

b. Personal loans from a bank or other financial institution, such as a mortgage or home equity loan used for the business

c. Business or corporate credit cards issued in the other owner's name(s)

$0100 \quad d$

r

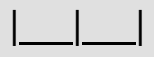

d. Personal loans from any family or friends

$0100 \quad d$

r

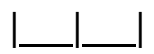

e. Personal loans from any other individuals not associated with the management of the business....

0100

d

r

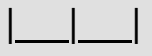

f. Any other sources? (SPECIFY)

0100

d

r 
F10a. IF ANSWERED "YES" TO F9a ITEMS a, c, ASK: As of December 31, 2006, what was the maximum credit line on the [NAME DEBT FINANCING OPTION] of (one of) the other owner(s)?

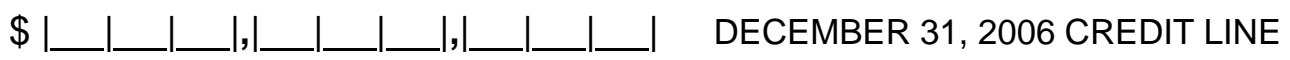

DON'T KNOW ................................................. d

REFUSED .......................................................

IF DON'T KNOW OR REFUSED, PROBE WITH RANGES: Would you say it waS . .

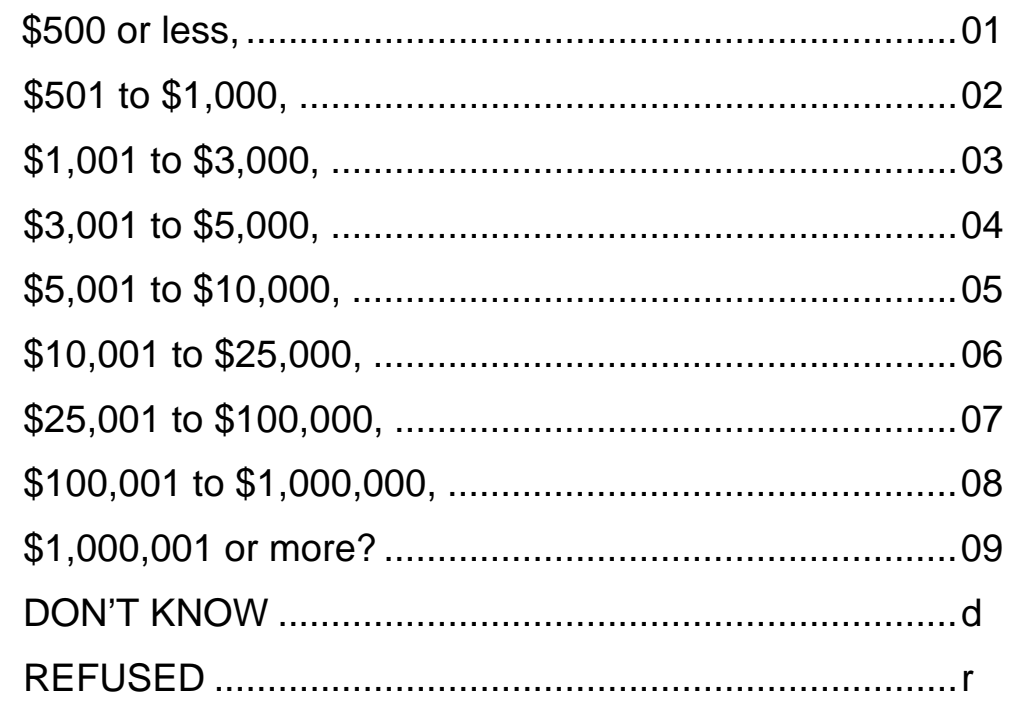


F10b. IF ANSWERED "YES" TO F9a ITEMS a, c, ASK: As of December 31, 2006, what was the outstanding balance on the [NAME DEBT FINANCING OPTION] used by (one of) the other owner(s)?

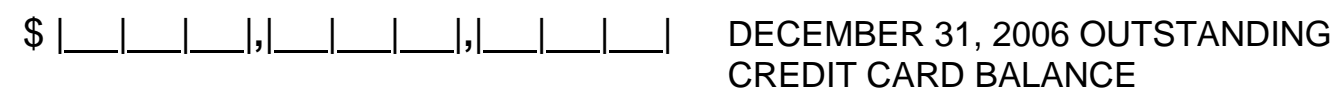

DON'T KNOW …....................................................

REFUSED .......................................................

IF DON'T KNOW OR REFUSED, PROBE WITH RANGES: Would you say it was . . .

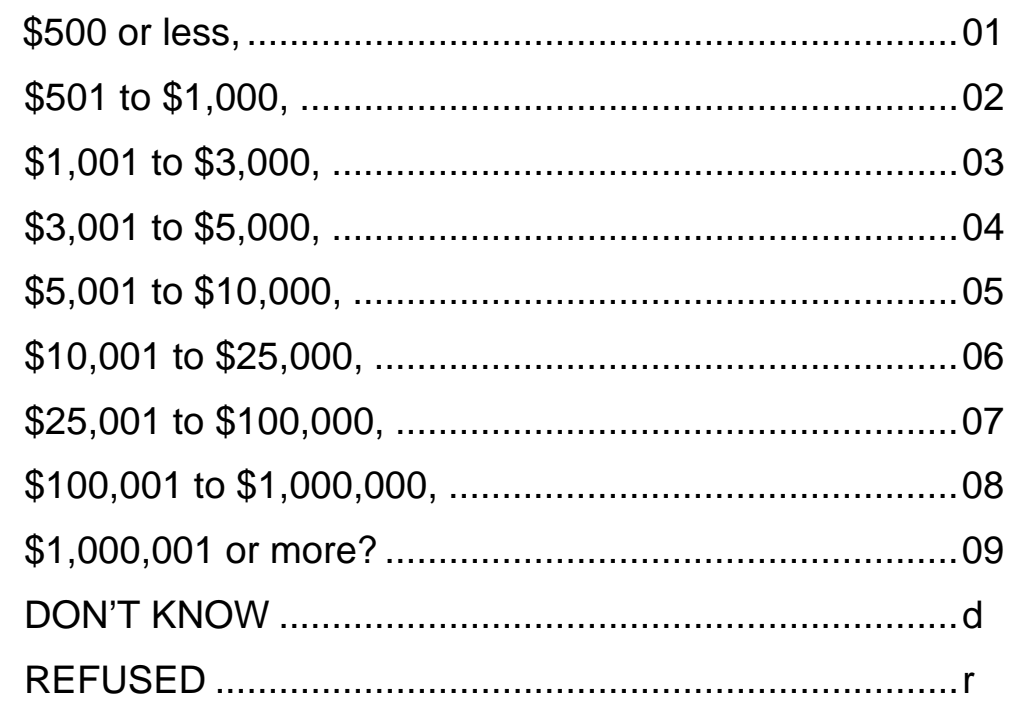

\section{IF F10b IS GREATER THAN F10a:}

Perhaps I made a mistake. The amount I recorded as the balance outstanding is greater than the amount reported as the maximum credit limit. 
F10c. IF ANSWERED "YES" TO F9a, ITEMS b, d, e, f, ASK: In calendar year 2006, how much was obtained from the [NAME DEBT FINANCING OPTION] other owners used?

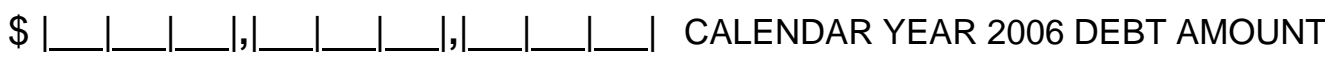

DON'T KNOW ..................................................... d

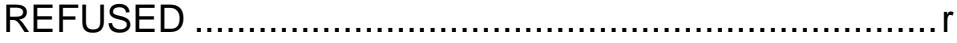

IF DON'T KNOW OR REFUSED, PROBE WITH RANGES: Would you say it was . .

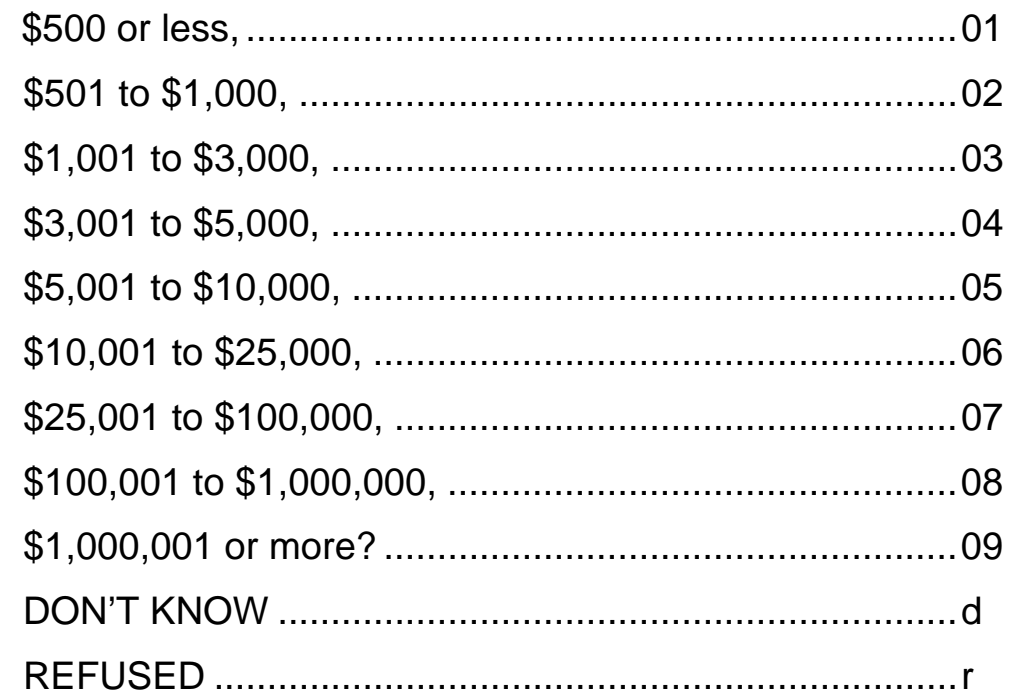


F10d. As of December 31, 2006, what was the estimated amount of the [NAME DEBT FINANCING OPTION] owed by other owners on behalf of [NAME BUSINESS]?

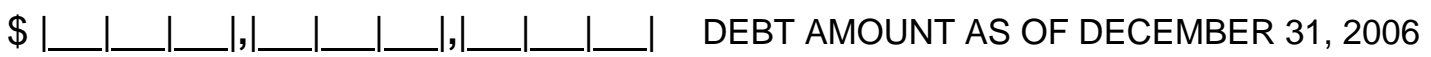
DON'T KNOW ................................................. d

REFUSED ......................................................

IF DON'T KNOW OR REFUSED, PROBE WITH RANGES: Would you say it was . . .

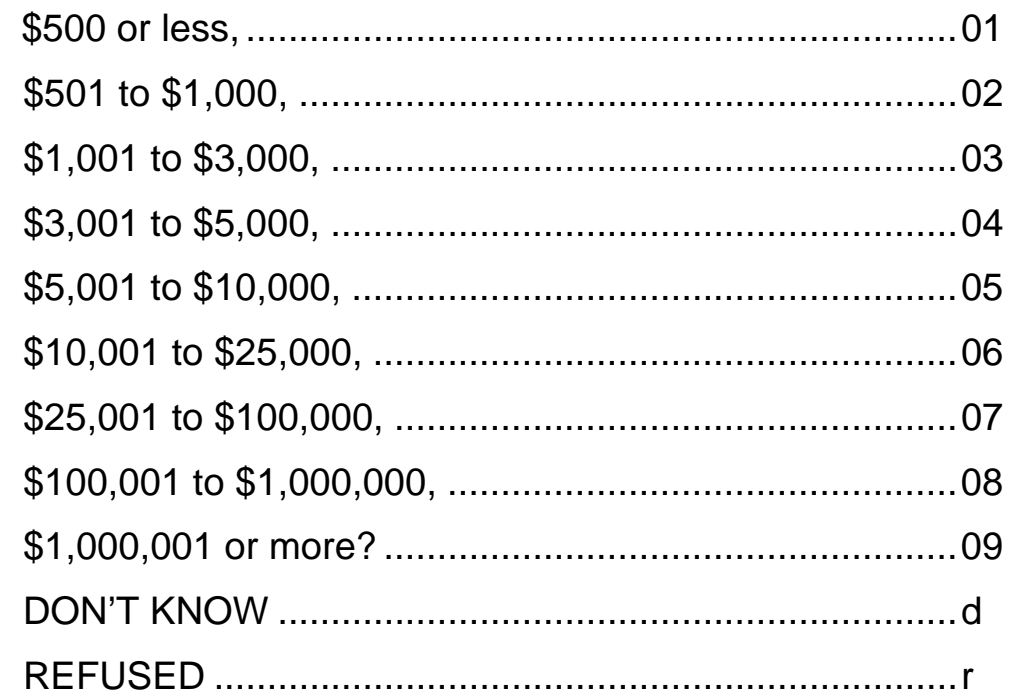


F11a. We are once again switching to another debt category. Now I'm going to ask you about some different types of debt financing that may have been obtained in the name of the business during calendar year 2006. This debt does not include amounts already reported in the previous sections about your debt or the debt of other owners. During calendar year 2006, did [NAME BUSINESS] use [NAME DEBT FINANCING OPTION FROM LIST]?

F11b. IN BELOW LIST, FOR EACH DEBT FINANCING OPTION BUSINESS REPORTED, ASK: How many [NAME DEBT FINANCING OPTION] did the business use to finance the operation or the business during calendar year 2006?

\begin{tabular}{|c|c|c|c|c|}
\hline YES & NO & $\begin{array}{c}\text { DON'T } \\
\text { KNOW }\end{array}$ & REFUSED & $\begin{array}{c}\text { NUMBER } \\
\text { USED }\end{array}$ \\
\hline
\end{tabular}

a. Business or corporate credit cards issued in the name of the business

b. Business loans from a commercial bank.

$0100 \quad d \quad r$

$0100 \quad d \quad r$

c. Business line of credit (READ IF NEEDED: a business line of credit is when a business has an agreement with a bank or other financial institution to borrow up to a certain amount of funds)

$01 \quad 00 \quad d$

$r$

d. Business loans from a non-bank financial institution

0100

d

0100

d

$r$ owners

f. Business loans from another owner of the business or a partner

0100

d

r

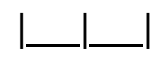

g. [IF HAVE EMPLOYEES AT C5] Loans to the business from employees that are not owners of the business.

$0100 \quad d$

0100

d 0100

d r

h. Loans from government agencies.

i. Loans from other businesses

j. Business loans from any other individuals not associated with the management of the business.... 01

k. Any other sources? (SPECIFY) 0100

d

$\begin{array}{ll}r & 1 \\ r & 1\end{array}$


F12a. IF ANSWERED "YES" TO F11a ITEMS a, c, ASK: As of December 31, 2006, what was the maximum credit line on the [NAME DEBT FINANCING OPTION]?

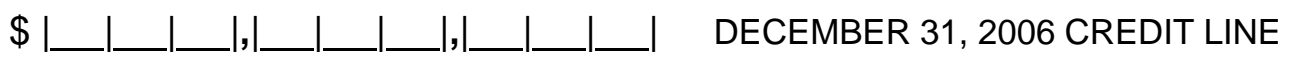

DON'T KNOW ................................................ d

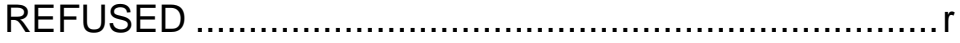

IF DON'T KNOW OR REFUSED, PROBE WITH RANGES: Would you say it was . .

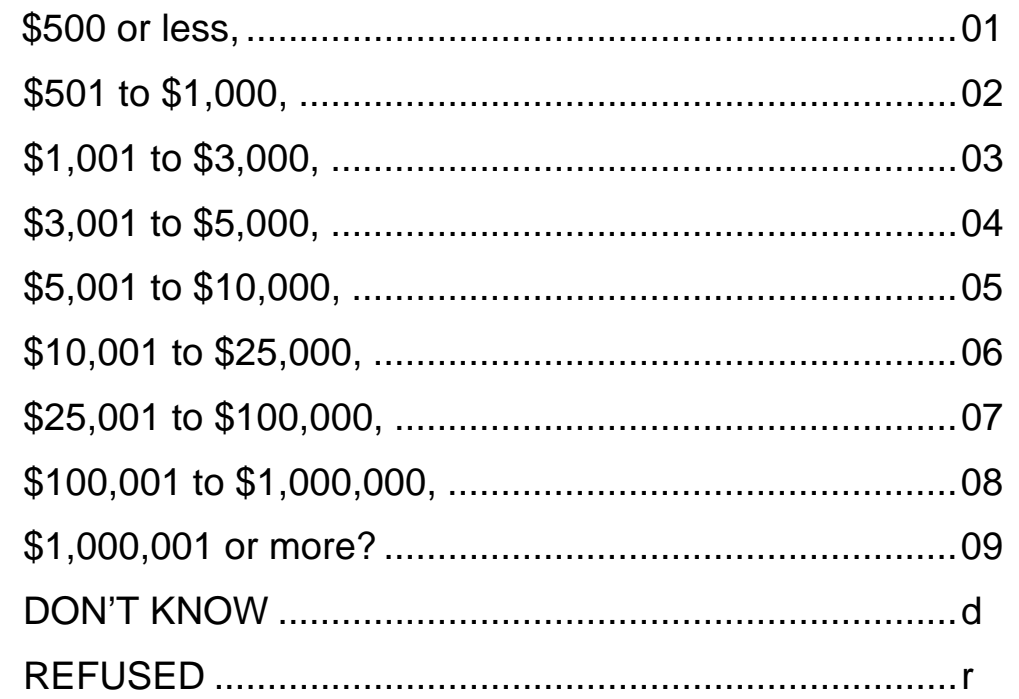


F12b. IF ANSWERED "YES" TO F11a ITEMS a, c, ASK: As of December 31, 2006, what was the outstanding balance on the [NAME DEBT FINANCING OPTION]?

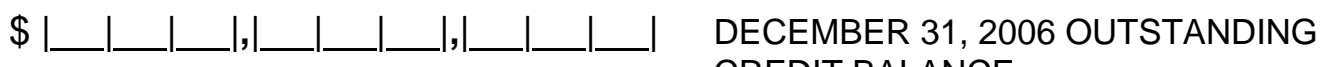
CREDIT BALANCE

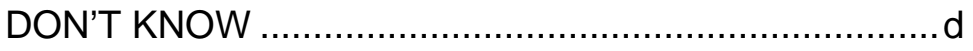

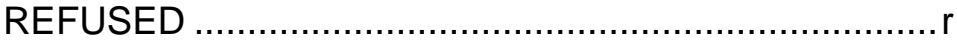

IF DON'T KNOW OR REFUSED, PROBE WITH RANGES: Would you say it was . .

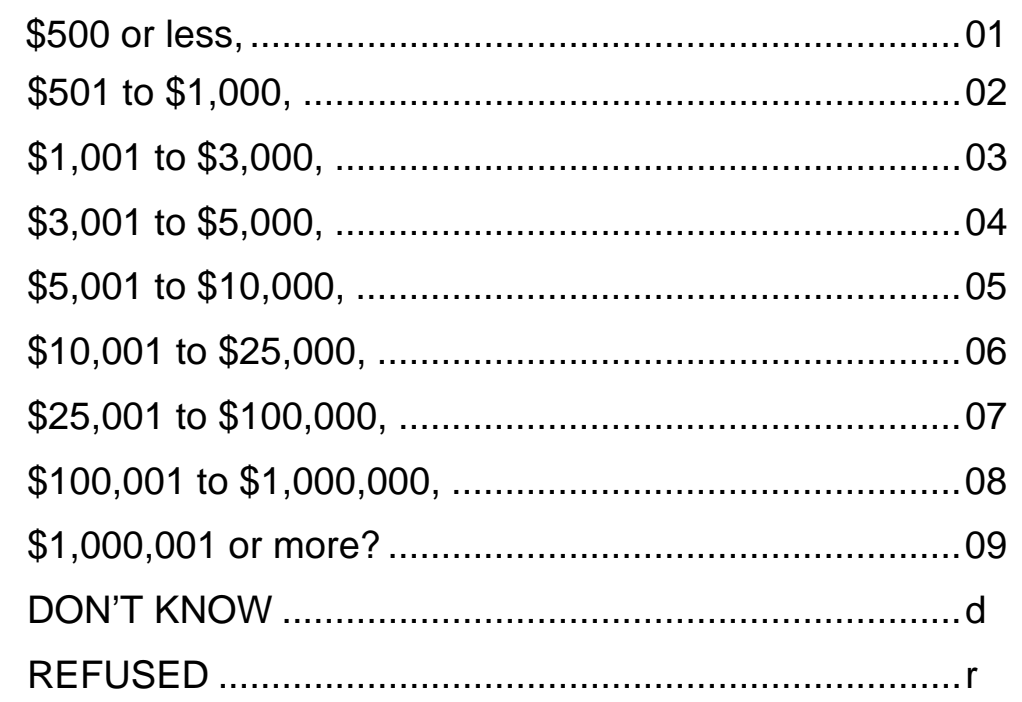

\section{IF F12a IS GREATER THAN F12b:}

Perhaps I made a mistake. The amount I recorded as the balance outstanding is greater than the amount reported as the maximum credit limit. 
F12c. IF ANSWERED "YES" TO F11a ITEMS b, d-k, ASK: In calendar year 2006, how much was the amount obtained from [NAME DEBT FINANCING OPTION] used by [NAME BUSINESS]?

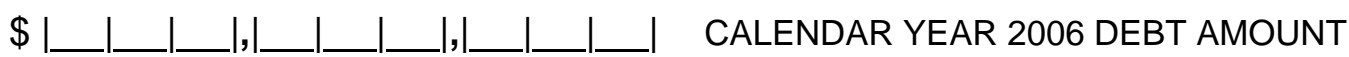

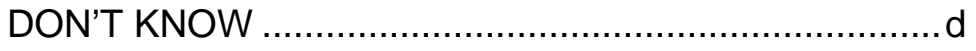

REFUSED ......................................................

IF DON'T KNOW OR REFUSED, PROBE WITH RANGES: Would you say it waS . .

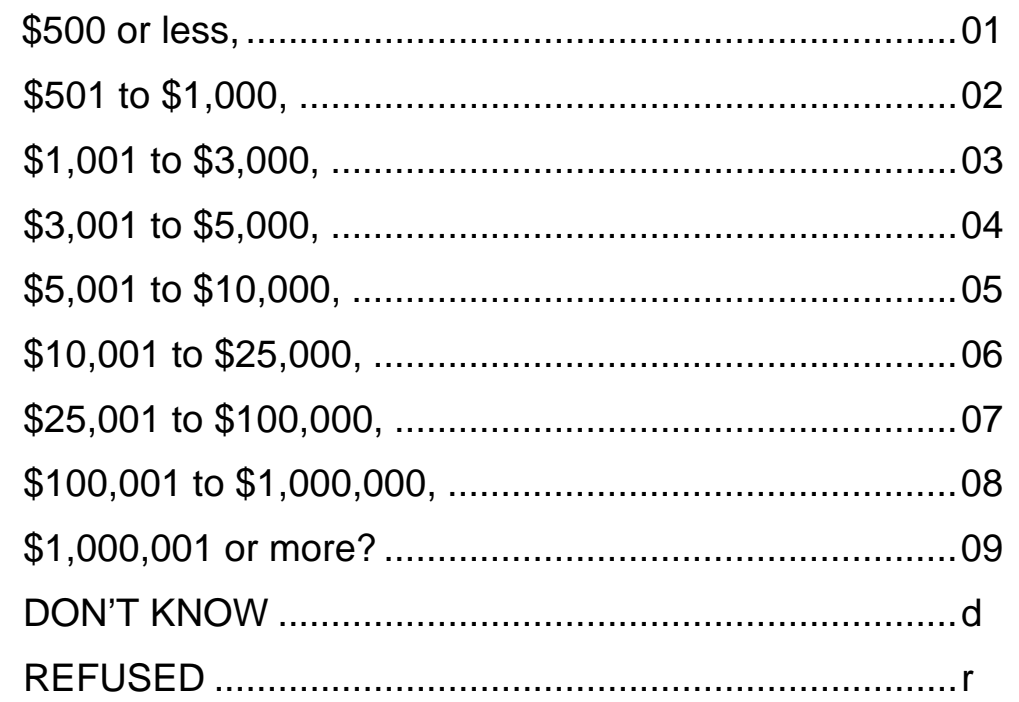


F12d. As of December 31, 2006, what was the estimated amount of the [NAME DEBT FINANCING OPTION] owed by [NAME BUSINESS]?

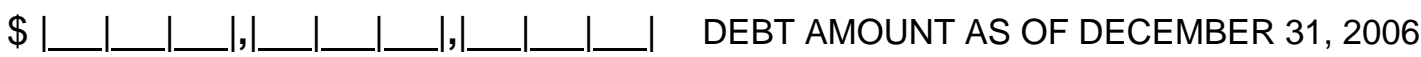

DON'T KNOW ................................................ d

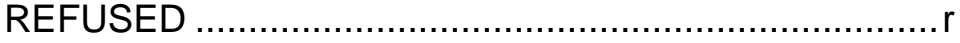

IF DON'T KNOW OR REFUSED, PROBE WITH RANGES: Would you say it was . .

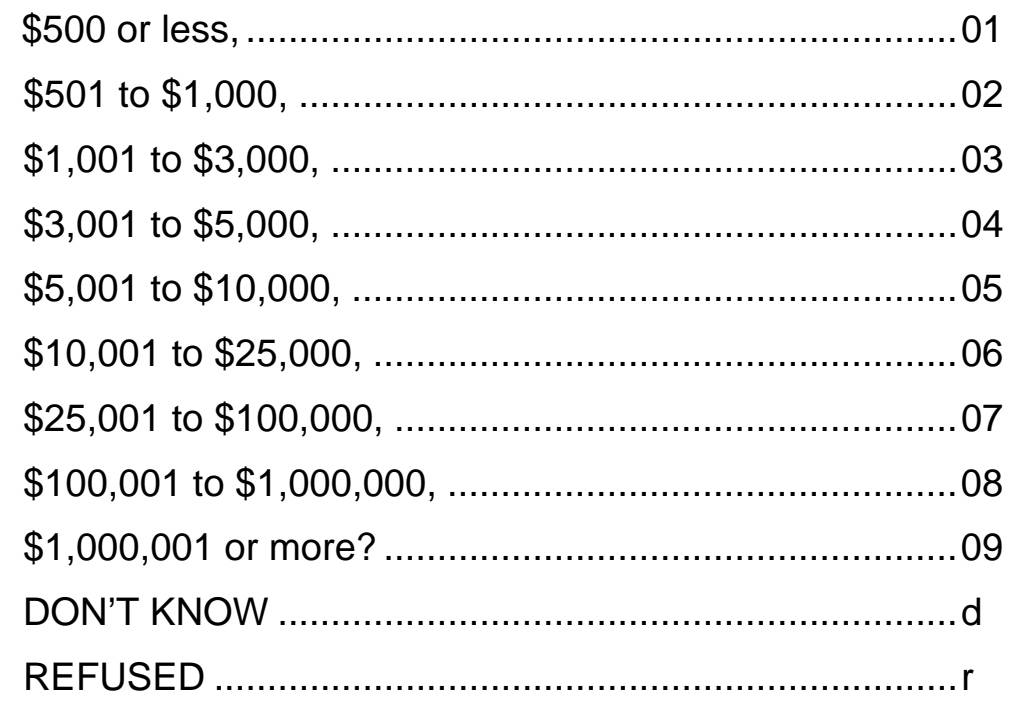

F13. Trade financing is where a business has an arrangement with a supplier to make purchases on account. In calendar year 2006, did [NAME BUSINESS] make any purchases through trade financing?

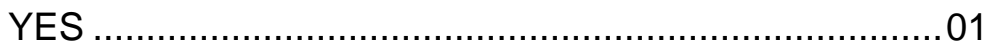

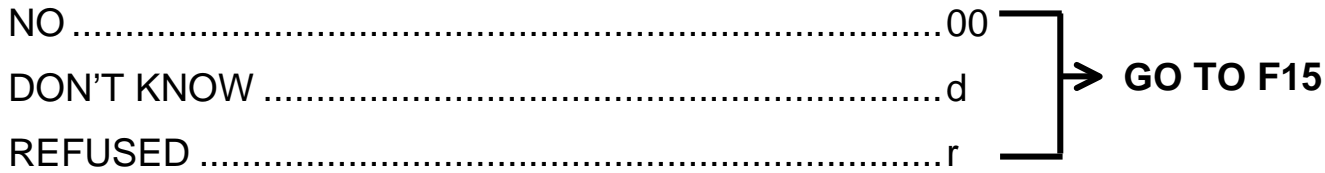


F14. IF YES: In calendar year 2006, what was the amount of purchases made through trade financing?

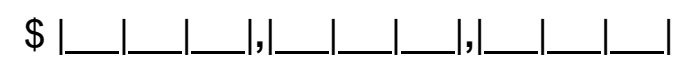

DON'T KNOW

REFUSED
CALENDAR YEAR 2006 AMOUNT OF TRADE PURCHASES

IF DON'T KNOW OR REFUSED, PROBE WITH RANGES: Would you say it waS . . .

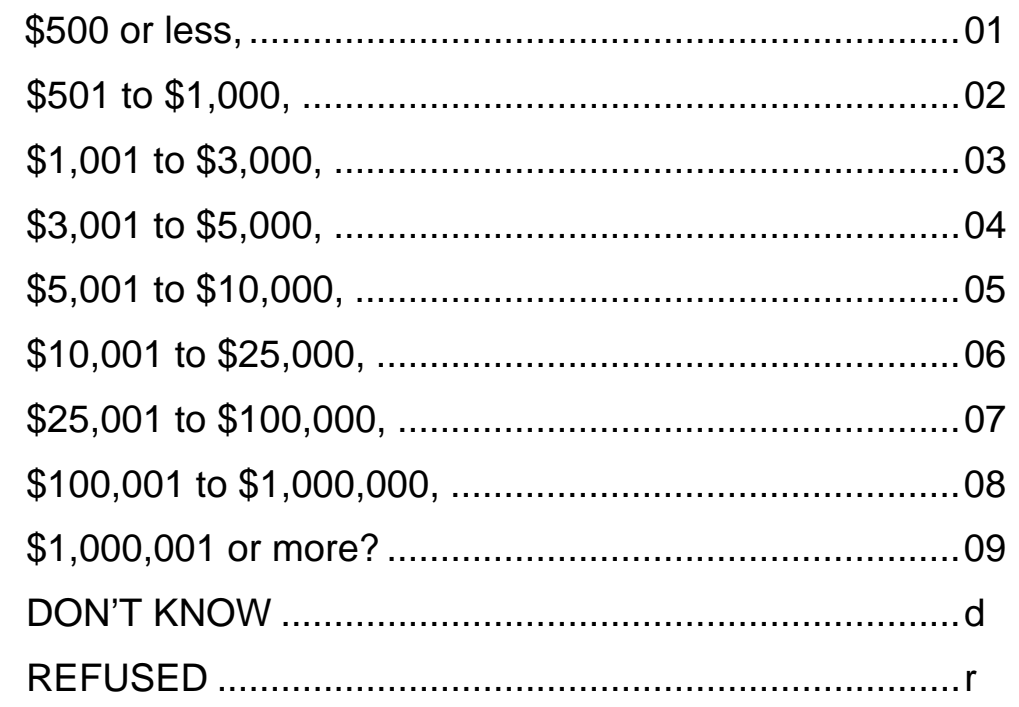

F15. In calendar year 2006, did [NAME BUSINESS] receive any revenue (money), from the sales of goods, services, or intellectual property? [IF SOLE PROPRIETORSHIP, ADD: This would be gross receipts reported on a Schedule $C$ or $C-E Z$ with your personal income tax return.]

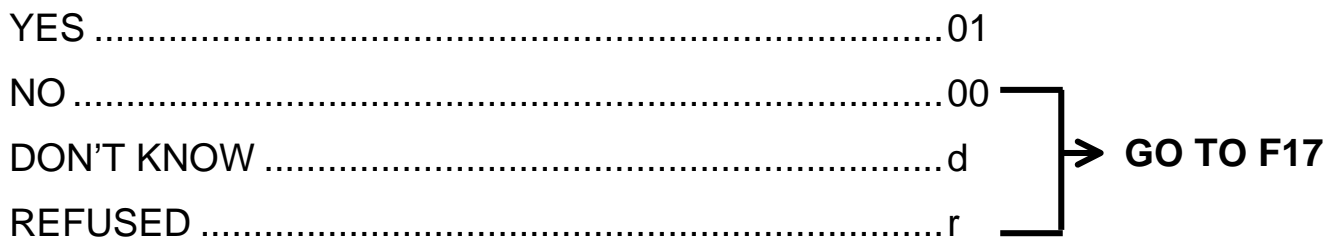


F16. What was [NAME BUSINESS]'s total revenue for calendar year 2006? [IF SOLE PROPRIETORSHIP, ADD: This would be gross receipts reported on a Schedule $C$ or C-EZ with your personal income tax return.]

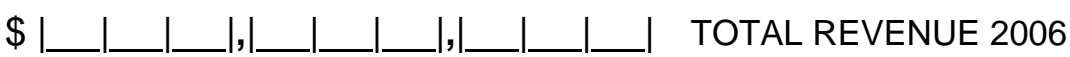

DON'T KNOW ................................................. d

REFUSED ......................................................

IF DON'T KNOW OR REFUSED, PROBE WITH RANGES: Would you say it waS . .

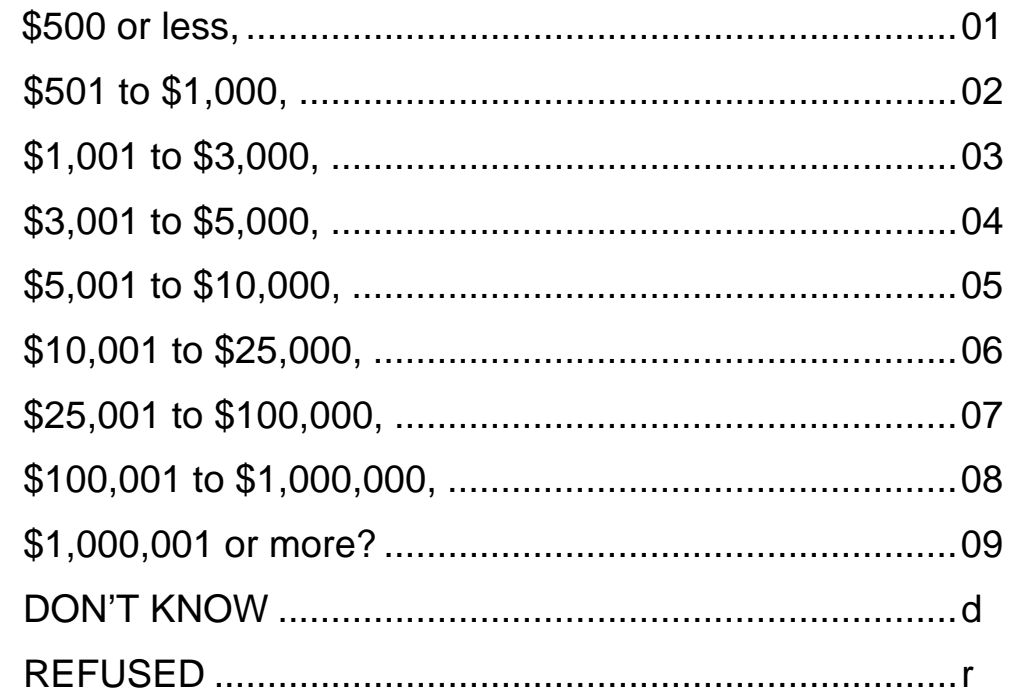

F16b. Was this an increase, a decrease, or no change in the amount of revenue for [NAME BUSINESS] in 2006 compared to 2005?

INCREASE .................................................... 01

DECREASE ......................................................... 02

NO CHANGE ..................................................... $03 \rightarrow$ GO TO F17

DON'T KNOW ..................................................... d

REFUSED .........................................................

F16c. And what was the percentage change in revenue in 2006 compared 2005? Your best estimate is fine.

I______ \% CHANGE IN REVENUE

DON'T KNOW …............................................... d

REFUSED ….................................................. 
F17. Now l'm going to ask about the expenses the business paid. Expenses are the costs paid for the operation of the business, including wages, salaries, interest on loans, capital leases, materials, etc. How much, if any, did [NAME BUSINESS] pay in expenses during calendar year 2006?

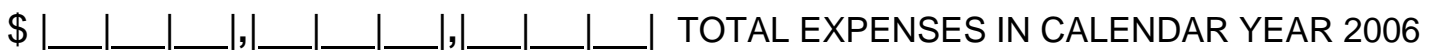

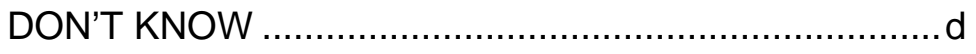

REFUSED .......................................................

IF DON'T KNOW OR REFUSED, PROBE WITH RANGES: Would you say it was . .

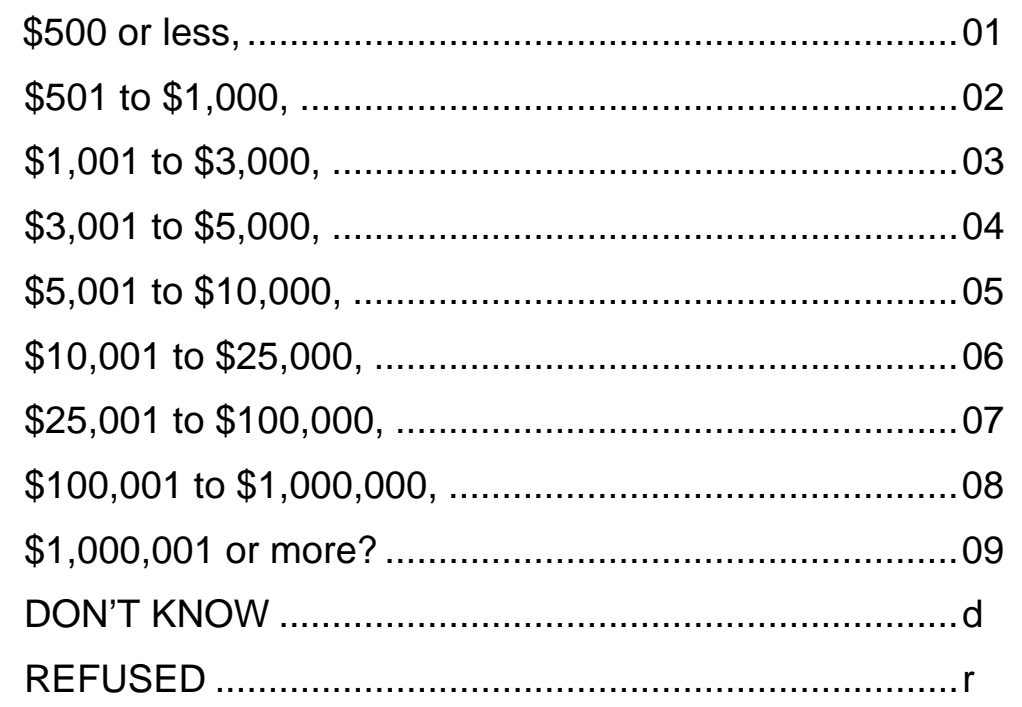

F17b. Was this an increase, a decrease, or no change in total expenses for [NAME BUSINESS] in 2006 compared to 2005?

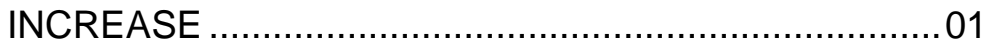

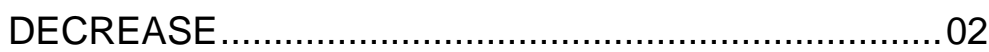

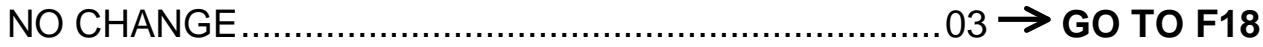

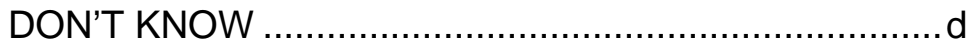

REFUSED ............................................................

F17c. And what was the percentage change in total expenses in 2006 compared 2005? Your best estimate is fine.

I_____ I \% CHANGE IN EXPENSES

DON'T KNOW ................................................ d

REFUSED ......................................................... 
F18. IF BUSINESS REPORTED “0” EMPLOYEES AT C5, GO TO F19.

How much, if any, did [NAME BUSINESS] pay in wages, salaries, and benefits to full-and part-time employees in calendar year 2006? Please do not include wages, salaries, and benefits to contract workers who work for the business but are not on the business' official payroll.

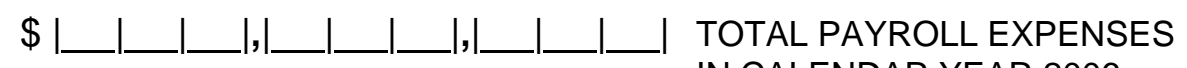
IN CALENDAR YEAR 2006

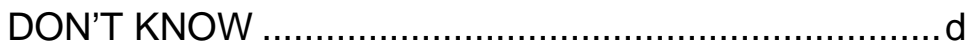

REFUSED ............................................................

IF DON'T KNOW OR REFUSED, PROBE WITH RANGES: Would you say it was . . .

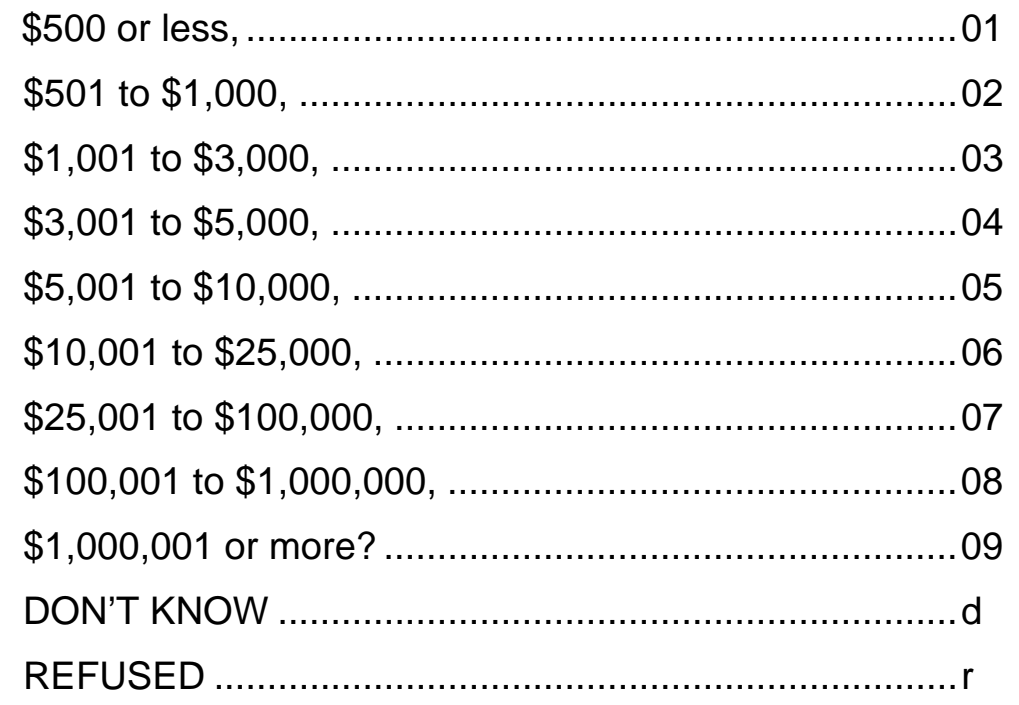

F19. Did [NAME BUSINESS] spend any money on research and development of new products and services during calendar year 2006?

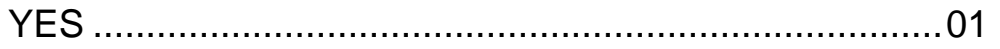

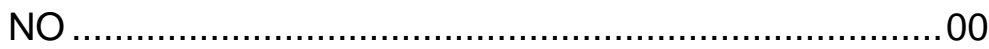

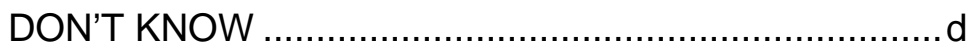

REFUSED .....................................................

F20. Did [NAME BUSINESS] spend any money on the purchase of new or used machinery or equipment during calendar year 2006?

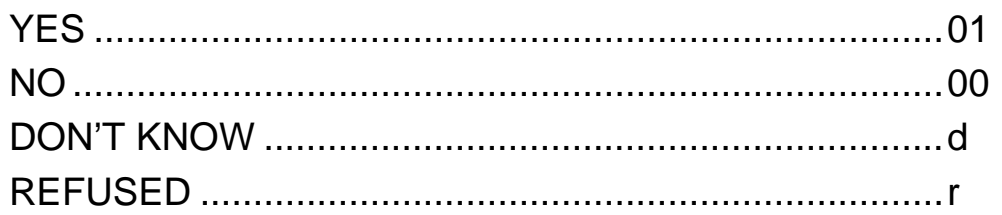


F21. Did [NAME BUSINESS] spend any money on rental or lease payments for buildings or other structures during calendar year 2006?

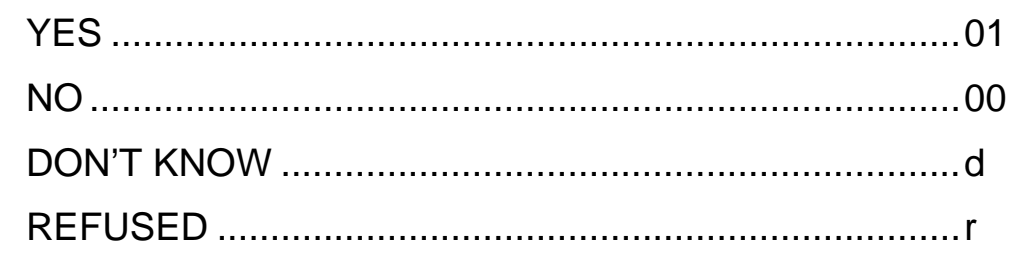

F22. Did [NAME BUSINESS] spend any money on rental or lease payments for machinery or equipment during calendar year 2006?

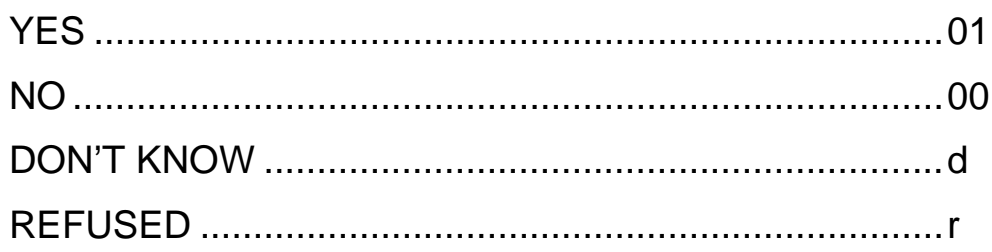

F23. Profit is the business' income after all expenses and taxes have been deducted. What was [NAME BUSINESS]'s total profit or loss for calendar year 2006?

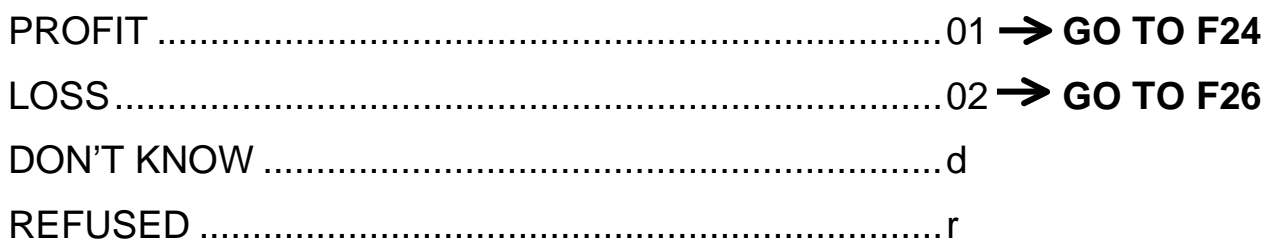

F24. ENTER PROFIT AMOUNT

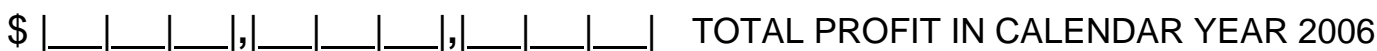

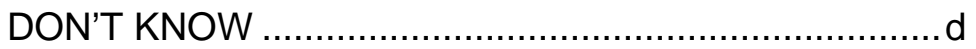

REFUSED ...................................................... 
F25. IF DON'T KNOW OR REFUSED, PROBE WITH RANGES: Would you say it was ...

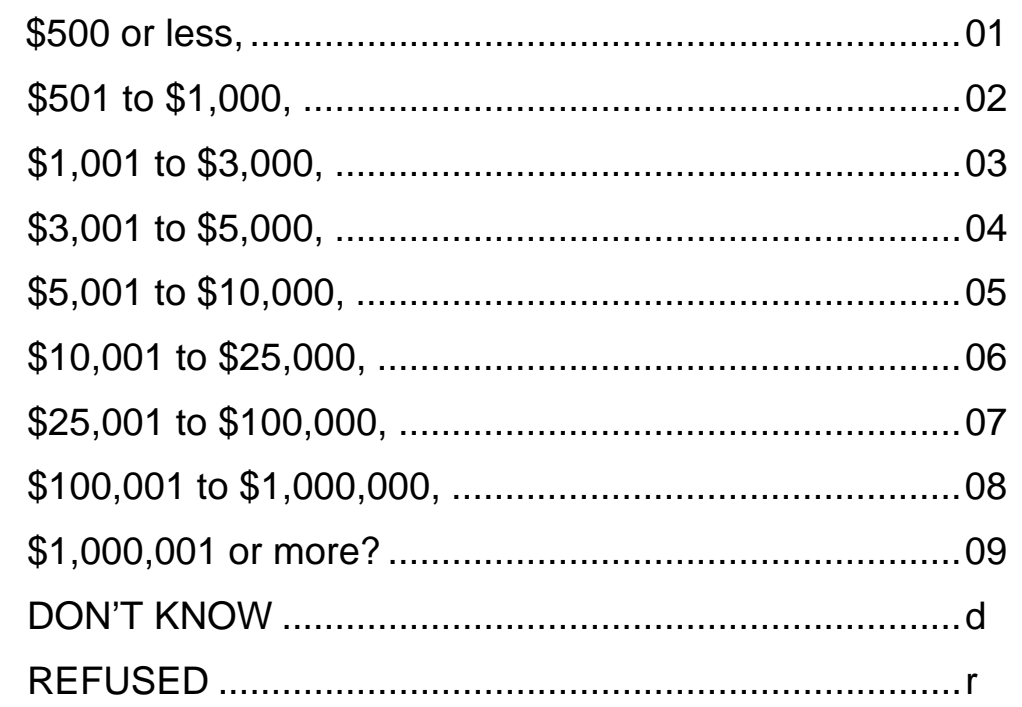

F26. ENTER LOSS AMOUNT

\$ I_____ DON'T KNOW .................................................. d

REFUSED ...................................................

F27. IF DON'T KNOW OR REFUSED, PROBE WITH RANGES: Would you say it was ...

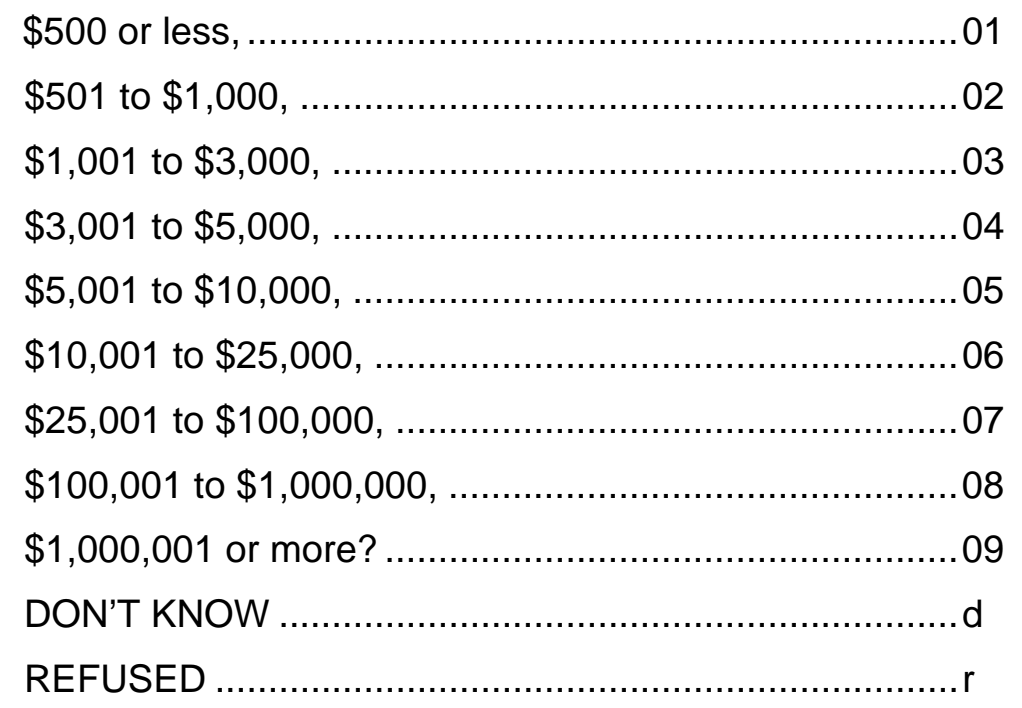


F28. Assets are what the business owns. As of December 31, 2006, did [NAME BUSINESS]'s assets include [NAME ASSET FROM LIST]?

\begin{tabular}{|c|c|c|c|c|}
\hline & YES & NO & $\begin{array}{l}\text { DON'T } \\
\text { KNOW }\end{array}$ & REFUSED \\
\hline 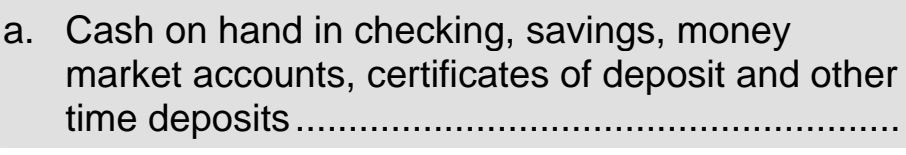 & 01 & 00 & $d$ & $r$ \\
\hline 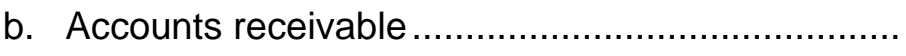 & 01 & 00 & d & r \\
\hline 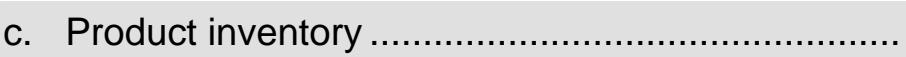 & 01 & 00 & d & r \\
\hline 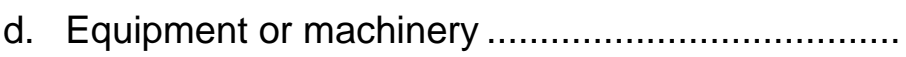 & 01 & 00 & d & r \\
\hline e. Land, buildings, and other structures ...................... & 01 & 00 & $d$ & r \\
\hline f. Vehicles....... & 01 & 00 & d & r \\
\hline g. Any other business owned property (SPECIFY)... & 01 & 00 & $d$ & r \\
\hline h. Any other assets? (SPECIFY).. & 01 & 00 & $d$ & $r$ \\
\hline
\end{tabular}

F29. FOR EACH ASSET BUSINESS REPORTED, ASK:

As of December 31, 2006, what was the estimated value of the [NAME OF ASSET] owned by [NAME BUSINESS]?

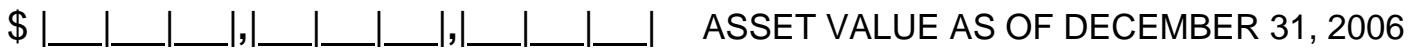

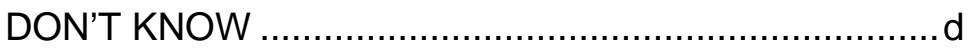

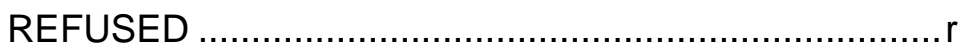

IF DON'T KNOW OR REFUSED, PROBE WITH RANGES: Would you say it was . . .

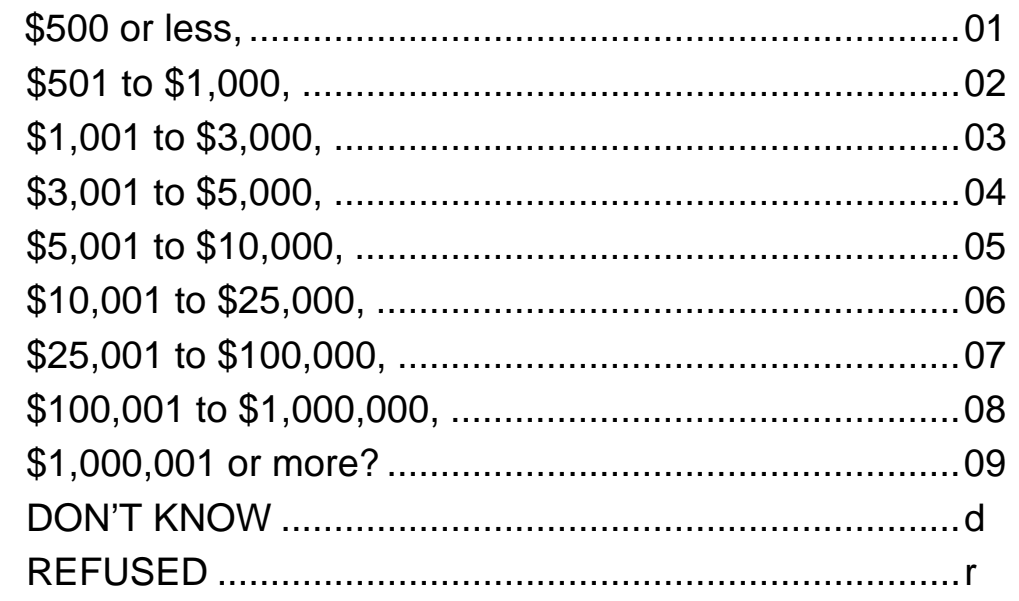


F30. Liabilities are what the business owes. Other than the loans and the financial debt we've already talked about, did [NAME BUSINESS]'s liabilities as of December 31, 2006 include [NAME LIABILITY FROM LIST]?

\begin{tabular}{|c|c|c|c|c|}
\hline & YES & NO & $\begin{array}{l}\text { DON'T } \\
\text { KNOW }\end{array}$ & REFUSED \\
\hline 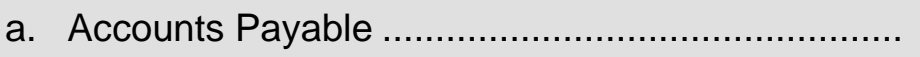 & 01 & 00 & d & r \\
\hline b. Pension and post retirement benefits.................... & 01 & 00 & $d$ & r \\
\hline 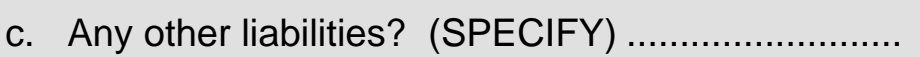 & 01 & 00 & $d$ & r \\
\hline
\end{tabular}

F31. FOR EACH LIABILITY BUSINESS HAS, ASK: As of December 31, 2006, what was the estimated value of [NAME BUSINESS]'s [NAME OF LIABILITY]?

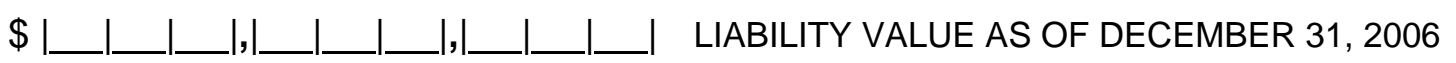

DON'T KNOW ................................................. d

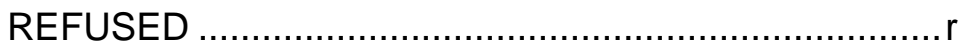




\section{G. WORK BEHAVIORS AND DEMOGRAPHICS OF OWNERIOPERATOR(S)}

The last section contains questions for classification purposes only.

C4 LISTING OF OWNER/OPERATORS SHOULD BE ASKED THIS SERIES IN THE ORDER THEY APPEAR IN C4

NO QUESTIONS WILL BE ASKED ABOUT OWNERIOPERATORS WHO HAVE LEFT THE BUSINESS.

FOR ALL FIRST FOLLOW-UP OWNER/OPERATORS IN C4, ASK BLOCK G1

FOR ALL NEW OWNER/OPERATORS, ASK BLOCK G2

\section{BLOCK G1-}

G1a. (Are/ls) (you/[OWNER B-J]) also a paid employee at [NAME BUSINESS]?

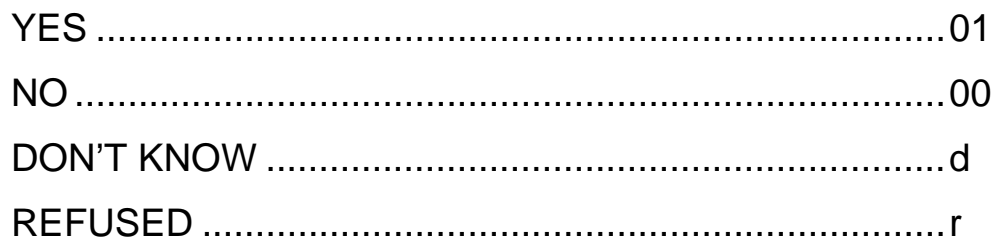

G1b. During the time [NAME BUSINESS] was in business during 2006, how many hours in an average week did (you/[OWNER B-J]) spend working at [NAME BUSINESS]?

I______ HOURS WORKED IN AVERAGE WEEK

DON'T KNOW ................................................... d

REFUSED .......................................................

IF DON'T KNOW OR REFUSED PROBE: Would you say it was . . .

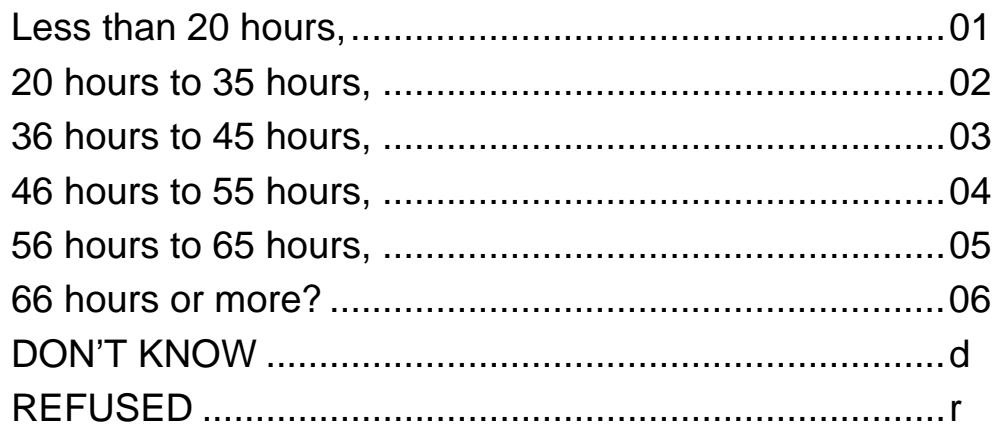


FIRST FOLLOW-UP OWNERS/OPERATORS: ANY DEMOGRAPHIC QUESTION G1d-G10a NOT ANSWERED IN FIRST FOLLOW-UP WILL BE ASKED AGAIN.

ENDBLOCK G1-FOR ALL FIRST FOLLOW-UP OWNERS.

\section{BLOCK bSectionG2-for all NEW OWNERS}

G1a. (Are/Is) (you/[OWNER B-J]) also a paid employee at [NAME BUSINESS]?

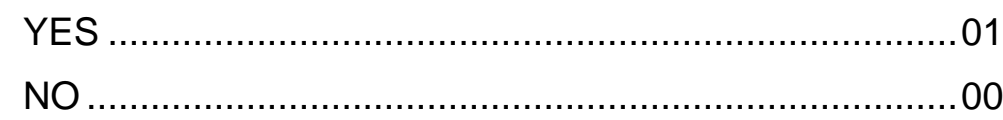

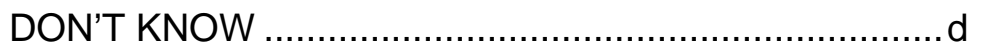

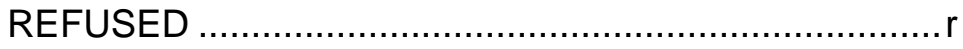

G1b. During the time [NAME BUSINESS] was in business during 2006, how many hours in an average week did (you [OWNER B-J] spend working at [NAME BUSINESS]?

I______ HOURS WORKED IN AVERAGE WEEK

DON'T KNOW ................................................... d

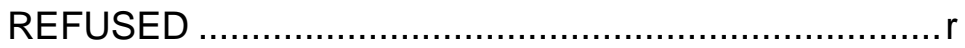

G1b1. IF DON'T KNOW OR REFUSED, PROBE: Would you say it was . .

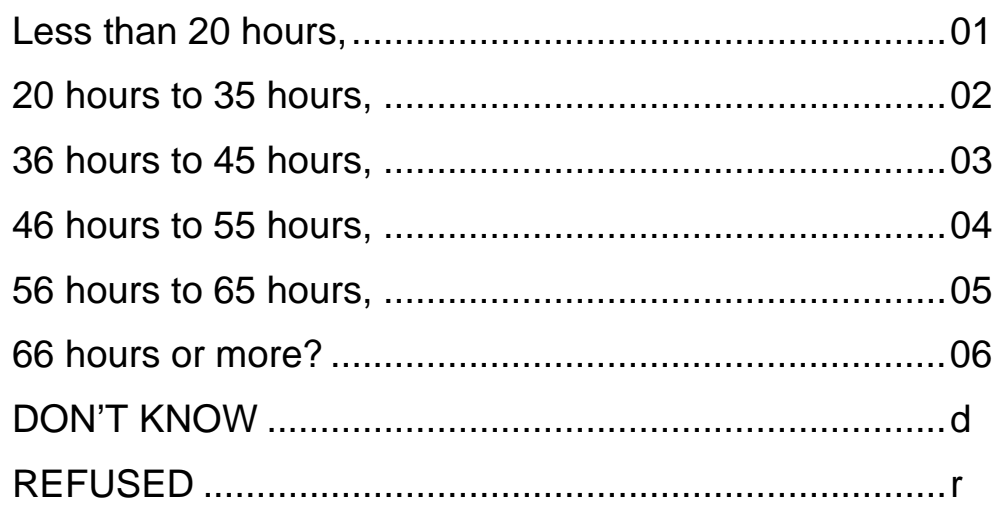


G2. How many years of work experience (have/has) (you/[OWNER B-J]) had in this industry-the one in which [NAME BUSINESS] competes?

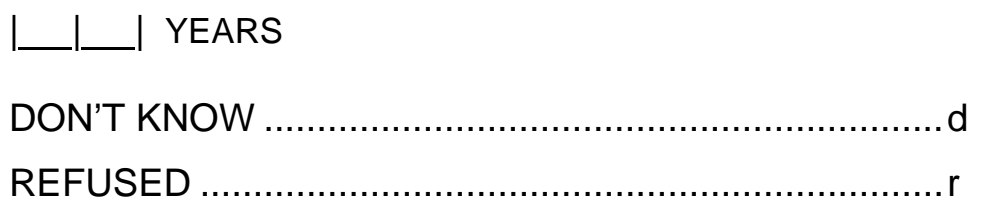

G3a. How many other new businesses (have/has) (you/[OWNER B-J]) started besides [NAME BUSINESS]?

I___ N N NUMBER OF BUSINESSES (ENTER "0" FOR NONE)

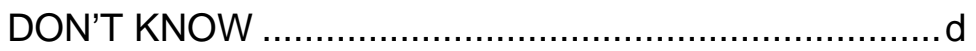

REFUSED ............................................................

\section{IF ZERO NEW BUSINESSES AT G3a, GO TO G4.}

G3b. (Was this/Were any of the) business(es) in the same industry as [NAME BUSINESS]?

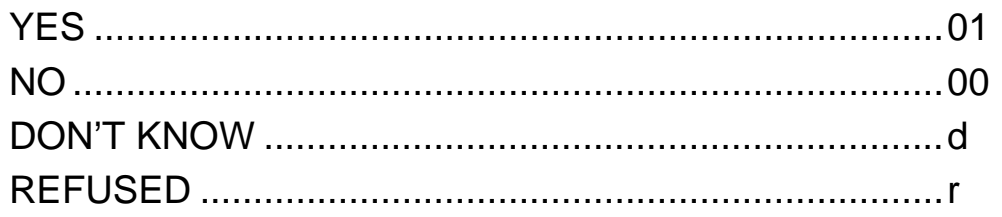

G4. How old will (you/[OWNER B-J]) be on (your/his/her) next birthday?

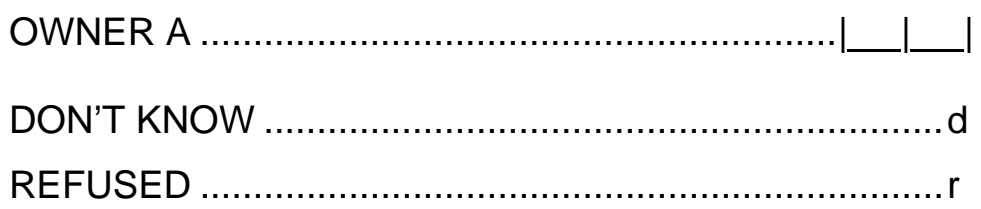

IF DON'T KNOW OR REFUSED, PROBE WITH RANGES: Would you say . . .

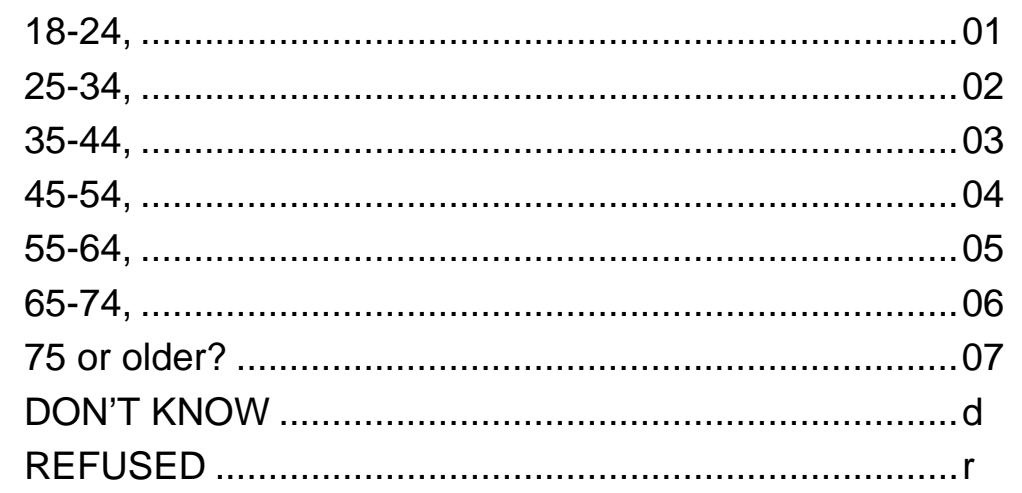




\section{if $\mathbf{G} 4$ is less than $\mathbf{G} 2$}

\section{CATI hard edit with wording as follows:}

Perhaps I made a mistake in recording your answer. (OWNER B-J/Your) age is less than (OWNER B-J) years of experience.

Now I have a few questions about race and ethnicity.

G5. (Are/ls) (you/[OWNER B-J]) of Hispanic or Latino origin?

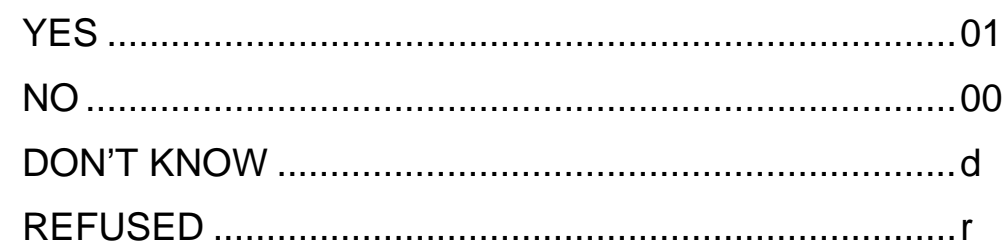

G6. I am going to read a list of race categories. Please choose one or more that best describes (your/[OWNER B-J]'s) race. Are (you [OWNER B-J]) American Indian or Alaska Native, Native Hawaiian or other Pacific Islander, Asian, Black or African American, or White?

AMERICAN INDIAN OR ALASKA NATIVE 01

NATIVE HAWAIIAN OR OTHER

PACIFIC ISLANDER 02

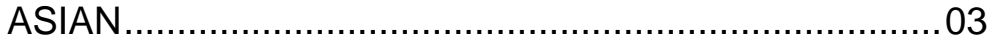

BLACK OR AFRICAN AMERICAN.............................. 04

WHITE ................................................................. 05

OTHER (SPECIFY) .............................................. 06

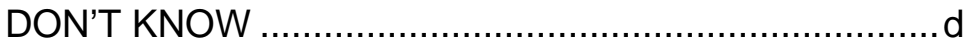

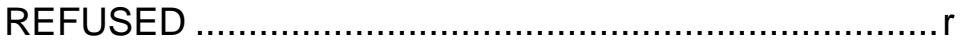

G7. (Were/Was) (you/[OWNER B-J]) born in the United States?

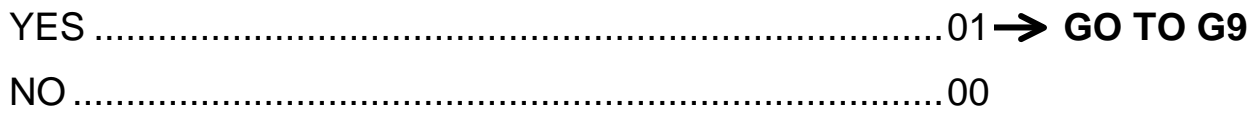

DON'T KNOW .......................................................... d

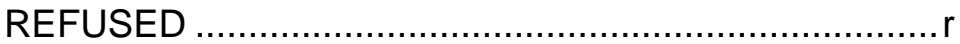


G8. (Are/ls) (you/[OWNER B-J]) a U.S. citizen?

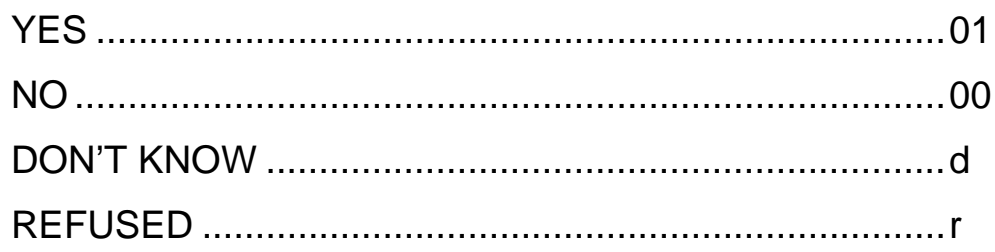

G9. What is the highest level of education (you/[OWNER B-J]) (have/has) completed so far? Would you say ...

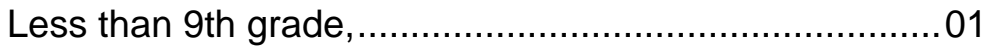

Some high school, but no diploma, ............................ 02

High school graduate (diploma or equivalent diploma [GED]), ............................................... 03

Technical, trade or vocational degree, ........................ 04

Some college, but no degree, .................................... 05

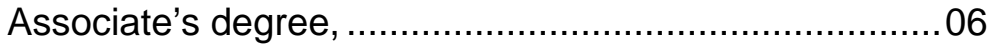

Bachelor's degree, .............................................. 07

Some graduate school but no degree, $\ldots \ldots \ldots \ldots \ldots \ldots \ldots \ldots . \ldots . \ldots . \ldots$

Master's degree, or ................................................ 09

Professional school or doctorate? ............................... 10

DON'T KNOW .......................................................

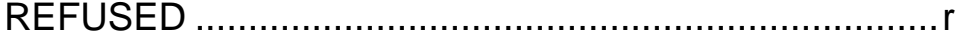

\section{BY OBSERVATION:}

G10a. (Are/ls) (you/[OWNER B-J]) male or female?

MALE .............................................................. 01

FEMALE ...................................................... 02

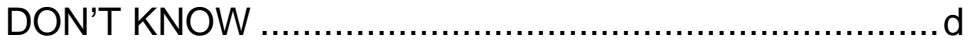

REFUSED ......................................................

\section{ENDBLOCK bSectionG2}

SECTION G ARRAYED UP TO 10 TIMES, ONCE FOR EACH NEW OWNER. 
G11. IF EMAIL ADDRESS COLLECTED AT BASELINE OR FIRST FOLLOW-UP:

Can we confirm your email address?

INTERVIEWER: READ E-MAIL ADDRESS AND CORRECT AS NECESSARY.

IF EMAIL ADDRESS FIELD BLANK FROM BASELINE AND FIRST FOLLOW-UP: Can you give us an email address where you can be reached?

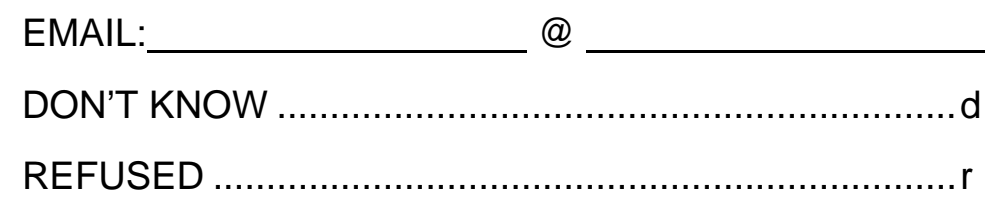

G12. IF WEBSITE ADDRESS COLLECTED AT BASELINE OR FIRST FOLLOW-UP: May we confirm your web site address as:

Web Address:

INTERVIEWER: CORRECT AS NECESSARY $\rightarrow$ GO TO G14

IF WEBSITE ADDRESS BLANK FROM BASELINE AND FIRST FOLLOW-UP: Does [NAME BUSINESS] have its own website?

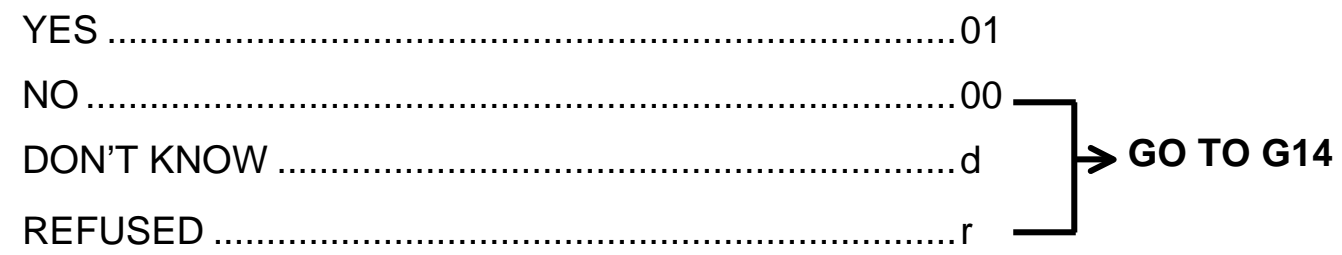

G13. Can you give me the web address?

WEB ADDRESS:

DON'T KNOW $d$

REFUSED ...r

G14. Is the business likely to move to another location in the next 12 months?

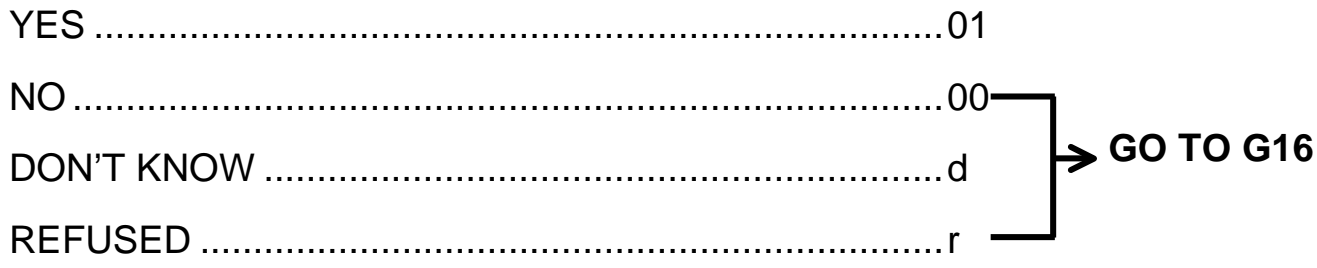


G15. What city and state is the business likely to move to?

CITY:

STATE:

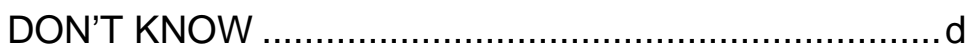

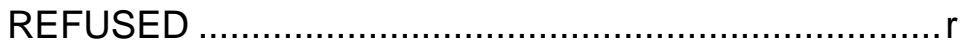

G16. IF CONTACT INFORMATION COLLECTED AT BASELINE OR FIRST FOLLOW-UP:

Here is the information we have for a contact person. This information will be held in the strictest confidence, and will only be used if we cannot contact you or someone else associated with the business at the current business phone number or address.

INTERVIEWER: PLEASE ASK FOR ANY INFORMATION THAT IS NOT FILLED IN.

NAME:

ADDRESS:

CITY:

STATE:

PHONE:

EMAIL:

@

DON'T KNOW ...................................................... d

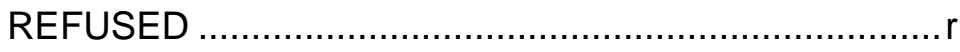


IF CONTACT INFORMATION IS BLANK FROM BASELINE AND FIRST FOLLOWUP:

In case we are unable to contact you, can you provide a name and contact information for a person besides yourself who would know how to reach you or someone else associated with [NAME BUSINESS]? All information collected will be held in the strictest confidence, and will only be used if we cannot contact you or someone else associated with the business at the current business phone number or address.

NAME:

ADDRESS:

CITY:

STATE:

PHONE:

EMAIL: @

DON'T KNOW $d$

REFUSED

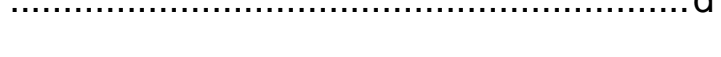

THANK AND TERMINATE 
APPENDIX C

\section{RESPONDENT MATERIALS}



Subject: Round 3--Kauffman Firm Survey

\section{Dear [FIRST FOLLOW-UP RESPONDENT NAME]:}

We are currently conducting the third round of the Kauffman Firm Survey. As one of only 4,500 businesses across the country that participated in earlier rounds, your continued participation is vital to the success of the study. We cannot replace your business with any other business.

You may wonder why we are interested in learning about how your business is doing each year. By studying firms over the crucial early years of their growth and development, we can begin to understand what factors help businesses succeed in becoming established. No other study has examined as many new businesses in as much detail. Once again, you will receive \$50 as a "thank you" for completing the interview. All information you provide will be kept confidential, and you will not be asked to buy anything or make a contribution. Below is the link to the Kauffman Firm Survey website which will take you directly into the study.

Link Address: www.kauffmansurvey.org

You can also access the survey by visiting kauffmansurvey.org and entering the Login Identification Number and Password listed below.

Login Identification Number:

Password:

If you have any questions, please contact us at KFS@mathematica-mpr.com or call Pat Jones toll-free at 1-877-542-6725. Thanks for your participation.

Exima nation

KAUFFMAN

Foundation 

May 29, 2006

«firstname» «FirstName» «MiddleInitial» «LastName»

«CEO_Title»

«BName»

«Address1»

«Address2»

«City», «State» «postalcode»

Dear «FirstName» «LastName»:

Welcome to the third round of the Kauffman Firm Survey. This study, sponsored by the Ewing Marion Kauffman Foundation of Kansas City, is designed to help us better understand how new businesses like yours develop over time. We greatly appreciate your participation in the earlier rounds of the study. As one of only 4,500 study participants nationwide, your continued participation is vital to the success of the study, and your business cannot be replaced by another business.

We encourage you to complete the study online at www.kauffmansurvey.org. If you received an email and have already logged on and completed the survey, please accept our thanks. If not, please log on to www.kauffmansurvey.org to do so. You will be asked for your Login Identification Number and Password, which are indicated below:

Login Identification Number: «username»

Password: «password»

As in the earlier rounds, you will receive $\$ 50$ as a "thank you" for completing the interview. All information you provide will be kept confidential. You will not be asked to buy anything or make a contribution.

Mathematica Policy Research, Inc., an independent research firm based in Princeton, New Jersey, is conducting the study. If you have any questions about the study, please contact Pat Jones toll-free at 877-542-6725 or email us at KFS@mathematica-mpr.com. Enclosed is a fact sheet with more information about the study and an instruction sheet to assist you in completing the online survey. Thank you in advance for your continuing participation.

Sincerely,

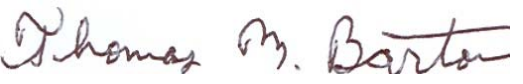

Survey Director 



\section{Web Survey Instructions}

1. Go to www.kauffmansurvey.org (this is a secure site).

2. On the opening screen, enter the login identification number and password shown below:

Login Identification Number: «username»

Password: «password»

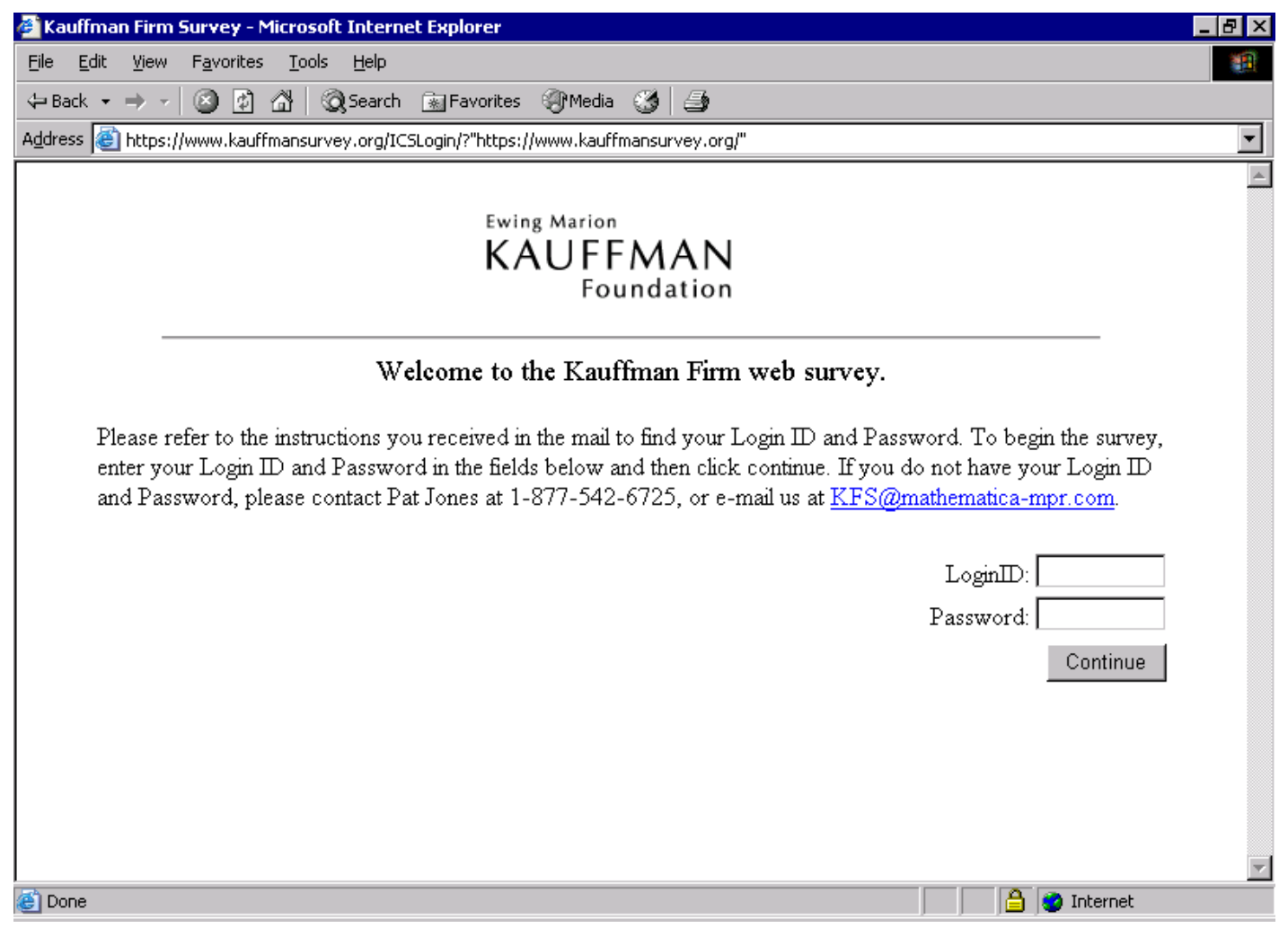

3. Once you log in, follow the instructions on the screen to complete the questionnaire.

4. For assistance, please call Pat Jones (toll-free) at 1-877-542-6725, or email us with questions at KFS@mathematica-mpr.com.

5. Please note that the survey itself, as well as all survey data, are transmitted using Secure Sockets Layer (SSL) encryption. This ensures that your responses will remain confidential.

\section{Thank you!}





\section{Frequently Asked Questions}

What is the purpose of the Kauffman Firm Survey?

The Kauffman Firm Survey is a research study sponsored by the Ewing Marion Kauffman Foundation of Kansas City. The study's purpose is to learn more about the challenges involved in owning and operating a new business. Because so many research studies focus on established companies, we know very little about what makes a business successful in its early years of existence.

\section{Didn't our business complete this already?}

Your business participated in round 1 of the study, which asked about your business' first year of operations. We also asked all businesses who participated in round 1 to take part in round 2, which asked about your business' second year of operations. We would now like to ask you about your third year in business. As one of a group of businesses scientifically selected for this study, your continued participation is vital to the success of the study. We cannot replace your business with another business.

Why are you asking about Year 3 of my business?

By studying businesses over the crucial early years of their growth and development, we can begin to understand what factors help businesses succeed in becoming established. No other study has examined as many new businesses in as much detail.

\section{Will I be paid for participating?}

You will again receive $\$ \mathbf{5 0}$ as a "thank you" for completing the interview. All information you provide will be kept confidential, and you will not be asked to buy anything or make a contribution.

What if my company is no longer in business or I have sold my business?

This information is important to us. We would greatly appreciate it if you would use the Web survey or call Pat Jones at 1-877-542-6725 to answer a few short questions, which will enable us to document what happened to your business.

\section{Will I get to see the results of the study?}

The Kauffman Foundation is committed to providing information from the study on its public Web site. Once the study has been completed, you can obtain the results by checking the Web site: 


\title{
Frequently Asked Questions
}

\section{Will the information I provide be kept confidential?}

Yes. All information you provide will be treated as confidential. The information will be used for research and statistical purposes only by the Kauffman Foundation, its contractors, and collaborating researchers for the purpose of analyzing data and preparing scientific reports and articles. Any information that is publicly released (such as statistical summaries) will appear in a form that does not personally identify your business or any individuals involved with the business.

\section{Will I be asked to make a donation to the Kauffman Foundation?}

No. This research study is not a disguised sales pitch or an attempt to solicit money. It is solely a research study. At no time will you be asked to buy anything or contribute money to any foundation. Your name and your business name will not be sold or provided to anyone-it will be kept strictly confidential.

\section{What is the Kauffman Foundation?}

The Ewing Marion Kauffman Foundation is a private foundation dedicated to studying and promoting entrepreneurship in the United States. The Foundation has hired Mathematica Policy Research, Inc., an independent research firm, to conduct the study. For additional information about the Kauffman Foundation, please visit its Web site:

www.kauffman.org

\section{Who is Mathematica Policy Research?}

Mathematica Policy Research is an independent research firm based in Princeton, New Jersey known for its high-quality, objective research designed to support decision making on the nation's most pressing issues. For additional information about Mathematica, please visit the company's Web site:

\section{www.mathematica-mpr.com}

\section{How can I contact you with further questions?}

If you have further questions about this study, please call Pat Jones at Mathematica tollfree at 1-877-542-6725, or you can email us at KFS@mathematica-mpr.com. You can also reach us by mail:

\author{
Kauffman Firm Survey \\ Mathematica Policy Research, Inc. \\ P.O. Box 2393 \\ Princeton, NJ 08543-2393
}




\section{Front}

\section{$\star$ The Kauffman Firm Survey $九$}

We still need your help! We recently sent you information about the third round of the Kauffman Firm Survey, and we urge you to participate again. The experiences you shared during the earlier rounds of the study were important contributions to the Kauffman Foundation's mission to understand and promote new business development.

Please log on to www.kauffmansurvey.org to complete the interview. (If you have already done so, please accept our thanks.) Because we know your time is valuable, you will receive $\$ 50$ as a "thank you" for completing the questionnaire.

If you have forgotten or lost your login identification number and password, or if you have any questions or comments, please contact Pat Jones toll-free at 1-877-542-6725 or at KFS@mathematica-mpr.com.

Thank you for your time and continuing participation!

\section{Back}

Kauffman Firm Survey (6091-340)

Mathematica Policy Research, Inc.

P.O. Box 2393

Princeton, NJ 08543-9809

Return Service Requested 

«FirstName» «MiddleInitial» «LastName»

«CEO_Title»

«BName»

«Address1»

«Address2»

«City», «State» «postalcode»

Dear «firstname» «LastName»: [NOTE: USE «FirstName» IF «firstname» IS MISSING]

We would like to thank you again for participating in the Kauffman Firm Survey, sponsored by the Ewing Marion Kauffman Foundation. Recently, we contacted you about participating in the third round of the study, but at that time you were unable to speak with us. I wanted to contact you to explain how important your continued cooperation is to the success of this study.

New businesses are vital to the economic future of the United States, and yet little is known about the challenges of running a business in the early years of development. Your participation in round three of the study will provide the Kauffman Foundation with a greater understanding about the challenges involved in owning and operating a new business. Participating will also help the Foundation's mission to support entrepreneurship.

Please help us by completing this brief interview. We will send you \$50 after you complete the interview as a token of our appreciation for your continuing participation in this study. All information you provide will be treated as confidential.

Mathematica Policy Research (MPR), an independent research firm based in Princeton, NJ, is conducting the study. If you have any questions about the study, please contact Pat Jones at 1-877542-6725 or email us at KFS@mathematica-mpr.com.

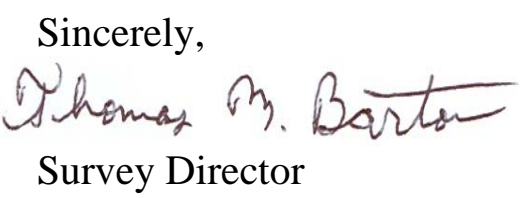





\section{APPENDIX D \\ KAUFFMAN FIRM SURVEY SECOND FOLLOW-UP ANNOTATED QUESTIONNAIRE}



MPR Reference No.: 6091-370

MATHEMATICA

Policy Research, Inc.

Kauffman Firm Survey

Second Follow-Up

Annotated Questionnaire

March 20, 2008 



\section{A. INTRODUCTION}

INTRO: Hello, my name is . I'm calling on behalf of the Kauffman Foundation.

May I speak with ([CEO/OWNER]/the owner or CEO of [NAME BUSINESS])?

CEO/OWNER = First Follow-Up Respondent for Section A.

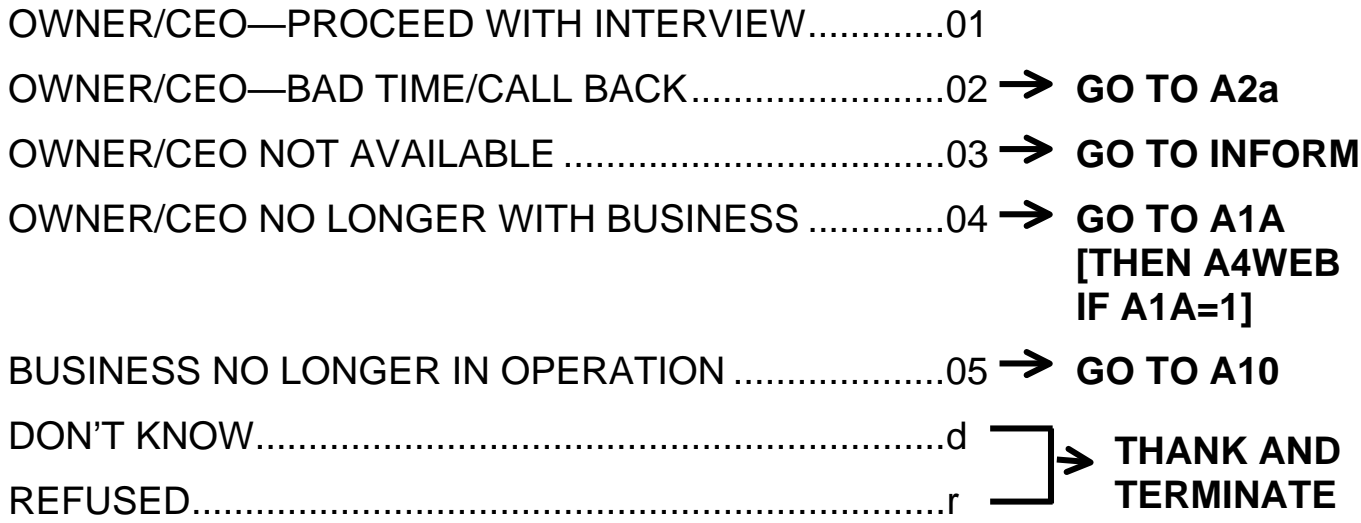

A1a. Your business has been participating in the Kauffman Firm Survey. Last year we asked you some questions about [NAME BUSINESS]'s operations in 2004 and 2005. Now we'd like to ask about calendar year 2006.

We'd like to confirm that the name of the business is [NAME BUSINESS] and that [NAME BUSINESS] is still operating.

[NAME BUSINESS] IS THE CURRENT NAME

AND [NAME BUSINESS] IS STILL OPERATING ..........01

THE BUSINESS NAME IS INCORRECT .....................02 $\rightarrow$ GO TO A2Web

[NAME BUSINESS] IS OUT OF BUSINESS ...............03 $\rightarrow$ GO TO A10

A1b. We'd like to confirm that you are [OWNER NAME] and you are you are still an owner of [NAME BUSINESS]?

[OWNER NAME] IS THE RESPONDENT AND IS

STILL AN OWNER OF [NAME BUSINESS].... 01

[OWNER NAME] IS THE RESPONDENT AND IS STILL AN OWNER OF [NAME BUSINESS], BUT CORRECT [OWNER NAME]'S NAME.... $.02 \rightarrow$ GO TO A4aWeb

RESPONDENT IS NOT [OWNER NAME]. $.03 \rightarrow$ GO TO A4Webz

THE RESPONDENT [OWNER NAME] IS NO LONGER AN OWNER OF [NAME BUSINESS] $.07 \rightarrow$ GO TO A5a Box 
A1c. We'd like to confirm that the title of your position is [TITLE]? Is that correct?

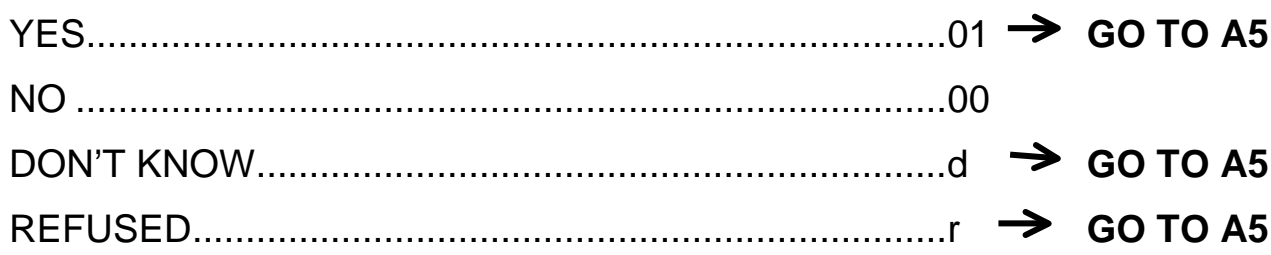

A1d. What is your job title?

INTERVIEWER: ENTER JOB TITLE.

Update Title

\section{GO TO A5}

A2a. I'm sorry. When would be a better time to reach (you/[OWNER])?

INTERVIEWER: ENTER CALLBACK DATE AND TIME.

READ: Is this the best number to reach you?

INTERVIEWER: UPDATE CONTACT INFORMATION AS NEEDED.

Thank you very much. Good-bye.

THANK AND TERMINATE

A2Web. What is the correct business name?

INTERVIEWER: TYPE IN BUSINESS NAME.

A3Web. Is this a corrected spelling, a name change but the same business, or a different business?

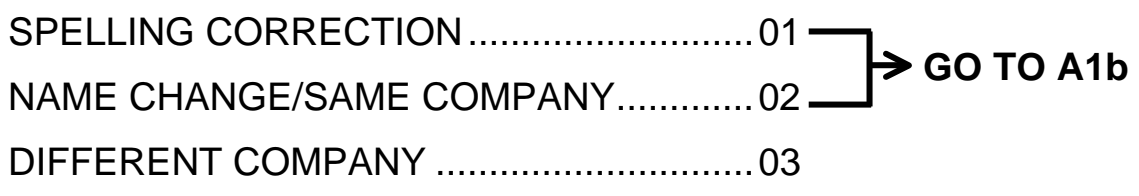


A3Webz. We are trying to find out what happened to [NAME BUSINESS]. Is [NAME BUSINESS] still in operation?

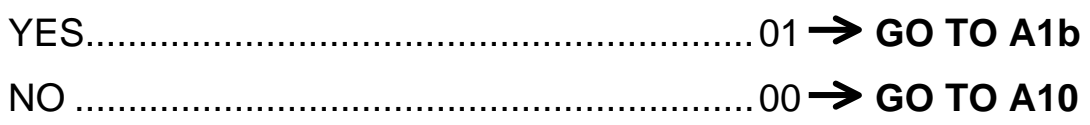

A4Webz Is [OWNER NAME] still an owner and actively involved in running [NAME BUSINESS]?

IF NEEDED: By actively involved, we mean providing regular assistance or advice with day-to-day operations of the business rather than providing only money or occasional operating assistance.

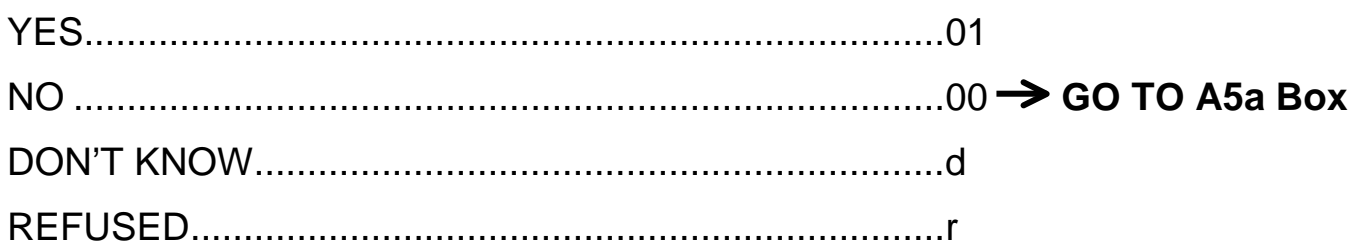

A4Webz1 Would [OWNER NAME] be available to do the study at another time?

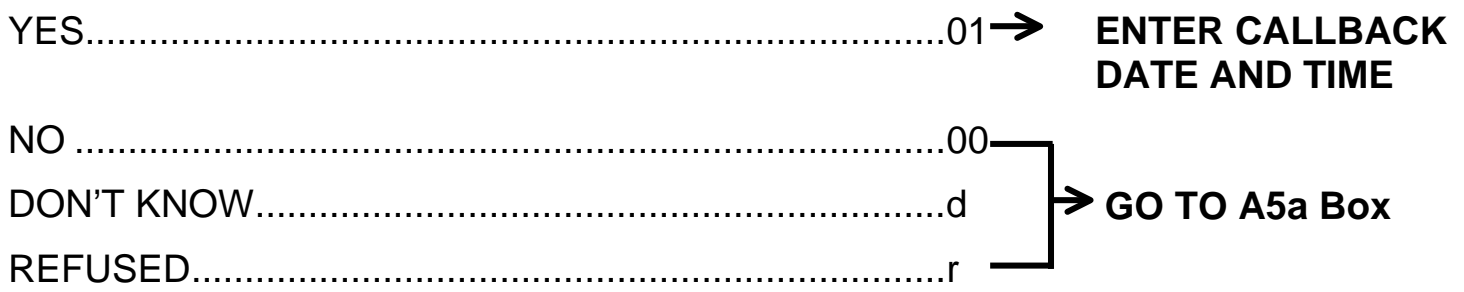

A4aWeb What is the correct spelling of your name?

NAME:

A5. Are you still actively involved in running [NAME BUSINESS]? By actively involved in running the business, we mean providing regular assistance or advice with day-to-day operations of the business rather than providing only money or occasional operating assistance.

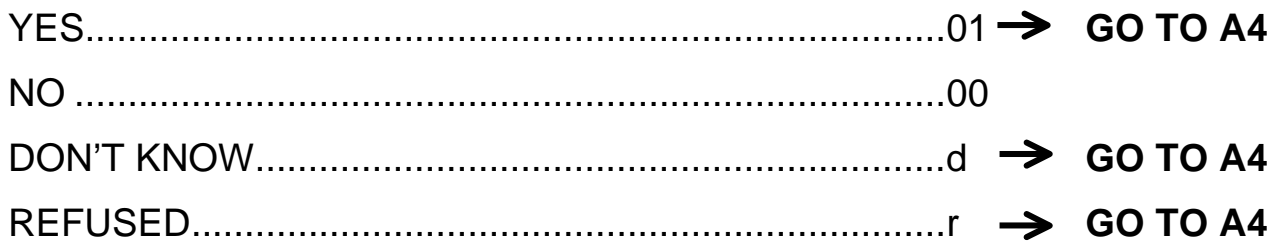

[A5_Actively_involved_S] 


\section{A5A BOX: \\ IF MORE THAN ONE OWNER-OPERATOR- FOUNDER FROM FIRST FOLLOW-UP, ASK A5a. ELSE, ASK A4Web.}

A5a. During the last interview with your business, we recorded other owners of [NAME BUSINESS]. Please tell me the person who is an owner of the business, is actively involved in running [NAME BUSINESS], and will answer this study.

By actively involved in running the business, we mean providing regular assistance or advice with day-to-day operations of the business rather than providing only money or occasional operating assistance.

READ THE OWNER NAMES BELOW. SELECT ONLY ONE.

NEW OWNER-OPERATOR WILL ANSWER .......................00 $\rightarrow$ GO TO A5aweb1

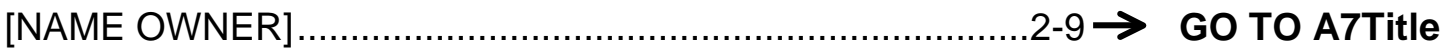

NON-OWNER WILL ANSWER .....................................11 $\rightarrow$ GO TO A5aweb1

INTERVIEWER: CODE 11 ONLY WITH SUPERVISOR PERMISSION AND WRITE NOTE DOCUMENTING CIRCUMSTANCES

A4Web Who is currently an (OWNER/CEO) of [NAME BUSINESS]?

NAME:

A4Webz2 Are you (OWNER/CEO)?

YES 01

NO

$00 \rightarrow$ GO TO Inform

A5new. And are you actively involved in running [NAME BUSINESS]? By actively involved in running the business, we mean providing regular assistance or advice with day-to-day operations of the business rather than providing only money or occasional operating assistance.

YES $01 \rightarrow$ GO TO A4new

NO .00

[A5New_Actively_involved_S] 
A7. Is there another owner of [NAME BUSINESS] who is actively involved in running [NAME BUSINESS], and can answer questions about the business?

PROBE: $\quad$ By actively involved in running the business, we mean providing regular assistance or advice with day-to-day operations of the business rather than providing only money or occasional operating assistance.

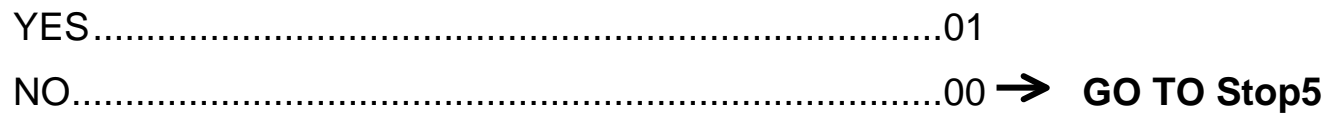

A5aWeb1 Who is another owner of [NAME BUSINESS] who is actively involved in running [NAME BUSINESS], and can answer questions about the business?

ENTER FIRST NAME

ENTER LAST NAME

ENTER JOB TITLE

A4Webz2 Are you (OWNER/CEO)?

YES

$.01 \rightarrow$ GO TO A4new

NO.

.00

Inform. Do you know a good time and date I can call to contact (OWNER/CEO)?

INTERVIEWER: ENTER CALLBACK DATE AND TIME.

THANK AND TERMINATE

Stop5. Thank you for your time.

THANK AND TERMINATE

A7Title. What is the title of [OWNER NAME]?

A4Webz2 Are you (OWNER NAME)?

YES

$.01 \rightarrow$ GO TO A4new

NO.

$.00 \rightarrow$ GO TO Inform 
A4. You participated last year in the Kauffman Firm Survey. We asked some questions about [NAME BUSINESS] operations in 2004 and 2005. Now we'd like to ask about the year 2006. Again, your answers will be completely confidential, and you will once again receive a $\$ 50$ payment as a token of our appreciation.

\section{GO TO A8}

A4new. Your business participated last year in the Kauffman Firm Study. We asked some questions about [NAME BUSINESS]'s operation in 2004 and 2005. Now we'd like to ask about the year 2006. Again, your answers will be kept confidential, and you will receive a $\$ 50$ payment as a token of our appreciation.

A8. I'd like to confirm your business' mailing address. Is [NAME BUSINESS]'s mailing address (ADDRESS, CITY, STATE, ZIP)?

WEB: Our records indicate that the mailing address for [NAME BUSINESS] is (ADDRESS, CITY, STATE, ZIP). Is this correct?

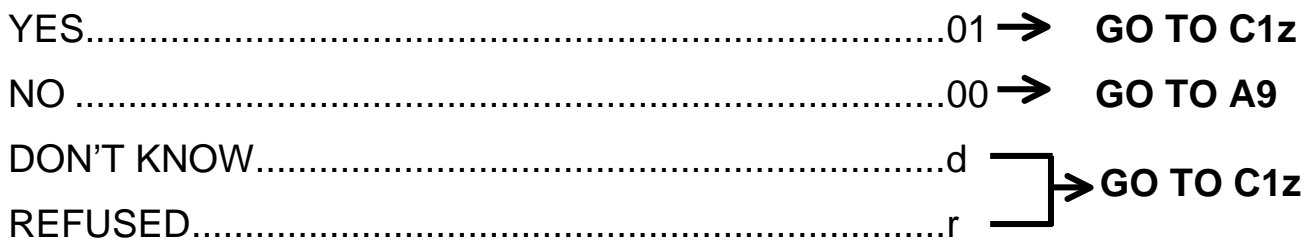

[A8_Addr_ver_S]

A9. What is [NAME BUSINESS]'s correct mailing address?

INTERVIEWER: UPDATE MAILING ADDRESS INFORMATION.

ADDRESS:

CITY:

STATE:

ZIP:

DON'T KNOW......................................................

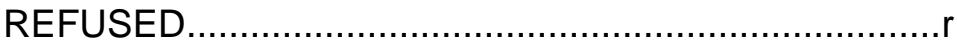

GO TO C1z 
A10. What is the main reason [NAME BUSINESS] is out of business?

SOLD TO ANOTHER BUSINESS .............................01

MERGED WITH ANOTHER BUSINESS ......................02

TEMPORARILY STOPPED OPERATIONS ..................03

PERMANENTLY STOPPED OPERATIONS .................04 $\rightarrow$ GO TO A11a

OTHER (SPECIFY) ......................................... 05

DON'T KNOW

REFUSED.............................................................

[A10_Out_Of_Business_S]

[A10_Other_Specify_S]

\section{THANK AND TERMINATE}

A11a. Did [NAME BUSINESS] file for bankruptcy?

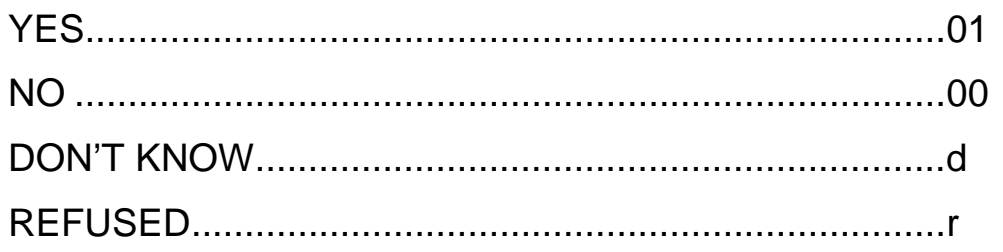

[A11a_Bankruptcy_S]

THANK AND TERMINATE 


NO SECTION B

Prepared by Mathematica Policy Research, Inc. 


\section{BUSINESS CHARACTERISTICS}

All of the following questions I'm going to ask are about [NAME BUSINESS]. Some of the questions will ask to confirm information about your business which you provided to us previously. As we go through the interview, please tell me if any of the information about your business is incorrect and needs to be updated.

C1z. Our records show that [NAME BUSINESS] had a legal status of [tOWNERshipModel]. As of December 31, 2006, is that still the legal status of [NAME BUSINESS]?

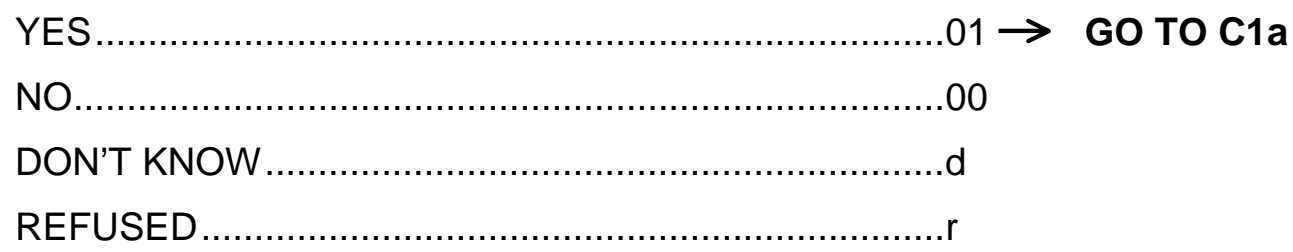

[C1z_Confirm_Legal_Status_S] 
C1z2. I'm going to read you a list of some different forms of legal status a business can have. As of December 31, 2006, which form of legal status did [NAME BUSINESS] have? Was it a . .

\section{READ LIST AND READ DESCRIPTIONS AS NEEDED:}

Sole Proprietorship: A type of business ownership in which a business is owned and managed by one individual and no subchapter S-corporation or C-corporation has been established.

Limited Liability Company: A cross between a corporation and a partnership, and offering some of the benefits of both. Similar to S corporations, income produced by a limited liability company flows through to owners (known as "members") who pay their own taxes as individuals. Unlike S-corporations, however, limited liability companies are not subject to as many government restrictions.

Subchapter S-Corporation: Corporations in which all profits and losses are passed through to shareholders, just as they are passed through to partners in a partnership.

C-Corporation: Legal entities separate from their owners that may engage in business, make contracts, own property, pay taxes, and sue and be sued by others.

General Partnership: An association of two or more people who co-own a business for the purpose of making a profit and no subchapter S-corporation or C-corporation has been established.

Limited Partnership: A partnership in which one or more partners are general partners who manage the business and others are limited partners who invest in the business but forego any right to manage the company.

Sole Proprietorship, ............................................ 01

Limited Liability Company, ....................................02

Subchapter S-Corporation, ......................................03

C-Corporation, ............................................... 04

General Partnership, ,....................................... 05

Limited Partnership, or ..............................................

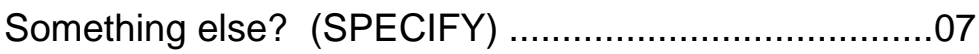

[C1z2_Legal_Status_S]

[C1z2OtherSpecify_S]

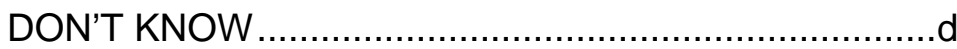

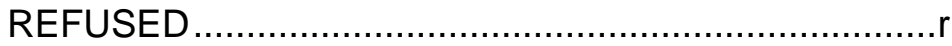


C1a. Our records indicate the principal activity of the business was [D\&B NAICS CODE DESCRIPTION]. Was that still the principal activity of the business as of December 31, 2006?

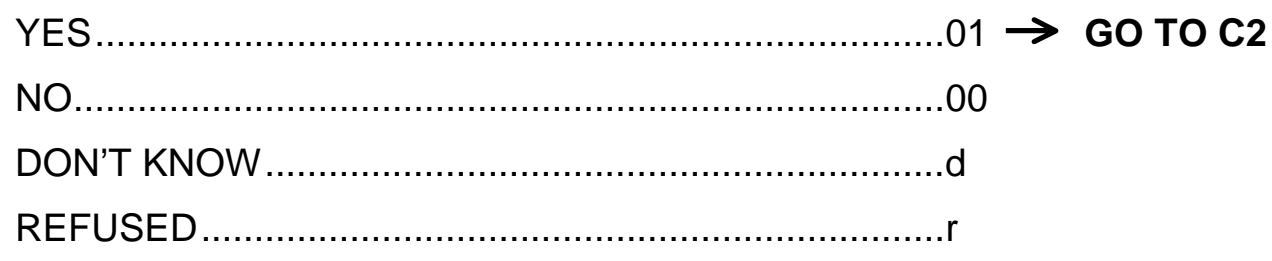

[C1a_NAICS_verification_S]

C1b. As of December 31, 2006, what was the principal activity of the business?

IF SOLE PROPRIETORSHIP IN [tOWNERshipModel] [or C1z2], GO TO C5.

C2. As of December 31, 2006, how many individuals or entities owned [NAME BUSINESS]? Please include all individuals or entities who owned shares in the business.

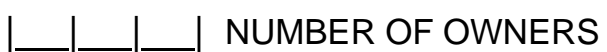

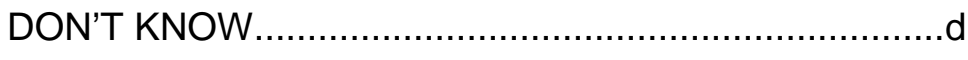

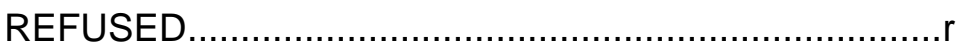

[C2_Owners_S]

C3. Of the [NUMBER OF OWNERS FROM C2] owners as of December 31, 2006, how many owners actively helped to run [NAME BUSINESS]? By helped to run the business we mean that they provided regular assistance or advice with day-to-day operations of the business, rather than providing only money or occasional operating assistance.

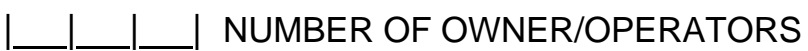

DON'T KNOW..................................................d

REFUSED ........................................................

[C3a_Owner_Operators_S] 
IF ONE OWNER/OPERATOR REPORTED AT C3, GO TO C5. IF MORE THAN ONE OWNER/OPERATOR REPORTED AT C3, ASK:

C4. FOR EACH FIRST FOLLOW-UP OWNER/OPERATOR WHO IS NOT THE RESPONDENT, ASK:

Was [OWNER NAME] still an owner who actively helped run [NAME BUSINESS]—as of December 31, 2006?

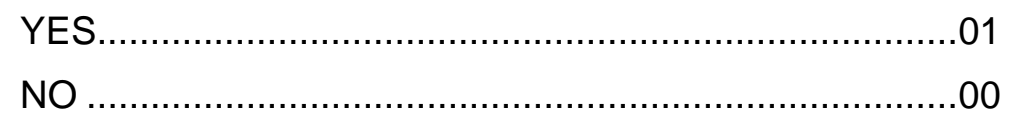

YES BUT THE NAME IS MISSPELLED ......................02

DON'T KNOW.....................................................

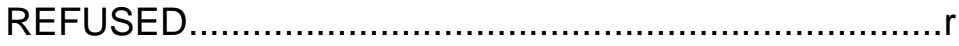

FOR ALL MISSPELLED NAMES, ASK:

How do you spell (your/his/her) name?

\section{INTERVIEWER: ENTER NAME}

\section{THEN ASK:}

How many other people, not previously listed, were owners actively helping to run [NAME BUSINESS] as of December 31, 2006.

\section{INTERVIEWER: PREVIOUSLY LISTED PEOPLE ARE STATED BELOW. NUMBER OF OWNERS STATED IN C3: [FILL FROM C3]}

I want to record with you the first and last names of these owners. These are the people who joined the business between the last time we talked to you and December 31, 2006. I'm going to be asking some questions about each of the owners who actively helped run [NAME BUSINESS]. Can you tell me the first and last name of the other owner(s) of $A B C$ Business?

\section{INTERVIEWER: $\quad$ ENTER FIRST AND LAST NAMES.}


C4Confirm. I have listed:

FIRST NAME

LAST NAME

OWNER A (RESPONDENT)

OWNER B

OWNER C

OWNER D

[C4_NumOwners_Confirm_S]

Are there any other owner-operators as of December 31, 2006 of [NAME BUSINESS] that I have not mentioned?

INTERVIEWER: CONFIRM SPELLING OF NAMES. TO CORRECT NAMES, ARROW BACK TO TABLE.

ADD ANOTHER NAME OR

CORRECT A MISSPELLING ...................................01

NO CHANGES ................................................02

NOTE: UP TO 10 OWNER/OPERATOR/FOUNDERS WILL BE INCLUDED.

C5. Not counting owner(s), on December 31, 2006, how many people worked for [NAME BUSINESS]? Please include all full- and part-time employees, but exclude contract workers who work for the business either full- or part-time but are not on the business' official payroll.

I_____ NUMBER OF EMPLOYEES ON DECEMBER 31, 2006

DON'T KNOW.................................................... d

REFUSED .........................................................

[C5_Num_Employees_S]

C5b. Was this change an increase, a decrease, or no change in the number of people who worked for [NAME BUSINESS] on December 31, 2006 compared to December 31, 2005?

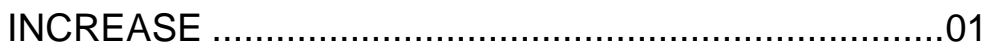

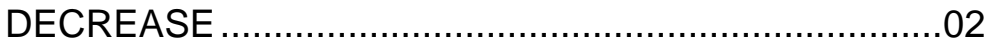

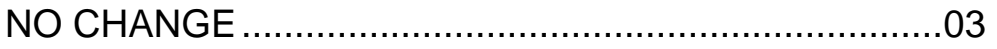

DON'T KNOW..........................................................

REFUSED .......................................................

[C5b_Num_Employees_Change_S] 
C5c. And what was the (increase/decrease) in the number of people who worked for [NAME BUSINESS] on December 31, 2006 compared to December 31, 2005? Your best estimate is fine.

\section{|____ CHANGE IN NUMBER OF EMPLOYEES}

DON'T KNOW..........................................................

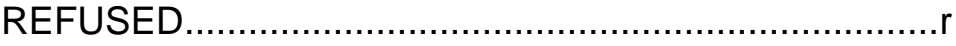

[C5c_Num_Employees_Change_Amt_S]

\section{IF BUSINESS REPORTED “0” EMPLOYEES AT C5, GO TO C8Z.}

C6. And of those [NUMBER FROM C5], how many were full-time?

(IF NEEDED: Full-time is considered 35 hours or more per week)

|_____ NUMBER OF DECEMBER 31, 2006 FULL-TIME EMPLOYEES

DON'T KNOW............................................................

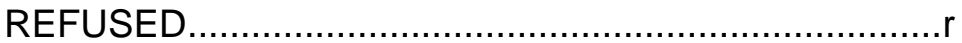

[C6_Num_FT_Employees_S]

C7. And how many were part-time? (IF NEEDED: Part-time is considered less than 35 hours per week)

I_L___ NUMBER OF DECEMBER 31, 2006 PART-TIME EMPLOYEES

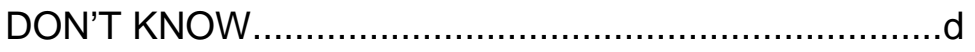

REFUSED ......................................................

[C7_Num_PT_Employees_S]

C8z. Our records show that the primary location where [NAME BUSINESS] operates is [tPrimaryLocation]. Is that correct?

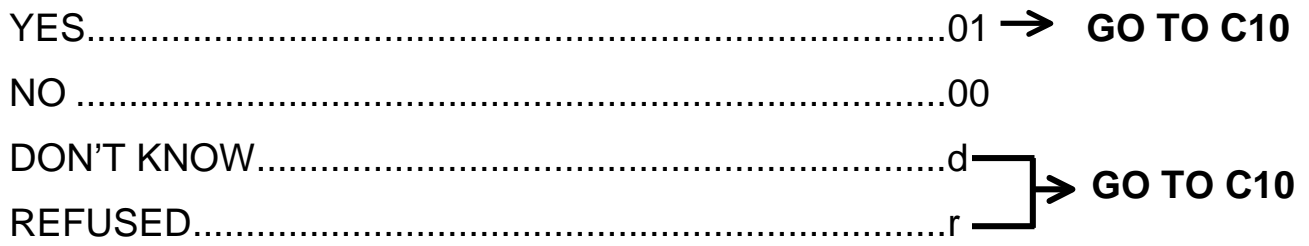

[C8z_Primary_Loc_Confirm_S] 
C8. How would you describe the primary location where [NAME BUSINESS] operates? Is it ...

A residence such as a home or garage,$\ldots \ldots \ldots \ldots \ldots \ldots \ldots . . . . . . .1$

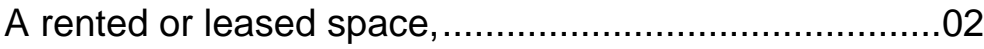

Space the business purchased, ................................ 03

A site where a client is located, or ................................ 04

Some other location? (SPECIFY) ...........................05

DON'T KNOW

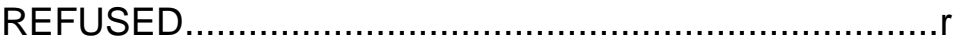

[C8 Primary Loc S]

[C8_Primary_Loc_Specify_S]

C9. What was the main reason for the change of location?

Previous location too expensive ................................

Needed more space due to growth of business ............02

Moved closer to customers........................................03

Moved business and residence to new location .............04

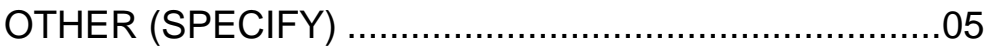

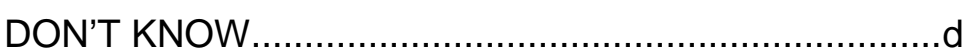

REFUSED ..........................................................

[C9_Loc_Change_Reason_S]

[C9OtherSpecify_S]

C10. As of December 31, 2006, did [NAME BUSINESS] operate in more than one location?

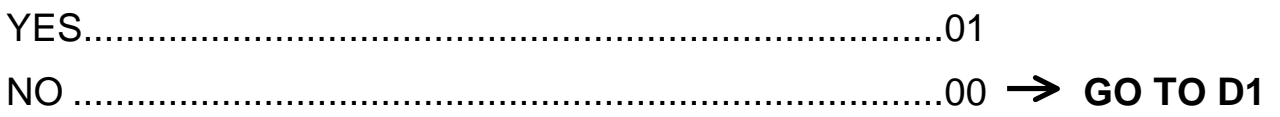

[C10_MoreLocations_S]

C11. And as of December 31, 2006, how many locations did [NAME BUSINESS] operate in?

NUMBER OF LOCATIONS AS OF DECEMBER 31, 2006

[C11_Num_Locations_S]

C11a. In what month and year did you open your second location?

Month

Year I 2 I 0 | $0 \mid$

[C11a_2ndOpening_Month_S[MPR1]]

[C11a_2ndOpening_Year_S] 


\section{STRATEGY AND INNOVATION}

D1. Does [NAME BUSINESS] provide (READ ITEM)?

\begin{tabular}{|c|c|c|c|}
\hline YES & NO & $\begin{array}{c}\text { DON'T } \\
\text { KNOW }\end{array}$ & REFUSED \\
\hline
\end{tabular}

a. A service

[D1a_Provide_Service_S]

$01 \quad 00$

d

$r$

b. A product

[D1b_Provide_Product_S]

$01 \quad 00$

d

r

D2. Businesses often have to compete with other businesses. A competitive advantage is something unique or distinctive a business provides that gives it an advantage compared to competitors. In calendar year 2006, did [NAME BUSINESS] have a competitive advantage over its competitors?

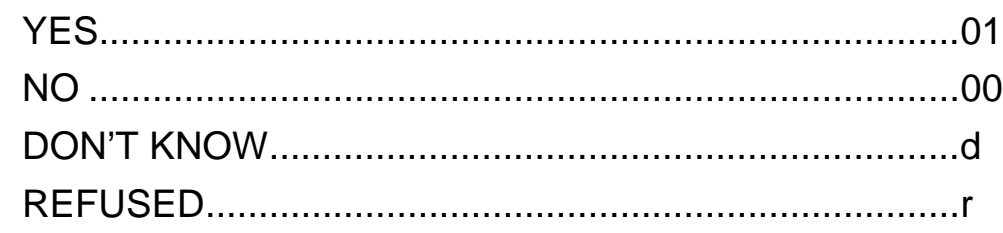

[D2_Comp_Advantage_S] 
D3. Whether assigned by an owner or obtained in some other way, does [NAME BUSINESS] have any of the following? (READ LIST)

FOR EACH “YES," ASK: How many (READ ITEM) does [NAME BUSINESS] have?

\section{INTERVIEWERS IF NEEDED:}

Patent: A patent is a right given by the government to preclude others from making and selling an invention for 20 years from the date of application in return for disclosure of how the invention operates.

Copyright: The legal right granted to authors, composers, artists and publishers to protect their thoughts and ideas for exclusive publication, reproduction, sale and distribution of their works.

Trademark: Words, names, symbols or devices, or any combination of these used to identify the goods of a business and to distinguish these goods from the goods of others.

\begin{tabular}{lc|c|c|c|c|} 
& YES & NO & $\begin{array}{l}\text { DON'T } \\
\text { KNOW }\end{array}$ & REFUSED & $\begin{array}{c}\text { NUMBR BUSINESS } \\
\text { HAS }\end{array}$ \\
$\begin{array}{l}\text { a. Patents } \\
\text { [D3_a_Have_Patent_S] }\end{array}$ & 01 & 00 & $\mathrm{~d}$ & $\mathrm{r}$ & $\begin{array}{l}\text { [D3_a_Num_Patent] } \\
\begin{array}{l}\text { b. Copyrights } \\
\text { [D3_b_Have_Copyright_S] }\end{array}\end{array}$ \\
$\begin{array}{l}\text { C. Trademarks } \\
\text { [D3_c_Have_Trademark_S] }\end{array}$ & 01 & 00 & $\mathrm{~d}$ & $\mathrm{r}$ & $\begin{array}{l}\text { [D3_b_Num_Copyright] } \\
\text { [D3_c_Num_Trademark] }\end{array}$
\end{tabular}

D4. "Licensing out" is licensing patents, copyrights, or trademarks owned by the business to other parties under a licensing agreement. In calendar year 2006, did [NAME BUSINESS] license out any (READ ITEM)?

\begin{tabular}{|l|l|l|l|}
\hline YES & NO & $\begin{array}{c}\text { DON'T } \\
\text { KNOW }\end{array}$ & REFUSED \\
\hline
\end{tabular}
a. Patents

[D4_a_Lic_Out_Patents_S]

01

00

d

$r$

b. Copyrights

[D4_b_Lic_Out_Copyrights_S]

01

00

d

r

C. Trademarks

[D4_C_Lic_Out_Trademarks_S]

01

00

d

r 
D5. "Licensing in" is acquiring the right to use intellectual property such as patents, copyrights, or trademarks created by someone outside the business through a licensing agreement. In calendar year 2006, did [NAME BUSINESS] license in any (READ ITEM)?

\begin{tabular}{|l|l|l|l|}
\hline YES & NO & DON'T & \\
KNOW & REFUSED \\
\hline
\end{tabular}

a. Patents .....

[D5_a_Lic_In_Patent_S]

01

00

d

$r$

b. Copyrights

[D5_b_Lic_In_Copyright_S]

$01 \quad 00$

d

r

c. Trademarks

[D5_c_Lic_In_Trademark_S]

$01 \quad 00$

d

r

D6. Did [NAME BUSINESS] have any customers or sales in calendar year 2006?

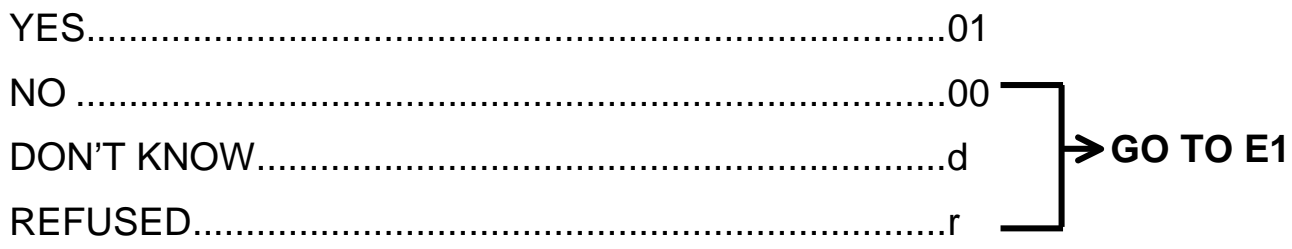

[D6_Have_Sales_S] 
D7. I'd like to learn more about the type of customers that [NAME BUSINESS] had during calendar year 2006. I am going to ask you to estimate the percent of the business' sales that were made to individuals, businesses, and government agencies. The total should equal $100 \%$.

a. During calendar year 2006, what percentage of the business' sales were to private individuals?

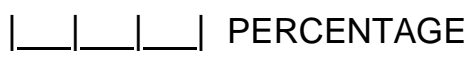

DON'T KNOW.......................................................... d

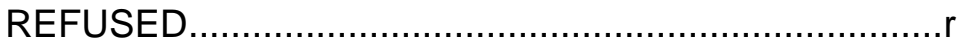

[D7_Perc_Sales_Indiv_S]

b. What percentage of the business' sales were to other businesses?

[IF NEEDED: Please include sales to for-profit and not-for-profit business.]

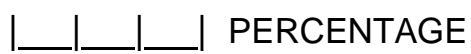

DON'T KNOW.......................................................... d

REFUSED ......................................................

[D7_Perc_Sales_Bus_S]

c. What percentage of the business' sales were to government agencies?

I____ PERCENTAGE

DON'T KNOW...................................................

REFUSED .......................................................

[D7_Perc_Sales_Govt_S] 


\section{E. BUSINESS ORGANIZATION AND HR BENEFITS}

\section{IF ONE OWNER REPORTED AT C2 AND BUSINESS REPORTED “0” EMPLOYEES AT C5, GO TO F1.}

Next, l'd like to ask about how [NAME BUSINESS] is organized and about the benefits that are offered to employees.

E1. On December 31, 2006, how many employees or owners, if any, did [NAME BUSINESS] have who were primarily responsible for (READ ITEM)? Please include only full- and parttime employees, but not contract workers who work for the business but are not on the business' official payroll.

a. Human resources such as employee benefits, recruitment, or hiring

\begin{tabular}{|c|c|c|}
\hline $\begin{array}{c}\text { NUMBER } \\
\text { EMPLOYEES OR } \\
\text { OWNERS }\end{array}$ & $\begin{array}{c}\text { DON'T } \\
\text { KNOW }\end{array}$ & REFUSED \\
\hline
\end{tabular}

[E1_a_Num_Human_Res_S]

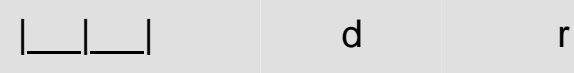

b. Sales or Marketing such as sales, market research, customer analysis, or promotional activities......... [E1_b_Num_Sales_S]

c. Executive administration functions such as strategic planning, competitive analysis, shareholder relations, or general management

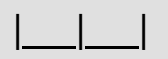

d r [E1_c_Num_Exec_Admin_S]

d. Research and development on new products or services

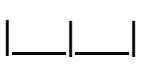

d

$r$ [E1_d_Num_ResDev_S]

e. Production or manufacturing such as producing materials or products, production planning, production control, quality control, or storage ......

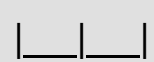

d r [E1_e_Num_Prod_Manu_S]

f. General administration such as office management, responding to maintenance requests, purchase supplies, or training employees in office procedures

[E1_f_Num_Gen_Admin_S]

g. Financial administration such as accounting procedures, budgeting, financial analysis, or investment activities.

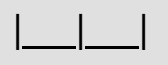

d

$r$ [E1_g_Num_Fin_Admin_S]

h. Does [NAME BUSINESS] have employees with any other key responsibilities? (SPECIFY) [E1_h_Num_Other_S]

[E1_h_Other_Specify_S] 
E2a. As of December 31, 2006, did [NAME BUSINESS] offer full-time employees or owners (READ ITEM):

\begin{tabular}{|l|l|l|l|}
\hline YES & NO & DON'T & \\
KNOW & REFUSED \\
\hline
\end{tabular}

a. A health insurance plan either through the business or an association...

[E2a_FT_Emp_HIth_Plan_S]

01

00

d

$r$

b. A retirement plan such as profit sharing, pension, including $401 \mathrm{~K}$, annuity, Keogh, etc.

[E2a_FT_Emp_Retire_Plan_S]

01

00

d

$r$

C. Stock options or other stock ownership [E2a_FT_Emp_Stock_Own_S]

01

00

d

r

d. A bonus plan

[E2a_FT_Emp_Bonus_Plan_S]

$01 \quad 00$

d

r

e. Tuition reimbursement [E2a_FT_Emp_Tuit_Reim_S]

01

00

d

$r$

f. Paid vacation [E2a_FT_Emp_Paid_Vaca_S]

01

00

d

r

g. Paid sick days

[E2a_FT_Emp_Paid_Sick_S]

01

00

d

$r$

h. Alternative work schedules such as flex time or job sharing

[E2a_FT_Emp_Flex_Time_S]

01

00

d

r

i. Any other benefits? (SPECIFY)

[E2a_FT_Emp_Other_S]

01

00

d

r

[E2a_Other_Specify_S] 
IF ZERO PART-TIME EMPLOYEES AT C7, GO TO F1.

E2b. As of December 31, 2006, did [NAME BUSINESS] offer part-time employees (READ ITEM):

a. A health insurance plan either through the business or an association

[E2b_PT_Emp_HIth_Plan_S]

\begin{tabular}{l|l|l|l|} 
YES & NO & $\begin{array}{c}\text { DON'T } \\
\text { KNOW }\end{array}$ & REFUSED \\
\hline
\end{tabular}

b. A retirement plan such as profit sharing, pension, including 401K, annuity, Keogh, etc.

[E2b_PT_Emp_Retire_Plan_S]

01

00

d

$r$

Stock options or other stock ownership

[E2b_PT_Emp_Stock_Own_S]

01

00

d

r

d. A bonus plan

[E2b_PT_Emp_Bonus_Plan_S]

$01 \quad 00$

00

d

r

e. Tuition reimbursement

[E2b_PT_Emp_Tuit_Reim_S]

01

00

d

r

f. Paid vacation

[E2b_PT_Emp_Paid_Vaca_S]

$01 \quad 00$

d

r

g. Paid sick days .... [E2b_PT_Emp_Paid_Sick_S]

$01 \quad 00$

d

$r$

h. Alternative work schedules such as flex time or job sharing

[E2b_PT_Emp_Flex_Time_S]

01

00

d

r

i. Any other benefits? (SPECIFY) [E2b_PT_Emp_Other_S]

01

01

00

d

$r$

[E2b_PT_Emp_Other_S]

[E2bOtherSpecify_S] 


\section{F. BUSINESS FINANCES}

F1. Now l'd like to ask about [NAME BUSINESS]'s financing. Businesses can get money from the savings or investments of the owner(s), money from spouses, family or other individuals, from companies, borrowing in an owner's name, venture funds, or by borrowing in the name of the business. Some of the funds must be paid back and other funds represent an equity stake or share of the business. We will ask some questions about what happened during calendar year 2006, some questions about what has happened since the business began, and other questions about balances as of December 31, 2006.

F1a. First, in calendar year 2006, did [you/OWNER B-J] put any of your own money into [NAME BUSINESS] in return for an ownership share of the business? Please do not include any money borrowed from others or from credit cards.

IF NEEDED: This would include all additional money invested by [you/OWNER B-J] in the business during calendar year 2006.

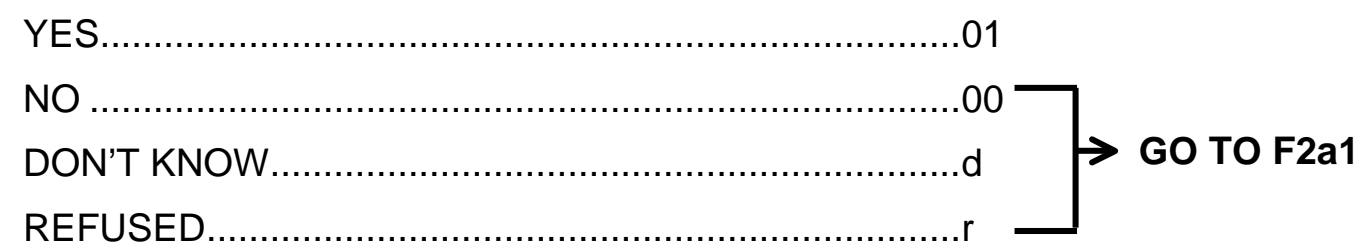

[F2_Owner_Eq_Invest_01_S] 
F2a. IF YES: How much of [your/her/his] own money did [you/he/she] put into the business during calendar year 2006?

IF NEEDED: Your best estimate is fine.

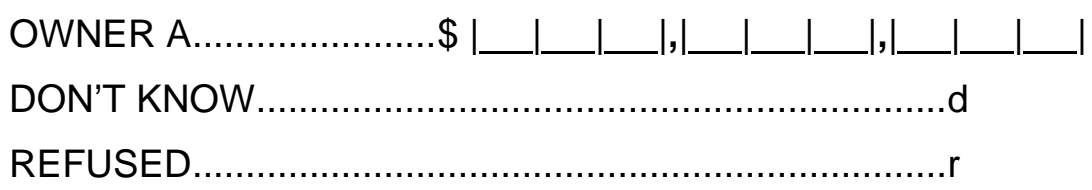

[F2_Owner_Amt_Eq_Invest_01_S]

IF DON'T KNOW OR REFUSED, PROBE WITH RANGES: Would you say it was ...

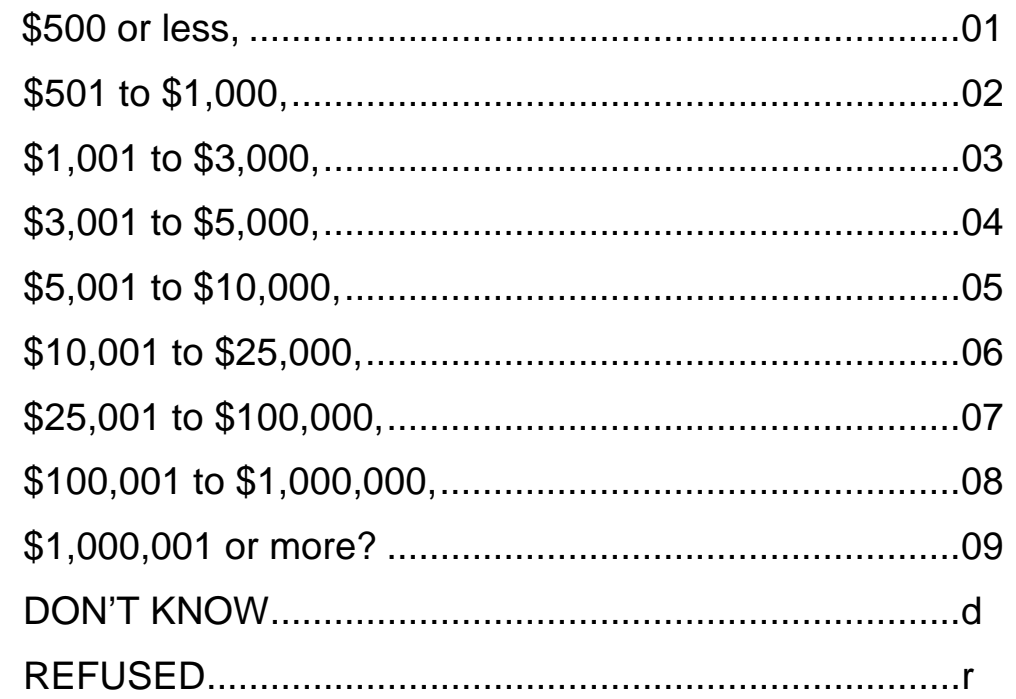

[F2_Ownr_Amt_EqInvest_Range_01_S] 
F2a1. Counting all years, how much of [your/OWNER B-J's] own money did [you/she/he] put into [NAME BUSINESS] as of December 31, 2006?

IF NEEDED: This includes all money [you/she/he] invested in the business as of December 31, 2006.

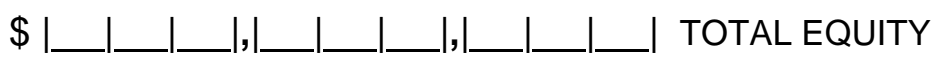

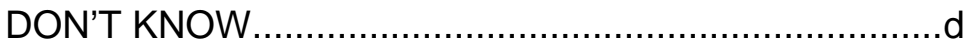

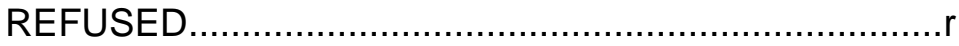

[F2_Ownr_Amt_EqInvest_AlIYrs_01_S]

PROBE: IF DON'T KNOW OR REFUSED, PROBE WITH RANGES: Would you say it was...

$\$ 500$ or less, ..................................................... 01

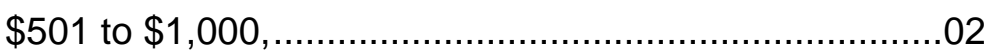

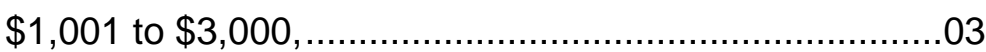

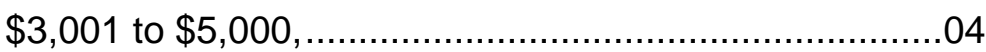

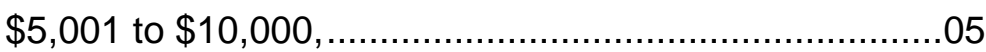

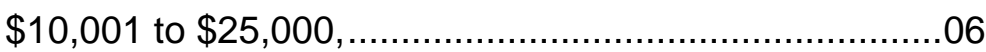

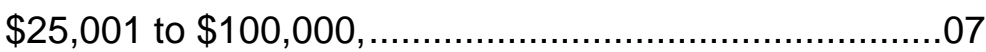

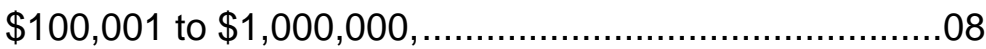

$\$ 1,000,001$ or more? ...............................................

DON'T KNOW....................................................... d

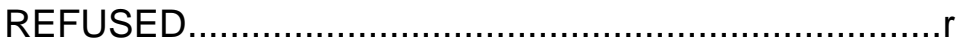

[F2_Ownr_EqInvst_AllYrs_Range01_S]

IF F2a IS GREATER THAN F2a1:

I may have made a mistake. The amount invested in 2006 is greater than the amount invested in all years combined. Is there an error?

F2b. What percentage of the business did [you/OWNER B-J] own on December 31, 2006?

I_____ PERCENTAGE OF BUSINESS

DON'T KNOW..................................................... d

REFUSED ..............................................................

[F2_Owner_Perc_Own_01_S]

IF MORE THAN ONE OWNER/OPERATOR AT C4, ASK F1a-F2b FOR EACH OWNERIOPERATOR. OTHERWISE, GO TO F3. 
IF SOLE PROPRIETORSHIP AT QUESTION C1Z OR C1z2, GO TO F6b.

F2 series asked of up to 10 owner-operators.

[F2 Owner Eq Invest $02 \mathrm{~S}$ ]

[F2_Owner_Amt_Eq_Invest_02_S]

[F2_Ownr_Amt_EqInvest_Range_02_S]

[F2_Ownr_Amt_Eqlnvest_AllYrs_02_S]

[F2_Ownr_EqInvst_AllYrs_Range02_S]

[F2_Owner_Perc_Own_02_S]

[F2_Owner_Eq_Invest_03_S]

[F2_Owner_Amt_Eq_Invest_03_S]

[F2_Ownr_Amt_EqInvest_Range_03_S]

[F2_Ownr_Amt_EqInvest_AlIYrs_03_S]

[F2_Ownr_EqInvst_AllYrs_Range03_S]

[F2_Owner_Perc_Own_03_S]

[F2_Owner_Eq_Invest_04_S]

[F2_Owner_Amt_Eq_Invest_04_S]

[F2_Ownr_Amt_EqInvest_Range_04_S]

[F2 Ownr_Amt EqInvest AllYrs 04 S]

[F2_Ownr_EqInvst_AllYrs_Range04_S]

[F2_Owner_Perc_Own_04_S]

[F2_Owner_Eq_Invest_05_S]

[F2_Owner_Amt_Eq_Invest_05_S]

[F2_Ownr_Amt_EqInvest_Range_05_S]

[F2_Ownr_Amt_EqInvest_AllYrs_05_S]

[F2_Ownr_EqInvst_AllYrs_Range05_S]

[F2_Owner_Perc_Own_05_S]

[F2_Owner_Eq_Invest_06_S]

[F2_Owner_Amt_Eq_Invest_06_S]

[F2_Ownr_Amt_EqInvest_Range_06_S]

[F2_Ownr_Amt_EqInvest_AllYrs_06_S]

[F2_Ownr_EqInvst_AlIYrs_Range06_S]

[F2_Owner_Perc_Own_06_S]

[F2_Owner_Eq_Invest_07_S]

[F2_Owner_Amt_Eq_Invest_07_S]

[F2_Ownr_Amt_EqInvest_Range_07_S]

[F2_Ownr_Amt_EqInvest_AllYrs_07_S]

[F2_Ownr_EqInvst_AllYrs_Range07_S]

[F2_Owner_Perc_Own_07_S]

[F2_Owner_Eq_Invest_08_S]

[F2_Owner_Amt_Eq_Invest_08_S]

[F2_Ownr_Amt_EqInvest_Range_08_S]

[F2_Ownr_Amt_EqInvest_AllYrs_08_S]

[F2_Ownr_EqInvst_AllYrs_Range08_S]

[F2_Owner_Perc_Own_08_S]

[F2_Owner_Eq_Invest_09_S]

[F2_Owner_Amt_Eq_Invest_09_S]

[F2_Ownr_Amt_EqInvest_Range_09_S]

[F2_Ownr_Amt_EqInvest_AlIYrs_09_S]

[F2_Ownr_EqInvst_AllYrs_Range09_S]

[F2_Owner_Perc_Own_09_S]

[F2_Owner_Eq_Invest_10_S]

[F2_Owner_Amt_Eq_Invest_10_S]

[F2_Ownr_Amt_EqInvest_Range_10_S]

[F2_Ownr_Amt_EqInvest_AllYrs_10_S]

[F2_Ownr_EqInvst_AlIYrs_Range10_S]

[F2_Owner_Perc_Own_10_S] 
F3. Equity investment is money received in return for some portion of ownership, and it is another way to fund business expenses. During calendar year 2006, did the business obtain equity financing from any of the following sources?

\begin{tabular}{|l|l|l|l|}
\hline YES & NO & DON'T & \\
KNOW & REFUSED \\
\hline
\end{tabular}

a. Spouses or life partners of owners of the business. This does not include spouses or life partners already named as owners

[F3a_Eq_Invest_Spouse_S]

0100

d

r

b. Parents, in-laws or children of owners of the business ....... [F3b_Eq_Invest_Parents_S]

01
00

d

r

c. Individuals who are not spouses or life partners, parents, inlaws or children of the owners, excluding venture capitalists

[F3c_Eq_Invest_Angels_S]

$0100 \quad d$

$r$

d. Other companies

[F3d_Eq_Invest_Companies_S]

$01 \quad 00 \quad d$

r

e. Government agencies [F3e_Eq_Invest_Govt_S]

$01 \quad 00$

d

r

f. Venture capitalists

[F3f_Eq_Invest_Vent_Cap_S]

$01 \quad 00$

d

$r$

g. Any other sources? (SPECIFY).

[F3g_Eq_Invest_Other_S]

01

00

d

r

[F3_Other_Specify_S] 
F4. FOR EACH EQUITY FINANCING OPTION REPORTED AS "YES" ABOVE, ASK:

In calendar year 2006, how much money did [NAME BUSINESS] receive from [EQUITY OPTION]?

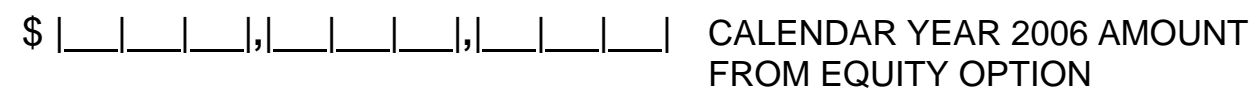

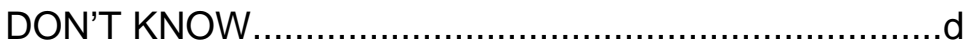

REFUSED .........................................................

[F4_Eq_Amt_Spouse_S]

[F4_Eq_Amt_Parents_S]

[F4_Eq_Amt_Angels_S]

[F4_Eq_Amt_Companies_S]

[F4_Eq_Amt_Govt_S]

[F4_Eq_Amt_Vent_Cap_S]

[F4_Eq_Amt_Other_S]

IF DON'T KNOW OR REFUSED, PROBE WITH RANGES: Would you say it was . .

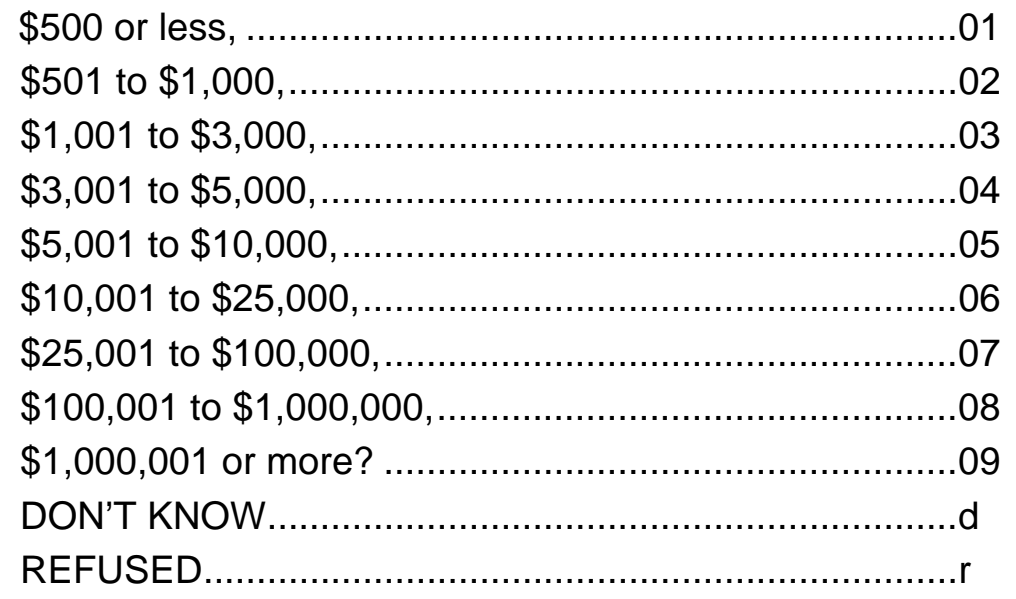

[F4a_Eq_Amt_Spouse_Ranges_S]

[F4a_Eq_Amt_Parents_Ranges_S]

[F4a_Eq_Amt_Angels_Ranges_S]

[F4a_Eq_Amt_Companies_Ranges_S]

[F4a_Eq_Amt_Govt_Ranges_S]

[F4a_Eq_Amt_Vent_Cap_Ranges_S]

[F4a_Eq_Amt_Other_Ranges_S 
F4a. Counting all years, how much did [EQUITY OPTION] put into [NAME BUSINESS] as of December 31, 2006?

PROBE: This includes all money invested by [EQUITY OPTION] in all years.
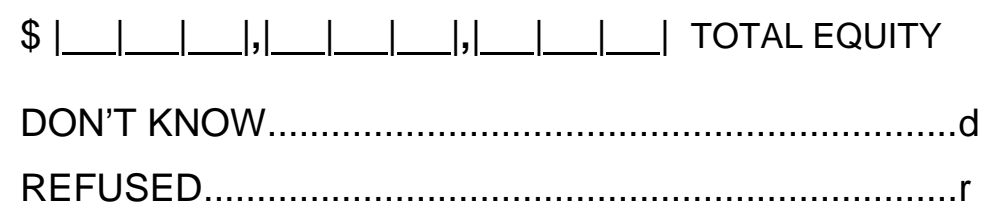

[F4 Eq_Amt Spouse_AllYrs S]

[F4_Eq_Amt_Parents_AllYrs_S]

[F4_Eq_Amt_Angels_AllYrs_S]

[F4_Eq_Amt_Companies_AllYrs_S]

[F4_Eq_Amt_Govt_AllYrs_S]

[F4_Eq_Amt_Vent_Cap_AllYrs_S]

[F4_Eq_Amt_Other_AllYrs_S]

PROBE: IF DON'T KNOW OR REFUSED, PROBE WITH RANGES: Would you say it was...

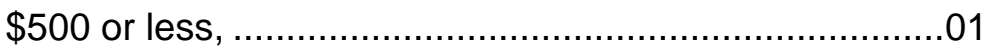

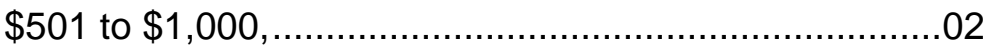

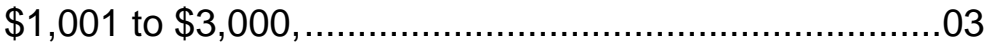

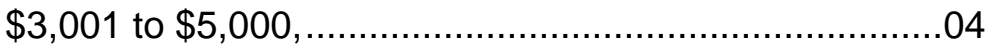

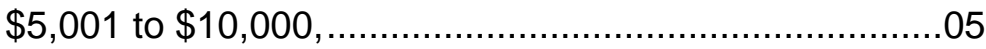

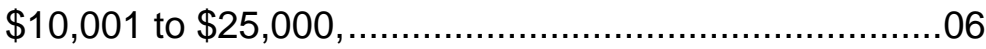

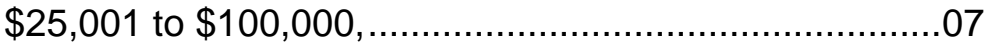

$\$ 100,001$ to $\$ 1,000,000, \ldots \ldots \ldots \ldots \ldots \ldots \ldots \ldots \ldots \ldots \ldots \ldots \ldots \ldots \ldots \ldots \ldots \ldots \ldots \ldots \ldots . . .08$

$\$ 1,000,001$ or more? ........................................................

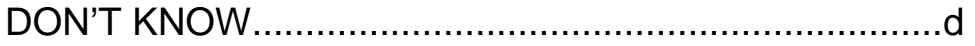

REFUSED ..........................................................

[F4_Eq_Amt_Spouse_AllYrs_Ranges_S]

[F4_Eq_Amt_Parents_AllYrs_Range_S]

[F4_Eq_Amt_Angels_AllYrs_Ranges_S]

[F4_Eq_Amt_Comp_AllYrs_Range_S]

[F4_Eq_Amt_Govt_AllYrs_Ranges_S]

[F4_Eq_Amt_VentCap_AlIYrs_Range_S]

[F4_Eq_Amt_Other_AllYrs_Ranges_S]

\section{IF F4 IS GREATER THAN F4a:}

I may have made a mistake. The amount invested in 2006 is greater than the amount invested in all years combined. Is there an error? 
F5. FOR EACH EQUITY FINANCING OPTION REPORTED AS "YES" ABOVE, ASK: What was the total percentage of the business owned by the [EQUITY OPTION] who invested money in the business as of December 31, 2006?

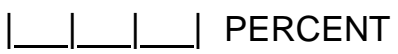

DON'T KNOW...................................................... d

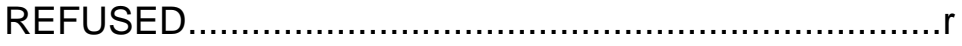

[F5_Perc_Owned_Spouse_S]

[F5_Perc_Owned_Parents_S]

[F5_Perc_Owned_Angels_S]

[F5_Perc_Owned_Companies_S]

[F5_Perc_Owned_Govt_S]

[F5_Perc_Owned_Vent_Cap_S]

[F5_Perc_Owned_Other_S]

INTERVIEWER CHECK BOX: CHECK ANSWER FROM F2b AND F5 FOR TOTAL PERCENTAGE OF BUSINESS ACCOUNTED FOR.

[F6Check_S]

IF TOTAL PERCENTAGE EQUALS $100 \%$, GO TO F6a

IF TOTAL EQUALS LESS OR MORE THAN 100\%

F6. So far, you've given me the following information on who owns [NAME BUSINESS]: [LIST EQUITY INVESTORS FROM F2b AND F5]. Can we review this list?

\section{REVIEW LIST OF OWNERS AND PERCENTAGES WITH RESPONDENT. MAKE CHANGES AS NEEDED, ADDING NEW OWNERS AND/OR PERCENTAGES AS NECESSARY.}

DON'T KNOW. d

REFUSED. r

[F6_Owner1_PercentOwned_S]

[F6_Owner2_PercentOwned_S]

[F6_Owner3_PercentOwned_S]

[F6_Owner4_PercentOwned_S]

[F6_Owner5_PercentOwned_S]

[F6_Owner6_PercentOwned_S]

[F6_Owner7_PercentOwned_S]

[F6_Owner8_PercentOwned_S]

[F6_Owner9_PercentOwned_S]

[F6_Owner10_PercentOwned_S]

[F6_Owner11_PercentOwned_S]

[F6_Owner12_PercentOwned_s] 
F6a. Have you or other owners withdrawn money from the business for personal use in 2006? INTERVIEWER: IF NEEDED This does not include owner salaries.

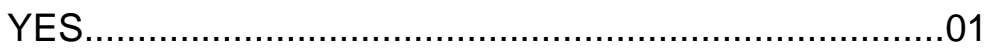

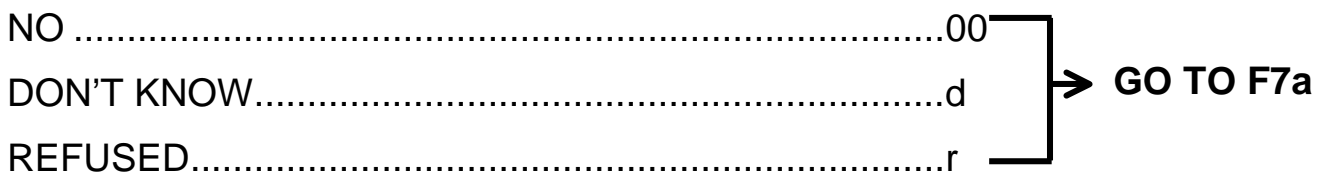

[F6a_Personal_Use_S]

F6b. IF YES: Thinking of calendar year 2006 only, how much money, if any, did you and other owners withdraw from the business for personal use? This includes any dividends paid.

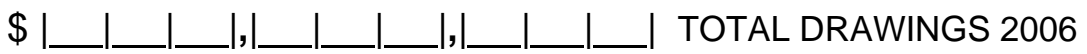

DON'T KNOW......................................................

REFUSED..............................................................

[F6b_Personal_Use_Amt_2006_S]

IF DON'T KNOW OR REFUSED, PROBE WITH RANGES: Would you say it was . .

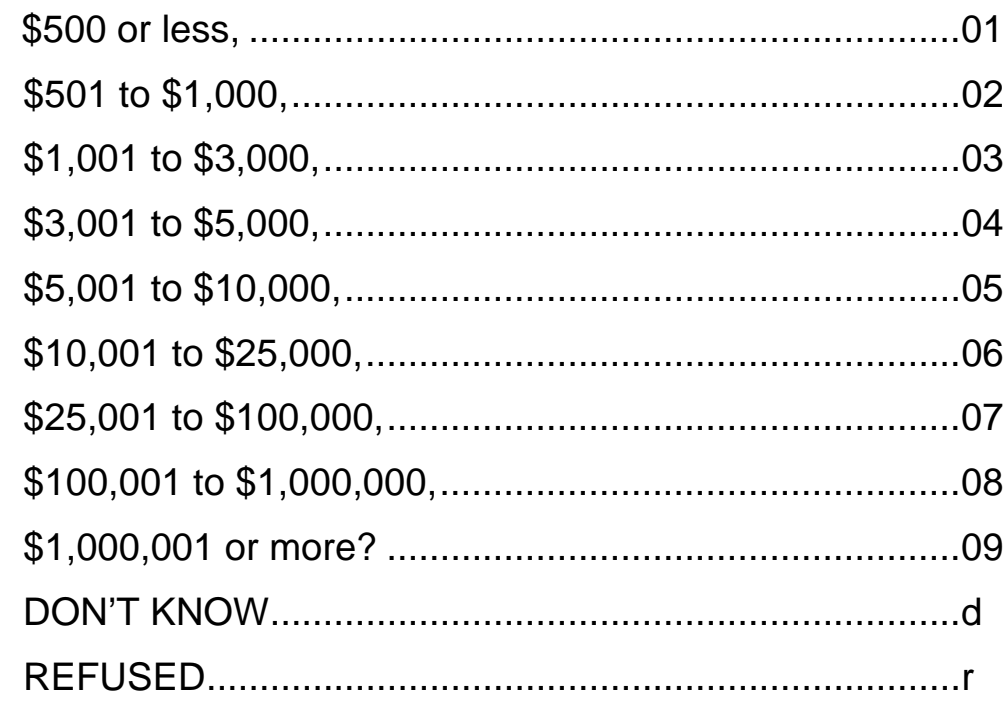

[F6b_PersonalUse_Amt_2006_Range_S[MPR2]] 
F7a. Another way to finance a business is debt financing. Debt is money borrowed that has to be paid back with or without interest.

We will be talking about categories of debt based on who is responsible for paying it back. For each category, l'll ask you about several sources of debt business owners or businesses can use to fund operations. We want to make sure that any business-related debt is reported in the right category, and is reported only once. I will identify each category and remind you when I change categories. Here is the first category.

I'm going to ask you about some different types of debt financing you may have borrowed in your name on behalf of [NAME BUSINESS]. For each, please tell me if you used this type at any time during calendar year 2006. Did you use [NAME FINANCING OPTION FROM LIST]?

F7b. IN BELOW LIST, FOR EACH DEBT FINANCING OPTION BUSINESS REPORTED, ASK: How many [NAME DEBT FINANCING OPTION] did you use to finance the operation of the business during calendar year 2006?

\begin{tabular}{|c|c|c|c|}
\hline YES & NO & $\begin{array}{l}\text { DON'T } \\
\text { KNOW }\end{array}$ & REFUSED \\
\hline
\end{tabular}

a. Personal credit cards for businessrelated purposes.
01
d
$r$

[F7a_Pers_CredCard_S]

[F7b_Pers_CredCard_NumUsed_S]

b. Personal loans from a bank or other financial institution, such as a mortgage or home equity loan used for the business [F7a_Pers_Loan_Bank_S]

$0100 \quad d \quad r$

c. Business or corporate credit cards issued in your name [F7a_Bus_CredCard_S]

$0100 \quad d \quad r$

d. Personal loans from any family or friends.

$0100 \quad d \quad r$
[F7a_Pers_Loan_Fam_S]

e. Personal loans from any other individuals not associated with the management of the business [F7a_Pers_Loan_Other_S]

$0100 \quad d \quad r$

$\begin{array}{llll}0 & 00 & d & r\end{array}$ f. Any other sources? (SPECIFY)........ [F7a_Pers_Other_S]

[F7_Pers_Other_Specify_S]
[F7b_Pers_Loan_Bank_NumUsed_S]
[F7b_Pers_Loan_Fam_NumUsed_S]

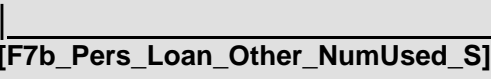


F8a. IF ANSWERED "YES" TO F7a ITEMS a, c, ASK: As of December 31, 2006, what was the maximum credit line on the [NAME DEBT FINANCING OPTION]?

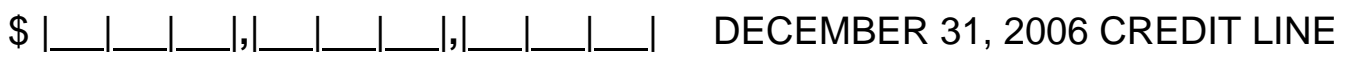

DON'T KNOW................................................. d

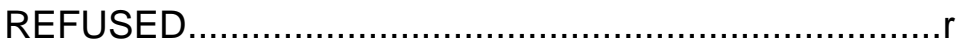

[F8a_Pers_CredCard_Line_S]

[F8a_Bus_CredCard_Line_S

IF DON'T KNOW OR REFUSED, PROBE WITH RANGES: Would you say it was . . .

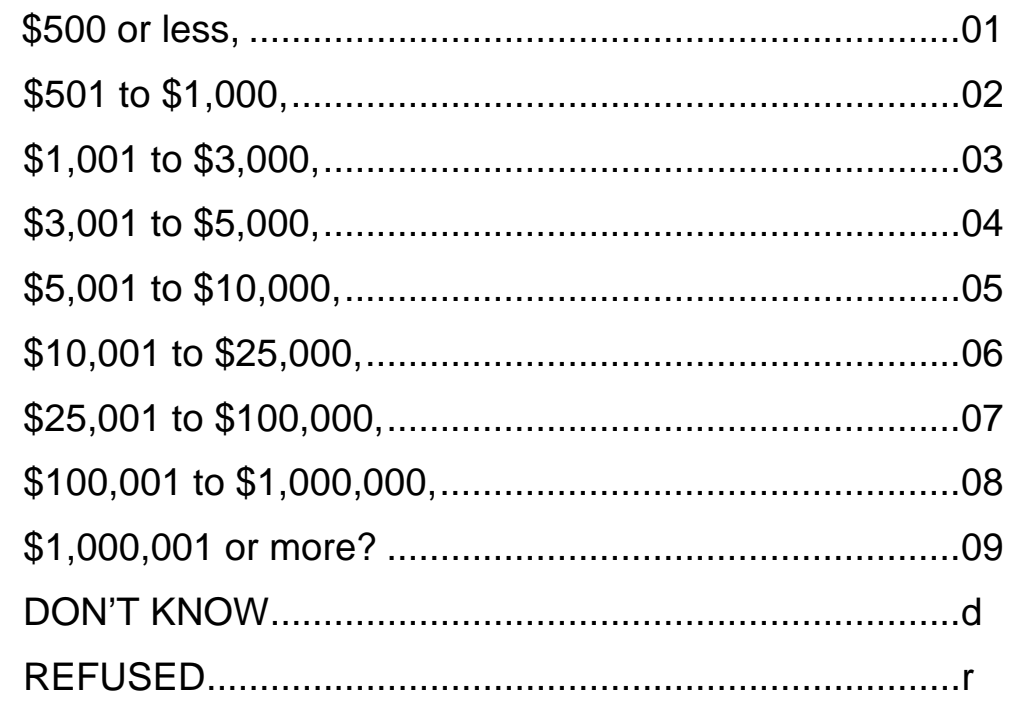

[F8a_Pers_CredCard_Line_Ranges_S]

[F8a_Bus_CredCard_Line_Ranges_S] 
F8b. IF ANSWERED "YES" TO F7a ITEMS a, c, ASK: As of December 31, 2006, what was the outstanding balance on the [NAME DEBT FINANCING OPTION]?

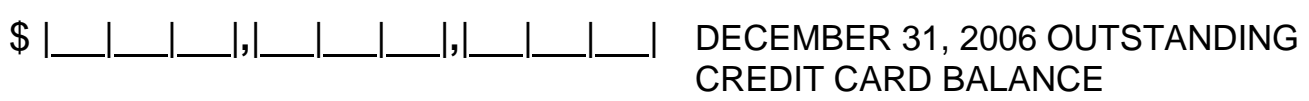

DON'T KNOW ......................................................

REFUSED ......................................................

[F8b_Pers_CredCard_Bal_S]

[F8b_Bus_CredCard_Bal_S]

IF DON'T KNOW OR REFUSED, PROBE WITH RANGES: Would you say it was . . .

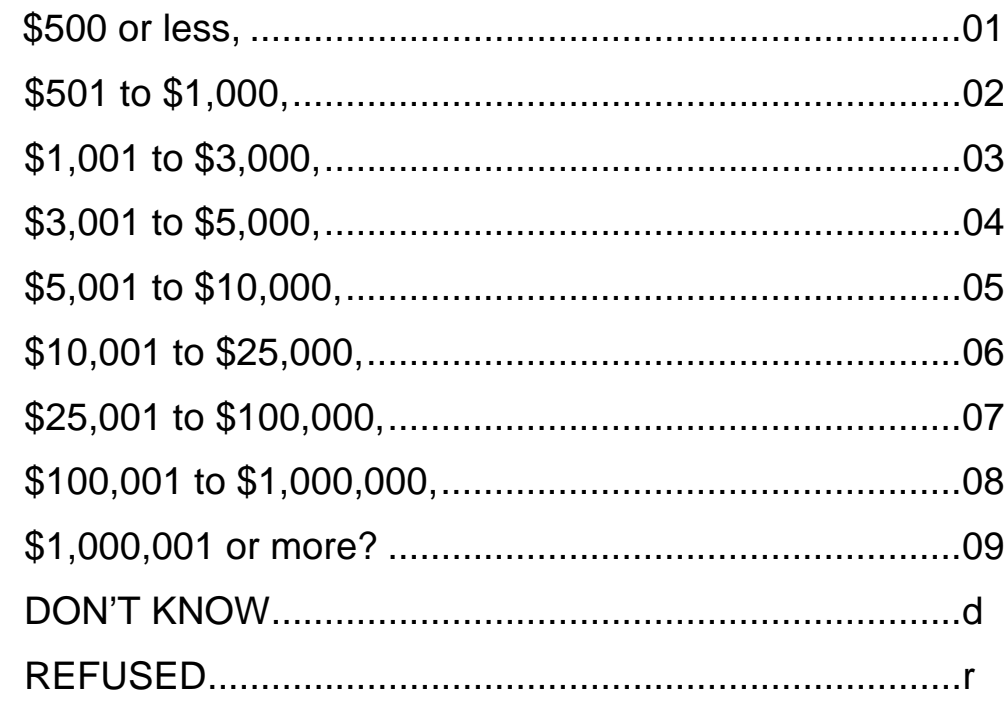

[F8b_Pers_CredCard_Bal_Ranges_S]

[F8b_Bus_CredCard_Bal_Ranges_S]

\section{IF F8b IS GREATER THAN F8a:}

Perhaps I made a mistake. The amount I recorded as the balance outstanding is greater than the amount reported as the maximum credit limit. 
F8c. IF ANSWERED “YES" TO F7a ITEMS b, d, e, f, ASK: In calendar year 2006, how much was obtained from the [NAME DEBT FINANCING OPTION]?

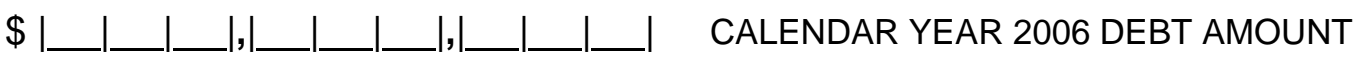

DON'T KNOW......................................................

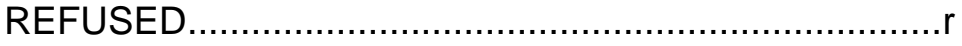

[F8c_Pers_Loan_Bank_Amt_S]

[F8c_Pers_Loan_Fam_Amt_S]

[F8c_Pers_Loan_Other_Amt_S]

[F8c_Pers_Other_Amt_S]

IF DON'T KNOW OR REFUSED, PROBE WITH RANGES: Would you say it was . . .

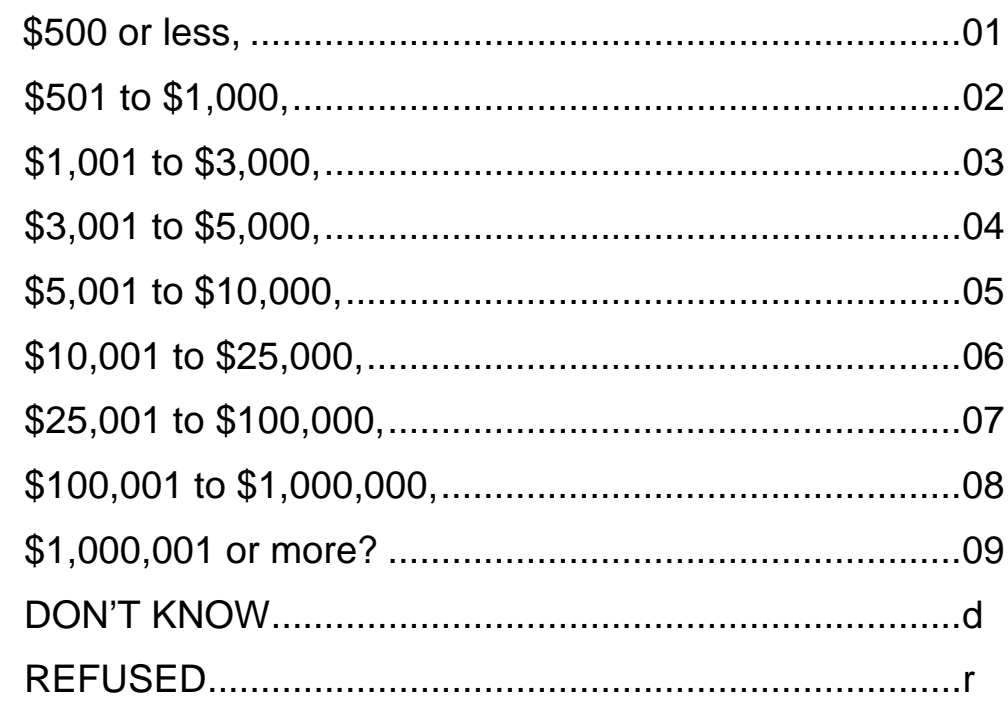

[F8c Pers Loan Bank_Amt Ranges S]

[F8c_Pers_Loan_Fam_Amt_Ranges_S]

[F8c_Pers_Loan_Other_Amt_Ranges_S]

[F8c_Pers_Other_Amt_Ranges_S] 
F8d. As of December 31, 2006, what was the estimated amount of the [NAME DEBT FINANCING OPTION] owed by you on behalf of [NAME BUSINESS]?

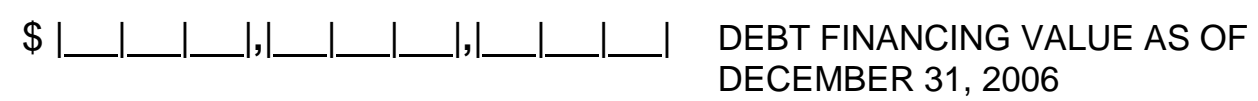

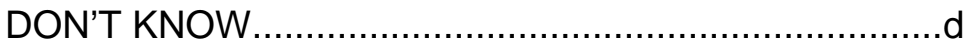

REFUSED ........................................................

[F8d_Pers_Loan_Bank_Owed_S]

[F8d_Pers_Loan_Fam_Owed_S]

[F8d_Pers_Loan_Other_Owed_S]

[F8d_Pers_Other_Owed_S]

IF DON'T KNOW OR REFUSED, PROBE WITH RANGES: Would you say it was . . .

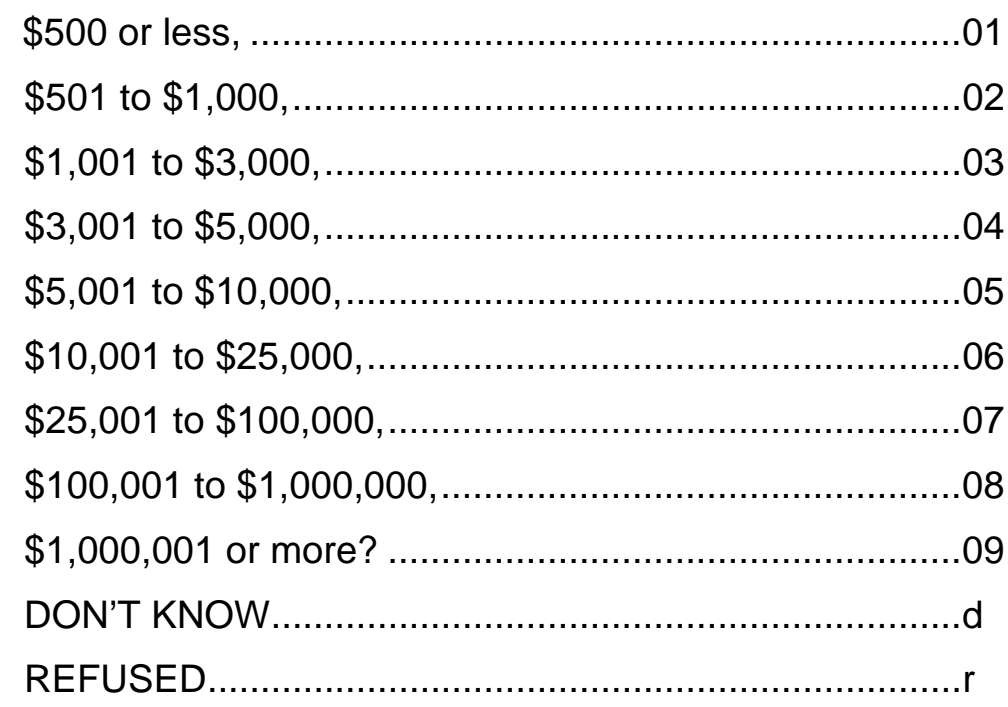

[F8d_Pers_Loan_Bank_Owed_Ranges_S]

[F8d_Pers_Loan_Fam_Owed_Ranges_S]

[F8d_PersLoan_Other_Owed_Range_S]

[F8d_Pers_Other_Owed_Ranges_S] 


\section{IF MORE THAN ONE OWNERIOPERATOR AT C4, ASK F9a. OTHERWISE, GO TO}

F11a.

F9a. Here is the next debt category. I'm going to ask you about some different types of debt financing that other owners may have borrowed on behalf of [NAME BUSINESS]. This debt does not include amounts already reported in the previous section about your debt. For each, please tell me if other owners used this type at any time during calendar year 2006. Did other owners use [NAME DEBT FINANCING OPTION FROM LIST]?

F9b. IN BELOW LIST, FOR EACH DEBT FINANCING OPTION BUSINESS REPORTED, ASK: How many [NAME DEBT FINANCING OPTION] did other owners use to finance the operation of the business during calendar year 2006?

a. Personal credit cards for business-related purposes

\begin{tabular}{|l|l|l|l|}
\hline YES & NO & DON'T & \\
KNOW & REFUSED \\
\hline
\end{tabular}

\section{NUMBER USED}

[F9a_Pers_CredCard_S]

$0100 \quad d \quad r$

b. Personal loans from a bank or other financial institution, such as a mortgage or home equity loan used for the business [F9a_Pers_Loan_Bank_S]

$0100 \quad d \quad r$

c. Business or corporate credit cards issued in the other owner's name(s)

$0100 \quad d \quad r$

[F9a_Bus_CredCard_S]

[F9b_Bus_CredCard_NumUsed_S]

d. Personal loans from any family or friends..... [F9a_Pers_Loan_Fam_S]

$0100 \quad d \quad r$

e. Personal loans from any other individuals not associated with the management of the business

01

00

d

$r$

[F9a_Pers_Loan_Other_S]

f. Any other sources? (SPECIFY) [F9a_Pers_Other_S]

01

00

d

[F9b_Pers_Loan_Other_NumUsed_S

[F9_Pers_Other_Specify_S] 
F10a. IF ANSWERED "YES" TO F9a ITEMS a, c, ASK: As of December 31, 2006, what was the maximum credit line on the [NAME DEBT FINANCING OPTION] of (one of) the other owner(s)?

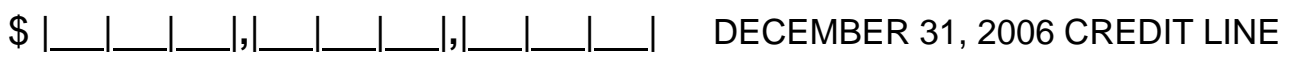

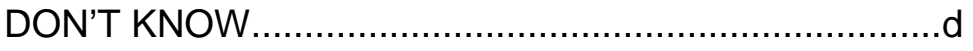

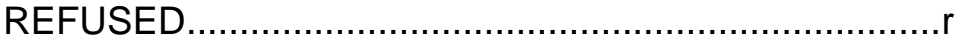

[F10a_Pers_CredCard_Line_S]

[F10a_Bus_CredCard_Line_S]

IF DON'T KNOW OR REFUSED, PROBE WITH RANGES: Would you say it was . . .

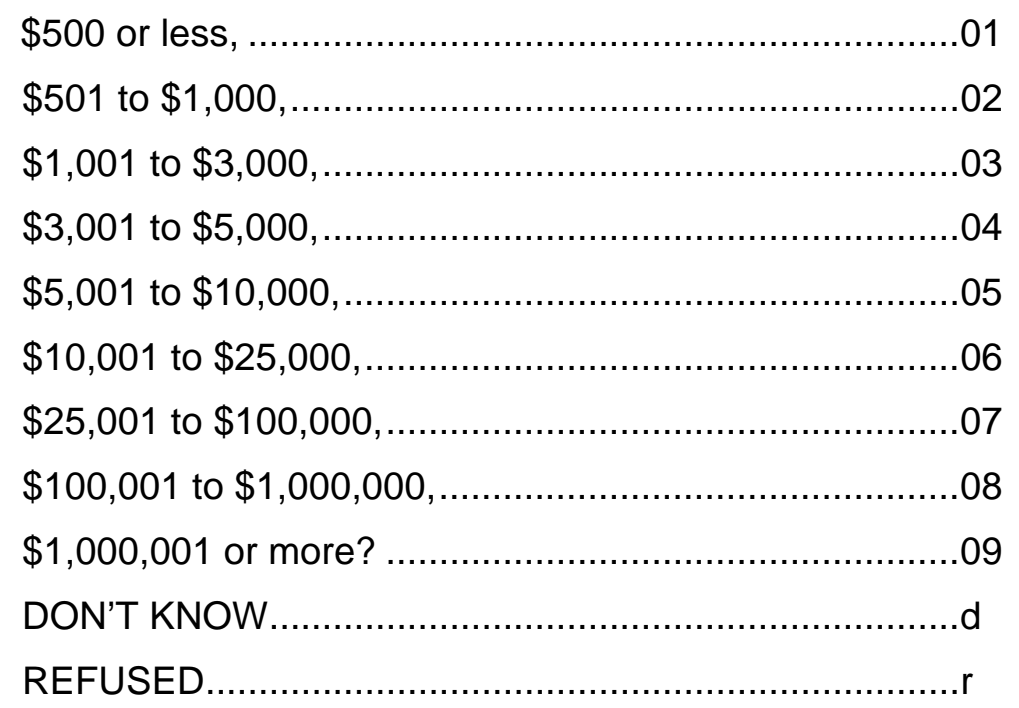

[F10a Pers_CredCard Line Ranges_S]

[F10a_Bus_CredCard_Line_Ranges_S] 
F10b. IF ANSWERED "YES" TO F9a ITEMS a, c, ASK: As of December 31, 2006, what was the outstanding balance on the [NAME DEBT FINANCING OPTION] used by (one of) the other owner(s)?

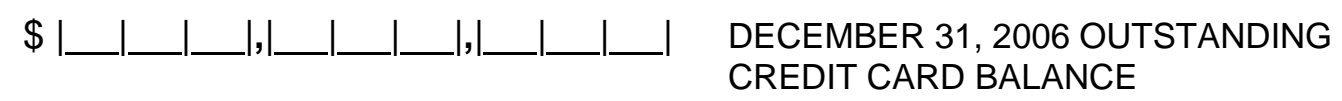

DON'T KNOW.........................................................

REFUSED ........................................................

[F10b_Pers_CredCard_Bal_S]

[F10b_Bus_CredCard_Bal_S]

IF DON'T KNOW OR REFUSED, PROBE WITH RANGES: Would you say it was . . .

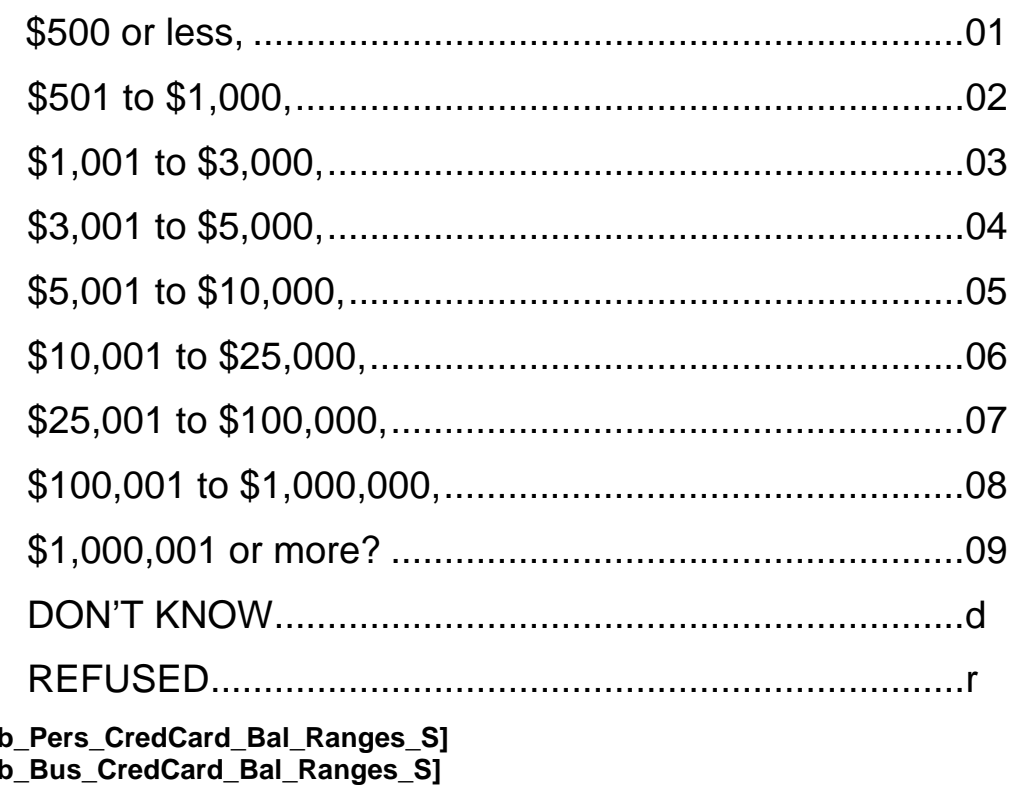

\section{IF F10b IS GREATER THAN F10a:}

Perhaps I made a mistake. The amount I recorded as the balance outstanding is greater than the amount reported as the maximum credit limit. 
F10c. IF ANSWERED "YES" TO F9a, ITEMS b, d, e, f, ASK: In calendar year 2006, how much was obtained from the [NAME DEBT FINANCING OPTION] other owners used?

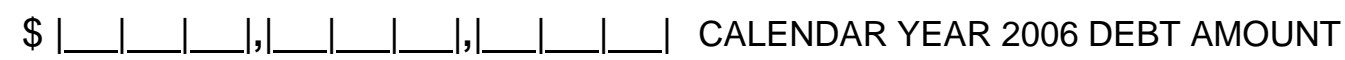

DON'T KNOW................................................. d

REFUSED ..........................................................

[F10c_Pers_Loan_Bank_Amt_S]

[F10c_Pers_Loan_Fam_Amt_S]

[F10c_Pers_Loan_Other_Amt_S]

[F10c_Pers_Other_Amt_S]

IF DON'T KNOW OR REFUSED, PROBE WITH RANGES: Would you say it was . . .

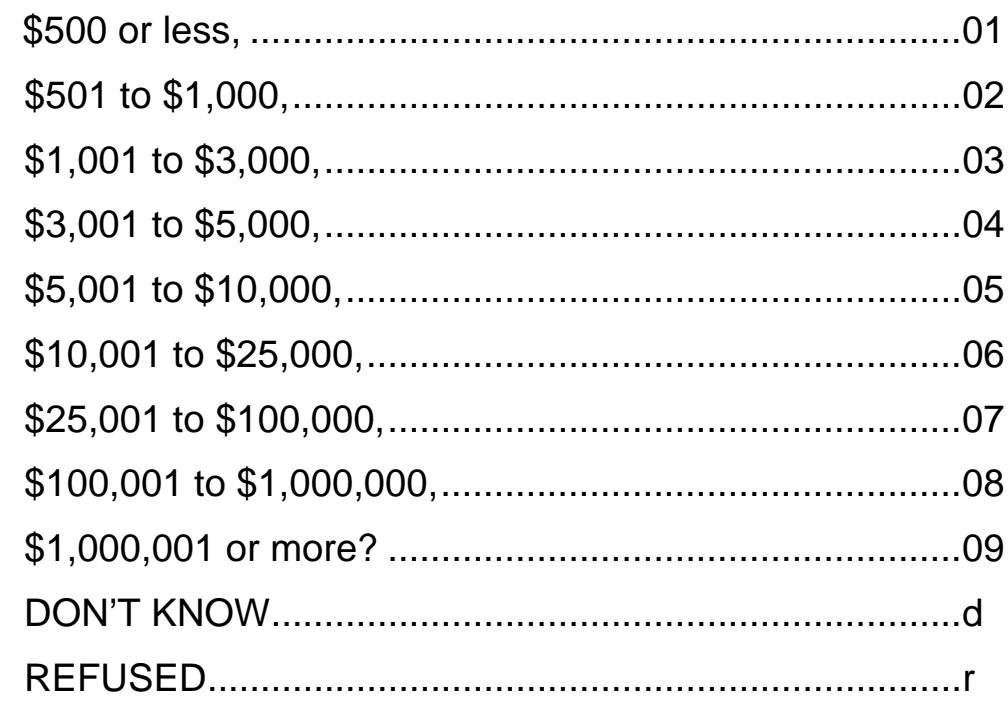

[F10c_Pers_Loan_Bank_Amt_Ranges_S]

[F10c_Pers_Loan_Fam_Amt_Ranges_S]

[F10c_PersLoan_Other_Amt_Range_S]

[F10c_Pers_Other_Amt_Ranges_S] 
F10d. As of December 31, 2006, what was the estimated amount of the [NAME DEBT FINANCING OPTION] owed by other owners on behalf of [NAME BUSINESS]?

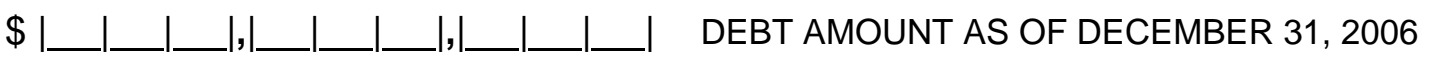

DON'T KNOW.................................................. d

REFUSED ..........................................................

[F10d_Pers_Loan_Bank_Owed_S]

[F10d_Pers_Loan_Fam_Owed_S]

[F10d_Pers_Loan_Other_Owed_S]

[F10d_Pers_Other_Owed_S]

IF DON'T KNOW OR REFUSED, PROBE WITH RANGES: Would you say it was . .

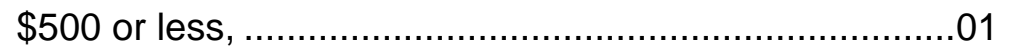

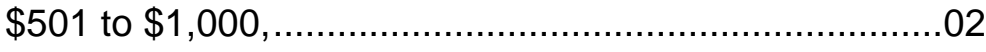

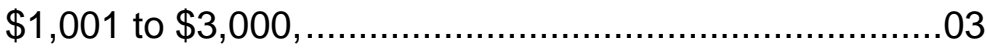

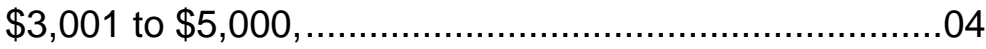

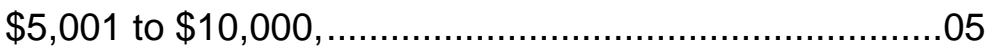

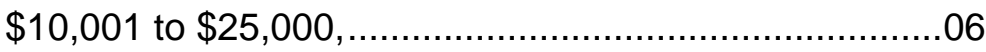

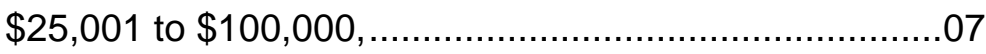

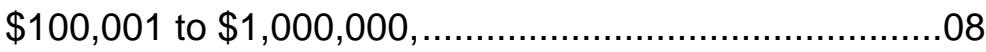

$\$ 1,000,001$ or more? ..............................................

DON'T KNOW.................................................. d

REFUSED ......................................................

[F10d_PersLoan_Bank_Owed_Range_S]

[F10d_Pers_Loan_Fam_Owed_Ranges_S]

[F10d_PersLoan_Other_Owed_Range_S]

[F10d_Pers_Other_Owed_Ranges_S] 
F11a. We are once again switching to another debt category. Now I'm going to ask you about some different types of debt financing that may have been obtained in the name of the business during calendar year 2006. This debt does not include amounts already reported in the previous sections about your debt or the debt of other owners. During calendar year 2006, did [NAME BUSINESS] use [NAME DEBT FINANCING OPTION FROM LIST]?

F11b. IN BELOW LIST, FOR EACH DEBT FINANCING OPTION BUSINESS REPORTED, ASK: How many [NAME DEBT FINANCING OPTION] did the business use to finance the operation or the business during calendar year 2006?

\begin{tabular}{|c|c|c|c|}
\hline YES & NO & $\begin{array}{l}\text { DON'T } \\
\text { KNOW }\end{array}$ & REFUSED \\
\hline
\end{tabular}

a. Business or corporate credit cards issued in the name of the business [F11a_Bus_CredCard_S]

$0100 \quad d \quad r$

Business loans from a commercial bank [F11a_Bus_Loans_Bank_S]

$0100 \quad d \quad r$

C. Business line of credit (READ IF

NEEDED: a business line of credit is when a business has an agreement with a bank or other financial institution to borrow up to a certain amount of funds) $0100 \quad d \quad r$ [F11a_Bus_Cred_Line_S] [F11b_Bus_CredCard_NumUsed_S]

. Business loans from a non-bank financial institution [F11a_Bus_Loans_Nonbank_S]

e. Business loans from any family or friends of the owners. [F11a_Bus_Loans_Fam_S]

f. Business loans from another owner of the business or a partner .... [F11a_Bus_Loans_Owner_S]

g. [IF HAVE EMPLOYEES AT C5] Loans to the business from employees that are not owners of the business [F11a_Bus_Loans_Emp_S]

$0100 \quad d \quad r$

h. Loans from government agencies [F11a_Bus_Loans_Govt_S]

$0100 \quad d \quad r$

$0100 \quad d \quad r$

$0100 \quad d \quad r$

[F11b_Bus_Loans_Owner_NumUsed_S] [F11b_Bus_Loans_Bank_NumUsed_S]

Loans from other businesses [F11a_Bus_Loans_Other_Bus_S]

$0100 \quad d \quad r$ [F11b_Bus_Loans_Emp_NumUsed_S]

Business loans from any other individuals not associated with the management of the business. [F11a_Bus_Loans_Other_Ind_S]

$\begin{array}{llll}0 & 0 & d & r\end{array}$

k. Any other sources? (SPECIFY) [F11a_Bus_Other_S]

$0100 \quad d \quad r$

[F11b_Bus_Loans_Govt_NumUsed_S]

[F11_Bus_Other_Specify_S] 
F12a. IF ANSWERED “YES” TO F11a ITEMS a, c, ASK: As of December 31, 2006, what was the maximum credit line on the [NAME DEBT FINANCING OPTION]?

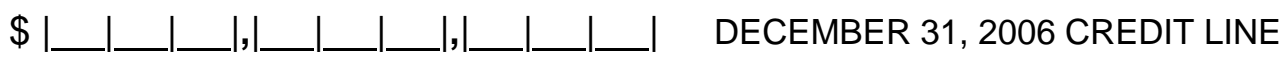

DON'T KNOW................................................. d

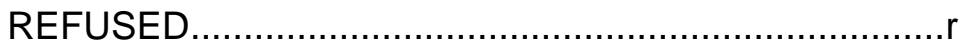

[F12a_Bus_CredCard_Line_S]

[F12a_Bus_Cred_Line_S]

IF DON'T KNOW OR REFUSED, PROBE WITH RANGES: Would you say it was . . .

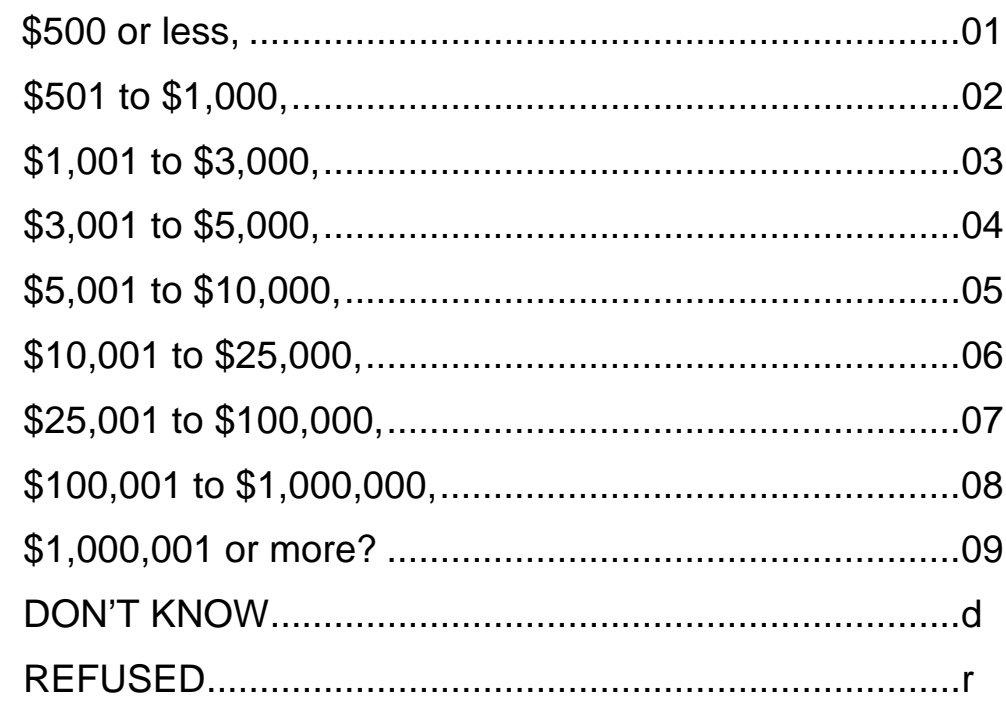

[F12a_Bus_CredCard_Line_Ranges_S]

[F12a_Bus_Cred_Line_Ranges_S] 
F12b. IF ANSWERED “YES" TO F11a ITEMS a, c, ASK: As of December 31, 2006, what was the outstanding balance on the [NAME DEBT FINANCING OPTION]?

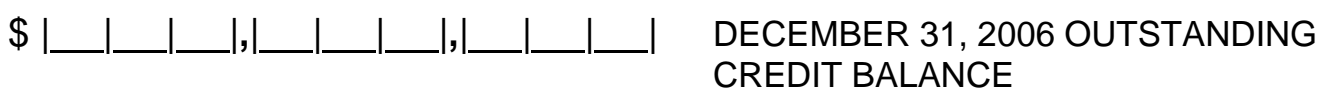

DON'T KNOW.................................................... d

REFUSED ......................................................

[F12b_Bus_CredCard_Bal_s]

[F12b_Bus_Cred_Line_Bal_S]

IF DON'T KNOW OR REFUSED, PROBE WITH RANGES: Would you say it was . . .

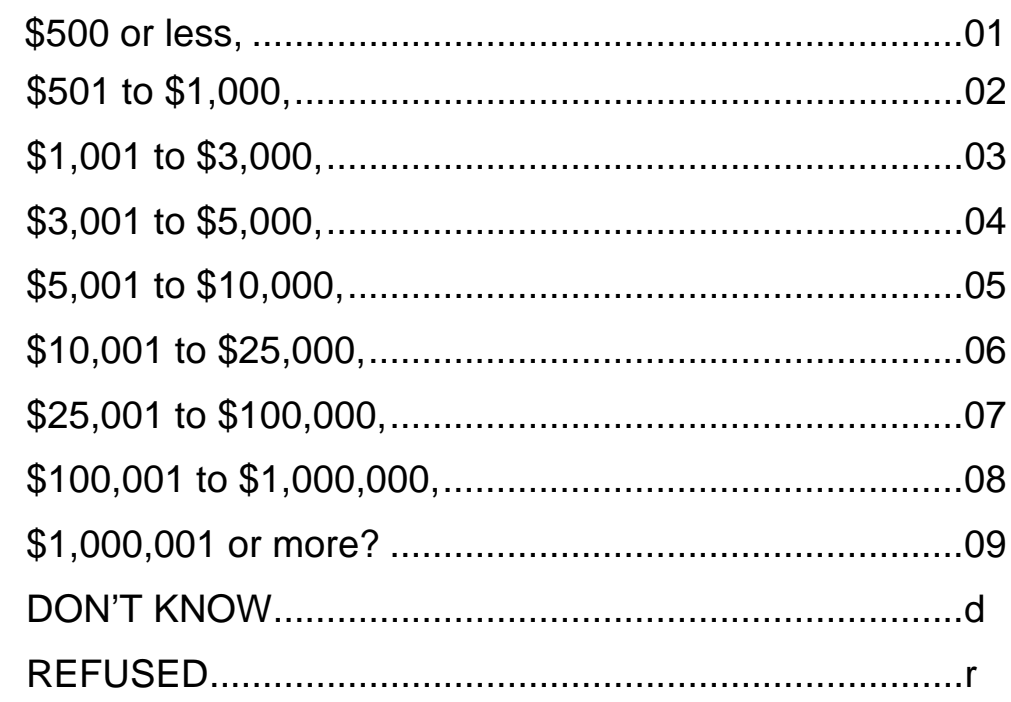

[F12b_Bus_CredCard_Bal_Ranges_S]

[F12b_Bus_Cred_Line_Bal_Ranges_S]

\section{IF F12a IS GREATER THAN F12b:}

Perhaps I made a mistake. The amount I recorded as the balance outstanding is greater than the amount reported as the maximum credit limit. 
F12c. IF ANSWERED "YES" TO F11a ITEMS b, d-k, ASK: In calendar year 2006, how much was the amount obtained from [NAME DEBT FINANCING OPTION] used by [NAME BUSINESS]?

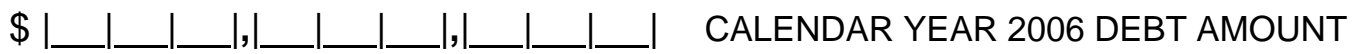

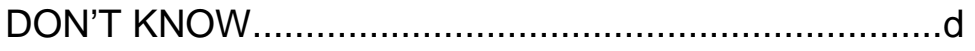

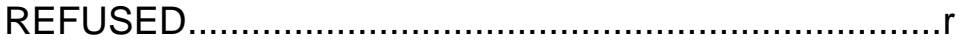

[F12c_Bus_Loans_Bank_Amt S]

[F12C_Bus_Loans_Nonbank_Amt_S]

[F12C_Bus_Loans_Fam_Amt_S]

[F12c_Bus_Loans_Owner_Amt_S]

[F12c_Bus_Loans_Emp_Amt_S]

[F12c_Bus_Loans_Govt_Amt_S]

[F12C_Bus_Loans_Bus_Amt_S]

[F12c_Bus_Loans_Other_Ind_Amt_S]

[F12c_Bus_Other_Amt_S]

IF DON'T KNOW OR REFUSED, PROBE WITH RANGES: Would you say it was . . .

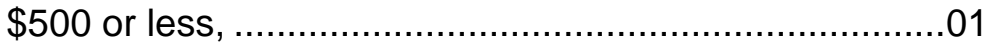

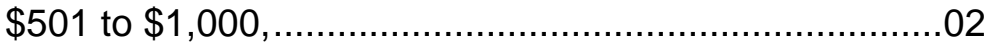

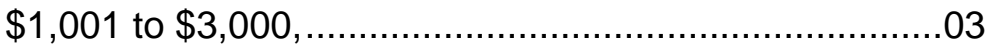

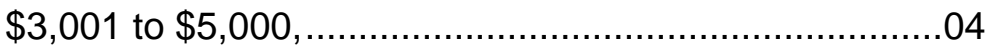

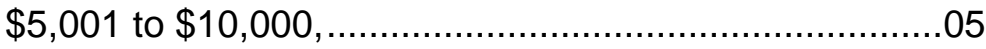

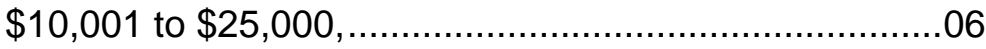

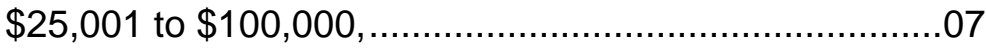

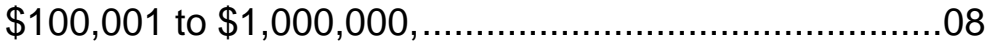

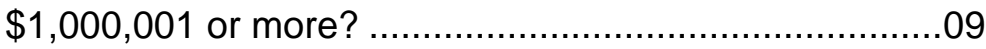

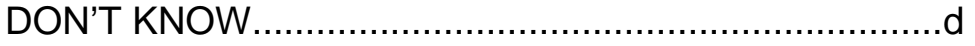

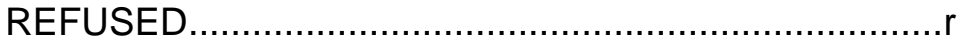

[F12c_Bus_Loans_Bank_Amt_Ranges_S]

[F12c_BusLoans_Nonbnk_Amt_Range_S]

[F12c_Bus_Loans_Fam_Amt_Ranges_S]

[F12c_BusLoans_Owner_Amt_Range_S]

[F12c_Bus_Loans_Emp_Amt_Ranges_S]

[F12c_Bus_Loans_Govt_Amt_Ranges_S]

[F12c_Bus_Loans_Bus_Amt Ranges_S]

[F12c_BusLoans_OtherInd_Amt_Range_S]

[F12C_Bus_Other_Amt_Ranges_S] 
F12d. As of December 31, 2006, what was the estimated amount of the [NAME DEBT FINANCING OPTION] owed by [NAME BUSINESS]?

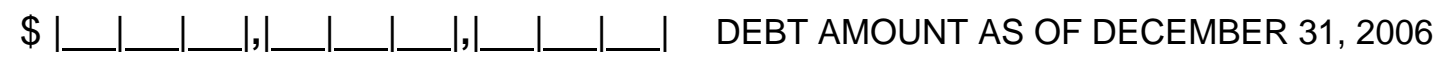

DON'T KNOW.................................................. d

REFUSED .........................................................

[F12d_Bus_Loans_Bank_Owed_S]

[F12d_Bus_Loans_Nonbank_Owed_S]

[F12d_Bus_Loans_Fam_Owed_S]

[F12d_Bus_Loans_Owner_Owed_S]

[F12d_Bus_Loans_Emp_Owed_S]

[F12d_Bus_Loans_Govt_Owed_S]

[F12d_Bus_Loans_Bus_Owed_S]

[F12d_Bus_Loans_Other_Ind_Owed_S]

[F12d_Bus_Other_Owed_S]

IF DON'T KNOW OR REFUSED, PROBE WITH RANGES: Would you say it was ...

$\$ 500$ or less, ...................................................... 01

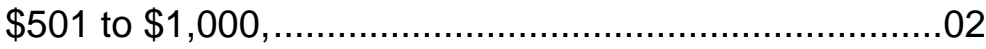

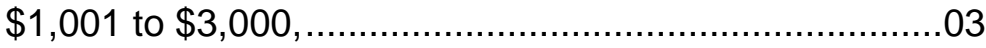

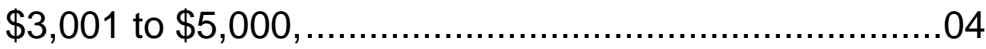

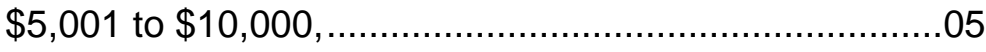

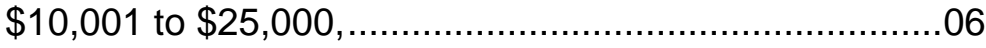

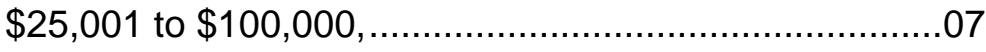

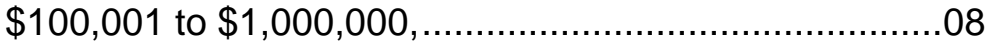

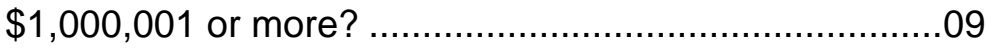

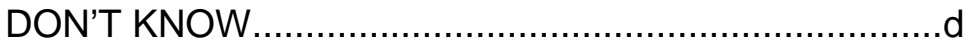

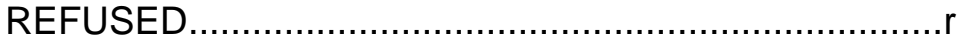

[F12d_BusLoans_Bank_Owed_Range_S]

[F12d_BusLoan_Nonbnk_Owed_Range_S]

[F12d_Bus_Loans_Fam_Owed_Ranges_S]

[F12d_BusLoans_Owner_Owed_Range_S]

[F12d_Bus_Loans_Emp_Owed_Ranges_S]

[F12d_BusLoans_Govt_Owed_Range_S]

[F12d_Bus_Loans_Bus_Owed_Ranges_S]

[F12d_BusLoan_OthrInd_Owed_Range_S]

[F12d_Bus_Other_Owed_Ranges_S] 
F13. Trade financing is where a business has an arrangement with a supplier to make purchases on account. In calendar year 2006, did [NAME BUSINESS] make any purchases through trade financing?

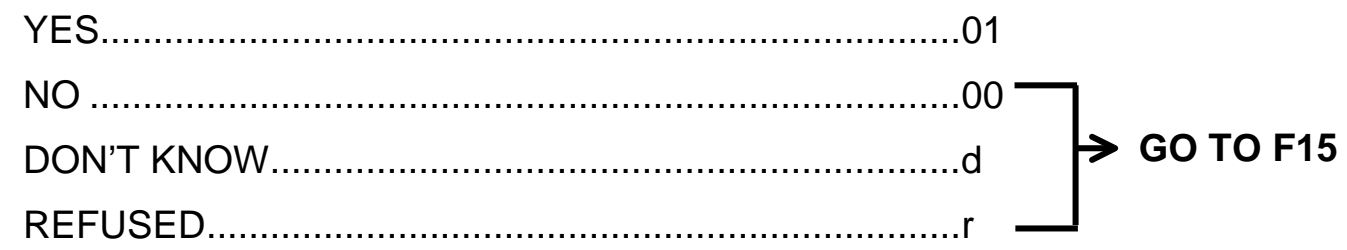

[F13_Trade_Fin_S]

F14. IF YES: In calendar year 2006, what was the amount of purchases made through trade financing?

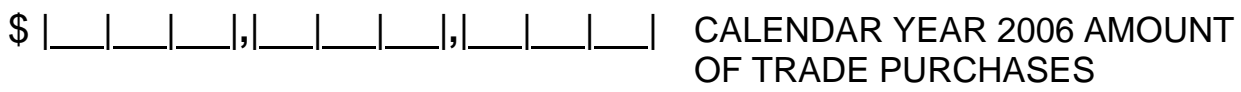

DON'T KNOW....................................................... d

REFUSED ..........................................................

[F14a_Trade_Fin_Amt_S]

IF DON'T KNOW OR REFUSED, PROBE WITH RANGES: Would you say it was . . .

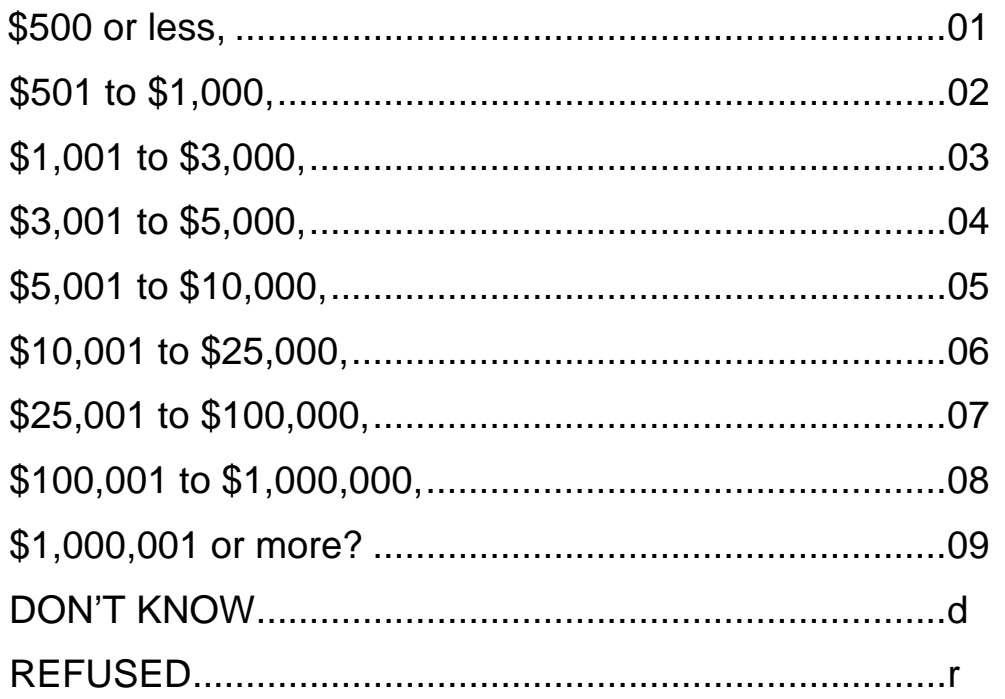

[F14a_Trade_Fin_Amt_Ranges_S] 
F15. In calendar year 2006, did [NAME BUSINESS] receive any revenue (money), from the sales of goods, services, or intellectual property? [IF SOLE PROPRIETORSHIP, ADD: This would be gross receipts reported on a Schedule C or C-EZ with your personal income tax return.]

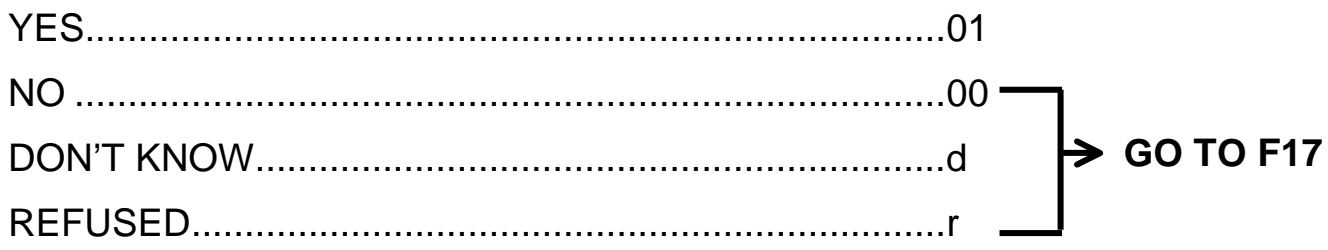

[F15_Revenue_2006_S]

F16. What was [NAME BUSINESS]'s total revenue for calendar year 2006? [IF SOLE PROPRIETORSHIP, ADD: This would be gross receipts reported on a Schedule C or CEZ with your personal income tax return.]

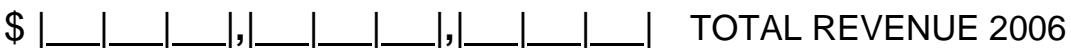

DON'T KNOW..........................................................

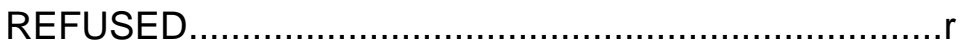

[F16a_Rev_2006_Amt_S]

IF DON'T KNOW OR REFUSED, PROBE WITH RANGES: Would you say it was . . .

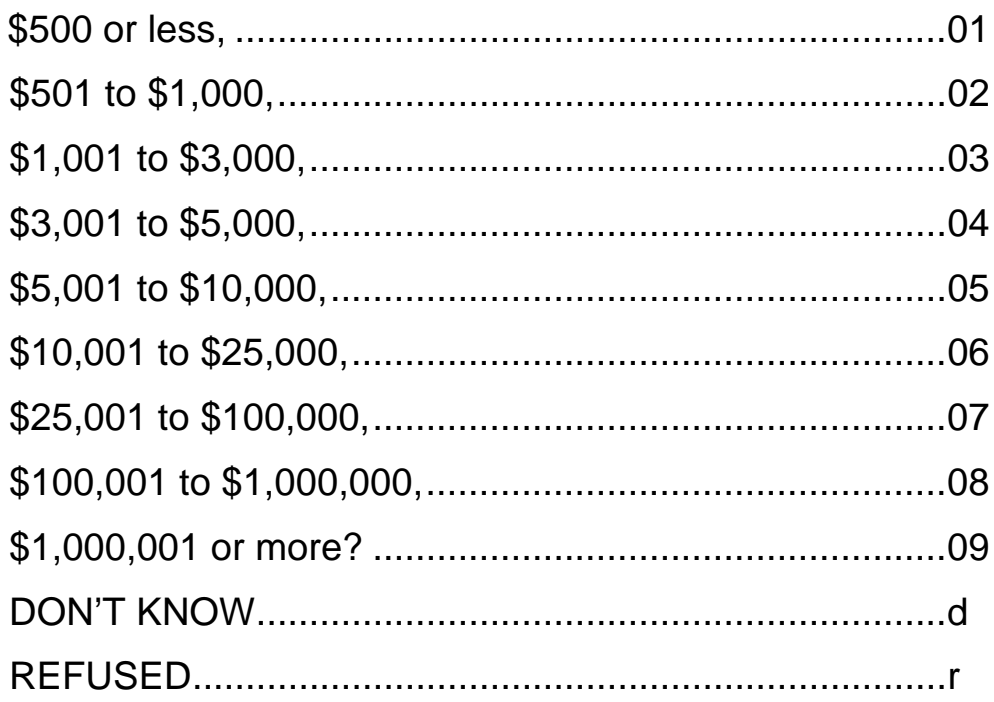

[F16a_Rev_2006_Amt_Ranges_S] 
F16b. Was this an increase, a decrease, or no change in the amount of revenue for [NAME BUSINESS] in 2006 compared to 2005?

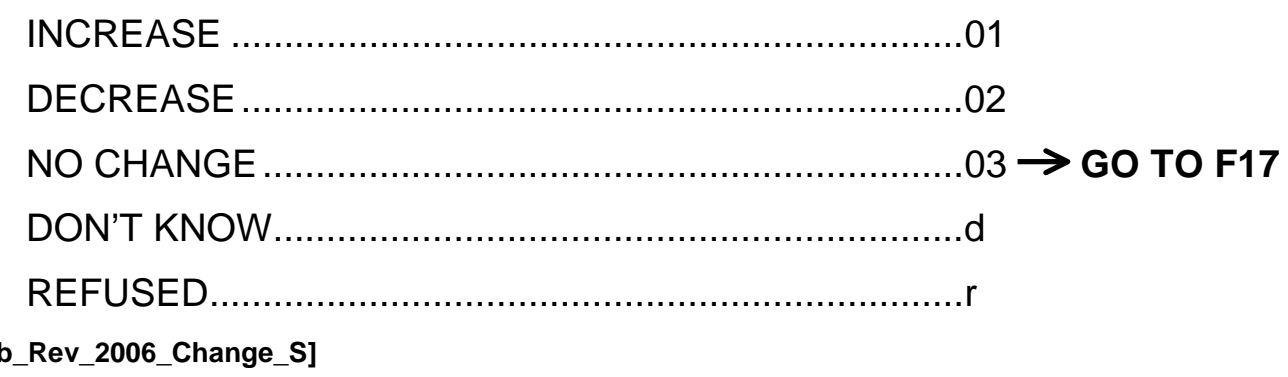

F16c. And what was the percentage change in revenue in 2006 compared 2005? Your best estimate is fine.

\section{I______ \% CHANGE IN REVENUE}

DON'T KNOW........................................................

REFUSED........................................................

[F16c_Perc_Change_S] 
F17. Now l'm going to ask about the expenses the business paid. Expenses are the costs paid for the operation of the business, including wages, salaries, interest on loans, capital leases, materials, etc. How much, if any, did [NAME BUSINESS] pay in expenses during calendar year 2006?

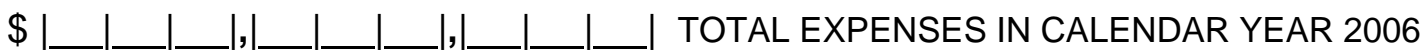

DON'T KNOW...................................................

REFUSED .............................................................

[F17a_Total_Exp_2006_Amt_S]

IF DON'T KNOW OR REFUSED, PROBE WITH RANGES: Would you say it was . .

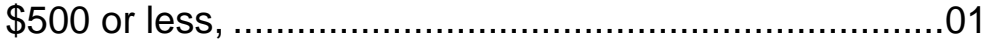

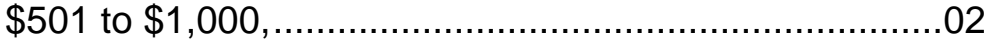

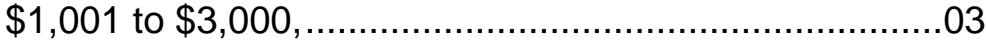

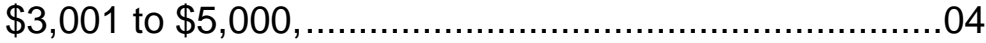

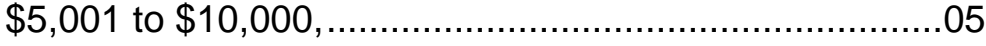

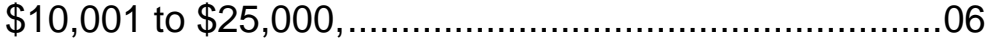

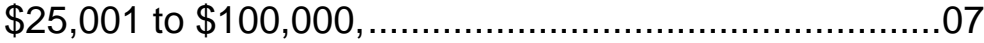

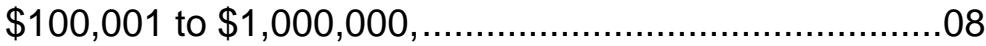

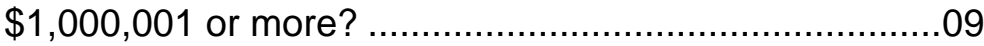

DON'T KNOW ..........................................................

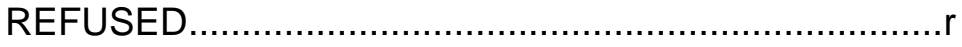

[F17a_Total_Exp_2006_Amt_Ranges_S]

F17b. Was this an increase, a decrease, or no change in total expenses for [NAME BUSINESS] in 2006 compared to 2005 ?

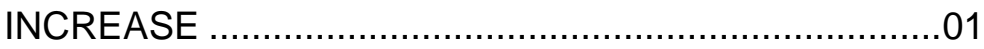

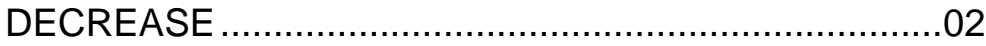

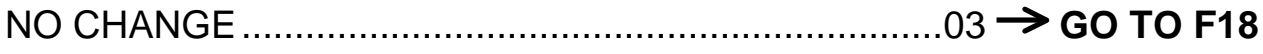

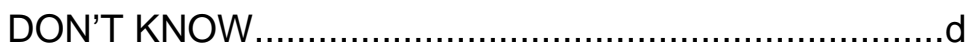

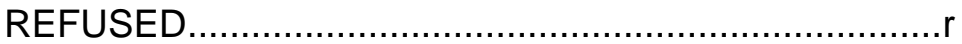

[F17b_Total_Exp_2006_Change_S] 
F17c. And what was the percentage change in total expenses in 2006 compared 2005? Your best estimate is fine.

\section{I______ I CHANGE IN EXPENSES}

DON'T KNOW...................................................d

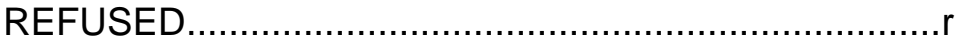

[F17c_Perc_Change_S]

F18. IF BUSINESS REPORTED “0” EMPLOYEES AT C5, GO TO F19.

How much, if any, did [NAME BUSINESS] pay in wages, salaries, and benefits to full-and part-time employees in calendar year 2006? Please do not include wages, salaries, and benefits to contract workers who work for the business but are not on the business' official payroll.

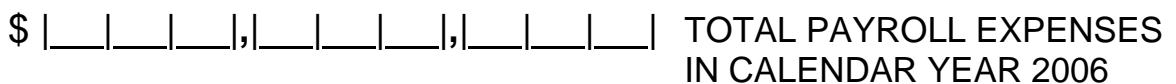

DON'T KNOW.....................................................

REFUSED .............................................................

[F18a_Wage_Exp_2006_Amt_S]

IF DON'T KNOW OR REFUSED, PROBE WITH RANGES: Would you say it was . . .

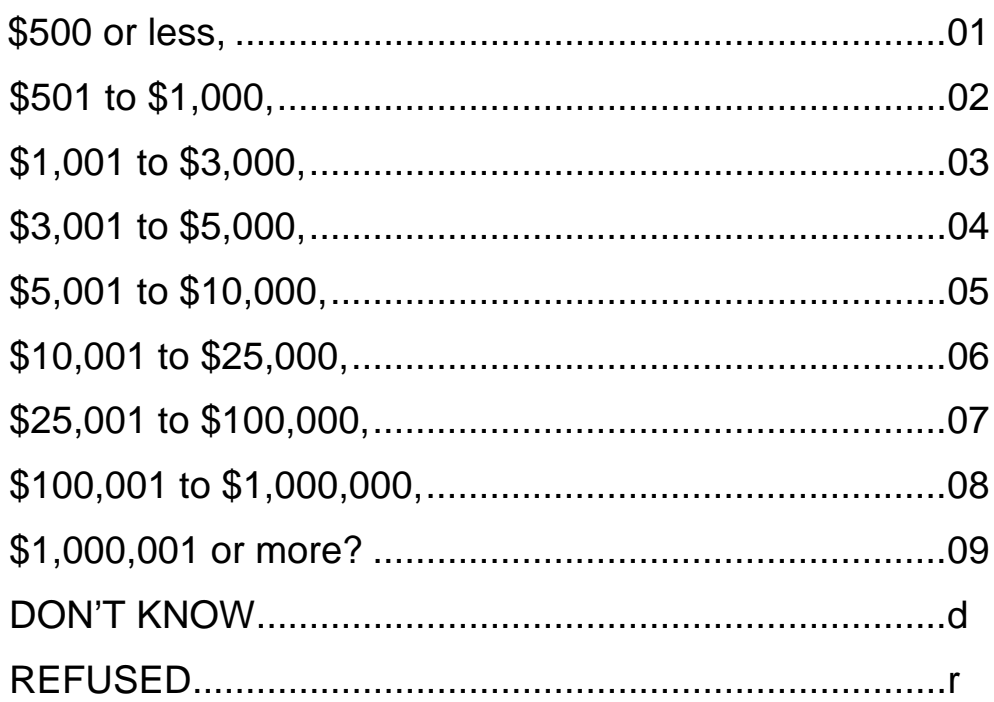

[F18b_Wage_Exp_2006_Amt_Ranges_S] 
F19. Did [NAME BUSINESS] spend any money on research and development of new products and services during calendar year 2006?

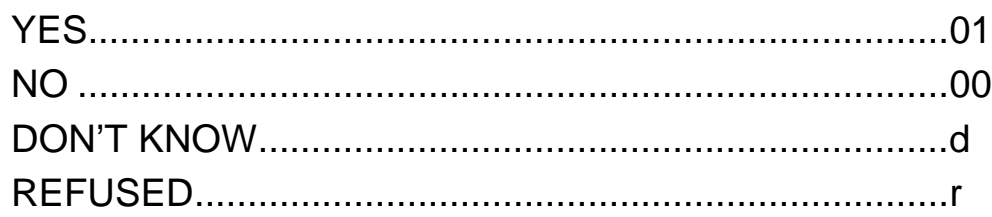

[F19_Res_Dev_S]

F20. Did [NAME BUSINESS] spend any money on the purchase of new or used machinery or equipment during calendar year 2006?

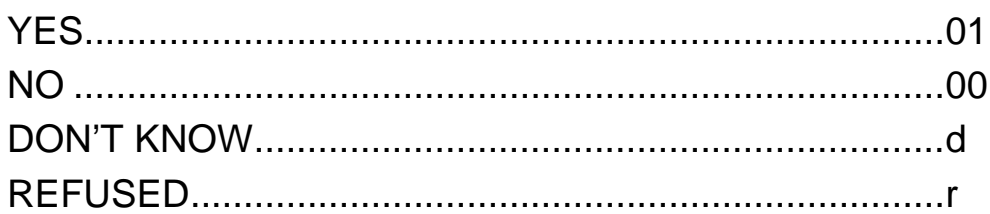

[F20_Mach_S]

F21. Did [NAME BUSINESS] spend any money on rental or lease payments for buildings or other structures during calendar year 2006?

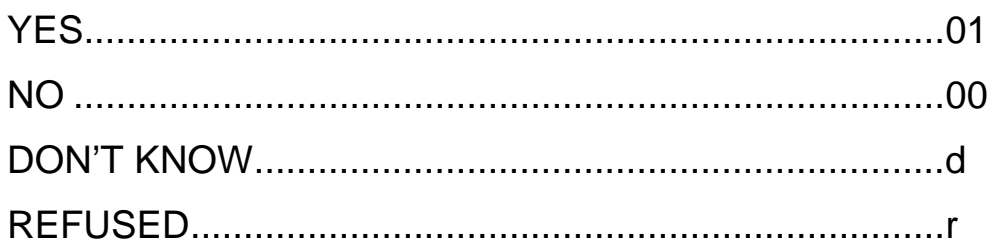

[F21_Land_Rent_S]

F22. Did [NAME BUSINESS] spend any money on rental or lease payments for machinery or equipment during calendar year 2006?

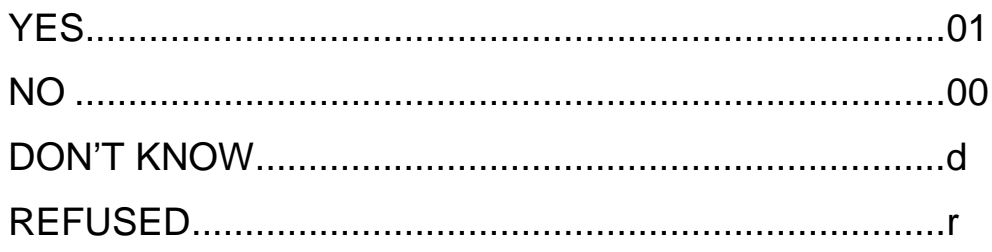

[F22_Mach_Rent_S] 
F23. Profit is the business' income after all expenses and taxes have been deducted. What was [NAME BUSINESS]'s total profit or loss for calendar year 2006?

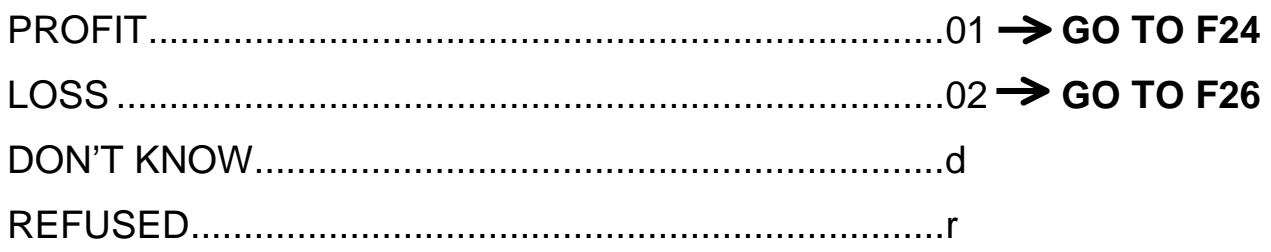

[F23_Profit_Or_Loss_S]

F24. ENTER PROFIT AMOUNT

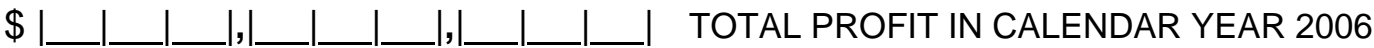

DON'T KNOW...................................................... d

REFUSED ..............................................................

[F24_Profit_Amt_S]

F25. IF DON'T KNOW OR REFUSED, PROBE WITH RANGES: Would you say it was ...

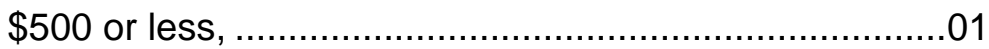

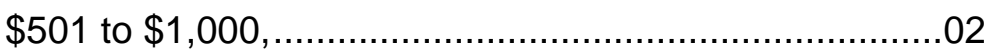

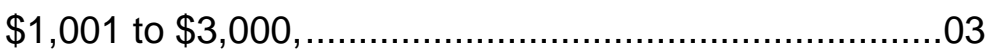

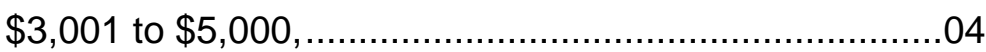

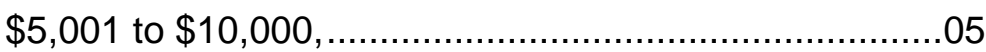

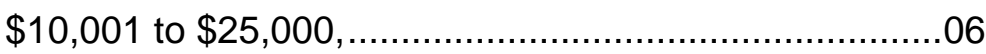

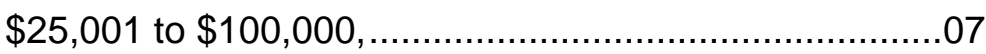

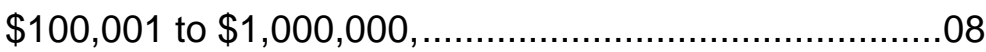

$\$ 1,000,001$ or more? ...............................................

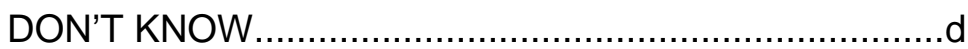

REFUSED ............................................................

F25_Profit_Amt_Ranges_S]

F26. ENTER LOSS AMOUNT

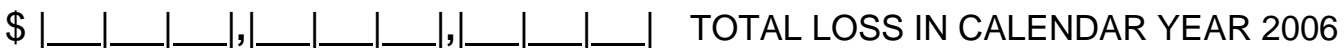

DON'T KNOW......................................................... d

REFUSED ..........................................................

[F26_Loss_Amt_S] 
F27. IF DON'T KNOW OR REFUSED, PROBE WITH RANGES: Would you say it was ...

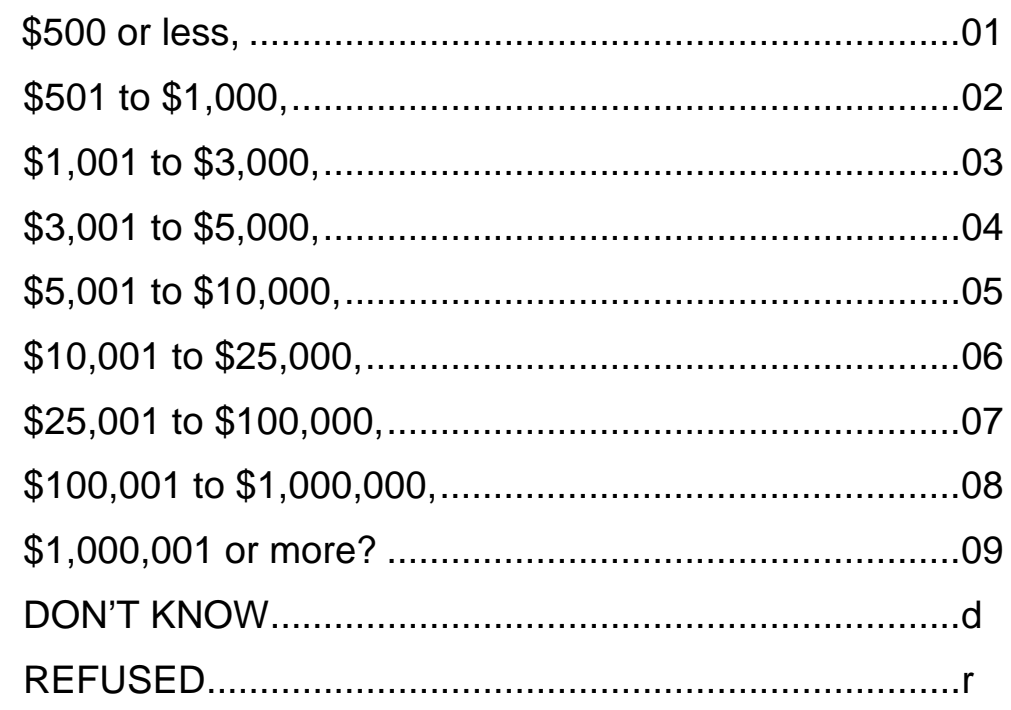

[F27_Loss_Amt_Ranges_S]

F28. Assets are what the business owns. As of December 31, 2006, did [NAME BUSINESS]'s assets include [NAME ASSET FROM LIST]?

\begin{tabular}{|l|l|l|l|}
\hline YES & NO & DON'T & \\
KNOW & REFUSED \\
\hline
\end{tabular}

a. Cash on hand in checking, savings, money market accounts, certificates of deposit and other time deposits..... [F28a_Asset_Cash_S]

$01 \quad 00 \quad d$

$r$

b. Accounts receivable [F28b_Asset_Acct_Rec_S]

$01 \quad 00 \quad d$

d

r

C. Product inventory [F28c_Asset_Inv_S]

$0100 \quad d$

r

d. Equipment or machinery [F28d_Asset_Equip_S]

$01 \quad 00$

d

r

e. Land, buildings, and other structures $01 \quad 00$

d r

f. Vehicles [F28f_Asset_Veh_S]

$01 \quad 00$

d

r

g. Any other business owned property (SPECIFY) ... [F28g_Other_Bus_Prop_S]

0100

d

$r$

[F28_Other_Bus_Prop_Specify_S]

h. Any other assets? (SPECIFY).

[F28h_Other_Assets_S]

$01 \quad 00$

d

r

[F28_Other_Specify_S] 
F29. FOR EACH ASSET BUSINESS REPORTED, ASK:

As of December 31, 2006, what was the estimated value of the [NAME OF ASSET] owned by [NAME BUSINESS]?

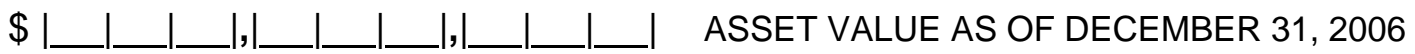

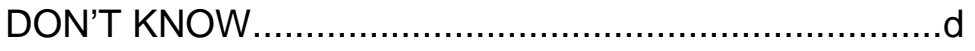

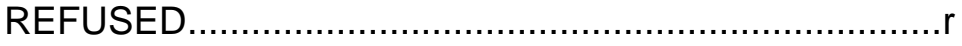

[F29_AssetVal_Cash_S]

[F29_AssetVal_AcctRec_S]

[F29_AssetVal_Inv_S]

[F29_AssetVal_Equip_S]

[F29_AssetVal_LandBuild_S]

[F29_AssetVal_Veh_S]

[F29_AssetVal_OthBusProp_S]

[F29_AssetVal_Other_S]

IF DON'T KNOW OR REFUSED, PROBE WITH RANGES: Would you say it was . .

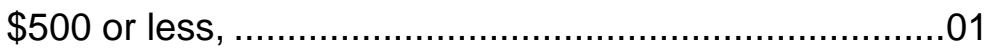

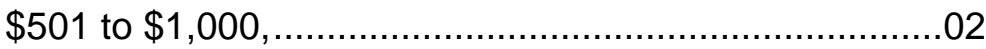

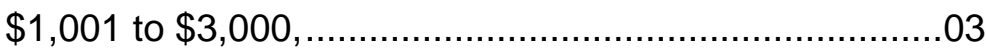

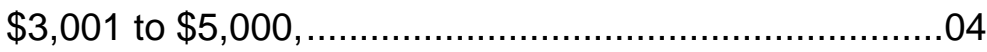

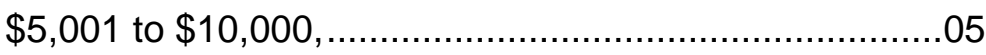

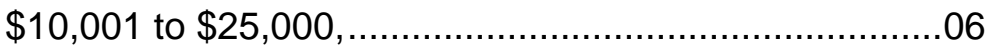

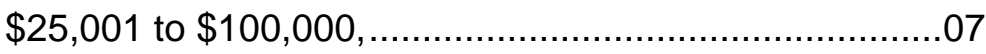

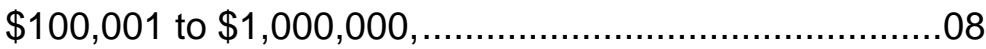

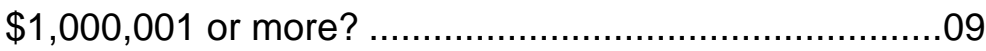

DON'T KNOW........................................................ d

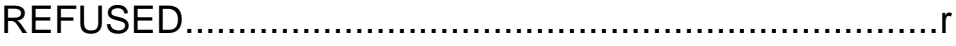

[F29_AssetVal_Cash_Ranges_S]

[F29_AssetVal_AcctRec_Ranges_S]

[F29_AssetVal_Inv_Ranges_S]

[F29_AssetVal_Equip_Ranges_S]

[F29_AssetVal_LandBuild_Ranges_S]

[F29_AssetVal_Veh_Ranges_S]

[F29_AssetVal_OthBusProp_Ranges_S]

[F29_AssetVal_Other_Ranges_S] 
F30. Liabilities are what the business owes. Other than the loans and the financial debt we've already talked about, did [NAME BUSINESS]'s liabilities as of December 31, 2006 include [NAME LIABILITY FROM LIST]?

\begin{tabular}{|l|l|l|l|}
\hline YES & NO & $\begin{array}{l}\text { DON'T } \\
\text { KNOW }\end{array}$ & REFUSED \\
\hline
\end{tabular}

a. Accounts Payable. [F30a_Liab_AcctPay_S]

0100

b. Pension and post retirement benefits [F30b_Liab_Pension_S]
$01 \quad 00$

$01 \quad 00$ d

d

d r

r

c. Any other liabilities? (SPECIFY) [F30c_Liab_Other_S]

[F30_Other_Specify_S]

F31. FOR EACH LIABILITY BUSINESS HAS, ASK: As of December 31, 2006, what was the estimated value of [NAME BUSINESS]'s [NAME OF LIABILITY]?

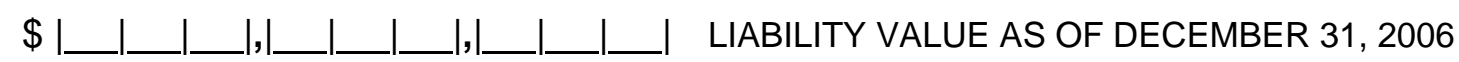

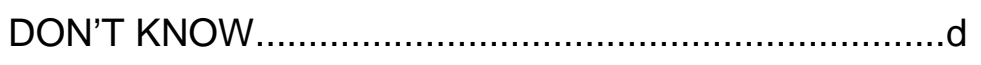

REFUSED..........................................................

[F31_Value_AcctPay_S]

[F31_Value_Pension_S]

[F31_Value_Other_S]

IF [MPR3]DON'T KNOW OR REFUSED, PROBE WITH RANGES: Would you say it was . . .

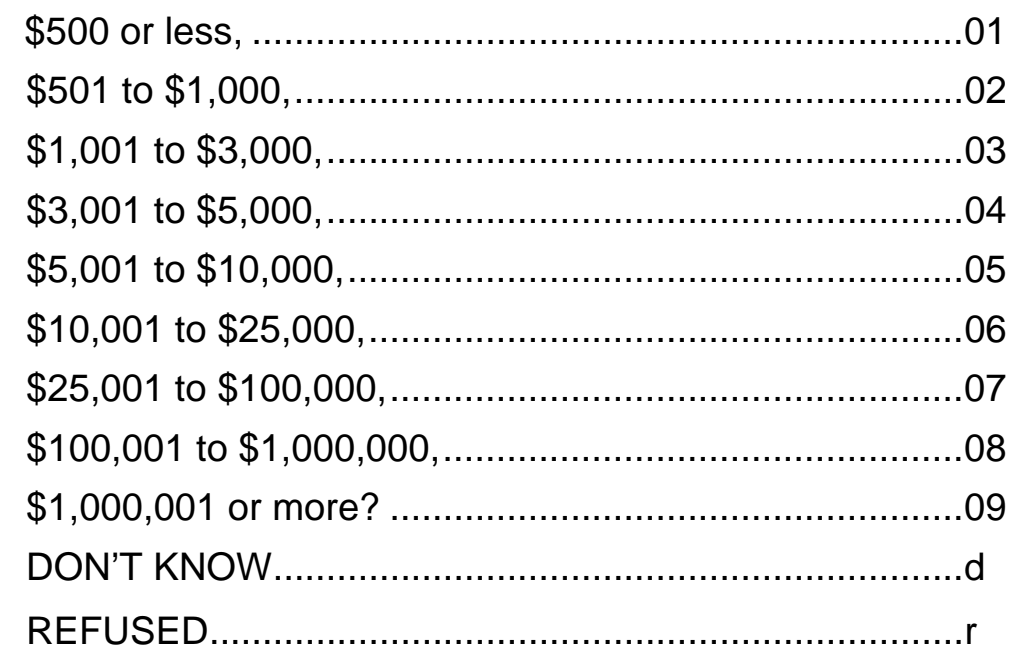

[F31_Value_AcctPay_Ranges_S]

[F31_Value_Pension_Ranges_S]

[F31_Value_Other_Ranges_S] 


\section{G. WORK BEHAVIORS AND DEMOGRAPHICS OF OWNER/OPERATOR(S)}

The last section contains questions for classification purposes only.

C4 LISTING OF OWNER/OPERATORS SHOULD BE ASKED THIS SERIES IN THE ORDER THEY APPEAR IN C4

NO QUESTIONS WILL BE ASKED ABOUT OWNER/OPERATORS WHO HAVE LEFT THE BUSINESS.

FOR ALL FIRST FOLLOW-UP OWNER/OPERATORS IN C4, ASK BLOCK G1

FOR ALL NEW OWNERIOPERATORS, ASK BLOCK G2

BLOCK G1-

G1a. (Are/Is) (you/[OWNER B-J]) also a paid employee at [NAME BUSINESS]?

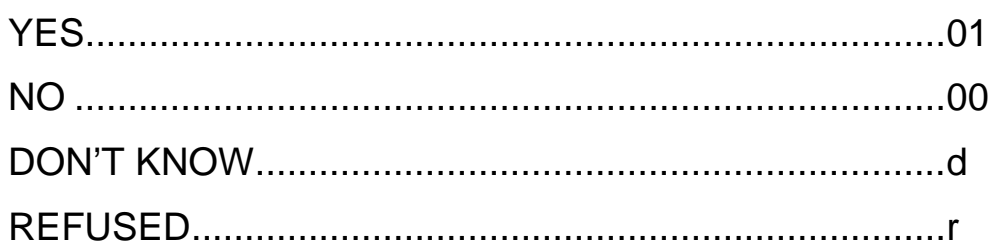

[G1a_Emp_Owner_01_S] THROUGH [G1a_Emp_Owner_10_S]

G1b. During the time [NAME BUSINESS] was in business during 2006, how many hours in an average week did (you/[OWNER B-J]) spend working at [NAME BUSINESS]?

I______ HOURS WORKED IN AVERAGE WEEK

DON'T KNOW..................................................d

REFUSED .......................................................

[G1b1_Hours_Owner_01_S] THROUGH [G1b1_Hours_Owner_10_S]

IF DON'T KNOW OR REFUSED PROBE: Would you say it was . . .

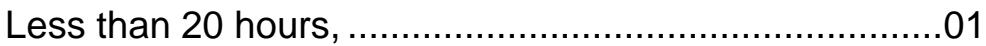

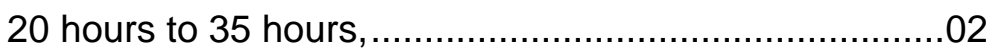

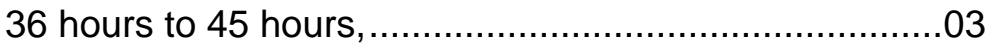

46 hours to 55 hours, ......................................... 04

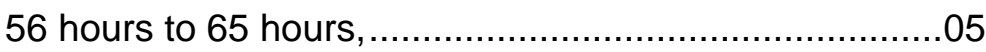

66 hours or more? ................................................

DON'T KNOW.....................................................

REFUSED ............................................................

[G1b2_Hours_Ranges_Owner_01_S] THROUGH [G1b2_Hours_Ranges_Owner_10_S] 
FIRST FOLLOW-UP OWNERS/OPERATORS: ANY DEMOGRAPHIC QUESTION G1d-G10a NOT ANSWERED IN FIRST FOLLOW-UP WILL BE ASKED AGAIN.

ENDBLOCK G1-FOR ALL FIRST FOLLOW-UP OWNERS.

BLOCK bSectionG2-for all NEW OWNERS

G1a. (Are/Is) (you/[OWNER B-J]) also a paid employee at [NAME BUSINESS]?

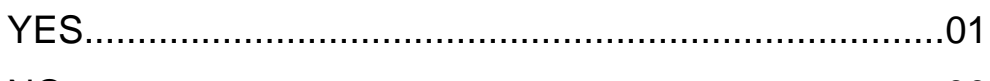

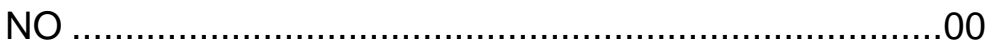

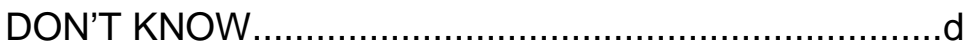

REFUSED ........................................................

[G1a_Emp_Owner_01_S] THROUGH [G1a_Emp_Owner_10_S]

G1b. During the time [NAME BUSINESS] was in business during 2006, how many hours in an average week did (you [OWNER B-J] spend working at [NAME BUSINESS]?

I______ HOURS WORKED IN AVERAGE WEEK

DON'T KNOW..................................................d

REFUSED........................................................

[G1b1_Hours_Owner_01_S] THROUGH [G1b1_Hours_Owner_10_S]

G1b1. IF DON'T KNOW OR REFUSED, PROBE: Would you say it was ...

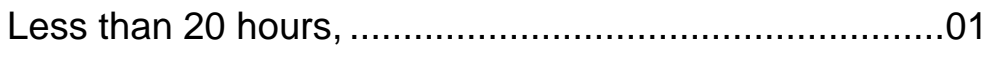

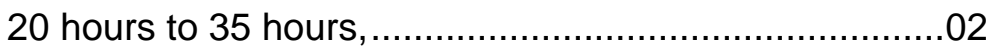

36 hours to 45 hours, ....................................... 03

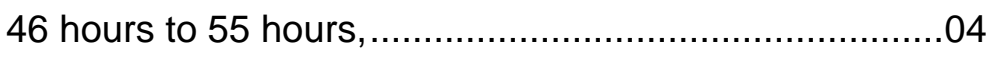

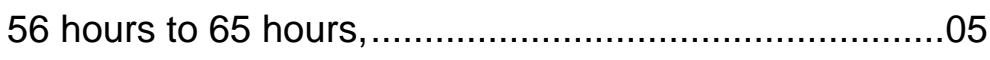

66 hours or more? ............................................06

DON'T KNOW.................................................... d

REFUSED ..................................................

[G1b2_Hours_Ranges_Owner_01_S] THROUGH [G1b2_Hours_Ranges_Owner_10_S]

G2. How many years of work experience (have/has) (you/[OWNER B-J]) had in this industrythe one in which [NAME BUSINESS] competes?

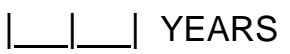

DON'T KNOW..................................................d

REFUSED ....................................................

[G2_Work_Exp_Owner_01_S] THROUGH [G2_Work_Exp_Owner_10_S] 
G3a. How many other new businesses (have/has) (you/[OWNER B-J]) started besides [NAME BUSINESS]?

\section{I___ I NUMBER OF BUSINESSES (ENTER "O" FOR NONE)}

DON'T KNOW.................................................. d

REFUSED ........................................................

[G3a_Oth_Bus_Owner_01_S] THROUGH [G3a_Oth_Bus_Owner_10_S]

\section{IF ZERO NEW BUSINESSES AT G3a, GO TO G4.}

G3b. (Was this/Were any of the) business(es) in the same industry as [NAME BUSINESS]?

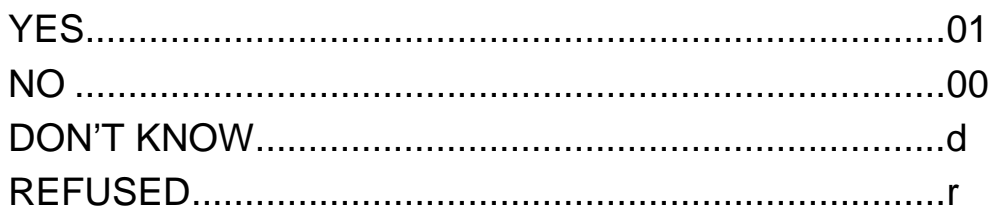

[G3b_Bus_Same_Ind_Owner_01_S] THROUGH [G3b_Bus_Same_Ind_Owner_10_S]

G4. How old will (you/[OWNER B-J]) be on (your/his/her) next birthday?

OWNER A.

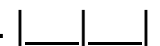

DON'T KNOW...................................................... d

REFUSED ..........................................................

[G4_Age_Owner_01_S] THROUGH [G4_Age_Owner_10_S]

IF DON'T KNOW OR REFUSED, PROBE WITH RANGES: Would you say . . .

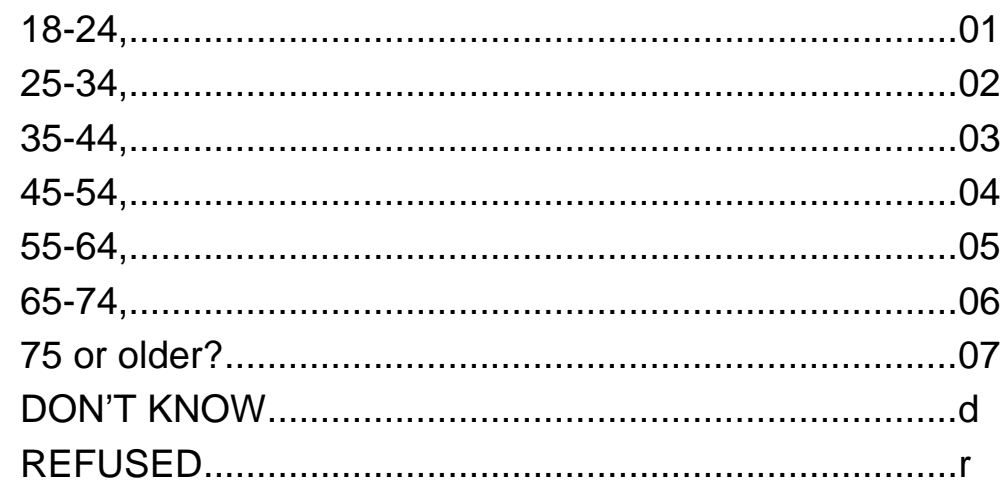

[G4a_Age_Ranges_Owner_01_S] THROUGH [G4a_Age_Ranges_Owner_10_S]

\section{IF G4 IS LESS THAN G2}

CATI HARD EDIT WITH WORDING AS FOLLOWS:

Perhaps I made a mistake in recording your answer. (OWNER B-J/Your) age is less than (OWNER B-J) years of experience. 
Now I have a few questions about race and ethnicity.

G5. (Are/ls) (you/[OWNER B-J]) of Hispanic or Latino origin?

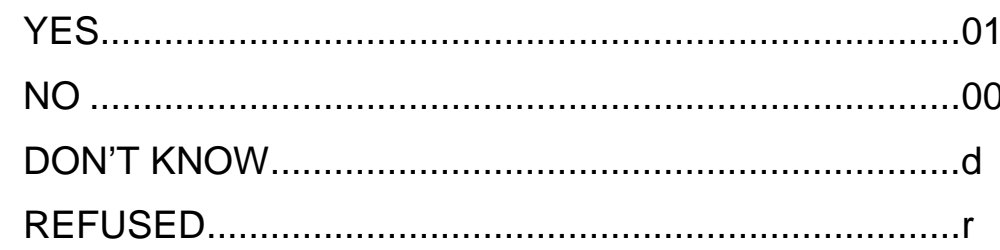

[G5_Hisp_Origin_Owner_01_S] THROUGH [G5_Hisp_Origin_Owner_10_S]

G6. I am going to read a list of race categories. Please choose one or more that best describes (your/[OWNER B-J]'s) race. Are (you [OWNER B-J]) American Indian or Alaska Native, Native Hawaiian or other Pacific Islander, Asian, Black or African American, or White?

AMERICAN INDIAN OR ALASKA NATIVE ...................01

[G6_Race_AmInd_Owner_01_S] THROUGH [G6_Race_AmInd_Owner_10_S]

NATIVE HAWAIIAN OR OTHER

PACIFIC ISLANDER .......................................02

[G6_Race_NatHaw_Owner_01_S] THROUGH [G6_Race_NatHaw_Owner_10_S]

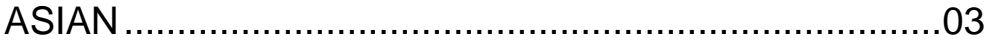

[G6_Race_Asian_Owner_01_S] THROUGH [G6_Race_Asian_Owner_10_S]

BLACK OR AFRICAN AMERICAN ........................04

[G6_Race_Black_Owner_01_S] THROUGH [G6_Race_Black_Owner_10_S]

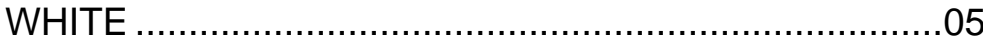

[G6_Race_White_Owner_01_S] THROUGH [G6_Race_White_Owner_10_S]

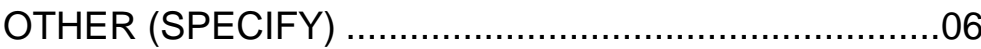

[G6_Race_Other_Owner_01_S] THROUGH [G6_Race_Other_Owner_10_S]

[G6_OtherSpecify_Owner_01_S] THROUGH [G6_OtherSpecify_Owner_10_S]

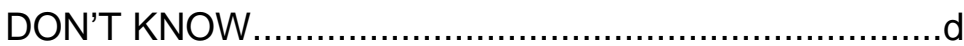

REFUSED..........................................................

G7. (Were/Was) (you/[OWNER B-J]) born in the United States?

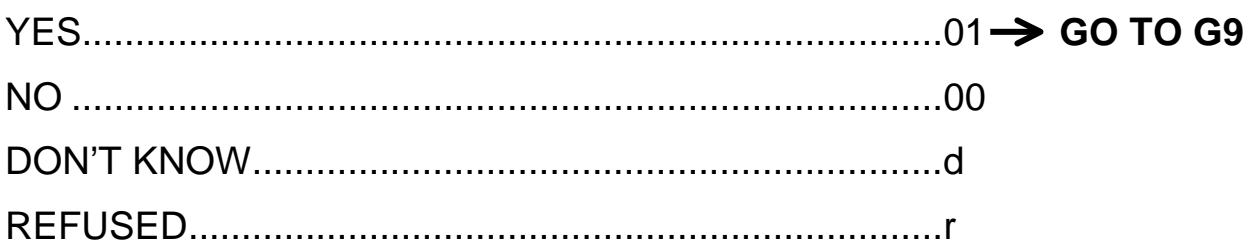

[G7_Native_Born_Owner_01_S] THROUGH [G7_Native_Born_Owner_10_S] 
G8. (Are/ls) (you/[OWNER B-J]) a U.S. citizen?

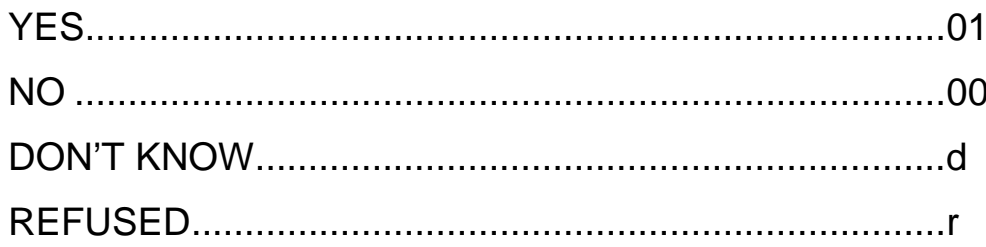

[G8_US_Cit_Owner_01_S] THROUGH [G8_US_Cit_Owner_10_S]

G9. What is the highest level of education (you/[OWNER B-J]) (have/has) completed so far? Would you say ...

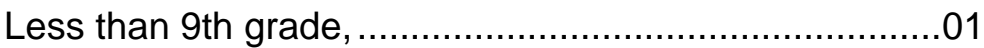

Some high school, but no diploma, ............................02

High school graduate (diploma or equivalent diploma [GED]), ................................................... 03

Technical, trade or vocational degree, ........................04

Some college, but no degree, ................................05

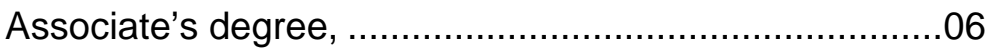

Bachelor's degree, ,................................................ 07

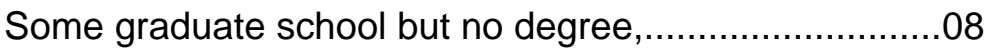

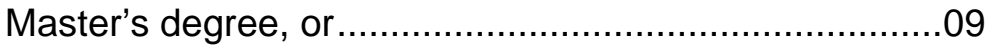

Professional school or doctorate? ...............................10

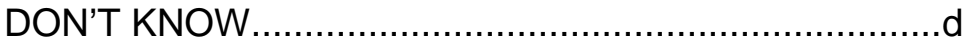

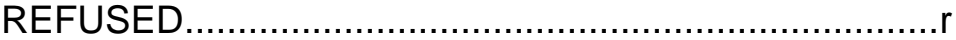

[G9_Education_Owner_01_S] THROUGH [G9_Education_Owner_10_S]

BY OBSERVATION:

G10a. (Are/ls) (you/[OWNER B-J]) male or female?

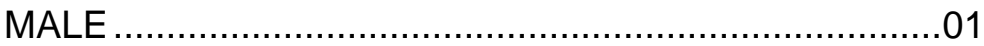

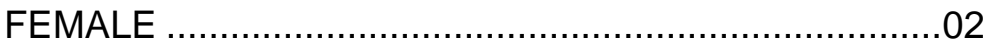

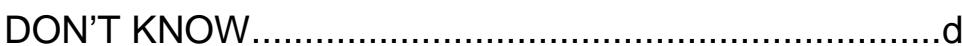

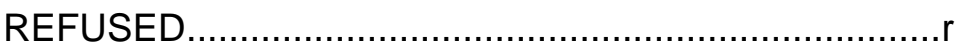

[G10_Gender_Owner_01_S] THROUGH [G10_Gender_Owner_10_S]

\section{ENDBLOCK bSectionG2}

SECTION G ARRAYED UP TO 10 TIMES, ONCE FOR EACH NEW OWNER. 
G11. IF EMAIL ADDRESS COLLECTED AT BASELINE OR FIRST FOLLOW-UP:

Can we confirm your email address?

INTERVIEWER: READ E-MAIL ADDRESS AND CORRECT AS NECESSARY.

IF EMAIL ADDRESS FIELD BLANK FROM BASELINE AND FIRST FOLLOW-UP: Can you give us an email address where you can be reached?

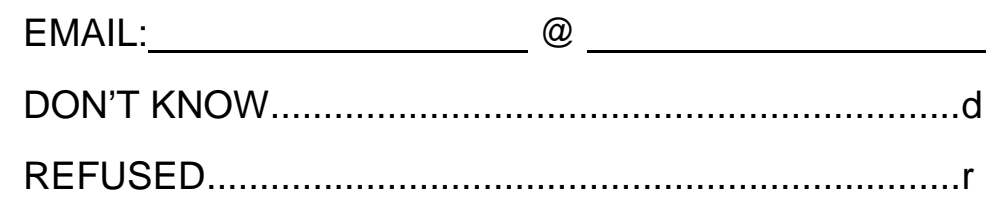

G12. IF WEBSITE ADDRESS COLLECTED AT BASELINE OR FIRST FOLLOW-UP: May we confirm your web site address as:

Web Address:

INTERVIEWER: CORRECT AS NECESSARY $\rightarrow$ GO TO G14

IF WEBSITE ADDRESS BLANK FROM BASELINE AND FIRST FOLLOW-UP:

Does [NAME BUSINESS] have its own website?

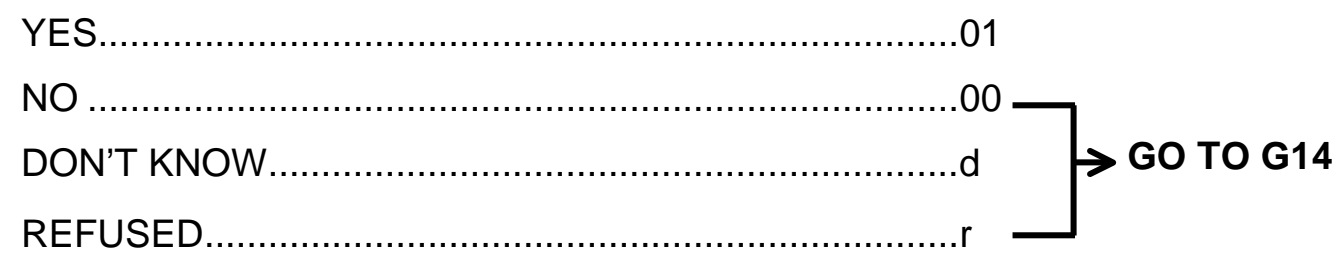

G13. Can you give me the web address?

WEB ADDRESS:

DON'T KNOW $d$

REFUSED. .r.

G14. Is the business likely to move to another location in the next 12 months?

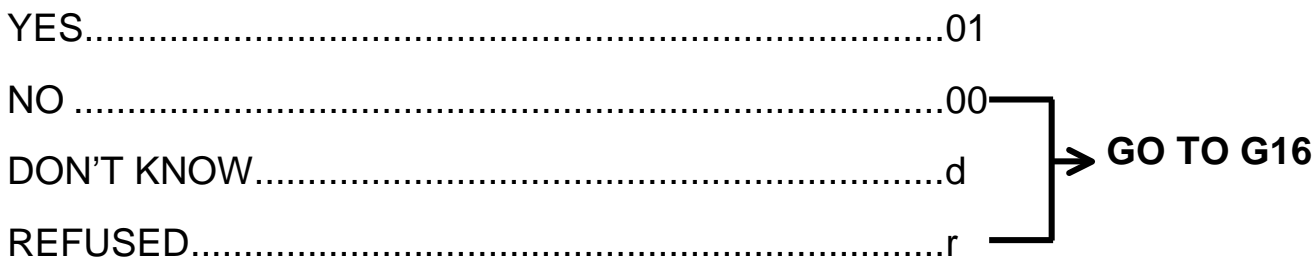


G15. What city and state is the business likely to move to?

CITY:

STATE:

DON'T KNOW..................................................... d

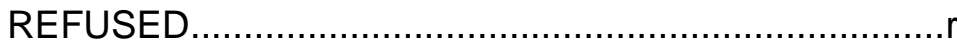

G16. IF CONTACT INFORMATION COLLECTED AT BASELINE OR FIRST FOLLOW-UP:

Here is the information we have for a contact person. This information will be held in the strictest confidence, and will only be used if we cannot contact you or someone else associated with the business at the current business phone number or address.

INTERVIEWER: PLEASE ASK FOR ANY INFORMATION THAT IS NOT FILLED IN.

NAME:

ADDRESS:

CITY:

STATE:

PHONE:

EMAIL:

@

DON'T KNOW........................................................ d

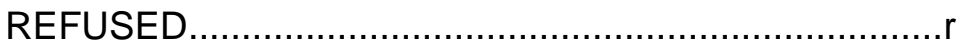


IF CONTACT INFORMATION IS BLANK FROM BASELINE AND FIRST FOLLOW-UP:

In case we are unable to contact you, can you provide a name and contact information for a person besides yourself who would know how to reach you or someone else associated with [NAME BUSINESS]? All information collected will be held in the strictest confidence, and will only be used if we cannot contact you or someone else associated with the business at the current business phone number or address.

NAME:

ADDRESS:

CITY:

STATE:

PHONE:

EMAIL: $@$

DON'T KNOW

d

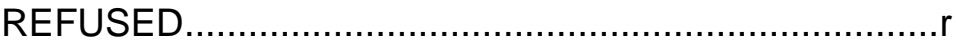

THANK AND TERMINATE 
APPENDIX E

\section{DATA DOCUMENTATION MEMO}



FROM: $\quad$ David DesRoches and Betsy Santos

DATE: $3 / 20 / 2008$

KFS - 113

SUBJECT: Kauffman Firm Survey (KFS) data documentation for longitudinal data file

This memo provides information about the longitudinal KFS data file, which includes data collected during the Baseline, First Follow-Up, and Second Follow-Up Surveys. This includes information on how item non-response was handled within variables in the data file, as well as a description of variables not documented in the KFS questionnaire. It also documents variables used in constructing the survey weights and all constructed variables. Several of the variables included here were provided with the Dun \& Bradstreet (D\&B) listings of sampled businesses that may provide additional context during the analysis. For variables derived directly from the KFS Baseline, First Follow-Up or Second Follow-Up questionnaires, the annotated versions of these questionnaires serve as the codebooks.

\section{NON-RESPONSE CLEANING STEPS}

All values for "Don’t Know” and "Refusal” responses were recoded to blanks (“.”) in all variables.

\section{VARIABLE-SPECIFIC INFORMATION}

Variable names in the longitudinal dataset are similar between the Baseline, First Follow-Up, and Second Follow-Up Surveys. First Follow-Up variables include an “_F” suffix, while Second Follow-Up variables include an “_S” suffix. Unless indicated, the variables in this memo are listed according to the Baseline name. 
MEMO TO: E. J. Reedy, Ewing Marion Kauffman Foundation

FROM: David DesRoches and Betsy Santos

DATE: $\quad 3 / 20 / 2008$

PAGE: 2

\section{A. Weighting and non-response adjustment variables - Baseline}

VARIABLE

sampleinfo_samplestrata

FSTATUS

RESP

SamplingWeight

WGT_INI

WGT_PLOCT

wgt_final

LOCT

\section{DEFINITION}

The technology and gender ownership sampling strata MPR used to select the KFS sample.

$101=$ high tech, woman owned

102 = high tech, not woman owned

201 = medium tech, woman owned

202 = medium tech, not woman owned

$301=$ non tech, woman owned

$302=$ non tech, not woman owned

The response status of Baseline Survey cases

1 = Complete

21 = Ineligible, out of business

$22=$ Ineligible, does not meet project requirements

$3=$ Refusal

$4=$ Unlocatable

Response Indicator - All completes and ineligibles are considered respondents under this measure.

$1=$ Respondent

$0=$ Non-respondent

Initial sampling weight when the sample was drawn

Weight after release adjustment

Weight after location model

Final weight after non-response model

Location indicator - Indicates whether business was located

$1=$ Located

$0=$ Unlocated 
MEMO TO: E. J. Reedy, Ewing Marion Kauffman Foundation

FROM: David DesRoches and Betsy Santos

DATE: $\quad 3 / 20 / 2008$

PAGE: $\quad 3$

B. Weighting and non-response adjustment variables - First \& Second Follow-Up

VARIABLE DEFINITION

Fstatus_F

Resp_F

Wgt_Final_F

FSTATUS_f2_S

RESP_f2_S

Wgt_Final_F2_S

Wgt_final_f12_long_S
The response status of First Follow-Up cases

1 = Complete

21 = Ineligible, out of business

22 = Ineligible, does not meet project expectations

$3=$ Refusal

4 = Unlocatable

Response Indicator for First Follow-Up cases - All completes and ineligibles are considered respondents under this measure.

$1=$ respondents

$0=$ non-respondents

Final weight after non-response model for First Follow-Up cases.

The response status of Second Follow-Up cases

1 = Complete

21 = Ineligible, out of business

22 = Ineligible, does not meet project expectations

$3=$ Refusal

$4=$ Unlocatable

Response Indicator for Second Follow-Up cases- All completes and ineligibles are considered respondents under this measure.

$1=$ respondents

$0=$ non-respondents

Second Follow-Up final weight - Cross- Sectional

Second Follow-Up final weight - Longitudinal 
MEMO TO: E. J. Reedy, Ewing Marion Kauffman Foundation

FROM: David DesRoches and Betsy Santos

DATE: $\quad 3 / 20 / 2008$

PAGE: 4

B. Weighting and non-response adjustment variables - First \& Second Follow-Up (Continued)

Resp_f12_long_S Indicates if there is a Second Follow-Up longitudinal weight

$1=$ Yes (Response for both First and Second Follow-Up)

$0=$ No (otherwise)

\section{Survey Management Variables}

VARIABLE

MPRID

Final_Status_Code

Final_Status_Code_F

\section{DEFINITION}

The identification number provided by MPR to each sampled business.

Final Disposition Code for sampled businesses in the Baseline Survey.

$10=$ Telephone Complete

$30=$ Web Complete

Final Disposition Code for sampled businesses in the First Follow-Up Survey.

$10=$ Telephone Complete

$30=$ Web Complete

$200=$ Refusal

$210=$ Refusal by gatekeeper

$220=$ Refusal by other

$330=$ Effort ended/Case retired

401 = Language Barrier (Spanish)

$450=$ Business moved out of country

$463=$ No Longer in Business

465 = Started Previous to 2004 - The business was engaged in new business activity prior to calendar year 2004. New business activity is defined as applying for an EIN, submitting a Schedule C or C-EZ, paying state unemployment insurance taxes, or making FICA payments $590=$ Unlocatable 
MEMO TO: E. J. Reedy, Ewing Marion Kauffman Foundation

FROM: David DesRoches and Betsy Santos

DATE: $\quad 3 / 20 / 2008$

PAGE: 5

\section{Survey Management Variables (continued)}

VARIABLE

Final_Status_Code_S

TotalCalls

SampleInfo_Wave

\section{DEFINITION}

Final Disposition Code for sampled businesses in the Second Follow-Up Survey.

$10=$ CATI complete

$30=$ Web Complete

200 = Refusal by known respondent

209 = Adamant refusal by known respondent

$210=$ Refusal by gatekeeper

$220=$ Refusal by unknown person

$330=$ Effort ended/Case retired

$463=$ No Longer in Business

$468=$ Duplicate case

$590=$ Final unlocatable by phone center

Total number of calls made to interviews completed via Computer Assisted Telephone Interviewing (CATI).

The sample wave number the sample business was included in. 
MEMO TO: E. J. Reedy, Ewing Marion Kauffman Foundation

FROM: David DesRoches and Betsy Santos

DATE: $\quad 3 / 20 / 2008$

PAGE: 6

\section{Survey Management Variables (continued)}

VARIABLE

SampleInfo_Strata

\section{DEFINITION}

The high-tech strata of businesses in the D\&B sample frame were defined by using the SIC codes of businesses listed below.

\section{$1=$ High Tech}

28 Chemicals and allied products

35 Industrial machinery and equipment

36 Electrical and electronic equipment

38 Instruments and related products

2 = Medium Tech

131 Crude Petroleum and natural gas operations

211 Cigarettes

229 Miscellaneous textile goods

261 Pulp mills

267 Miscellaneous converted paper products

291 Petroleum refining

299 Miscellaneous petroleum and coal products

335 Nonferrous rolling and drawing

348 Ordnance and accessories, not elsewhere classified

371 Motor vehicles and equipment

372 Aircraft and parts

376 Guided missiles, space vehicles, parts

379 Miscellaneous transportation equipment

737 Computer and data processing services

871 Engineering and architectural services

873 Research and testing services

874 Management and public relations

899 Services, not elsewhere classified

$3=$ Not High Tech

Includes all other industries not listed above. 
MEMO TO: E. J. Reedy, Ewing Marion Kauffman Foundation

FROM: $\quad$ David DesRoches and Betsy Santos

DATE: $\quad 3 / 20 / 2008$

PAGE: $\quad 7$

\section{Survey Management Variables (continued)}

VARIABLE

SampleInfo_Release

SampleInfo_Release_F

SampleInfo_Release_S

\section{DEFINITION}

The Baseline Survey sample was released in six batches:

$1=1$ st release sent $7 / 29 / 05$

$2=2$ nd release sent $9 / 23 / 05$

$3=$ 3rd release sent $11 / 4 / 05$

$4=4$ th release sent $12 / 1 / 05$

$5=5$ th release sent $1 / 11 / 06$

$6=6$ th release sent $2 / 28 / 06$

The First Follow-Up Survey sample was released in four batches:

$1=1$ st release sent $6 / 14 / 06$

$2=2$ nd release sent $7 / 6 / 06$

$3=$ 3rd release sent 08/07/06

$4=4$ th release sent $08 / 31 / 06$

The Second Follow-Up Survey sample was released in three batches:

$1=1$ st release sent $5 / 17 / 07$

$2=2$ nd release sent $5 / 31 / 07$

$3=$ 3rd release sent $06 / 25 / 07$

InterviewDate

The date the interview was completed.

The time zone the business is located in:

$2=$ Hawaiian/Aleutian Time Zone

$3=$ Alaska Time Zone

$4=$ Pacific Time Zone

$5=$ Mountain Time Zone

$6=$ Central Time Zone

$7=$ Eastern Time Zone 
MEMO TO: E. J. Reedy, Ewing Marion Kauffman Foundation

FROM: David DesRoches and Betsy Santos

DATE: $\quad 3 / 20 / 2008$

PAGE: $\quad 8$

\section{Variables provided with $D \& B$ sampling frame}

These variables appear once in the longitudinal file, as they were included in the original D\&B listing and were not updated during the surveys.

VARIABLE

SampleInfo_Sex

SampleInfo_Sales_Volume

SampleInfo_Sales_Volume_ Code

SampleInfo_Employees_Total

SampleInfo_Manufacturing_ Indica

SampleInfo_Legal_Status

\section{DEFINITION}

The gender variable for the business principal provided with the $\mathrm{D} \& \mathrm{~B}$ listing.

1 = Male

$2=$ Female

Sales volume provided by D\&B for the sampled business.

Code provided by D\&B that helps define the SampleInfo_Sales_Volume variable.

$0=$ SampleInfo_Sales_Volume contains a real value

1 = SampleInfo_Sales_Volume contains the low end of a real range 2 (with an all zero SampleInfo_Sales_Volume) = SampleInfo_Sales_Volume is unknown 2 (with a non-zero SampleInfo_Sales_Volume) = SampleInfo_Sales_Volume is an estimate based on defined norms for this industry and size of business

Total employees provided by D\&B for the sampled business.

Code provided by D\&B indicating whether manufacturing operations occur at this location.

$0=$ Manufacturing is done here

$1=$ No manufacturing done here

Code provided by D\&B indicating the legal status of the establishment.

$000=$ not available

$003=$ corporation

$012=$ partnership of unknown type

$013=$ proprietorship type 
MEMO TO: E. J. Reedy, Ewing Marion Kauffman Foundation

FROM: David DesRoches and Betsy Santos

DATE: $\quad 3 / 20 / 2008$

PAGE: $\quad 9$

\section{Variables provided with D\&B sampling frame (continued)}

VARIABLE

SampleInfo_Major_Industry _Category

SampleInfo_line_business

SampleInfo_SIC_1

SampleInfo_SIC_2

SampleInfo_SIC_3

SampleInfo_SIC_4

SampleInfo_SIC_5

SampleInfo_SIC_6

\section{DEFINITION}

Code provided by D\&B that denotes the major industry category under which a sampled business falls.

1 = agriculture

$2=$ mining

$3=$ construction

4 = manufacturing

$5=$ transportation, communications, utilities

$6=$ wholesale trade

$7=$ retail trade

8 = finance, insurance, real estate

$9=$ services

A brief description of the line of business provided by D\&B for the sampled business based on the SIC code.

The first Standard Industrial Classification (SIC) code provided by $\mathrm{D} \& \mathrm{~B}$ for the sampled business. The SIC code taxonomy assigns a code to businesses and other organizations, classifying and subdividing the activity performed by the establishment at that location.

The second SIC code provided by D\&B for the sampled business.

The third SIC code provided by D\&B for the sampled business.

The fourth SIC code provided by D\&B for the sampled business.

The fifth SIC code provided by D\&B for the sampled business.

The sixth SIC code provided by D\&B for the sampled business. 
MEMO TO: E. J. Reedy, Ewing Marion Kauffman Foundation

FROM: David DesRoches and Betsy Santos

DATE: $\quad 3 / 20 / 2008$

PAGE: $\quad 10$

\section{Variables provided with D\&B sampling frame (continued)}

VARIABLE

Subsidiary_Indicator

SampleInfo_NAICS_Code

SampleInfo_NAICS_Desp

SampleInfo_Woman_owned

Sampleinfo_fips_msa

\section{DEFINITION}

Indicating if this business is a corporation that is more than $50 \%$ owned by another company according to D\&B:

$0=$ Non subsidiary

$3=$ Subsidiary

The NAICS code provided by D\&B for the sampled business. Refer to NAICS-North American Industry Classification System for additional documentation of this variable.

Descriptions of the NAICS code provided by D\&B for the sampled business. Refer to NAICS-North American Industry Classification System for additional documentation of this variable.

Code provided by $\mathrm{D} \& \mathrm{~B}$ indicating if the majority of the establishment is owned by a woman.

$\mathrm{Y}=$ Yes, woman owned

$\mathrm{N}=$ Not woman owned

The Federal Information Processing System (FIPS)

Metropolitan Statistical Area (MSA) code provided by D\&B for the sampled business. Refer to Current Lists of Metropolitan and Micropolitan Statistical Areas and Definitions for additional documentation of this variable. 
MEMO TO: E. J. Reedy, Ewing Marion Kauffman Foundation

FROM: David DesRoches and Betsy Santos

DATE: $\quad 3 / 20 / 2008$

PAGE: $\quad 11$

\section{E. Other Variables}

\section{VARIABLE}

TotalOwners

F6Check

NAICS_Code

State_final

Zip_Final

Respondent_F

Respondent_S

Owner_Active_01_F

Owner_Active_02_F

Owner_Active_03_F

Owner_Active_04_F

Owner_Active_05_F

Owner_Active_06_F

Owner_Active_07_F

Owner_Active_08_F

Owner_Active_09_F

Owner_Active_10_F

\section{DEFINITION}

The total number of owners of the business, including owneroperators collected at question $\mathrm{C} 4$, and non-operating equity owners collected at question F3.

The total percentage of ownership accounted for prior to reconciliation. This includes the percentages collected among owner-operators at the question F2 series and among non-operating equity owners at question F5.

Primary industry of the business confirmed or updated during the surveys. Refer to NAICS - North American Industry Classification System for additional documentation of this variable.

The state abbreviation for the sampled business.

The zip code for the sampled business

Owner who completed the First Follow-Up Survey

Owner who completed the Second Follow-Up Survey

Active owner(s) 1-10 at time of First Follow-Up Survey 
MEMO TO: E. J. Reedy, Ewing Marion Kauffman Foundation

FROM: David DesRoches and Betsy Santos

DATE: $\quad 3 / 20 / 2008$

PAGE: $\quad 12$

\section{E. Other Variables (continued)}

VARIABLE

Owner_Active_01_S

Owner_Active_02_S

Owner_Active_03_S

Owner_Active_04_S

Owner_Active_05_S

Owner_Active_06_S

Owner_Active_07_S

Owner_Active_08_S

Owner_Active_09_S

Owner_Active_10_S
DEFINITION

Active owner(s) 1-10 at time of Second Follow-Up Survey 
MEMO TO: E. J. Reedy, Ewing Marion Kauffman Foundation

FROM: $\quad$ David DesRoches and Betsy Santos

DATE: $\quad 3 / 20 / 2008$

PAGE: $\quad 13$

\section{CONSTRUCTED VARIABLES}

For the final data file, additional variables were constructed for ease of analysis. The constructed variables fall into several categories, each of which is explained below. Variables using First Follow-Up data have the same name stem as the Baseline variable with the "_F” suffix. Similarly, variables using Second Follow-Up data have the same name stem as the Baseline variable with the “_S” suffix.

\section{A. Total Intellectual Property Variables}

These variables create a total number of patents, copyrights, or trademarks the businesses possessed at the time of each interview. For each type of intellectual property, the variables were constructed using data from the following questions:

- "Indicator” questions, such as Question D3a (“Does the business have any patents?”)

- "Exact value” measures, such as Question D3b ("How many patents does the business have?”)

The construction was specified by the rules provided in the table below.

\begin{tabular}{|c|c|}
\hline \multicolumn{2}{|c|}{ Intellectual Property Variable Specifications } \\
\hline Condition & Value of Constructed Variable \\
\hline "Indicator" variable $=0$ & 0 \\
\hline "Exact value" variable $>0$ & Value of "Exact value" variable \\
\hline "Indicator" variable = BLANK & BLANK \\
\hline "Indicator" variable $=1$ and "Exact" variable $=$ BLANK & BLANK \\
\hline
\end{tabular}

The following variables were created using these specifications:

Total_Patents

Total_Copyrights

Total_Trademarks 
MEMO TO: E. J. Reedy, Ewing Marion Kauffman Foundation

FROM: $\quad$ David DesRoches and Betsy Santos

DATE: $\quad 3 / 20 / 2008$

PAGE: $\quad 14$

\section{B. Amount Variables}

These variables were constructed for the specific types of equity, debt, revenue, assets, and liabilities the businesses possessed at the time of each interview. For each type, variables were constructed using data from the following survey questions:

- “Indicator” questions, such as Question F1 ("First, in calendar year 2004, did you put any of your own money into the business in return for an ownership share of the business?”)

- "Exact value” measures such as Question F2a ("How much of your own money did you put into the business during calendar year 2004?”)

- "Range" questions asked of respondents who could or would not provide an exact figure

The construction was specified by the rules provided in the table below.

\begin{tabular}{|l|c|}
\hline \multicolumn{2}{|c|}{ Amount Variable Specifications } \\
\hline \multicolumn{1}{|c|}{ Condition } & Value of Constructed Variable \\
\hline “Indicator" variable $=0$ & 0 \\
\hline “Exact value” variable $>0$ & $\begin{array}{c}\text { Value of "Exact value” variable } \\
\text { converted to range value }\end{array}$ \\
\hline "Indicator" variable $=1$ and "Exact” variable = BLANK & Range value \\
\hline "Indicator" variable $=$ BLANK & BLANK \\
\hline $\begin{array}{l}\text { "Indicator” variable }=1 \text { and "Exact” and "Range” variables } \\
\text { BLANK }\end{array}$ & BLANK \\
\hline
\end{tabular}

The range values for these amount variables are listed in the table below:

\begin{tabular}{|c|r|}
\hline \multicolumn{2}{|c|}{ Range definition - Amount } \\
\hline Value & \multicolumn{1}{c|}{ Range } \\
\hline 1 & $\$ 500$ or less \\
\hline 2 & $\$ 501$ to $\$ 1,000$ \\
\hline 3 & $\$ 1,001$ to $\$ 3,000$ \\
\hline 4 & $\$ 5,001$ to $\$ 5,000$ \\
\hline 5 & $\$ 10,001$ to $\$ 25,000$ \\
\hline 6 & $\$ 25,001$ to $\$ 100,000$ \\
\hline 7 & $\$ 100,001$ to $\$ 1,000,000$ \\
\hline 8 & $\$ 1,000,001$ or more \\
\hline
\end{tabular}


MEMO TO: E. J. Reedy, Ewing Marion Kauffman Foundation

FROM: David DesRoches and Betsy Santos

DATE: $\quad 3 / 20 / 2008$

PAGE: $\quad 15$

\section{B. Amount Variables (continued)}

This process was used to construct the following variables:

Tot_Equity_Owner_1_R

Tot_Equity_Owner_2_R

Tot_Equity_Owner_3_R

Tot_Equity_Owner_4_R

Tot_Equity_Owner_5_R

Tot_Equity_Owner_6_R

Tot_Equity_Owner_7_R

Tot_Equity_Owner_8_R

Tot_Equity_Owner_9_R

Tot_Equity_Owner_10_R

Tot_Equity_Spouse_R

Tot_Equity_Parents_R

Tot_Equity_Angels_R

Tot_Equity_Companies_R

Tot_Equity_Govt_R

Tot_Equity_Vent_Cap_R

Tot_Equity_Other_R

Tot_Pers_CredCard_Line_Resp_R

Tot_Pers_CredCard_Bal_Resp_R

Tot_Pers_Loan_Bank_Resp_R

Tot_Bus_CredCard_Line_Resp_R

Tot_Bus_CredCard_Bal_Resp_R

Tot_Pers_Loan_Fam_Resp_R

Tot_Pers_Loan_Other_Resp_R

Tot_Pers_Other_Resp_R

Tot_Pers_CredCard_Line_Others_R

Tot_Pers_CredCard_Bal_Others_R

Tot_Pers_Loan_Bank_Others_R

Tot_Bus_CredCard_Line_Others_R

Tot_Bus_CredCard_Bal_Others_R

Tot_Pers_Loan_Fam_Other_Owners_R

Tot_Pers_Loan_Other_Owners_R

Tot_Pers_Other_Other_Owners_R

Tot_CredCard_Line_Bus_R

Tot_CredCard_Bal_Bus_R

Tot_Loan_Bank_Bus_R

Tot_Cred_Line_Bus_Line_R

Tot_Cred_Line_Bus_Bal_R

Tot_Loan_NonBank_Bus_R 
MEMO TO: E. J. Reedy, Ewing Marion Kauffman Foundation

FROM: $\quad$ David DesRoches and Betsy Santos

DATE: $\quad 3 / 20 / 2008$

PAGE: $\quad 16$

\section{B. Amount Variables (continued)}

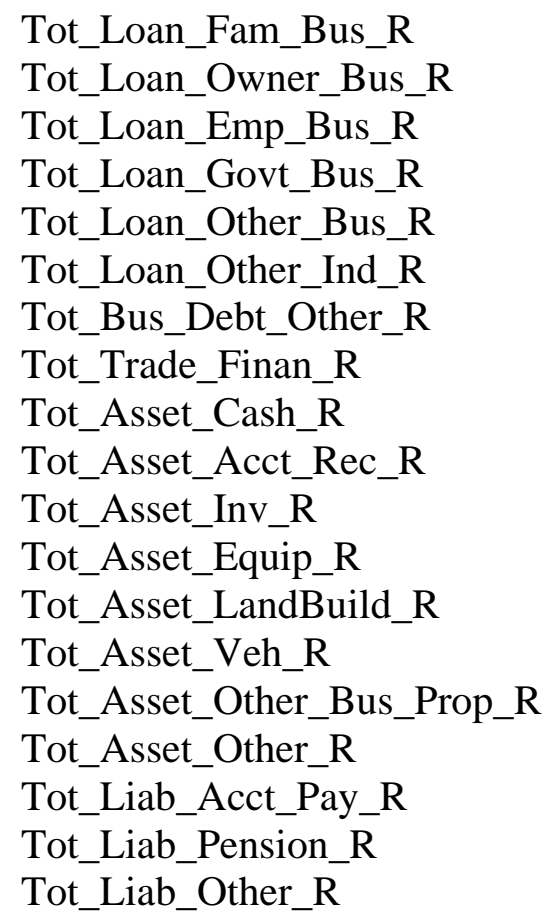

The following constructed variables are specific to the First and Second Follow-Up Surveys only. The First Follow-Up variables are shown below, and the Second Follow-Up variables are denoted by a “_S” suffix instead of a “_F” suffix.

Tot_Equity_AllYrs_Owner_01_R_F

Tot_Equity_AllYrs_Owner_02_R_F

Tot_Equity_AllYrs_Owner_03_R_F

Tot_Equity_AllYrs_Owner_04_R_F

Tot_Equity_AllYrs_Owner_05_R_F

Tot_Equity_AllYrs_Owner_06_R_F

Tot_Equity_AllYrs_Owner_07_R_F

Tot_Equity_AllYrs_Owner_08_R_F

Tot_Equity_AllYrs_Owner_09_R_F

Tot_Equity_AllYrs_Owner_10_R_F

Tot_Equity_Spouse_AllYrs_R_F

Tot_Equity_Parents_AllYrs_R_F

Tot_Equity_Angels_AllYrs_R_F

Tot_Equity_Comp_AllYrs_R_F

Tot_Equity_Govt_AllYrs_R_F

Tot_Equity_Vent_Cap_AllYrs_R_F

Tot_Equity_Other_AllYrs_R_F 
MEMO TO: E. J. Reedy, Ewing Marion Kauffman Foundation

FROM: David DesRoches and Betsy Santos

DATE: $\quad 3 / 20 / 2008$

PAGE: $\quad 17$

\section{B. Amount Variables (continued)}

Tot_Pers_Loan_Bank_Owed_Resp_R_F

Tot_Pers_Loan_Fam_Owed_Resp_R_F

Tot_PersLoan_Other_Owed_Resp_R_F

Tot_Pers_Other_Owed_Resp_R_F

Tot_PersLoan_Bank_Owed_Othrs_R_F

Tot_PersLoan_Fam_Owed_Othrs_R_F

Tot_PersLoan_Othr_Owed_Othrs_R_F

Tot_Pers_Other_Owed_Others_R_F

Tot_Bus_Loans_Bank_Owed_R_F

Tot_Bus_Loans_Nonbank_Owed_R_F

Tot_Bus_Loans_Fam_Owed_R_F

Tot_Bus_Loans_Owner_Owed_R_F

Tot_Bus_Loans_Emp_Owed_R_F

Tot_Bus_Loans_Govt_Owed_R_F

Tot_Bus_Loans_OtherBus_Owed_R_F

Tot_Bus_Loans_OtherInd_Owed_R_F

Tot_Bus_Loans_Other_Owed_R_F

Tot_Personal_Use_2004_R_F

Tot_Personal_Use_2005_R_F 
MEMO TO: E. J. Reedy, Ewing Marion Kauffman Foundation

FROM: $\quad$ David DesRoches and Betsy Santos

DATE: $\quad 3 / 20 / 2008$

PAGE: $\quad 18$

\section{Expense Variables}

The variables created for both total expenses and wage expenses are similar to those detailed in Section III.B above, but at these questions there was no "Indicator" question. The variables were constructed using data from the following types of survey questions:

- “Exact value” measures such as Question F17 (“How much, if any, did the business pay in expenses during calendar year 2004?”),

- "Range" questions asked of respondents who could or would not provide an exact figure at the "Exact value" variable.

The construction was specified by the rules provided in the table below using the series of equity questions as an example.

\begin{tabular}{|l|c|}
\hline \multicolumn{2}{|c|}{ Amount Variable Specifications } \\
\hline \multicolumn{1}{|c|}{ Condition } & Value of Constructed Variable \\
\hline "Exact value" variable $=0$ & 0 \\
\hline "Exact value" variable $>0$ & $\begin{array}{c}\text { Value of "Exact value" variable converted } \\
\text { to range value }\end{array}$ \\
\hline "Exact value" variable = BLANK & Range value \\
\hline "Exact value" and "Range” variables = BLANK & BLANK \\
\hline
\end{tabular}

These variables used the same amount range values as those described above in III.B. The following variables were created using these specifications:

Tot_Expenses_R

Tot_Wages_R 
MEMO TO: E. J. Reedy, Ewing Marion Kauffman Foundation

FROM: $\quad$ David DesRoches and Betsy Santos

DATE: $\quad 3 / 20 / 2008$

PAGE: $\quad 19$

\section{Total Amount Variables}

These variables create total amounts of equity, debt, revenue, assets, and liabilities the businesses possessed at the time of each interview, combining the values reported for each individual type. For example, the variable “Tot_Equity_Owner_Operators_R” sums all values in the owner-operator variables (Tot_Equity_Owner_1_R through Tot_Equity_Owner_10_R), which is then translated into the amount range values described above in III.B and III.C. The variables created in this way are listed below along with the component variables.

\begin{tabular}{|c|c|}
\hline \multicolumn{2}{|r|}{ Total Amount Variables } \\
\hline Variable Name & Variables used to create \\
\hline Tot_Equity_Owner_Operators_R & \begin{tabular}{|l} 
Tot_Equity_Owner_1_R, Tot_Equity_Owner_2_R, \\
Tot_Equity_Owner_3_R, Tot_Equity_Owner_4_R, \\
Tot_Equity_Owner_5_R, Tot_Equity_Owner_6_R, \\
Tot_Equity_Owner_7_R, Tot_Equity_Owner_8_R, \\
Tot_Equity_Owner_9_R, Tot_Equity_Owner_10_R
\end{tabular} \\
\hline Tot_Equity_OwnerOper_AllYrs_R_F* & \begin{tabular}{|l} 
First Follow-Up: \\
Tot_Equity_AllYrs_Owner_01_R_F, Tot_Equity_AllYrs_Owner_02_R_F \\
Tot_Equity_AllYrs_Owner_03_R_F, Tot_Equity_AllYrs_Owner_04_R_F \\
Tot_Equity_AllYrs_Owner_05_R_F, Tot_Equity_AllYrs_Owner_06_R_F \\
Tot_Equity_AllYrs_Owner_07_R_F, Tot_Equity_AllYrs_Owner_08_R_F \\
Tot_Equity_AllYrs_Owner_09_R_F, Tot_Equity_AllYrs_Owner_10_R_F
\end{tabular} \\
\hline Tot_Equity_OwnerOper_AllYrs_R_S* & $\begin{array}{l}\text { Second Follow-Up: } \\
\text { Tot_Equity_AllYrs_Owner_01_R_S, Tot_Equity_AllYrs_Owner_02_R_S } \\
\text { Tot_Equity_AllYrs_Owner_03_R_S, Tot_Equity_AllYrs_Owner_04_R_S } \\
\text { Tot_Equity_AllYrs_Owner_05_R_S, Tot_Equity_AllYrs_Owner_06_R_S } \\
\text { Tot_Equity_AllYrs_Owner_07_R_S, Tot_Equity_AllYrs_Owner_08_R_S } \\
\text { Tot_Equity_AllYrs_Owner_09_R_S, Tot_Equity_AllYrs_Owner_10_R_S }\end{array}$ \\
\hline Tot_Equity_Non_Owner_Operators_R & $\begin{array}{l}\text { Tot_Equity_Spouse_R, Tot_Equity_Parents_R, } \\
\text { Tot_Equity_Angels_R, Tot_Equity_Companies_R, } \\
\text { Tot_Equity_Govt_R, Tot_Equity_Vent_Cap_R, } \\
\text { Tot_Equity_Other_R }\end{array}$ \\
\hline Tot_Equity_NonOwnerOp_AllYrs_R_F* & $\begin{array}{l}\text { First Follow-Up: } \\
\text { Tot_Equity_Spouse_AllYrs_R_F, Tot_Equity_Parents_AllYrs_R_F } \\
\text { Tot_Equity_Angels_AllYrs_R_F, Tot_Equity_Comp_AllYrs_R_F } \\
\text { Tot_Equity_Govt_AllYrs_R_F, Tot_Equity_Vent_Cap_AllYrs_R_F } \\
\text { Tot_Equity_Other_AllYrs_R_F }\end{array}$ \\
\hline Tot_Equity_NonOwnerOp_AllYrs_R_S* & $\begin{array}{l}\text { Second Follow-Up: } \\
\text { Tot_Equity_Spouse_AllYrs_R_S, Tot_Equity_Parents_AllYrs_R_S } \\
\text { Tot_Equity_Angels_AllYrs_R_S, Tot_Equity_Comp_AllYrs_R_S } \\
\text { Tot_Equity_Govt_AllYrs_R_S, Tot_Equity_Vent_Cap_AllYrs_R_S } \\
\text { Tot_Equity_Other_AllYrs_R_S }\end{array}$ \\
\hline Tot_Equity_R & \begin{tabular}{|l} 
Tot_Equity_Owner_Operators_R, \\
Tot_Equity_Non_Owner_Operators_R
\end{tabular} \\
\hline
\end{tabular}

* First Follow-Up and Second Follow-Up data only 
MEMO TO: E. J. Reedy, Ewing Marion Kauffman Foundation

FROM: David DesRoches and Betsy Santos

DATE: $\quad 3 / 20 / 2008$

PAGE: $\quad 20$

\section{Total Amount Variables (continued)}

\begin{tabular}{|c|c|}
\hline \multicolumn{2}{|r|}{ Total Amount Variables } \\
\hline Variable Name & Variables used to create \\
\hline Tot_Pers_Debt_Resp_R & $\begin{array}{l}\text { Tot_Pers_CredCard_Bal_R, Tot_Pers_Loan_Resp_R, } \\
\text { Tot_Bus_CredCard_Bal_Resp_R, Tot_Pers_Loan_Fam_Resp_R, } \\
\text { Tot_Pers_Loan_Other_Resp_R, Tot_Pers_Other_Resp_R }\end{array}$ \\
\hline Tot_Pers_Debt_Owed_Resp_R_F* & $\begin{array}{l}\text { First Follow-Up: } \\
\text { Tot_Pers_CredCard_Bal_Resp_R } \\
\text { Tot_Bus_CredCard_Bal_Resp_R } \\
\text { Tot_Pers_Loan_Bank_Owed_Resp_R_F } \\
\text { Tot_Pers_Loan_Fam_Owed_Resp_R_F } \\
\text { Tot_PersLoan_Other_Owed_Resp_R_F } \\
\text { Tot_Pers_Other_Owed_Resp_R_F }\end{array}$ \\
\hline Tot_Pers_Debt_Owed_Resp_R_S* & $\begin{array}{l}\text { Second Follow-Up: } \\
\text { Tot_Pers_CredCard_Bal_Resp_R } \\
\text { Tot_Bus_CredCard_Bal_Resp_R } \\
\text { Tot_Pers_Loan_Bank_Owed_Resp_R_S } \\
\text { Tot_Pers_Loan_Sam_Owed_Resp_R_S } \\
\text { Tot_PersLoan_Other_Owed_Resp_R_S } \\
\text { Tot_Pers_Other_Owed_Resp_R_S }\end{array}$ \\
\hline Tot_Pers_Debt_Other_Owners_R & $\begin{array}{l}\text { Tot_Pers_CredCard_Bal_Others_R, Tot_Pers_Loan_Bank_Others_R, } \\
\text { Tot_Bus_CredCard_Bal_Others_R, } \\
\text { Tot_Pers_Loan_Fam_Other_Owners_R, } \\
\text { Tot_Pers_Loan_Other_Other_Owners_R, } \\
\text { Tot_Pers_Other_Other_Owners_R }\end{array}$ \\
\hline Tot_Pers_Debt_Owed_OthrOwnrs_R_F* & $\begin{array}{l}\text { First Follow-Up: } \\
\text { Tot_Pers_CredCard_Bal_Others_R_F } \\
\text { Tot_Bus_CredCard_Bal_Others_R_F } \\
\text { Tot_PersLoan_Bank_Owed_Othrs_R_F } \\
\text { Tot_PersLoan_Fam_Owed_Othrs_R_F } \\
\text { Tot_PersLoan_Othr_Owed_Othrs_R_F } \\
\text { Tot_Pers_Other_Owed_Others_R_F }\end{array}$ \\
\hline Tot_Pers_Debt_Owed_OthrOwnrs_R_S* & $\begin{array}{l}\text { Second Follow-Up: } \\
\text { Tot_Pers_CredCard_Bal_Others_R_S } \\
\text { Tot_Bus_CredCard_Bal_Others_R_S } \\
\text { Tot_PersLoan_Bank_Owed_Othrs_R_S } \\
\text { Tot_PersLoan_Sam_Owed_Othrs_R_S } \\
\text { Tot_PersLoan_Othr_Owed_Othrs_R_S } \\
\text { Tot_Pers_Other_Owed_Others_R_S }\end{array}$ \\
\hline
\end{tabular}


MEMO TO: E. J. Reedy, Ewing Marion Kauffman Foundation

FROM: David DesRoches and Betsy Santos

DATE: $\quad 3 / 20 / 2008$

PAGE: 21

\section{Total Amount Variables (continued)}

\begin{tabular}{|c|c|}
\hline \multicolumn{2}{|r|}{ Total Amount Variables } \\
\hline Variable Name & Variables used to create \\
\hline Tot_Debt_Owner_Operators_R & Tot_Pers_Debt_Resp_R, Tot_Debt_Other_Owners_R \\
\hline Tot_Debt_Bus_R & $\begin{array}{l}\text { Tot_CredCard_Bal_Bus_R, Tot_Loan_Bank_Bus_R, } \\
\text { Tot_Cred_Line_Bus_Bal_R, Tot_Loan_NonBank_Bus_R, } \\
\text { Tot_Loan_Fam_Bus_R, Tot_Loan_Owner_Bus_R, } \\
\text { Tot_Loan_Emp_Bus_R, Tot_Loan_Govt_Bus_R, } \\
\text { Tot_Loan_Other_Bus_R, Tot_Loan_Other_Ind_R, } \\
\text { Tot_Bus_Debt_Other_R }\end{array}$ \\
\hline Tot_Bus_Debt_Owed_R_F* & $\begin{array}{l}\text { First Follow-Up: } \\
\text { Tot_Bus_Loans_Bank_Owed_R_F } \\
\text { Tot_Bus_Loans_Nonbank_Owed_R_F } \\
\text { Tot_Bus_Loans_Fam_Owed_R_F } \\
\text { Tot_Bus_Loans_Owner_Owed_R_F } \\
\text { Tot_Bus_Loans_Emp_Owed_R_F } \\
\text { Tot_Bus_Loans_Govt_Owed_R_F } \\
\text { Tot_Bus_Loans_OtherBus_Owed_R_F } \\
\text { Tot_Bus_Loans_OtherInd_Owed_R_F } \\
\text { Tot_Bus_Loans_Other_Owed_R_F }\end{array}$ \\
\hline Tot_Bus_Debt_Owed_R_S* & $\begin{array}{l}\text { Second Follow-Up: } \\
\text { Tot_Bus_Loans_Bank_Owed_R_S } \\
\text { Tot_Bus_Loans_Nonbank_Owed_R_S } \\
\text { Tot_Bus_Loans_Sam_Owed_R_S } \\
\text { Tot_Bus_Loans_Owner_Owed_R_S } \\
\text { Tot_Bus_Loans_Emp_Owed_R_S } \\
\text { Tot_Bus_Loans_Govt_Owed_R_S } \\
\text { Tot_Bus_Loans_OtherBus_Owed_R_S } \\
\text { Tot_Bus_Loans_OtherInd_Owed_R_S } \\
\text { Tot_Bus_Loans_Other_Owed_R_S }\end{array}$ \\
\hline Tot_Debt_R & Tot_Debt_Owner_Operators_R, Tot_Debt_Bus_R \\
\hline Tot_Assets_R & \begin{tabular}{|l} 
Tot_Asset_Cash_R, Tot_Asset_Acct_Rec_R, Tot_Asset_Inv_R, \\
Tot_Asset_Equip_R, Tot_Asset_LandBuild_R, Tot_Asset_Veh_R, \\
Tot_Asset_Other_Bus_Prop_R, Tot_Asset_Other_R
\end{tabular} \\
\hline Tot_Liab_R & Tot_Liab_Acct_Pay_R, Tot_Liab_Pension_R, Tot_Liab_Other_R \\
\hline
\end{tabular}


MEMO TO: E. J. Reedy, Ewing Marion Kauffman Foundation

FROM: David DesRoches and Betsy Santos

DATE: $\quad 3 / 20 / 2008$

PAGE: 22

\section{E. Variables constructed using the “Quarter” range}

These variables were constructed for questions (in the Baseline Survey only) collecting the month in 2004 businesses first paid unemployment insurance or FICA taxes. The components of the constructed variables include:

- Exact values such as Question B9 ("For what month in 2004 were the first unemployment taxes paid”),

- "Range" questions asked of respondents who could or would not provide an exact figure value - the response choices were "The 1st quarter of 2004 (January to March)," “The 2nd quarter of 2004 (April to June)," etc.

\begin{tabular}{|c|c|}
\hline \multicolumn{2}{|c|}{ Range definition - Quarter } \\
\hline Value & Range (months) \\
\hline 1 & $1-3$ \\
\hline 2 & $4-6$ \\
\hline 3 & $7-9$ \\
\hline 4 & $10-12$ \\
\hline
\end{tabular}

This process was used to construct the following variables:

UI_Month_R

FICA_Month_R 
MEMO TO: E. J. Reedy, Ewing Marion Kauffman Foundation

FROM: $\quad$ David DesRoches and Betsy Santos

DATE: $\quad 3 / 20 / 2008$

PAGE: $\quad 23$

\section{F. Variables constructed using the "Hours" range}

These variables were constructed for the question collecting the average number of hours per week owner-operators worked at the business. The components of the constructed variables include:

- Exact values collected at Question G1b ("During the time [NAME BUSINESS] was in business during 2004, how many hours in an average week did (you/[owner B-J]) spend working at [NAME BUSINESS]?”)

- "Range” questions asked of respondents who could or would not provide an exact value. The range definitions are provided below.

\begin{tabular}{|c|c|}
\hline \multicolumn{2}{|c|}{ Range definition - Hours } \\
\hline Value & Range \\
\hline 1 & $1-19$ \\
\hline 2 & $20-35$ \\
\hline 3 & $36-45$ \\
\hline 4 & $46-55$ \\
\hline 5 & $56-65$ \\
\hline 6 & $66+$ \\
\hline
\end{tabular}

This process was used to construct the following variables:

Total_Hours_Owner_01_R

Total_Hours_Owner_02_R

Total_Hours_Owner_03_R

Total_Hours_Owner_04_R

Total_Hours_Owner_05_R

Total_Hours_Owner_06_R

Total_Hours_Owner_07_R

Total_Hours_Owner_08_R

Total_Hours_Owner_09_R

Total_Hours_Owner_10_R 
MEMO TO: E. J. Reedy, Ewing Marion Kauffman Foundation

FROM: David DesRoches and Betsy Santos

DATE: $\quad 3 / 20 / 2008$

PAGE: 24

\section{G. Variables constructed using the "Age” range}

These variables were constructed for the question collecting the ages of owner-operators of the business. The components of the constructed variables include:

- Exact values collected at Question G4 ("How old will (you/[OWNER B-J]) be on (your/his/her) next birthday?”)

- "Range" questions asked of respondents who could or would not provide an exact value. The range definitions are provided below.

\begin{tabular}{|c|c|}
\hline \multicolumn{2}{|c|}{ Range definition - Age } \\
\hline Value & Range \\
\hline 1 & $18-24$ \\
\hline 2 & $25-34$ \\
\hline 3 & $35-44$ \\
\hline 4 & $45-54$ \\
\hline 5 & $55-64$ \\
\hline 6 & $65-74$ \\
\hline 7 & $75+$ \\
\hline
\end{tabular}

This process was used to construct the following variables:

Age_Owner_01_R

Age_Owner_02_R

Age_Owner_03_R

Age_Owner_04_R

Age_Owner_05_R

Age_Owner_06_R

Age_Owner_07_R

Age_Owner_08_R

Age_Owner_09_R

Age_Owner_10_R 